\title{
APATHY AND THE MODERN SELF: THE AFFLICTIONS OF MODERNITY AND ORIENTATION TOWARD THE GOOD
}

\author{
By
}

Aaron C. Pingree

Master of Arts University of Waterloo 2006

Bachelor of Arts (Hons) University of Waterloo 2004

A dissertation

\author{
presented to Ryerson University and York University \\ in partial fulfillment of the \\ requirements for the degree of \\ Doctor of Philosophy \\ in the Program of \\ Communication and Culture
}

Toronto, Ontario, Canada, 2013

(C)Aaron C. Pingree 2013 


\section{AUTHOR'S DECLARATION FOR ELECTRONIC SUBMISSION OF A DISSERTATION}

I hereby declare that I am the sole author of this dissertation. This is a true copy of the dissertation, including any required final revisions, as accepted by my examiners.

I authorize Ryerson University to lend this dissertation to other institutions or individuals for the purpose of scholarly research.

I further authorize Ryerson University to reproduce this dissertation by photocopying or by other means, in total or in part, at the request of other institutions or individuals for the purpose of scholarly research.

I understand that my dissertation may be made electronically available to the public. 
Apathy and the Modern Self: The Afflictions of Modernity and Orientation Toward the Good.

PhD 2013

Aaron C. Pingree, Communication and Culture, Ryerson University and York University

\begin{abstract}
Research to date on apathy has been limited to the technical spheres of politics, pedagogy, mass media, and business. Contrary to apathy's characterization in recent scholarship, this work claims that apathy cannot be understood in terms of a decline in political engagement alone. Through a history of the idea of apathy beginning with the Stoic concept of apatheia, this work locates apathy in the epochal shift in epistemology and subjectivity which occurred between antiquity and modernity, and claims that apathy is a philosophical (rather than political) problem. Guiding research questions include: what allowed for the possibility of modern apathy, and what means might we have at our disposal to address apathy?

Rather than treating symptoms, I argue that any response to apathy must engage with its epochal grounding conditions, and so rather than suggesting policy reforms or new legislation, I assess problems accompanying modern subjectivity and epistemology, and the place of the Good under modernity.
\end{abstract}

This project also participates in the longstanding debate concerning the possibility of uniting sense and reason, a problem known in antiquity and addressed by communication theorists and Romantic poets. I argue that the commingling of sense and reason is another way of describing openness to an encounter with the Good, and under modernity such commingling might result from aesthetic exercises. 
I consider McLuhan and Foucault thinkers whose work can be read as a form of áskēsis that extends the ancient philosophical tradition into modernity in order to encourage spiritual work in the present. Through readings of McLuhan and Foucault's engagement with antiquity, I then suggest that aesthetic exercises arising out of the modern milieu may offer a response to apathy and its grounding epistemological and subjective conditions.

This work attempts to broaden the contemporary understanding of apathy, and to reconnect the discourse on apathy to its grounding conditions - subjective and epistemological sunderings which have been intensified and normalized under modernity. This broadening and reconnection demand that apathy is understood in a more complete way, not simply in terms of its immediate consequences for the technological society. 


\section{ACKNOWLEDGEMENTS}

There is no way to adequately thank everyone who supported me during this process, but certain people deserve special mention. I extend a heartfelt thanks to friends and family for tolerating me during what was at times a rather isolating process. Without the loving support of my parents, my incredible brother Jay (who continues to be an inspiration), my grandparents, and the patience and encouragement of my wonderful girlfriend Stef, I would surely have faltered.

During my time at Ryerson and York, I have been privileged to work with some extraordinary individuals to whom I owe a great deal. Special thanks go to Steve Bailey of York University for fruitful and provocative discussions in coffee shops, and for a hearty helping of insightful criticisms, good advice and humour. Steve brought his keen acumen to bear on my work, and challenged me to explore alternate perspectives. Additional special thanks go to Betty Trott of Ryerson University for swooping in and agreeing to sit on my committee at the last moment. Betty offered many thoughtful criticisms and was always happy to sit and chat about anything and everything, from philosophy, film, pedagogy, and family, to the etymology of surnames. Her passion and enthusiasm for philosophy are contagious.

Gary Genosko of UOIT performed a very careful and detailed reading of my work, offered a most thoughtful commentary, and did not shy away from posing many deep, provocative, and penetrating questions. For that I sincerely thank him. I am also greatly appreciative of Robert Murray and Martin Antony of Ryerson University for ensuring an engaging and lively defense. 
I am grateful to Paul Moore, Ryerson University Communication and Culture program director, for his strong support and generous spirit, and to Jo Ann Mackie for helping me to navigate the program, for putting up with my ineptitude regarding paperwork and deadlines, and for offering a great deal of helpful advice and a friendly ear. Thanks also go to Stuart Murray of Carleton University, for reading an early draft and offering some helpful suggestions.

I owe a tremendous debt to Stan Fögel, Sylvia Wray, and Carl Draksler, teachers and friends without whom the direction of my life would have been very different.

Finally, I would like to extend tremendous gratitude to my supervisor, Bruce Elder, who I saddled with a number of bungling early drafts (of which I'm still mortified), and whose patience, guidance, demand for rigor, and wisdom saw me through the dissertation process, and encouraged me to grow as a scholar and as a person. Bruce has helped to rekindle my faith that there are those who still resist the carelessness of our times. If one day I am even marginally as inspiring a teacher and as profound and provocative a thinker as Bruce, I will be content. 


\section{DEDICATION}

For Gran. 


\section{TABLE OF CONTENTS}

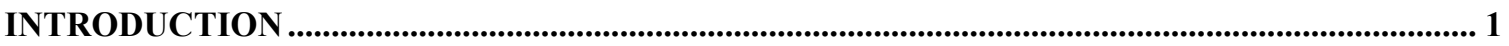

CHAPTER 1 - ANCIENT APATHEIA AND ÁSKËSIS ............................................................. 23

CHAPTER 2 - ANCIENT PROGRESS: PERSONAL AND SPIRITUAL MOVEMENT ................... 54

CHAPTER 3 - MODERN PROGRESS: COLLECTIVE AND TECHNICAL MOVEMENT ........... 88

CHAPTER 4 - MODERN APATHY: A SELF NOT CARED FOR ................................................... 117

CHAPTER 5 - ART AND ESTRANGEMENT: MODERN ÁSKĒSIS AND THE REKINDLING OF

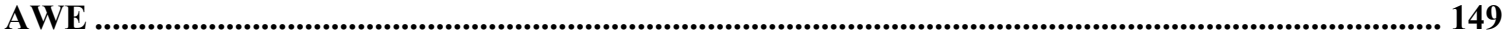

CHAPTER 6 - THE GOOD, HARMONY, AND MODERNITY .................................................... 188

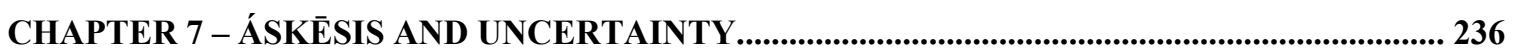

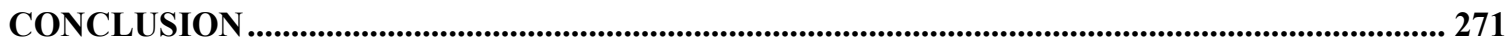

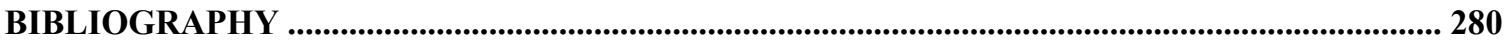




\section{$\underline{\text { Introduction }}$}

From its inception, this project has grown considerably. My research and writing style is what Edward T. Hall describes as Dionysian - it evolves as I go. What began as a study strictly on manifestations of contemporary apathy has lead toward fundamental philosophical questions: how can we, who live in a disenchanted world, a world without a ground for authority, lead good and meaningful lives? What is the predominate form of self under modernity, and is such a self conducive to living a good life? If such a self is afflicted by problems that accompany a loss of authority or worldlessness, how might we address these issues?

This work takes as its starting point the position (advanced by such thinkers as McLuhan, Foucault, Bury, and Ferry), that there has been an epochal, subjective shift from pre-modern to modern culture, and that according to (among others) Weber, Taylor, Arendt, and Grant, this is experienced as disenchantment, groundlessness, worldlessness, and a language of willing (rather than a language of Good). Granted, this is only an interpretation of history, but one which I feel carries the most weight.

In the following pages I will use the term modernity to designate a period from roughly the sixteenth century to the present characterized by a shift in thought and subjectivity. While critiquing many of the consequences of modernity, I do celebrate its material benefits, its social benefits (including giving a voice to those "others" who have historically been relegated to the margins), and the possibilities opened up in the realm of thought (aesthetic exercise, objectivity which grants distance enough to engage in autocritique, and an art that is shocking and creative rather than mimetic). 
While ostensibly about apathy, this is really a project about the relationship between care and knowledge. The aim of this project is twofold. First, by providing a history of the idea of apathy, I hope to problematize our understanding of apathy, and expose this taken for granted malaise as something historically conditioned. I argue that in antiquity, apatheia was the end of a process of care designed to align the self with virtue, and that modern apathy is a philosophical problem resulting from a failure to care for the self and a disconnect from the Good. Bearing this in mind, chapters one through four work to establish both our familiarity with and difference from antiquity, and to highlight the shift in thinking that began during the middle ages. Second, I suggest a uniquely modern response to the problem of apathy, which while inspired by an ancient understanding of care, emerges out of the modern milieu in the form of modern aesthetic exercises. This project is less about instituting practical reforms, and more about considering possibilities, and this is what the final three chapters engage in - an exploration of possibilities, or a series of "what if" scenarios. What if we consciously engaged in modern forms of áskēsis? What if we were able to endure uncertainty? Would this permit openness enough to touch the Good?

In antiquity, the care of the self "became a general and unconditional principle, a requirement addressed to everyone, all the time" (The Hermeneutics of the Subject 83). This work claims that such is no longer the case under modernity. And while I am interested in a kind of modern áskēsis, this is not the same as a call for a return. We ought not to look for a return, nor should we attempt to care in the same way as the ancients. Their forms of care, their áskēsis, emerged out of their cultural milieu and their own unique circumstances. We can look back to them for inspiration and perspective, and then 
care in our own ways. In A Brief History of Thought, Luc Ferry calls not for a "return, but for a "rethinking" (204), and Foucault put it quite tersely when he wrote "one should totally and absolutely suspect anything that claims to be a return" ("Space, Power and Knowledge" 168). Restoration masks and denies the force of change and new social conditions. I am interested not in a restoration of the grounding worldview which initially gave rise to áskēsis, but rather in looking back to antiquity for inspiration, and to spark an awareness of our own modern áskēsis. Opening awareness was the primary goal of McLuhan, who, like Foucault, councils us to "beware of those who announce programs for restoring man to the original state and language of the race" (Understanding Media 144). In his study of the eighteenth century, Neil Postman advocates looking back for guidance rather than for models to rigidly emulate, and for principles rather than specific details or tactics. In this spirit, my project looks back to antiquity in order to help us rethink the present, and realize that modernity is not inevitable; it is one interpretation, one way of being, advantageous in some ways, detrimental in others.

In an effort to avoid the seductiveness of emulation, I instead look to the idea of inspiration, which comes from the Latin inspiro, "to breath into." Through a look back at the ancients we may (I hope) inhale again the breath of the absolute and be uplifted - or at least be oriented toward such things. The term inspiration also suggests a rupture with everyday experience. In inhaling this divine breath, we are uplifted, or allowed to rise above the context of everyday life. In other words, inspiration implies estrangement, and the very term itself calls to mind a grander sense of the cosmos which has been lost over the past few centuries. 
Upon learning that my dissertation is about apathy, people invariably offer an approving nod (after, that is, making the standard joke(s) about not really caring about the topic), whereupon the conversation turns to politics and voter apathy. Recent popular understandings of apathy tend to be tied to voter indifference, and as such, I feel the need to make a few brief prefatory remarks explaining why I do not proceed in this direction. The fact that apathy is at present thought of in terms of voter indifference rather than as an historical phenomena is both interesting and quite telling. A popular obsession with voting (as seen in media campaigns which encourage us to vote), or with representative democracy, reveals the importance of voting not for direct democracy (which is to say the human community, or connections between selves and the larger community), but for the technological system - a managerial culture dedicated to control and efficiency. Voting in contemporary society amounts to a deferral of real power (the power to make real decisions), and an acquiescence of sorts. The system does not permit decisions of consequence; instead, citizens are permitted to select an intermediary between the working public and big business. In a large scale technological society, when we vote, we are in essence selecting our corporate liaisons. As George Grant stated so bluntly yet exquisitely, the practice of voting is ineffectual in a technological society:

The nineteenth-century idea of the democratic citizen making the society he inhabits by the vote and support of political parties must have less and less meaning. In local matters the citizen of an empire can achieve some minor goals. But he cannot shape the larger institutions or move the centres of power. Democratic citizenship is not a notion compatible with technological empires (Grant “A Critique of the New Left (1966)" 85).

Grant is certainly not the first to levy this type of critique. We need only think of Alexis de Tocqueville, for whom representative democracy leads to unthinking citizens, who 
"quit their state of dependence just long enough to choose their masters and then fall back into it" (693). Continuing his critique, de Tocqueville writes:

it does little good to summon those very citizens who have been made so dependent on the central power to choose the representatives of that power from time to time. However important, this brief and occasional exercise of free will will not prevent them from gradually loosing the faculty of thinking, feeling, and acting for themselves, so that they will slowly fall below the level of humanity (694).

We might also consider more recent critiques like those of comedian and social critic George Carlin, who, in a similar vein, claimed that we are only permitted to engage in meaningless consumer choices (17 flavours of bagel, variously coloured or "bedazzled" phones, etc.), a critique which echoes the writings of Jacques Ellul. Voting for representatives in a technological society grants us the illusion of power and participation, and the illusion of choice. While this characterization of apathy as something connected specifically to voting is revealing, and while it does have a history, it will be little more than a digression in the present work. My focus is on a more pervasive and general apathy that is a byproduct of the shift from a self cared for to a self to be known (and all of the attendant consequences), demonstrable through the language of interiority and freedom surrounding the self which developed in the wake of Descartes. I claim that at its core, apathy is not a political or social problem. Apathy is a kind of carelessness, and is first and foremost a problem of subjectivity, aesthetics, technology, and epistemology. In short, it is a set of philosophical problems. Any attempt at addressing apathy must look to its history, and must look to first understand its constitutive problems, rather than recent manifestations in various arenas.

While research has been conducted on the effects of apathy in political, pedagogical, media, and business contexts, such research tends to neglect the historical 
trajectory of the problem. The existence of these research programs speaks to an acknowledgement of the problem, but the focus is limited to the effects of apathy in specific forums, and these forums, taken in isolation, are practical and necessary for the technological system. In other words, research which focuses on specific forums is interested in addressing the effects of apathy only insofar as they affect technique, only insofar as they inhibit technological efficiency. Apathy as a real human problem is rarely touched on.

Underpinned by spiritual readings of Foucault and McLuhan, this work argues that apathy is a philosophical problem that accompanies the modern forgetting to care for the self and modern privileging of knowing over caring. This work considers McLuhan's thoughts on technology and the self alongside of Foucault's later work on antiquity and subjectivity, and treats both as philosophers concerned with the spiritual present of modernity. Chapters one and four engage in a history of the idea of apatheia/apathy. Chapters two and three engage in a history of progress meant to illustrate the epochal shift which occurred between ancient and modern thought, and its effects on the self and spiritual practice. Specifically, chapter three reveals modern progress to be technical in nature: it is collective, yet divisive. In contradistinction to ancient progress, this sort of technical progress marks a distinct repositioning of the self (and its relation to the world) as it becomes something to know, rather than care for. While this work illustrates a number of differences between antiquity and modernity, it also tries to highlight common threads which link them, and it does this by including modern thinkers in discussions of the ancients, and visa versa. Such balancing of proximity and distance is, as Foucault points out in his introduction to The Use of Pleasure, fundamental to the current of 
Western philosophy. In chapter four I briefly survey the corpus of scholarship on apathy before examining its history in the shift from caring to knowing and the language of freedom (and technical mastery) which distances us from the Good. With the aid of Simmel and McLuhan, I then sketch the kind of self that might fall prey to apathy, and the technological milieu in which that self lives.

In the final three chapters I suggest that personal spiritual exercises (in the tradition of ancient áskēsis) may offer the best chance for awareness of our condition. Something similar holds true for Jacques Ellul, who comments on the technical nature of modern progress, and the (necessarily) politically marginal nature of his own efforts. Ellul believes that politics has been subsumed by technique, and is thus ineffective in critiquing technical logic. "While crowds of people adopt all the technical developments, we can act only on individual levels. Hence, this is a true artisan's work." (Perspectives 65-6). Individuals on the margins are best poised to critique technique and offer alternatives. In a similar vein, McLuhan councils shock and the adoption of an extra environmental posture, while thinkers as diverse as Foucault and Perec and Brecht and Heidegger and even Orwell suggest we render the familiar strange, and though they differ in many respects Hannah Arendt and George Grant would have us resist the urge to acclimate ourselves to what Arendt calls the modern desert. These thinkers, each in their own way, suggest that the task before us is to surmount technique, rather than adapt to its imperatives.

Even the nineteenth century "new spirit of the age" (gain wealth forgetting all but self) speaks to the idea of apathy as carelessness, as forgetting to care for the self, and as distance from the Good. The modern centering of the self may seem (initially anyway) to 
be at odds with the idea of apathy as a forgetting to care for the self (and consequent distancing from the Good), until we recall that care of the self was intended to align that self with something larger. The self was cared for in order to work towards transcendence of self and knowledge of the Good, and to know the Good meant transforming one's very being. Under modernity, the self is centered to the exclusion of all else, becoming the new ground of knowledge.

This turn inward has lead to the logic of technique and perpetual progress which undergird our age, the primary consequences of which Jacques Ellul describes as the suppression of the subject and the suppression of meaning. By suppression of the subject, Ellul means that the subject has no choice but to adhere to the imperatives of technique. In other words, technique demands that we act a certain way (to use McLuhan's terminology, we become mere servos of our technological extensions). A consequence of this is that the subject becomes closed off from others. Thus, while knowledge of (and mastery over) an objective nature was supposed to allow us to exercise our wills and thereby secure freedom from the natural order, this turn inwards, this new ground of knowledge and the logic of technique it spawned, ended up mastering us and eradicating any idea of ends. This latter point is what Ellul refers to as the suppression of meaning, as "the ends of existence gradually seem to be effaced by the predominance of means" (Perspectives 40). The point of life is no longer to live well, nor to transcend the self nor to open oneself to the Good; the point of life is to progress for the sake of progress, to use means to produce further means.

Positioning McLuhan as an artist sleuth rather than a technological determinist, chapter five examines a selection of modern aesthetic exercises that carry within them 
something of the logic that underlies ancient áskēsis. While similar in some ways to their ancient counterparts (for example, in attempting to make strange), these modern exercises differ in that the distance they generate is not meant to reveal a priori essences, but to force contemplation and cause a confrontation with uncertainty - a confrontation which we must attempt to endure. While some moderns have engaged - and continue to engage - in spiritual exercises, they often lack awareness of their actions, which is to say, the ancients were conscious of their áskēsis, while moderns are often not. Áskesis is not as far removed as we might think: it is not merely a relic of antiquity, something lost to the past, only to be read about in ancient texts. Such exercises have been attempted by various moderns, and such modern attempts to care for and elevate the self are vital to our survival.

Chapter six examines the ancient understanding of the Good as harmony, and then goes on to assess modern thinkers (specifically George Grant and Simone Weil) who suggest that brushing up against the Good is possible under modernity. Chapter seven begins with an examination of Descartes and his drive for certainty before moving on to assess the relevance of Keatsian negative capability to modern spiritual exercises, and finally makes the claim that in order to re-orient ourselves towards the Good, we must, by way of áskēsis, work to "unself," and thereby learn to stand for uncertainty.

During the later chapters of this work I will be inquiring into the possibility of brushing up against the Good and sustaining uncertainty through metaphysical questioning. As such, I would like to make a few brief remarks about metaphysics. In offering a précis of metaphysics, I do not claim to map its comprehensive history, or to cover all of its possible interpretations, or to introduce all of the questions it raises, or to 
offer a definitive definition. I cannot explore it to the depth it assuredly deserves, but I can explain the idea as it connects to the present work.

While the term metaphysics owes its currency to a work of Aristotle which chronologically came "after the Physics," the actual questions posed by this branch of philosophy are Platonic in origin, and inquire into the real nature (that is, beyond interpretation, whether perceptual or symbolic) of existence in the world by looking toward ideal categories or Forms. Plato went above or beyond the physics of the preSocratics, and began to theorize about matters of being and our relation to the order of the cosmos, but something has stifled this impulse under modernity. Questions have become anchored to a calculative and technical end; if they do not contribute to such an end, if they do not act in the service of technical utility, they are often cast aside as irrelevant.

With this quest to understand the real nature of the cosmos and our place therein came a suspicion of the senses. There is in the Platonic theory of Forms (as set out in the Phcedo) a suspicion of the senses, but this suspicion reaches its full maturity with Descartes and his very different form of dualism (body/mind as opposed to the Platonic body/soul). Charles Taylor offers a point of clarification regarding the apparent similarity between Platonic and Cartesian dualism. For Plato, true Being or the supra-sensible nature of the soul can be realized when one turns toward the absolute. But for Descartes:

Coming to a full realization of one's being as immaterial involves perceiving distinctly the ontological cleft between the two [mind and matter], and this involves grasping the material world as mere extension. The material world here includes the body, and coming to see the real distinction requires that we disengage from our usual embodied perspective... We have to objectify the world, including our own bodies, and that means to come to see them mechanistically and functionally, in the same way that an uninvolved external observer would (Sources of the Self 145). 
The modern subject then, owes its existence to an understanding of the world as "mere" extension, or as a realm of objects, and such understanding emerges when mankind, to use Ferry's turn of phrase, puts himself in the position of the cosmos. For Descartes, "To be free from the illusion which mingles mind with matter is to have an understanding of the latter which facilitates its control" (Sources of the Self 149). If the commingling of sense and reason or simultaneity of thought and feeling is an apt way of describing an experience of the Good, then Descartes' problem with the senses - that they could not, he felt, accurately take stock of or report on the world - represents a move away from an experience of the Good. While for Plato "one's soul is ordered by the Good which presides over the cosmic order which one attends to and loves," Cartesian dualism has no place for such a Good (Sources of the Self 146). ${ }^{1}$

There have been recent attempts to unify such dualism while retaining the need for mystery and metaphysical questions, and these attempts are what connect metaphysics to the present work. Henri Bergson identifies two ways by which philosophers have sought to know a thing. The first begins from a stable viewpoint and uses symbols in order to move around the thing (through analysis), while the second starts from no fixed viewpoint and seeks to enter into the thing itself (through intuition). While permitting conscious reflection and granting awareness, the symbolic removes us from the world, and prevents immediate intuition; it prevents us from entering into the thing itself. The limits of symbolic or representative thought ensure that one can never quite reach the thing-in-itself; no matter how close they are to expressing the essence of a thing, all symbolic acts fall short. Representative concepts are as circles drawn around a thing,

\footnotetext{
${ }^{1}$ Henri Bergson describes the "partial eclipse" of metaphysics, which he locates in the nineteenth century, but this eclipse surely begins with Descartes and his turning away from the Good.
} 
none fitting it exactly (Bergson 140). For Bergson, the absolute can only be approached through intuition, that is, through immediate and non-mediated apprehension of the thing as it stands. This intuition transports one to the inner essence of a thing, so that one coincides with the inexpressible essence. A symbolic act occurs after the fact; it attempts to express a thing by means of another thing, which is to say, it is necessarily relative. Bergson describes metaphysics as "the science which claims to dispense with symbols" (Bergson 136); it aspires to the absolute through immediate intuition. Approaching what Eliot would call feeling-thinking, Bergson claims that "philosophizing consists in placing oneself within the object itself by an effort of intuition" (Bergson 150).

While Bergson's approach does shed a great deal of light on the idea of metaphysics, it nevertheless takes the form of analysis. This is to say, while describing metaphysics as a dispensing with symbols aimed at immediate intuition, Bergson is confined to using symbols, or to drawing approximate circles around this thing without actually entering into it. Heidegger takes a different approach, and while sharing some of Bergon's insights, works to avoid performing the same sort of analysis.

In his essay "What is Metaphysics?” Heidegger opts to forgo his eponymous question. We can better grasp his decision by recalling Bergson's understanding of metaphysics as a dispensing with symbols. Rather than using symbols to circle around metaphysics, Heidegger works to show us by immersing us directly within its practice. In declaring the need to "find a thing behind the word" (Bergson 145), or to avoid "an empty squabble over words" (Heidegger "What is Metaphysics?" 96), both thinkers draw our attention to the shortcomings of the symbolic, and would have us transcend representational thought. Heidegger's language is, for George Grant, one of the most 
venerable features of his work. In a letter to William Christian, Grant observed that Heidegger "seems not to be writing about things, but to summon up directly the things themselves" (Grant "Heidegger" 299). Such direct summoning is precisely what Heidegger hopes to accomplish by gradually revealing the answer to the question "what is metaphysics?"

Choices open to us under modernity seem infinite, but they are in fact finite and limited to the technical sphere. This limitation is due to the erosion of vast backcloths and the preference for calculative over meditative thinking. One of the reasons I am so drawn to Heidegger is because of his efforts at moving beyond or transcending the Cartesian understanding (and its implications) of what it means to be human in the world. In this sense, Heidegger works to rescue philosophy from modernity. In describing transcendence as "being beyond beings" ("What is Metaphysics?" 103), Heidegger counsels moving beyond the disengaged subject position to an understanding of the subject as it exists within the world. This, for Heidegger, is the essence of metaphysics: "Metaphysics is inquiry beyond or over beings, which aims to recover them as such and as a whole for our grasp" ("What is Metaphysics?" 106). Metaphysics is a kind of going beyond, and for Heidegger it belongs to the nature of Man, being "neither a division of academic philosophy nor a field of arbitrary notions. Metaphysics is the basic occurrence of Dasein. It is Dasein itself" (Heidegger "What is Metaphysics?" 109). Combining the thoughts of Bergson and Heidegger, we might say of metaphysics that it quests after pure, total, and immediate (rather than delayed and conceptual) understanding through the dissolution of symbolic thought, and that it asks meditative (rather than calculative) questions about the world and our place within the world. In brief, metaphysics, as 
understood in the present work, is interested in our being-in-the-world (how we "are" in the world). It understands there to be a grand harmonious order, a sense of which may be accessible through a commingling of sense and reason. Metaphysics asks questions about truth, beauty, goodness, the world and our place therein. Such questions are noninstrumental, and work to encourage us to lead good lives in the world. Perhaps even more important than the answers to such questions is the fact that they are posed in the first place and then sustained. Metaphysics does not aim at a practical application, and in this way it is not bound to, and is in fact antithetical to technique; hence my insistence on the importance of metaphysical questions for the present, as they may allow resistance to the technological ontology of the age. I understand the current need for metaphysics as a revival of our ability to conceive of possibilities and endure mystery, an idea to which we will return in the later chapters of this work on the Good and uncertainty respectively.

Is it possible to retain something of the modern subject position and its attendant virtues, and still re-orient ourselves towards the Good? I would suggest that it is (though with difficulty) through an áskēsis based in and emerging out of modern culture. The modern mindset, characterized by the desire for certitude, technique, mastery, and instrumentality, is so thoroughly engrained in our very form of subjectivity that any effort to alter this outlook will require an áskēsis that culminates in decreation, or transcendence of ego. Such transcendence of the Cartesian subject may permit a standing-for uncertainty, and under modernity, such uncertainty may be the best way to leave space enough for brushes with the Good. In suggesting that we stand for uncertainty, I am not advocating a stance of utter confusion. Quite simply, there are things which we do not know, and questions which are impossible to know, and rather than posit easy answers or 
refrain from asking such questions, we ought to maintain our uncertainty, and through this uncertainty force a wrestling with these questions ad infinitum. We desperately need to work on and care for the self. Such work and care is the beginning of transcendence and orientation toward the Good.

Admittedly, this work covers an expansive time frame and a wide array of thinkers and disciplines. From Platonism to late Stoicism, to modern thinkers such as Descartes, to Romantic poets, to twentieth century thinkers and artistic movements, this work might be described as eclectic. Such eclecticism is, I think, necessary when confronting such formidable problems as apathy and the modern sundering from the Good. Readers can expect to encounter the ideas of poets, playwrights, modern philosophers, and communications theorists alongside those of ancient thinkers, and upon closer examination, certain common threads will become apparent, for instance, the importance of care of the self and the role of áskēsis in such efforts of care, the connection between áskessis and aesthetics, and the connection between uncertainty and the Good. All of these themes are intimately linked to the problem of apathy. My eclecticism, my use of modern and ancient texts, reveals how widespread these concerns are, and highlights the proximal distance which both binds us to and separates us from antiquity.

I would now like to briefly foreground a number of issues I do not address, and try to justify my decision to not pursue certain avenues of thought. As I explain in chapter one, I do not treat the Stoic system in its entirety. Despite the fact that Stoicism comprised a unified whole, I am only focusing on its spiritual exercises and ethics. Thinkers such as Inwood, Hadas, Sorabji, Cooper, Brennan, Long, and Hadot, have 
provided more complete accounts of the holistic Stoic system, and I would direct readers to their excellent work to fill in any gaps.

I am aware that this decision to limit my focus to Stoic ethics may leave me susceptible to criticism (particularly by classicists). Foucault's treatment of antiquity has been subjected to similar criticisms, which claim that his work wrong-headedly decontextualizes the ancients. In a recent article Brendan Boyle defends Foucault's later work on care from classicist attack, claiming that such criticism results from misunderstanding. Likewise, Real Fillion describes such criticism as misguided, as accusations that Foucault misrepresents the Greeks fail to understand his project. To paraphrase Fillion, Foucault does not use ancient history in order to establish normative pre-modern foundations; he turns to antiquity in order to generate a sense of familiar difference through which we may engage in a critique of the present. Commentators like Long, Inwood, Sorabji, and Irvine have also expressed the value of reading ancient texts with a mind to modern problems, and so while my look back to antiquity may be met with resistance by some, I feel that I stand in good stead, as part of this Foucauldian tradition that has since been upheld by a number of eminent scholars.

My look at modern progress in chapter three is meant to highlight substantive changes in the treatment of the self, and the elevation of means over ends which accompanied the transition to modernity. I do not discuss a number of the social and economic consequences resulting from such changes, as they have been treated elsewhere (by, to name only a few examples: Marx, Freud, Nietzsche, Weber, and Simmel). The purpose of this work is not to offer a complete history of modernity (such a history would span numerous volumes, and would even then remain incomplete and controversial), but 
rather to problematize the concept of apathy by situating it within the shift from antiquity to modernity. If in my assessment of Descartes I am rather critical of certain features of modernity, such criticism is not meant as utter condemnation. On the contrary, Descartes' meditations have noble origins, have inspired numerous thinkers, have lead to a number of material benefits, and may in fact be read as spiritual work. If modernity is treated unsympathetically in chapters three and four, it will be (to an extent) redeemed in chapters five and seven, through an exploration of the possibility of aesthetic practices which it permits.

There have been a number of approaches to problems of meaning, the Good, and the self, under modernity. While not wholly condemnatory of the modern era, I locate myself within an intellectual tradition that is highly critical of the spiritual implications of modernity and which places greater import on transforming the self than on political action. Within this tradition are such thinkers as John Keats, Martin Heidegger, T.S. Eliot, Simone Weil, George Grant, and, despite their drastically different approaches, Michel Foucault and Marshall McLuhan. These thinkers draw inspiration from antiquity, as each treat philosophy as something lived, and while their individual responses to the malaise of modernity differ, they each work to cultivate a condition of openness or a standing for uncertainty. This work also engages with a problem which stretches back to antiquity, and which many modern commentators have trained their acumens upon: the alienation caused by the symbolic, and the possibility of reunifying sense and reason (which I suggest is another way of describing an encounter with the Good). Now, I would like to briefly justify my decision to abstain from engaging with some notable alternative 
approaches to problems of meaning, subjectivity, and good, including pragmatism, existentialism, a religious return, and psychoanalysis.

Dewey's move away from metaphysics has not solved problems, and actually limits human spirituality by eliminating a large swath of elusive questions so central to the human experience. Pragmatists hold a scientific, utilitarian, and instrumental view of truth; their truth is a shortcut which bypasses important questions. Only that which benefits concrete life is deemed good, thus, pragmatists discount anything that cannot be put to concrete ends. While pragmatists rightly point to the dialogical nature of the self, they seem to focus all of their energy on this interplay, rarely stopping to consider what that self (while, granted, constituted and constantly negotiating its subjectivity) might do for itself. In other words, they do not allow for care of the self, they do not allow for spiritual exercises (those practices performed on the self that alter the self's relation to truth). Pragmatists see philosophy as a tool rather than as a way of life, and though they are interested in avoiding the "dualisms" which we have inherited (mind/body, science/philosophy, etc.), their goal is not to touch the Good, but to empirically grow our understanding of practical human goods. William James for example, attributes to the absolute a number of "metaphysical paradoxes that are inacceptable [sic]" (James 157). Such frustration in the face of inconsistency sees James ill equipped to stand for uncertainty, which, as I see it, is a uniquely modern way of leaving space enough for an encounter with the Good. Wrestling with and enduring metaphysical paradoxes is vital.

While raising crucial questions concerning meaning, goodness, and subjectivity, an existential approach to problems of meaning and apathy also seems insufficient. Iris Murdoch for one rejects the radical freedom of the existentialists, who while at times 
critical of the modern project raise it to new heights. The view of solitary agents exercising freedom neglects the dialogical nature of the self and discounts a need for connection to something beyond the self.

A purely religious return is also insufficient for our times (late modernity). To propose a religious return would be to neglect contemporary conditions and the possibilities they offer. While the word spirituality does call to mind religious practice, we would do well not to conflate religion and spirituality. Religion offers a way of attempting to be spiritual, but it is not the only way. Religion may offer a viable form of spiritual practice for some, but modern culture as a whole has become secular. Kracauer argues that many participate in religion out of reflex rather than out of a deep commitment, and because of this I feel it would be unwise to simply advocate a religious return for all. In the following pages I focus not on religious faith, but on a standing for uncertainty. In a secular world, the way to remember that the world has ever been enchanted may not be through faith, but through a standing for uncertainty. Although faith was central for thinkers like Jacques Ellul, Simone Weil, George Grant, and Marshall McLuhan, we need not be religious to be spiritual. While a devout catholic, even McLuhan never advocated a purely religious return. In fact, he counseled against the idea of a pure return, and instead sought awareness through aesthetic exercise.

Psychoanalysis has sought to align Man with his environment, and various psychoanalytic thinkers have wrestled with the issue of leading a good and balanced life. Their ideas are certainly provocative, if at times conflictual. In the case of Freud, impulses and desires must be reigned in and aligned with the dictates of civil institutions, and as such, the goal of this branch of psychoanalysis is to address the trauma caused by 
this alignment, or to make the alignment as seamless as possible. In a reversal of Freud, R. D. Laing claims that what we call sanity (a civilization which represses desire) is actually collusive madness. Then, there is the Lacanian psychoanalytic camp which understands the subject to be eternally split. This is to say, it is in our nature to be alienated, and this alienation is the cost of abstract reason. If to be a subject is to be alienated, then to embark on a project of unification makes no sense. In yet another branch of the psychoanalytic family, Erich Fromm offers a sound critique of modernity, but his advocacy of a humanistic ethics which seeks a self that experiences unity and equilibrium (rather than necessary repression, or alienation) remains squarely within the Cartesian tradition, and his notion of good still falls prey to a current of modern practicality. While this lack of disciplinary unity creates some fertile tensions, due to the fact that psychoanalysis as a whole seems little interested, I would suggest that psychoanalysis is ill suited to deal with the matter of the Good under modernity.

While I think the history of the idea of apathy presented here is apt, practical limits demand that it be incomplete. The middle ages are treated in passing, and I certainly could not have covered the entire range of antiquity (hence my decision to focus on the later Stoics, whose work most fully expounds the idea of apatheia, and who rely heavily on áskêsis) in such a brief forum. While at numerous points I do intimate something of the effects of new media on the self (and by this I mean the digital milieu and the move toward an electric aural culture), the focus on apathy as a forgetting to care and disconnect from the Good demanded that I leave such matters for another time.

Attentive readers will also note my decision to refrain from devoting one single chapter to a literature review. Instead, and owing to the range of issues connected to the 
problem of apathy (including the look back to antiquity, the break between care and knowledge, the disconnect from the Good, the fragmentation of the sensorium, and the potential aesthetic response), each chapter contains (and in a sense is) its own literature review. In chapters one and two, I engage with primary and secondary material on the Stoics. Chapter three examines interpretations of the modern progress narrative, while chapter four surveys (and then moves beyond) recent scholarship on apathy. With an emphasis on McLuhan and his commentators, chapter five assesses modern approaches to aesthetics. Chapter six assesses the literature on the Platonic conception of the Good, including its modern commentators. Chapter seven engages with scholarship which examines Keatsian negative capability. Granted, this diffuse approach to a literature review is unconventional, but given the nature of the problem, and its far reaching connections, I find this to be the most suitable way of assessing the literature. To have compressed these seemingly disparate scholarly fields into one chapter would have been to court confusion.

While contained within the writing process itself, I would describe my methodology as a combination of close reading, a history of ideas, and (with a nod to McLuhan) a grammatically inclined mosaic. In the spirit of McLuhan (for whom artists have great foresight in these matters), and Ellul (for whom awareness of the technical milieu must come from personal artistic work), I refer to a number of literary examples, as artists often boast great foresight, and within literature we can read something of the tenor an age. This may be unsatisfying under a technical milieu where quantitative - or what Heidegger calls calculative - thought is often favoured, but this is precisely why I feel a qualitative or meditative approach to be so important. It is my hope that this work 
may act as a foundation for further research on the problem of apathy, that it may provide a platform for further analyses of modern spiritual practices, and that it may be used in conjunction with other work that analyzes the consequences of modern subjectivity, epistemology, and attendant sunderings.

Their eclecticism and scope aside, it is my hope that each of these chapters participate in a common program and contribute to one overarching message: though under modernity there is a tendency to forget self-care and connection to the Good, there are still modern means (inspired by an ancient sensibility) available to us, means which may allow us to endure uncertainty and leave space enough for encounters with the Good. This history of the idea of apathy and repositioning of apathy within a larger context may, I hope, encourage an awareness of this modern malaise and open it to new forms of critique. 


\section{Chapter 1 - Ancient Apatheia and Áskēsis}

For a modern take on apathy that is cognizant of the concept's ancient roots, we need only look to Kant's Metaphysical Principles of Virtue. Kant's take on apathy is reminiscent of the Stoics, as for him, virtue (the sole good in Stoic ethics) presupposes apathy. Kant notes that apathy has fallen into disrepute, and that it is often misinterpreted to mean a lack of feeling, and/or a subjective indifference (Metaphysical Principles of Virtue 68). Like the Stoics, Kant views apathy as freedom from the passions rather than universal indifference. Similarly, contemporary classicist Brad Inwood notes a "long legacy of misunderstanding which the Stoic doctrine of pathé and apatheia has left" (Inwood 1987:145). It is due to this "legacy of misunderstanding" that the concept of apatheia as presented in the writings of the later Stoics will be clarified and expounded upon.

In an effort to justify my approach, I would like to briefly touch upon potential difficulties that accompany any reading the Stoics from a modern context. To this end, I turn to the work of John Cooper. Cooper considers ancient philosophies as unified ways of life; this for him is their central feature. This means that Stoic ethics, physics, and logic, cannot be divorced if we want to understand the Stoic way of life, as these three subjects comprise a complete way of viewing and living in the world. That said, I will be focusing on the ethical dimension of Stoic thought, and taking for granted the fact that it is, along with physics and logic part of an integrated and whole way of living. An understanding of the metaphysical moorings, or what Cooper describes as the "cosmic context" of Stoicism, is essential if we are to properly understand this way of life (Cooper 215). While we cannot completely understand this way of life without viewing Stoicism 
as a totality, we can still appeal to ideas, methods, or a general ethos in order to supplement our own thought.

There are, as Cooper notes, certain difficulties that accompany any discussion of Stoic thought. For instance, there is no single author (and thus no solitary viewpoint) that can best be said to map out the Stoic position. Unlike Plato or Aristotle, the Stoic system comes to us from a variety of thinkers, commentators, and in a number of styles (from the historical commentary of Diogenes Laertius, to the literary rather than technical style of Seneca, to the elliptical and meandering meditations of Marcus Aurelius). Cooper also cautions that many of the reports and interpretations of Stoic thought come to us from thinkers who are unsympathetic to (or who simply do not fully understand) the Stoic way of life (Cooper 215). For this reason, I have decided to focus on the later Stoics, Epictetus (A.D. 55-135), Seneca (B.C. 4- A.D. 65), and Marcus Aurelius (A.D. 121-180), whose primary writings are still available to us. Cooper, who focuses on the "Old" Stoics (Zeno, Chrysippus, etc.), raises a difficulty specific to their study: the lack of primary material. Many accounts of the old Stoics come from interpretations and reports of commentators and historians, some of whom (like Plutarch) are staunch critics of the school. This is one more reason that I have, for the most part, limited my assessment to the later Stoics.

In contrast to modern apathy, which I have characterized as a forgetting to care for the self, ancient apatheia is something intentional, and is both the end and substance of a deliberate process of self care and transformation. As they are central to the rest of this work, this chapter will explain the ancient concept of apatheia, and the connected concept of spiritual exercise (áskēsis). Next, an initial discussion of apatheia will present 
some of the nuances which accompany the later Stoics views of this concept, and the metaphysical contours of apatheia will be explored. Following this look at the often misunderstood concept of apatheia, I will then turn to the inseparable matter of ancient spiritual practices, or áskēsis. Both the logic of these practices and some specific examples will be examined, as well as their grounding in metaphysics. Apatheia is the end of áskēsis, and such spiritual exercises constitute a course of sustained and deliberate caring for the self, designed to alter the subject's relation to truth. In the case of the Stoics, the truth is that we are part of the whole, and these exercises are meant to align the self with virtue, and move us toward a more immediate intuition of reality. With this understanding, it becomes clear that apatheia has a different relation to care than its modern counterpart. Where apatheia demands a program of exertion and care, modern apathy can be understood as carelessness and disconnection from the world.

Before examining the Stoic texts themselves, it is worth noting that their completely different understanding of apatheia is rooted (like all of their beliefs) in a metaphysical worldview. Part of what I will be arguing later (following the likes of Long, Inwood, Sorabji, and Irvine) is that Stoic ideas of apatheia and áskēsis need not remain anchored to their unique worldview. While Stoic practices and beliefs invariably emerged from a metaphysical outlook, this does not mean that certain practices and beliefs (or at least their underlying logic) cannot be borrowed from this context and used as inspiration in the modern world. Richard Sorabji writes that "ideas can also be revived with surprisingly little change... Ideas can be revived because, although they need a context, they can be transplanted into a new context" (Sorabji 12). Though as opposed to 
transplanting I would prefer to allow ancient ideas to inspire, I agree with the thrust of Sorabji's comment, and I am specifically interested in looking back to ancient ideas of áskēsis and apatheia (and in locating their presence within certain modern thinkers and artists) in the hope that such ideas might inspire moderns to care for themselves and leave openness enough to touch the Good.

The passions are central to any understanding of apatheia. According to Diogenes Laertius, the Stoics "believe that the passions are judgments" (cited in Inwood \& Gerson, 141). To state this more accurately, the passions are born of judgments. Hadot provides clarification on this point when he writes, "the Stoics believed that the human passions correspond to a misuse of human discourse. In other words, they are the result of errors in judgment and reasoning. We must therefore monitor our inner discourse to see whether erroneous value judgments have crept into it" (What is Ancient Philosophy? 135). Stoic apatheia then, does not strictly involve eliminating the passions, but rather the erroneous value judgments which give rise to the passions. What we experience as emotions are, in Stoic terms, mistaken ways of feeling and desiring (Cooper 161). The Stoics are not, as is often claimed, suggesting that we eliminate fundamental aspects of our natures (Cooper 163). Emotions do move us to action, they do indeed affect us. For the Stoics, what we experience as emotion is the result of wrong headed reasoning, or erroneous and distorted judgments concerning what matters and what does not matter. The Stoics saw the pathé as expressions of "serious moral, and intellectual failure" (Cooper 207). In order to preclude the passions, the Stoics argued that we must learn to make judgments which are virtuous (in accordance with nature). Despite their effort to preclude the passions, "the Stoic life is by no means without affect - without felt engagement, in a perfectly natural 
human way, both with the doings of one's duties and with all aspects of normal human relationships to other people and to one's own bodily and psychological satisfactions" (Cooper 207). The Stoics did not aspire to be automatons; they simply strove to cultivate their reason so as to avoid being led by the passions. It was essential that one manage one's inner discourse so as to ensure right reasoning, as reason had a role in determining what one should commit oneself to. Here, right reasoning refers to a self moving into concord with the whole, and this by ensuring that one care only for that which really matters. But, how can one know what really matters? What matters is that which is up to us, and all that is up to us is to decide that our judgments are in accordance with virtue. Making judgments is a highly active process that demands constant attention, and consequently, the Stoic understanding of apatheia bears no relation to modern apathy. In brief, we can think of modern apathy in terms of a forgetting to care for the self and a confusion regarding the Good; it is not freedom from the pathé won through effort and awareness, but a failure to feel and a lack of connection which afflicts from without. It is experienced as isolation or alienation from a wider world and is something passive, whereas Stoic apatheia (which was necessary in order to live in accord with the cosmos) involves nothing less than the deliberate exercise of right judgments and connection to something larger than the self.

Scholars have described apatheia in terms of right judgments, and in terms of eradication of passions. Contrary to the language of Knuuttila, and following understandings expressed by Inwood, Hadot, and Graver, I argue that apatheia is better understood in terms of right judgments, preclusion of the passions, and alignment with the Good, rather than as a coping mechanism whereby passions are eradicated. In 
simplest terms, I would like to characterize apatheia as freedom from the passions (pathé), as opposed to an alternative definition proposed by both Sorabji, and also Knuuttila: eradication of the emotions. Knuuttila writes of the eradication and extirpation of the pathé, and Sorabji also often uses aggressive language, describing apatheia as eradication of emotion. Why does Sorabji use such language when he acknowledges that "Stoicism can be very helpful in dealing with counter-productive emotion. But it is not a matter of gritting your teeth. It is about seeing things differently, so that you do not need to grit your teeth" (Sorabji 1), and when he notes that "The Stoics think we all tend to have the wrong evaluations, and they believe the remedy lies in a change of attitude. But the focus is on the situations themselves and how we see them. And this is useful because advice on this is probably less immediately accessible nowadays" (212). I find it puzzling that Sorabji recognizes both the role of awareness (and preclusion) in Stoic ethics, and yet still explains apatheia in an aggressive way, and as a redemptive (rather than preclusionary) effort of eradication. This view of apatheia as eradication may be due to a focus on earlier Stoics such as Chrysippus, while the view of apatheia as preclusion of the passions advanced here is based primarily on readings of the later Stoics (Epictetus, Seneca, Marcus Aurelius).

For the Stoics, both apatheia and áskēsis are tied to virtue or the Good; both are seen as part of a constant process, rather than as something ready-made which is given to us, or that happens to us. Apatheia is a state of contentment arrived at through spiritual exercises where one is free from the influence of the passions, or, more specifically, when one's judgments have been made sound, or have become aligned with nature so as to preclude the possibility of being lead by the passions. Apatheia can be thought of as a 
state of rational contentment, where one is aligned with the cosmos, and while it may be thought of in terms of contentment, apatheia is not merely a static state which one arrives at. It must be cultivated, and it requires work to maintain.

In his $9^{\text {th }}$ Letter, Seneca describes apatheia in greater detail: "what we mean by it, the man who refuses to allow anything that goes badly for him to affect him. Consider then whether it might not be preferable to call it a mind that is 'invulnerable' or 'above all suffering"' (48). The Roman conception of apatheia is not numbness, but rather stems from an engagement with ethical questions about what does and does not matter. To experience apatheia is to have reasoned soundly, thus precluding spontaneous eruptions of passion. Apatheia is contentment arising out of proper judgments which are in line with universal nature. In this case, judgments are made which pre-empt (rather than eradicate) passions. Seneca's use of the verb "refuses" is quite telling, as this signals an act of will(fulness), and a forceful one at that. Refusal goes beyond mere toleration or acceptance; it is a deliberate and willful rejection. Not a rejection of an event, but a rejection of our response to the consequence of the event. This is tantamount to an exercise of complete control over one's reactions to situations that are not up to us. This control involves much more than the retroactive managing of emotion. As Margaret Graver and Pierre Hadot have each pointed out, it should rather be thought of as control over one's judgments. This deliberate act of refusal can be thought of as making right judgments, or judgments in accordance with virtue or the Good. Hadot offers clarification on this point, claiming "The problem is not so much to repress such-and-such a passion, as it is to learn to see things "from above" in the grandiose perspective of universal nature and of humanity" (Philosophy as a Way of Life 284). The task then is not to exercise 
control over passions that have already erupted, but to align oneself with virtue and thus avoid the pathé altogether. ${ }^{2}$

Cooper gives an excellent account of what the Stoics meant by living in accord with virtue. We might think of this in a twofold way: as living in agreement with oneself (to be non-conflicted), and as having thoughts in accordance with the whole of nature. The term "in agreement" "has the word "reason" ( $\lambda$ ó $\gamma \circ \varsigma)$ as its root. It means literally "having reasoned thoughts that are the same or in common" "(Cooper 152). But one must be in agreement with more than just oneself:

living in agreement means that one thinks in some way some of the same thoughts as the world itself does... If one lives virtuously, for the Stoics, that means that one thinks some of the same thoughts about one's life, its circumstances, its successes and failures - about how one is leading it, and what one is doing at any moment in so leading it - as Zeus himself thinks about it, both in terms of one's general orientation, and with respect to particular actions one does at any moment (Cooper 152-3).

To live "in agreement" with nature then, means to have reasoned thoughts and actions which align harmoniously with the cosmos. Cooper provides further elaboration when he writes that our "individual minds stand in relation to a divine mind that is actually and actively present within the world of nature... Either we live in agreement with, and obedience to, it (and so, virtuously and happily), or we do not (and so, viciously and miserably)" (Cooper 154). We can choose to live in agreement with and submission to nature, or we can choose to contravene and attempt to overcome nature. The only thing up to us is this choice, and Stoic áskēsis are designed to cultivate right reasoning that will allow us to make the right choices.

\footnotetext{
${ }^{2}$ According to F. E. Peters, the pathé were described by Zeno of Citium, the founder of the Stoic school, as excessive impulses, or "irrational movements of the soul" (155).
} 
Returning to his description of apatheia, the fact that Seneca uses the word "badly" is also significant, as this implies that apatheia is not pure indifference or lack of care in general. In admitting that things can go badly, Seneca also admits that they can go well. There are recognizable categories of bad and good, and apatheia concerns the manner in which we judge the good and bad, and consequently, our reaction to this judgment. This refusal to allow things to affect us demands a focused and deliberate state of readiness or constant awareness (what might be called a focused presentness).

Attention or awareness is crucial for the Stoics. In the words of Epictetus, one should not act like a sheep (p93: II 9.3), by which he means that one should abstain from acting in a haphazard or inattentive way. According to Hadot, Stoic

philosophy was a unique act which had to be practiced at each instant, with constantly renewed attention (prosokhē) to oneself and to the present moment. The Stoic's fundamental attitude is this continuous attention, which means constant tension and consciousness, as well as vigilance exercised at every moment. Thanks to this attention, the philosopher is always perfectly aware not only of what he is doing, but also of what he is thinking... and of what he is - in other words, of his place within the cosmos (What is Ancient Philosophy? 138)

Through attention and practice, the philosopher is able to maintain a connection to reality.

Thinking still on Seneca's description of apatheia, it should be noted that freedom from the passions via "refusal" is a far cry from the "eradication" described by Sorabji and Knuuttila. To eradicate is to destroy, while freedom from by way of refusal implies a deliberate preventative measure. For Seneca, it seems we need not destroy the emotions outright, so much as deny them the opportunity of surfacing in the first place. In fact, I quite like Inwood's notion, that apatheia (what I've been calling freedom from the passions) can be summed up in the following way: "apatheia is eupatheia" (Inwood 
Ethics and Human Action in Early Stoicism173). In other words, freedom from the passions (pathé) leaves one with a remainder of noble feeling (eupatheia). Thus, without the passions to weigh us down, all we are left with are the noble feelings associated with virtue.

While Sorabji feels Stoicism can be useful in helping us cope with emotions, I wonder if "cope" is the right word? Perhaps the words "master", "govern", or "preclude" would be more fitting? With a nod to Graver, I think the term preclude would be most appropriate. We must make right judgments (in line with universal nature) so that the pathé (reactive feelings) are simply pre-empted. Coping is an ancillary action; it occurs after the fact and in response to. We only cope with things that have already taken shape and afflicted us. We cope with things that are beyond our power, and that we have allowed to afflict us. The Stoic idea was to avoid coping altogether. I suppose Sorabji is interested in what Stoicism can do for us now, and he feels that the emotions are not something that should (or can) be mastered or precluded.

Seneca's description refers to a mind "above all suffering," and it also likens apatheia to invulnerability. But does he mean above as in out of reach of, or above as in superior? I think both could be made to apply. Above as in out of reach suggests a method, while above as in superior suggests the ethical result. In training ourselves to make right judgments, we move ourselves beyond the sway of the passions. Once this distance has been achieved, we are now above the suffering caused by the passions. Marcus Aurelius observes something similar, when he writes that we must be "beyond the reach of passion" (48). In order to be beyond the reach of passion, we must train ourselves to make right judgments. If we value the wrong things (externals, rather than 
the Good/virtue), we will be susceptible to jealousy, the opinions of others, etc. If we consider once again apatheia as "eradication" versus apatheia as "freedom from," then both Seneca's description of a mind above suffering and Aurelius' claim that we must be beyond the reach of passion fit with an understanding of apatheia as "freedom from." A mind above speaks to a mind that has been cared for and worked on, and one that is no longer susceptible to erroneous judgments that allow the pathé to percolate to the surface. The same goes for the description given by Aurelius. To be beyond the reach of passion is to pre-emptively bar the very possibility of the passions. Both Seneca and Aurelius describe apatheia in a way that is vastly different from a combative and retroactive conception of apatheia as eradication.

Seneca's description of mental invulnerability also speaks to something willed, something that has been built up, a mind that has been cultivated, worked on, cared for. Being above suffering is not a byproduct of numbness; rather, one moves beyond suffering through disciplining oneself to the point that right judgments (in line with virtue) are always made, which in turn guarantees that no suffering can occur. I agree with Inwood here, that in the name of clarity, the later Stoics, especially Seneca, might have worded this differently. Instead of advocating rising above suffering, Seneca might have discussed willing the cessation of suffering, willing the preclusion of suffering, or even a pre-emption of erroneous judgments which lead to suffering. In other words, he might have emphasized the centrality of awareness, ${ }^{3}$ which is crucial in Stoic ethics. One must recognize the conditions that lead to suffering and through such cognizance, prevent them.

\footnotetext{
${ }^{3}$ As do both Epictetus and Marcus Aurelius, when they assert that one must first recognize that one's character requires care and cultivation before any progress can be made. We must be cognizant of our weakness.
} 
As with most of his central points, Aurelius repeats his notion of apatheia, asserting again and again that one must "be free from such passions [anger - the pathé] and full of affection for his fellow human beings" (Aurelius, 5). It is interesting that affection here implies connection with others, and is therefore not considered a reactionary passion by Aurelius. For the later Stoics, it is within one's control to choose to cultivate feelings for and connections with others. This demonstrates a point made by Hadot, that the Stoics are not advocating a retreat into the self. Rather, they are interested in caring for the self in order to properly care for others. After freeing oneself from the pathé, one is then able to show proper affection for other human beings while acting in accordance with nature. Apatheia does not involve a turning away from others; rather, it is ultimately a turning towards. Aurelius provides a perfect example when locating a model of inspiration within his brother, "whose character was able to stimulate me to cultivate my own nature" (Aurelius, 9). His brother's áskēsis acted as an example for Aurelius to follow. The brother did not necessarily desire to affect Aurelius; rather, his very character (that had no doubt been carefully cultivated) had a positive effect on him. This is a prime example of care of the self affecting others, and it is vastly different from the modern understanding of apathy, which has a kind of universal carelessness at its center. Considering these negative descriptions of apatheia as freedom from, the passions (and by this I mean, reactive feelings) are here seen as an affliction that hampers human connection. The passions, according to the Stoics, alienate us from the self, others, and the cosmos. Apatheia for them was a pre-emptive manoeuvre against global alienation, and it is for this reason that one of the things I'll be arguing in subsequent chapters is that the logic of áskēsis could be useful to us moderns. The very act of engaging in áskēsis 
has the potential to grant an awareness of the self, which may in turn grant a new awareness of one's surroundings.

Up to this point I have described apatheia as freedom from the passions, and have claimed that far from a modern understanding of apathy as a passive withdrawal owing to a forgetfulness regarding the care for the self (this is to say, moderns do not choose to be apathetic), the ancient concept of apatheia must be understood as an active principle. As such, the matter of choice is crucial here, and the Stoics spent a great deal of time discussing the importance of choice. A touchstone for Epictetus is the question of what is up to us versus what is not up to us. It is only when we consider indifferent those things that are not up to us that we can be free from passions, and thus be content. Epictetus makes it clear "[t]hat some things are good, some evil, and others indifferent: the good are virtue, and whatever partakes of virtue; the evil, the contrary; and the indifferent, riches, health, reputation" (The Discourses of Epictetus p94: II.9.15). Or, as he describes elsewhere, "things outside the sphere of choice are neither good nor bad, and all things within the sphere of choice are in our own power, and can neither be taken away from us, nor given to us" (The Discourses of Epictetus p104: II.13.10), and "it is in choice alone that good and evil lie" (The Discourses of Epictetus p282: IV.12.7). Choice is crucial for the Stoics, as it is all we have, and we must either direct it towards virtue, or not. Everything that is not up to us is to be treated as morally indifferent (as adiaphora, or those things unconnected to the ideal end of Man - living in harmony with nature). We can also see the importance of choice in the work of Seneca, for whom "[t]he highest good is found in the very act of choosing it" (Seneca Dialogues and Essays 92). Here the active process is ultimately more important than the targeted goal. 
Epictetus tells us that "[s]ome things are up to us and others are not. Up to us are opinion, impulse, desire, aversion, and, in a word, whatever is our own action. Not up to us are body, property, reputation, office, and, in a word, whatever is not our own action" (The Handbook of Epictetus p287: I). What is up to us is whatever cannot be taken away by another, while what is not up to us is whatever can be taken away by the actions of others. We don't judge things to be indifferent; they either are, or aren't. For the Stoics, virtue is the sole good. Epictetus reminds us that "[i]t is not the things themselves that disturb people but their judgments about those things" (The Handbook of Epictetus 289: V). In other words, external actions do not affect us; rather, our judgments concerning external events are what affect us. For example, if we judge it important that others hold us in high regard, their evaluation of us - something that is not in our power - can affect us. Such judgments - that being held in high esteem is important - open us to being affected by the opinions of others. But if we deem the most important thing in life to be contentment with what we have, then our well being is within our control. This is in line with the thought of Brennan, Graver, Hadot, and Gill, as for them, the Stoics are not interested in merely masking reactive emotions, but rather in ensuring that we make sound judgments, which will in turn move us towards freedom from the pathé.

In his Meditations Aurelius describes the desirability of "Imperturbability in the face of what comes to pass from a source outside yourself" (87). This is closely related to the matter of choice. It is not external objects which affect us, but rather how we respond to externals. Choice is so important for Epictetus that he asserts "not even Zeus himself can get the better of my choice" (The Discourses of Epictetus p7: I.1.23). Ultimately then, the only thing up to us is choice. We can either choose to live in accordance with virtue 
(and thus make judgments based on this), or, we can choose to focus on externals, and make judgments that will inflame the passions (and thus lead away from contentment, to misery).

As Epictetus tells us, "choice cannot be hindered or hurt by anything outside the sphere of choice, but only by itself' (The Discourses of Epictetus p184: III.19.2). In the end, choice is really the only thing that is up to us. Nothing indifferent is up to us, and therefore, we should focus on the act of choosing, and ensure that our choices are made in accordance with virtue. The importance of choice underscores the active and willed nature of ancient apatheia. Apatheia was not something that afflicted or happened to one, rather, it was chosen.

Apatheia, or freedom from the passions, is an ideal state occupied by the Stoic sage, but we might also think of it as the endpoint in a long and gradual process of áskēsis. Once one has exerted sufficient time and energy on spiritual practices, all of one's judgments will be aligned with virtue. In other words, through a lifetime spent in spiritual training, the natural inclinations will tend to move towards concordance with virtue. But until years of exercise and effort have been performed, one will have to focus intently on each moment and on each act, attempting to make sure it is aligned with virtue, and even once concordance has been reached, one will still have to maintain this manner of life. Consider the analogy of muscle memory. After a great deal of training and focus, certain repeated physical movements may become committed to the central nervous system, so that one no longer needs to consciously think about performing said actions. Walking is the most obvious example, however many sports or activities involving fine motor skills also involve muscle memory (a form of physical unconscious 
spontaneous right-action). Similarly, the Stoics sought to inculcate spontaneous rightjudgments in alignment with virtue through áskêsis, which we can think of this as a kind of spiritual memory, or the commitment of ethical judgments to the autonomic nervous system. As Kant points out in his Grounding for the Metaphysics of Morals, these judgments that are in accordance with virtue cannot spontaneously be willed one day. This is to say, one cannot simply decide to act in accordance with the Good, and then proceed to do so. Right judgments that are aligned with virtue are the result of effort and exercises or spiritual practices, which the Stoics called áskēsis. ${ }^{4}$

For Hadot, ancient spiritual exercises involved more than just thought; they transformed one's entire way of being. This view is upheld by looking to the writings of the later Stoics, who constantly wrote about the importance of effort, attention, awareness, and cultivation. Stoic áskêsis involved attempts at trying to return to the essence of things, what we might describe as adherence to mimesis, and extended use of the metaphor of cultivation.

On the importance of practice and training, Epictetus writes that "philosophers exhort us not to be contented with mere learning, but to add practice also, and then training" (The Discourses of Epictetus p94: II.9.13). This brief line reveals a great deal about Stoic áskēsis and epistemology. Why might practice and training be described separately here? It seems that Epictetus is using two senses of the word practice: practice as an act of repetition in order to advance towards perfection, and also, practice as simply the act of doing. Once we have begun practicing (whatever lesson we have learned), we

\footnotetext{
${ }^{4}$ Of the scholars who have written on áskēsis, I find Sorabji's approach to be quite refreshing. Though he does look at specific exercises, his primary focus is on the idea of exercises. Contrary to Irvine, who lists examples of specific Stoic spiritual exercises (and assesses their applicability in a modern context), Sorabji steps back from the content of the exercises themselves, and instead looks at how they are applied and practised. Sorabji emphasizes the logic and method rather than the specific act.
} 
then move on to train ourselves to automatically (and always) respond in a certain way. Training here refers to self-inculcation and internalization (what I have called the conditioning of right-judgments). Also of note is Epictetus' qualification of "mere" learning. For Epictetus, we must move beyond the idea that learning is simply a matter of passive accumulation. Rather, learning must also involve a practical element that transforms the self in some way. This is to say (with a nod to Foucault), that learning must be spiritual. Knowledge involves more than the memorization of facts. Once learning has occurred, we must apply what we have learned, and then train ourselves through repetition to maintain the practice or acting-out of our knowledge. Knowledge involves a transformation of one's very being.

Kant takes a similar position on learning, as for him, wisdom is about doing or not doing, rather than simply knowing (Grounding for the Metaphysics of Morals 16). Kant doesn't just link wisdom with a store of accumulated knowledge, or only with action, he links it to choice. Doing or not doing involves exertion of the will. The example of Kant illustrates that these ancient sensibilities are not extinct; they have endured and persist still, even if we are not always aware of them. There are threads which connect us to antiquity, threads more luxuriant, more prominent in some thinkers than others. We still ask many of the same questions, and this makes it well worth our time to look back to antiquity for inspiration.

Like the Stoics, Kant views virtue not as something given, but as something that must be earned: "That virtue can and must be taught follows from the fact that it is not innate" (Metaphysical Principles of Virtue 145). This view of virtue as the product of discipline and training is shared by Seneca, for whom virtue is only relevant if it requires 
discipline and an act of concerted effort to attain (and we must, of course, also make ourselves aware of this entire process). This leads us to Seneca's ruminations on primitive man and the earning of virtue. Seneca examines the status of virtue as it relates to both the primitive man, and the man of culture, as in his $90^{\text {th }}$ Letter he anticipates the claim of natural goodness later made by Rousseau. Beginning with an argument against civilization, Seneca eventually goes on to reveal (paradoxically) its absolute necessity if one is to live a virtuous life (the life of the sage). Seneca provides us with what would now be thought of as a Rousseauesque praising of primitive man, but with the proviso that although the innocent primitive was in possession of many of the qualities valued by the philosopher, these traits of character were attained through ignorance rather than effort or merit. For Seneca, philosophy must be cultivated, as he tells us "the process of becoming a good man is an art" (Letters from a Stoic, "Letter XC" 176). Note that Seneca does not speak of a state that has been or can be realized. With the suffix "ing" he implies that one may never actually and with finality become a good man. It is an ongoing art of becoming, or an art constantly in motion.

What does Seneca mean by "art"? I suppose something which is practiced, in which talent or aptitude is accrued, techniques learned and internalized. It is not enough to possess the qualities of a philosopher. One must have earned them through constant work and spiritual movement. The qualities of the sage must be cultivated. It is interesting that while critiquing civilization, Seneca uses a metaphor which springs directly from civilization - cultivation. In doing so, Seneca touches on a paradox: the primitive man acts as a philosopher would like to act, but the primitive does so out of ignorance, and therefore his noble conduct does not count. For Seneca, civilization leads 
us away from the noble qualities of the primitive, and yet it (and the abstract reason which gives rise to it) is necessary in order that we may be self conscious of our efforts to secure these qualities. These qualities mean nothing if they have not been earned or secured through effort or cultivation, and they mean nothing if we are not aware of the process which allowed them to flourish. So for Seneca, we must move away from nature in order to properly return to it, we must return to nature with a self-conscious and abstract understanding, an understanding based on reason.

Seneca makes it clear that in order to embark on any sort of enquiry, we must use language and concepts. Paradoxically, any attempt at re-acquainting ourselves with the immediate sensual experience that was lost when we began to speak, requires us to use symbols. In a similar move, Aurelius also attempts to use language to approach the essence of things. For Marcus Aurelius, all things do have an essential character. As the following example of áskēsis makes clear, there is a proper essential character or way-ofbeing inherent in all things:

When you have savories and fine dishes set before you, you will gain an idea of their nature if you tell yourself that this is the corpse of a fish, and that the corpse of a bird or a pig; or again, that wine is merely grape-juice, and this purple robe some sheep's wool dipped in the blood of a shellfish; and as for sexual intercourse, it is the friction of a piece of gut and, following a sort of convulsion, the expulsion of some mucus. Thoughts such as these reach through to the things themselves and strike to the heart of them, allowing us to see them as they truly are. So follow this practice throughout your life, and where things seem most worthy of your approval, lay them naked (46) This is somewhat similar to the Brechtian exercise of making the familiar strange, of stripping a thing or an act of its generally accepted significance. Both the exercise of Aurelius and that of Brecht attempt the same task, though for different reasons. The Brechtian exercise is intended to disrupt everyday notions and commonplace views, as is the exercise of Marcus Aurelius. However, where Brecht is interested in generating 
critical distance enough to grant a mild and contemplative confusion, Aurelius is interested in reaching the essence of things. ${ }^{5}$

Though I am tempted to describe this example of áskēsis using the Brechtian terminology of making strange (what Brecht called the Verfremdungseffekte, or, alienating effect), the expression doesn't quite fit. Perhaps it could be said that rather than making the familiar strange, Aurelius asks us to symbolically deflate (or drain the symbolic value from) what is in reality an everyday thing and a part of universal nature, thus allowing us to view it as it really is. In a sense Aurelius is making the familiar strange, but with the goal of trying to render a "truer" picture of that which is familiar and has an inflated symbolic value. Aurelius is approaching the notion that we are alienated from every aspect of our lives (including the Good) due to the alienating effect of language. Brecht is interested in using this effect to generate endless contemplation, while Aurelius wishes to make us aware of alienation in order to return to the essence of things. While this particular practice does in some ways resemble the practice of making strange, the language of Aurelius clearly demonstrates that for him, everything has an essence or a true nature, albeit an essence that is obscured by language and cultural pretension. Aurelius is stripping acts and objects of their social value, and is trying to remove these things (as much as is possible) from the symbolic realm. To lay a thing naked, as Aurelius puts it, to remove its garments, to remove its ornaments, to remove anything which has been made (including descriptive language) and which generates abstract or symbolic value is his goal. A naked thing is what it appears to be. With this

\footnotetext{
${ }^{5}$ Bertolt Brecht (1898-1956), German poet, dramatist, and theorist, perhaps most famous for his concept of the "alienation effect" (from his essay "Alienation Effects in Chinese Acting") whereby the artist prevents the spectator from "losing" herself in the performance in effort to foreground the strangeness of the event, and thus force contemplation.
} 
sort of unadulterated recognition, a thing's nature is on display, rather than some symbolic value that we have assigned it and which it now projects. This exercise can of course be extended beyond fine savories, and applied to any object or act that is thought to be un/desirable or that carries an inflated status.

Along similar lines, Aurelius advises us to "always define or describe whatever presents itself to your mind, so as to see what sort of thing it is when stripped to its essence" (Aurelius 21). This is rather like what I have called symbolic deflation. For Aurelius then, there are essences, and we have the ability to describe them. The fact that Aurelius follows the word define with "or describe" suggests that he has some doubts as to our actual ability to define the essential states of these things once and for all. If we cannot define them, then we must approach a fluid and approximate understanding through careful description or circling around a thing with the intent of actually entering into it.

Aurelius engages in more acts of symbolic deflation, as in the following passage, when he writes "How putrid is the matter which underlies everything. Water, dust, bones, stench! Again, fine marbles are calluses of the earth, and gold and silver its sediments, and our garments matted hairs, and the purple, blood from a shellfish" (Aurelius 88). Here Aurelius is stripping things of their symbolic cache, and revealing what he perceives to be their essence. What I have termed symbolic deflation, Sorabji describes in a more general way as, "Relabelling." A prestigious thing is relabeled and thus becomes something humble. This practice entails changing the language we use in order to change our relation to the thing itself and grant an awareness of the thing's true nature. With such an awareness of the thing's true nature, we will be more likely to judge it appropriately. 
Vivid descriptive words (which inflate the symbolic value of a thing or enhance its prestige) threaten to lead us toward false judgments. We see an ingot of gold and describe its lustre, we judge it to be desirable. But, Aurelius tells us, if we see gold for what it really is - earthly sediments - we will not esteem it so highly. The practice of relabelling is an important step in making right judgments, and while Aurelius does feel that relabelling is a viable tactic that can help us deflate symbolic value and approach the essence of things, he is still cautious and aware of its shortcomings. Likewise, both Seneca and Epictetus accept our reliance on language as a tool that can be used to attempt a return to essences, but both are also suspicious of language. They recognize its shortcomings (the fact that ultimately, language falls short), but also grasp its necessity if we are to be aware of the process of becoming a good person. If we are to be conscious of a thing, we must grasp it after the fact, or abstractly.

Aurelius again reveals his belief in both the existence of absolute essences and the ability of the symbolic to obscure said essences when he writes on mimesis, claiming that "the arts merely imitate natural things" (Aurelius 105). This is a fascinating claim, as the Stoics are vigorously working to ensure that their judgments are in line with universal nature, and are aware of the problems posed by the symbolic for the apprehension of the absolute, yet Aurelius and Seneca both liken life to art on numerous occasions. What does this imply? If life is an art, is it merely an imitation of something higher? Perhaps the linking of these terms signals a connection to the cosmos? In addition to being something that we must constantly cultivate, work at, and make, this seems to suggest that life is an attempt at approximating the Good, a task that is never complete and that is always progressing. And while life is an art that we must work at in order to have it 
approximate the Good, this admission that the arts merely imitate natural things suggests an awareness of the problems associated with this enterprise. This draws from an ancient understanding of art as mimesis, rather than the modern understanding of art as creation, or what McLuhan has called "outering” (consider Howard Roark from Ayn Rand's Fountainhead). This excerpt from Aurelius suggests that we tend to imitate (and often poorly) universal nature and circle around it using symbols, rather than actually enter into it. Subscription to mimetic ideas demonstrates the metaphysical character of apatheia and áskessis: there is an absolute Good (cosmos, universal nature), and everything we make (including our own lives) merely imitates this Good. Arne Melberg describes mimesis as a "loss of self," the basic idea being that as soon as we imitate something or someone else, we cease to be ourselves (Melberg 20). Mimesis is one way of working toward transcendence, for in imitating the state of nature (apprehended through beauty), we condition the self for transcendence, we move beyond the self. For Seneca and his rumination on the primitive and Aurelius and his practice of symbolic deflation, this is of course what we do with language. These respective arguments reveal a belief in the mimetic character of life and language, and thus speak to a metaphysical outlook, and yet, they also reveal a note of optimism (or perhaps more of a refusal to accept defeat how Stoic!). For Seneca, language pushes us away from the Good, and yet it is the only tool that can be used to attempt a return to that Good. And, as Aurelius' tactic of symbolic deflation reveals, we tend to hide behind cultural-linguistic pretences, and the only way to purge these pretences is via language. The Stoics are painfully aware of the role language plays in our alienation from the Good, as well as its role in allowing for the possibility of a return to the Good. Through a lifetime of exercises fostering awareness of 
one's judgments, the Stoics hoped to free themselves from the pitfalls of perception, and partake in the harmony of the cosmos.

Though focusing on the Stoic response to poetry, in his chapter on Stoicism and mimesis Halliwell also touches on the broader Stoic understanding of mimesis, the basic idea being that there is a higher truth and everything we know is a representation of that truth. This also applies to the symbolic, as all language seeks to apprehend reality, but it is of course always a step removed. Language always falls short. In a metaphysical view, there is an absolute Truth which we ape, and try to return to. The irony is that by trying to apprehend Truth via language/the symbolic, we drive ourselves ever further from this Truth. Seneca, Epictetus, and Aurelius were all aware of this paradox, and yet despite the difficulties, they each possess a measure of optimism regarding the potential of language (or an intense focus on language) to actually re-orient us towards the Good.

Earlier I cited Aurelius' description of the influence of his brother: "whose character was able to stimulate me to cultivate my own nature" (Aurelius, 9). I want to return to this line for a moment as paring the ideas of cultivation and nature seems contradictory. To "cultivate my own nature..." what does Aurelius mean by this? Aurelius is referring to an alignment with the cosmos, with fulfilling his purpose as a part of the whole. Under layers of language and social pretension we have buried our inner nature, which is to say, our connection to the absolute. This idea of cultivating a return to nature describes the need to engage in áskēsis in order to re-orient ourselves towards the Good. Language, that which alienates us from nature, is necessary if we are to return to that sage like state with awareness intact. For Aurelius, before abstraction and sensation can mingle, we must first make use of abstraction. If deep down, we are, as Aurelius tells 
us, an "emanation" of the cosmos (Meditations 11), then it would seem that the problem arises when this emanation (of the order and harmony of the cosmos of which we are a part) and its source becomes obfuscated or distorted beneath layers of language and social pretence. But if nature is an essential state, how is one to cultivate it? We see here the optimism of Aurelius, in his attempts at using áskēsis in order to realize one's place in the cosmos. When he writes of cultivating his own nature, Aurelius is really advocating the cultivation of an awareness of our own nature that has been buried under symbols as for him, there is an essential self that is part of universal nature, though it is sometimes forgotten. For Aurelius, there is a nature within us all (and that nature emanates from the Good), but one that is masked by culture. This is rather like Seneca, for whom we must move away from our natural ("primitive") state in order to properly (that is to say, consciously) return to it. Likewise, for Aurelius, an awareness of our nature (our connection with and affinity for the Good/cosmos/nature/etc., which exists within us all) must be cultivated.

I cannot stress enough that for the Stoics, philosophy was not simply a matter of a disconnected accumulation of knowledge; rather, it was a transformative practice that had to be lived. To the Stoics, "all of philosophy, however theoretical some parts may seem, are for the practical end of living well and happily, through making the contribution to the life of the cosmos that we, and only we, can make, through our decision making as we do all our actions and live our own individual lives" (Cooper 218).

Like Epictetus, who advises that we read, write, and re-read so as to keep our insights fresh, and Aurelius, whose Meditations are a personal attempt at following this practice, Seneca advocates using writing as an exercise: "Write it too, provided you read 
what you write and apply it all to practice and to allaying the mania of the passions.

Study not to increase your knowledge but to improve it” (Seneca 1968: 225). Here, knowledge is not a corpus that we add to, but a quality we work towards perfecting. Thus we can say that the Stoics operate on the principle of improvement rather than accretion. Put another way, knowledge is viewed qualitatively, rather than quantitatively. Aurelius tells us (and himself of course) to keep precepts close at hand for future reference (24), and as Hadot makes clear, this is what the meditations are: precepts to which Aurelius can refer time and time again in order to ensure that he is staying on a spiritual path aligned with virtue. Foucault's later work is indeed (as commentators like McGushin have pointed out) a spiritual effort. While differing in that his genealogical method looks to the "vicissitudes of history" rather than the "chimeras of the origin" ("Nietzsche, Genealogy, History" 144), Foucault is connected to this ancient tradition, a fact of which he is acutely aware. ${ }^{6}$ Such simultaneous distance and proximity is important for Foucault, as he describes the practice, fundamental to Western philosophy, of examining "both the difference that keeps us at a remove from a way of thinking in which we recognize the origin of our own, and the proximity that remains in spite of that distance which we never cease to explore" (Use of Pleasure 7 - footnote). It is in this spirit that I trace threads and look back. Weaving such ancient threads into his own work, Foucault writes that the essay,

which should be understood as the assay or test by which, in the game of truth, one undergoes changes, and not as the simplistic appropriation of others for the purpose of communication - is the living substance of philosophy, at least if we assume that philosophy is still what it was in times past, i.e., an "áskesis," askēsis, an exercise of oneself in the activity of thought (Use of Pleasure 9).

\footnotetext{
${ }^{6}$ Michel Foucault (1926-1984), variously described as a philosopher and historian, his later work focuses on subjectivity in the ancient Greek and Christian traditions.
} 
Foucault himself maintains a proximal distance with antiquity as for him, writing (and specifically the essay) is a very spiritual thing, in that it changes and challenges us. This is to say that the essay, or indeed any intellectual work should be transformative and involve spiritual growth.

Our discussion has gone from apatheia to áskēsis, and through áskēsis we have come up against two related terms that deserve further scrutiny: philosophy, and spirituality. I wish to clarify what is meant by both terms, and to do this, I turn to Foucault. In a reflection of his Kantianism, Foucault writes that philosophy is:

the form of thought that asks, not of course what is true and what is false, but what determines that there is and can be truth and falsehood and whether or not we can separate the true and the false. We will call "philosophy" the form of thought that asks what it is that enables the subject to have access to the truth and which attempts to determine the conditions and limits of the subject's access to the truth (Hermeneutics of the Subject 15).

Keeping this description in mind, let us move on to Foucault's explanation of spirituality:

the search, practice, and experience through which the subject carries out the necessary transformations on himself in order to have access to the truth. We will call "spirituality" then the set of these researches, practices, and experiences, which may be purifications, ascetic exercises, renunciations, conversions of looking, modifications of existence etc., which are, not for knowledge but for the subject, for the subject's very being, the price to be paid for access to the truth (Hermeneutics of the Subject 15).

Taken together (and they cannot be separated) Foucault's understanding of philosophy and spirituality point to the fact that philosophy is necessarily something spiritual, and conversely, that all spirituality is working towards philosophical questions. It is interesting that Foucault describes spirituality using the terms "search, practice, and experience", as these words all point to a kind of movement. Specifically, they suggest a movement in the way we relate to truth (or try to relate to an idea of truth). The words search and practice point to a form of deliberation or willfulness, but Foucault's final 
term, "experience," lacks this sense of something willed. Though it may indeed be willed or sought after, experience does not necessarily need to be willed (it can simply happen to us), but it must be reflected upon in order to be of value. In other words, it involves a taking stock, or self-reflexivity. There are two ways we might go about thinking through this passage. If we consider the terms "search, practice, and experience" independently, they can be seen to form a sequence of spiritual action. To search is to quest after, and in order to do this we must have an object in mind (or a void that needs to be filled by something intangible as of yet). Once this object has been established, or the presence of a void has been detected, we must embark on a path of spiritual practice. Finally, after recognizing an object worth questing after, and then engaging in spiritual practices, we may experience something transformative. If on the other hand, we consider the words "search, practice, and experience" as a unit constituting a cohesive idea - and we must, as Foucault describes them as a "set" - then spirituality itself is a process wherein each of these "steps" (each part of this "sequence") is actually carried out concurrently. The practices themselves (whether writing, reflection, negative visualization, relabeling, etc.) constitute an act of searching, and through this deliberate practice of searching we experience change. These changes are not something that we feel afterwards; rather, we feel them during and as a part of the act of searching. The experience is not generated by the researches and practices; rather, it is part of the researches and practices. To put this another way, the researches and practices constitute the experience, as these are the very things which change the subject and its relation to truth. There is a simultaneity of experience and abstraction here, which is important because such commingling of sense and reason is analogous to an encounter with the Good. 
I raise these ideas for two reasons. First, this type of process is precisely what we've seen in our look at Stoic apatheia and áskessis. The ideal of apatheia and the process of áskēsis necessary in any attempt at reaching it engage in this sort of search, practice, and experience, wherein the subject's very being is necessarily involved and modified. Second, Foucault's understanding of philosophy and spirituality, and his description of a search, practice, and experience, speak to a kind of spiritual progress that is quite different from the taken for granted idea of progress reigning under modernity.

In this chapter I have characterized apatheia as a freedom from the passions that is willed and earned through áskēsis, and I have also sought to illuminate the metaphysical contours of these related concepts. The Stoics suggest the possibility of transcendence through mimesis, and stress the need to use language in order to return to the state of nature while retaining awareness of the process. Perhaps most importantly, awareness of one's transformative practices is crucial. Through my inclusion of modern thinkers who we can say have an affinity for or who are sympathetic toward the ancients, I have also worked to highlight the fact that despite the vast differences between antiquity and modernity, there are threads which unite us, which have not been wholly lost. There are common questions (concerning for example, the role of the symbolic in keeping us at a remove, and the role of art as something mimetic versus constructive), and while we may answer them differently, the questions persist.

As I mentioned earlier, this chapter is also meant to act as a foundation for subsequent chapters, which will see the underlying logic of these Stoic concepts and tactics related to the modern context. But how can apatheia and áskēsis be of any use in an age of technological overcoming, or in an age of many sunderings? As Long observes, 
"there is no modern counterpart to the Stoics' conception of the world as a vitalist and completely rational system, causally determined by a fully immanent and providential God." Long continues, noting "From this, it does not follow that we moderns cannot make use of individual Stoic concepts, isolating them from their original cosmological, theological, and epistemic underpinnings" (368). Individual concepts (specific practices) can be taken and used in different contexts, despite the fact that Stoic doctrine comprises a holistic system rooted in metaphysics. While I am more interested in how the underlying logic of áskêsis and apatheia can inspire us moderns (and how this logic is sometimes tacitly and unconsciously applied by various moderns already) than in harnessing and grafting specific exercises onto a modern context, understanding these concepts and their place within the ancient world is central to this project.

Subsequent chapters will attempt to reveal the glaring contrast between Stoic apatheia and modern apathy, and will also enumerate and foreground reasons why áskēsis is vitally important for us moderns (and is, in some cases, still at work in select examples of modern art and theory). Through the concept of apatheia, which has been referred to in terms of invulnerability, imperturbability, freedom from, absence, and acceptance, the Stoics, in their own way, raise and attempt to deal with problems of meaning, truth, alienation, and the relation of language to these things. In order to engage with these problems, the Stoics utilized various spiritual exercises designed to transform the self while maintaining awareness of this transformative process.

While the "end" of apatheia is the desired outcome of a life of spiritual exercises, Marcus Aurelius provides some cautionary advice: "You should not hope for Plato's ideal state," writes Aurelius, "but be satisfied to make even the smallest advance" (87). 
Though we will likely never experience a unity of sense and reason or an absolute and immediate understanding (or align ourselves with virtue and realize apatheia), we must still move towards this end. It is the effort, the constant striving, the act of choosing to live in accordance with virtue that is important. Aurelius is here referring to a kind of spiritual movement, and this understanding of progress as something spiritual will be the focus of the next chapter. 


\section{Chapter 2 -Ancient Progress: Personal and Spiritual Movement}

"Philosophy was a method of spiritual progress which demanded a radical conversion and transformation of the individual's way of being"

Pierre Hadot, Philosophy as a Way of Life 265

What does it mean to progress? The modern interpretation of progress is connected with (among other things) technological optimism and the desire for universal human emancipation ushered in by our own designs, techniques, and actions at the expense of nature. J. B. Bury, who's seminal work The Idea of Progress nimbly explicates the ins and outs of modern progress, asserts that in antiquity, there was no understanding of progress comparable to the now commonplace doctrine of unyielding advance. And while Bury is correct in the strictest sense, I would like to add to his account and suggest that the ancients did indeed have their own interpretation of progress, albeit of an entirely different character than modern progress.

As moderns ${ }^{7}$ we accept the value of change, or what has been called the logic of overcoming; however, by change we understand primarily something technological, economic, or material, rather than something spiritual. Change or movement is crucial for both the Stoics and moderns, yet each centers a different object of change. For the Stoics, change of a spiritual sort (through áskēsis) is paramount, as evidenced in the work of Marcus Aurelius and Seneca, for whom there is a constant emphasis on movement. Theirs is, however, a movement of the spirit, whereas in modernity there is also constant movement, but it is a movement of novelty, economy, and technological overcoming.

\footnotetext{
7 And again, by "modernity" I am referring to epochal shifts in thinking (disenchanted world, individual self, technological progress, loss of authority, privileging of knowledge over care, etc.) which gained prominence during the period from roughly 1500 to the present.
} 
While considering the importance of change, Marcus Aurelius touches on the personal nature of ancient progress when he asks, "what can take place without change? And what is nearer and dearer to universal nature?... Can anything else of value be accomplished without change? And do you not see, then, that change in yourself is of a similar nature, and similarly necessary to universal nature?" (59-60). Clearly, Aurelius views change as an integral constituent of universal nature or the cosmos. Aurelius also chooses to emphasize a certain variety of change, namely, change in the self (read spiritual change), noting that this type of change in the self is necessary for all things of worth. If change in the self (what we might call spiritual movement) is "necessary to universal nature", then this implies the existence of an intimate connection between all selves and the cosmos. In other words, there is a correlation between the act of working on and changing the self, and the good of the whole. Moreover, Aurelius also implies that things of value can only be accomplished through change. But what is it that we should value? Aurelius asks this very question (47), and answers: "In this world there is only one thing of real value, to pass our days in truth and justice" (54). There is an absolute right, and we act in accordance with this right by aligning ourselves with nature, or in being virtuous. Aurelius here echoes Epictetus, who comments that "if you are acting in harmony with nature, give me evidence of that, and I will say that you are making progress" (Epictetus p13: I,4,15). We need only consider the title of Chapter 2 Book III of Epictetus' Discourses: "What A Person Must train Himself In If He Is To Make Progress" to see that progress, for the Stoics, is something we do to and for ourselves, rather than some sweeping trend or ideal that occurs on a mass scale. 
While the Stoic understanding of progress is centered primarily on the individual, it is, by extension, also concerned with aligning that individual with the cosmos, for as individuals progressing towards virtue, we are acting in accordance with the larger good. In this chapter, I argue that ancient progress is something deeply personal, yet with a mind to the whole. Foucault touches on the personal nature of Hellenistic philosophy when he observes that the ancients "sought in philosophy rules of conduct that were more personal" ("The Cultivation of the Self" 41), and yet he also makes it clear that this emphasis on the personal is not pure interiorization, and is not a turning away from others and the wider world. Accompanying this turn inwards is a "need to fulfill one's obligation to mankind, to one's fellow-citizens, and to one's family" ("The Cultivation of the Self" 42), and as such this turn inwards, or what Rousseau would later call self-love (as opposed to selfishness), is the way towards concordance with the larger world, and hence works towards the common good. This care of the self must not be confused with the interiorization and isolation of the ascetic, as for the Stoics, the process of engaging in spiritual practices "is at once personal and social" ("The Cultivation of the Self" 58).

Conversely, the form of modern Progress emphasizes a grand collective technological movement, while simultaneously lauding the idea of the individual, thus leading to increasing alienation, atomization, and fractured selves that are disconnected from any moral sources or larger good. From this brief observation we can begin to see the ethical dimension of progress, as it signifies a set of movements thought to be advantageous within a given cultural context. Yet ancient and modern progress look to different ends, take different forms, and operate on different scales. Connected as it is to ancient ideas of apatheia and áskēsis, I am proposing that the Stoic conception of 
progress still has worth, and (if reflected upon) could go a long way towards addressing some of the afflictions of modernity. Understanding what progress means to a specific group can tell us a great deal about their aspirations, beliefs, anxieties, etc., and this prising open and consequent reevaluation of ancient progress could, I hope, turn our attention towards our own understanding of progress and its attendant values.

The different forms of progress (whether spiritual or technological) result from differing arrangements of agency. The ancient world, with its metaphysical moorings, saw agency located in the cosmos, or in something larger than the self, which resulted in the individual striving to reacquaint him/herself with that larger world from which s/he had become estranged by culture. Modern disenchantment saw the site of agency internalized into the mass of humanity, thus while progress ostensibly became a collective effort (an apparent move towards universal human emancipation), its effects were focused on the individual rather than the cosmos, and despite the nobility of its targeted ends of liberty and equality, resulted in its opposite and saw the domination and atomization of that mass of humanity.

In order to elucidate this point we'll first need to garner an awareness of ancient progress: what it entails, how the ancients viewed it, what it was not. With such an end in mind, throughout this chapter we will excavate several core ideas that were central to ancient progress, namely: agency, knowledge, and fate. While under modernity we have unhitched our metaphysical moorings and so reconstituted the idea of progress, in antiquity to progress meant to engage in áskēsis, and to thereby move oneself toward concordance with the Good. This is significant because our current understanding of progress as inevitable and universal is but one interpretation, and one which neglects care 
and sacrifices connection with the Good. A look back to the ancient interpretation of progress may help unsettle the modern progress narrative, and allow us to dwell in a diminutive confusion.

Bury considers Progress in its doctrinal or ideological sense, as he rightly describes Progress (which he is always sure to capitalize) as the "controlling idea" of modernity. This idea of modern progress has replaced the previous controlling idea of salvation, and an insight by Rick Roderick can help us add to Bury's observation.

Roderick acknowledges that people still believe in moral sources (though in a haphazard and not altogether sincere way), but very few people now BELIEVE with heart and soul. A committed and unwavering faith in salvation has been replaced by faith in progress. And while this is so, we must admit that Bury's idea of Progress is but one interpretation of history, and not incontestably true. There have been a number of interpretations. Karl Löwith for example, claimed that the progress narrative is a secularized version of eschatological doctrines of salvation, and in a response to Löwith, Hans Blumenberg argued that modernity cannot simply be reduced to a secularization of Christian doctrine, and is therefore not merely the illegitimate heir of Christianity. And yet in reading his claim we must be cautious, for as Bernard Yack maintains, Blumenberg's "demonstration of the "legitimacy of the modern age" does not demonstrate its desirability" (Yack 259). While Blumenberg does to an extent work to eulogize modernity and its consequences, his claims about the legitimacy of the modern age speak more to its historical necessity than to its desirability. Blumenberg does mark a break with the past in the form of what he (borrowing the term from Nietzsche) describes as the adoption of a "ruthless curiosity" (Blumenberg 380). The ancient grammarians were interested in reading and 
aligning themselves with the harmonious cosmos, and for them, curiosity was personal and meditative. According to Blumenberg, during the seventeenth century, theoretical curiosity emerged, a form of curiosity that was collective and calculative and aimed at knowing and controlling nature. And while for thinkers as diverse as Rousseau, Heidegger, Adorno, T. S. Eliot, e.e. cummings and Zerzan (among others) modernity registers a loss, Blumenberg attempts to legitimize this theoretical and "ruthless curiosity." For Blumenberg, while marking a shift from past attempts at understanding the world, the ruthless curiosity typical of modernity emerged out of historical conditions, ${ }^{8}$ and must therefore be understood as legitimate. Yack claims that rather than justify one particular attitude toward the world (for example, the Romantic and antiEnlightenment claim that we have lost any sense of an harmonious whole), Blumenberg works to illustrate how various attitudes toward the world (whether belief in myth, self assertion against nature, identification with the cosmos, etc.) grew out of the real conditions of existence. Blumenberg's opus is indeed provocative and makes a valid contribution to the study of modernity and history, but it does tend to downplay features of antiquity which I deem important. I locate myself in the Romantic tradition, and maintain that something has been lost under modernity. We live, as Eliot put it so well, "In an age which advances progressively backwards" (Eliot "Choruses from the Rock" VII, 161). And while we have lost touch with the vast backdrops which formerly provided meaning, modernity, in its own way, may permit opportunities to reconnect with the backdrop in new ways. Blumenberg argues against restoration of past conditions,

\footnotetext{
${ }^{8}$ Blumenberg maintains that Christianity was a necessary precondition of modernity, in that it established a range of problems that could only begin to be answered by the ruthless theoretical curiosity of modernity. In other words, the medieval world demanded that tradition be overcome by reason. See Yack's "Myth and Modernity: Hans Blumenberg's Reconstruction of Modern Theory" for a fine summary of this claim.
} 
and I would not have my work mistaken as a call for a pure return. Instead, I am suggesting that in allowing ourselves to be inspired by the ancient sensibility and the perspective which it grants, we might position ourselves to better respond to modern malaise, and through modern means, leave space enough for an encounter with the Good.

Taking a rather different position than Blumenberg, Bruno Latour argues that "we have never been modern." Modernity is here understood as a set of distinctions or ruptures (between nature/culture, or non-human/human), and in order to be properly modern, these distinctions must be maintained. But according to Latour, these distinctions have not been (and in fact cannot be) maintained. Practices of distinction will eventually reveal that the line between nature and culture has been blurred all along. "No one has ever been modern. Modernity has never begun. There has never been a modern world" (Latour 47). While Latour may be right in arguing that there has been an ever present blurring or hybridity between the categories of nature/culture, there has been an epochal shift in thought and subjectivity, attitudes towards technology, and orientation toward the Good. Whether or not the distinction between modern and pre-modern is as sharp as Latour would like, I think it is present, and I locate myself in the tradition which claims that substantive changes occurred approximately five centuries ago. I would like to emphasize the importance of agency in any understanding of progress, and to suggest that the ancients did have a radically different understanding of progress than moderns. An analysis of these differences will reveal fundamental epochal changes in thought (caring versus knowing), subjectivity, and in our orientation towards the Good.

Bury clearly links the idea of Progress to human agency, which is another hallmark of modernity, and one way in which modern Progress differs from its ancient 
counterpart. A central point of distinction between antiquity and modernity can be made regarding the respective locations of agency, and Bury aptly observes this with regards to the idea of Progress: "The process must be the necessary outcome of the psychical and social nature of man; it must not be at the mercy of any external will; otherwise there would be no guarantee of its continuance and its issue, and the idea of Progress would lapse into the idea of Providence" (7). Bury readily admits that progress (small "p") was something sporadically understood by ancient and medieval thinkers, but this inkling, this sporadic understanding of a progression from a "primitive" to a "civilized" state is a far cry from a universally accepted ethos or controlling idea responsible for regulating an age. Modern Progress involves faith in Man rather than faith in God or submission to the cosmos. Drawing on the work of Bury, Robert Nisbet argues that the ancients did indeed have a clear sense of progress, and while he makes many valid points, Nisbet's observations are fundamentally separated from those of Bury as the two approach progress in completely different ways. For Bury, Progress is a controlling idea that is universally accepted by an age, and it signifies the indefinite advance into the future generated by human agency and technology (what he calls "the tapping of nature"). Bury claims "the distinctive idea of Progress was not conceived of in antiquity or in the Middle Ages, or even in the Renaissance period" (8). Nisbet on the other hand writes of only the most general inkling of progress, and as such it is difficult for his observations to be wrong (if by progress we mean the realization that we once lived in caves, and now we do not - in other words, things change). Bury's pivotal study deftly illustrates the contours of modern Progress as dominant narrative, and Nisbet's more recent reappraisal 
of progress revives the question of what is meant by progress, but neither adequately paints a clear picture of the specific variety of progress advocated by the late Stoics.

In his argument for the historical ubiquity of progress, Nisbet quite rightly observes two distinct strands of progress, yet he views them as existing concomitantly in every era. These two strands of progress are the spiritual and material, and while on a general level Nisbet is correct (for example, some modern thinkers, such as Foucault, Hadot, Adorno, McLuhan, Ellul, Taylor, etc. are indeed concerned with spiritual progress), overall, the tenor of ancient progress stands in stark contrast with modern progress. Nisbet makes an initial distinction between varieties of progress (spiritual/material), but then seems content to lump these two together and simply speak of progress in general. His argument revolves around the idea that the ancients did indeed have a clear sense of practical progress, that they sought to progress by means of their own agency, and that they recognized that practical progress occurred over a period of time. The ancients were certainly aware of material progress, but only in the most general sense, and while they recognized that things change, they tended to celebrate spiritual rather than technological progress. While ancient spiritual progress did demand an act of intense willing and thus a measure of agency, theirs was a world wholly saturated by metaphysics - the gods/cosmos/fate still moved all events and aligning oneself with the Good was of the utmost importance. As Marcus Aurelius reminds us, change was a part of life, but this sense of change was spiritual rather than material, and it had not yet assumed the form of an ideology central to an era. This is put best by Bury, who observes the science of the ancients "did little or nothing to transform the conditions of life or to open any vista into the future" (9). The ancients "were never self-consciously "modern" 
as we are" (Bury 9). This is to say, the world had not yet been disenchanted, the shift in the seat of agency and the emergence of print culture and mechanization had not caused the proliferation of a linear and detached viewpoint, and Descartes "doubt of all things" had not taken hold as the dominant paradigm. In short, we had not yet opened ourselves up to the possibility of auto-critique, agency had not yet become internalized, and we had not yet adapted ourselves to the logic of technique.

Nisbet notes that both streams of progress (spiritual and material) have existed for thousands of years, and while this may be true, he neglects the fact that the ancients privileged the spiritual vein of progress, while moderns view technological progress as the weightier task. Obviously there are exceptions (and demonstrating this point is where the value of Nisbet's work lies), ${ }^{9}$ however, I think it fair to claim that there has been an epochal shift from pre-modern to modern. Nisbet also observes the postmodern disavowal of the progress narrative, which in itself suggests that even if it was approximated in certain ancient thinkers, the progress narrative gained its runaway momentum during modernity.

What Nisbet neglects is the difference between a vague inkling of progress towards the future, and a driving logic of Progress that occupies a central place in a culture and depends upon a certain conception of knowledge, a certain understanding of time, a certain positioning of agency, and a certain relation to technology. The ancients were indeed aware (as Nisbet rightly claims) of progress in the most general terms, but faith in Progress as an imperative is something unique to modernity. Nisbet notes a general appreciation of change in Hesiod and Seneca among others, but for him, this awareness of a difference between past and future is enough to cite a belief in progress.

\footnotetext{
${ }^{9}$ Though ultimately, he uses exceptions in an attempt at validating a rule, and thus his analysis falls flat.
} 
In Hesiod's Works and Days, we are offered a vision of a world before cultivation, mortality, work, pain, sorrow, and a world that is gradually moving through different ages (gold, silver, bronze, and iron). On the surface, this might appear to support Nisbet's assertion that the ancients possessed an understanding of and a belief in progress, but returning to Bury's comment on external will, we ought to ask: where is agency located in Hesiod's work? Who is the mover of deeds? Is there a faith in progress here? Is progress established as a controlling idea, or is there simply a pale glimmer of progress? Of course the agency is external to humanity as the gods move world events and are responsible for the lost golden age. There is less a faith in progress than an observation of regress; the ideal age is in the past, and people look ahead without optimism.

Likewise, in Ovid's Metamorphosis, we are given access to a world in which there is no need for authority, no toil, no want, no environmental destruction, no war, no cultivation of the land, and no ambition. As in Hesiod's Works and Days, we are forced to bear witness to the general decline of this idyllic state via movement through various ages. While evidence of an understanding of change (or progress in the broadest sense), this idea of a lost golden age reveals a tendency to look backwards rather than forwards, and an idea of regress rather than progress. Hesiod and Ovid have authored worlds where the agency lies in some external force, where technological progress (while present) is certainly not the dominant narrative, and where there is no faith in progress as a propulsive and incremental advance into the future. Nisbet is correct then, that we may observe broad intimations of cultural change in ancient texts, but the centrality of and devotion to Progress as a motivating doctrine and the concurrent centering of agency in humanity is lacking. For the ancients progress (again, small "p") was not a grand 
universally held narrative and was unconnected to a sense of linear technological advancement; it was something personal, and something intensely spiritual. To demonstrate this point, I turn now to Seneca's $89^{\text {th }}$ and $90^{\text {th }}$ letters.

"One definition of wisdom is "knowledge of things divine and human" (The Stoic Philosophy of Seneca, Letter 89, 221). Wisdom itself may be something static, but philosophy is always in motion; it is practice, an act (or set of acts) carried out in perpetuity. In this instance, wisdom is a noun, while philosophy must be a verb. Read in this way, wisdom becomes something ultimately unattainable, and progress something spiritual. And if wisdom itself is unattainable, then an awareness of wisdom is what we ought to generate. Writing on the distinction between philosophy and wisdom, Seneca makes the observation that "The subject and the object of the act of seeking cannot be identical" (The Stoic Philosophy of Seneca, Letter 89, 221). Philosophy (comprised of spiritual exercises) is the means by which one moves towards wisdom, but wisdom cannot be acquired until one reaches the state of sagehood. To know wisdom, is to be a sage. Here, knowledge is dependant on care, and it demands a transformation. This process, this act of seeking, this spiritual progress is a move towards wisdom, but the fact that one is still seeking means that one is not yet its possessor. In other words, one's being has not yet undergone the requisite transformations needed to know wisdom (to become a sage). "What is precious and magnificent about it [wisdom]" writes Seneca, "is that it does not merely happen to people but that the individual is himself responsible for it and cannot obtain it from others" (The Stoic Philosophy of Seneca, Letter 90, 226). Wisdom must be earned. We must work towards it, and it is up to us. This returns us to the importance of áskessis, and the fact that these spiritual exercises are progressive. They 
reflect a type of progress: not a grand controlling idea of so-called universal Progress, but a more personal form of progress, where progress means caring for - and in so doing transforming - the self. If we understand spirituality in Foucauldian terms, then this form of ancient progress is both extremely personal (though personal with a mind to the whole), and intensely spiritual. Foucault notes that for Seneca, we must hasten to the ideal end point of life, "not in the sense that it will have reached its most distant chronological term, but complete by the fact of having achieved its fullness" (The Hermeneutics of the Subject 262). This speaks to a sharp distinction between ancient and modern forms of progress, as for moderns, progress is bound up with perpetual technical overcoming in time, while for Seneca, time and quantity is far less important than the quality of one's life. Foucault also notes that Seneca advocates a turning away from historical learning (The Hermeneutics of the Subject 263), which suggests that Seneca is less concerned with the march of time than with the quality of life, and the kind of self that one is becoming.

Like Foucault, Hadot notes that spiritual practices were an integral part of ancient philosophy, and were "all intended to effect a modification and a transformation in the subject who practiced them" (What is Ancient Philosophy 6). Susan Sontag offers what I think is a fruitful addition to the understanding of spirituality presented to us by Foucault and Hadot: "Spirituality = plans, terminologies, ideas of deportment aimed at resolving the painful structural contradictions inherent in the human situation, at the completion of human consciousness, at transcendence" (Styles of Radical Will 3). If we add Sontag's take on spirituality to Foucault's, then spirituality becomes a set of practices performed on the self designed not only to grant the subject access to truth, but also to remedy the 
alienation that follows closely behind the symbolic. To put this another way, through spiritual exercises, we may attempt to return to the primitive semblance of virtue with our self-consciousness intact. Through spiritual practice we may move toward transcendence of the self that has been alienated by its symbolic faculty, and experience the world through a simultaneity of sense and reason. This is what the Stoics sought through their progress; they sought to transform their very being by conditioning themselves to make only right judgments in line with virtue, and thus they worked to gradually re-orient themselves toward the Good.

In a (mis)reading of Seneca's $90^{\text {th }}$ Letter, Nisbet argues that despite this Stoic's earlier writing, Seneca's later works heap "lavish" praise on "human ingenuity" and a progressive march forwards. While Nisbet is correct to a point, he overemphasizes the role of material progress for Seneca, and neglects the distinct character of material versus spiritual progress. Nisbet's reading of Seneca's $90^{\text {th }}$ Letter would lead us towards the conclusion that Seneca privileged invention over the love of wisdom, or that he saw greater merit in the work of the inventor than that of the philosopher, a conclusion that is simply untrue. Seneca does indeed invoke the disparity between the "primitive" versus the "civilized" person (which does, granted, reveal a general awareness of change), but his invocation is designed to make us aware of the necessity of self-consciousness (granted by way of language and garnered through áskēsis), or to generate an awareness of our place in the world via language. This self-consciousness does of course require culture in order to germinate, but paradoxically, this process of cultivation pushes us further from the idyllic state which we seek. On the other hand, the idyllic state occupied by the "primitive" means nothing without effort and cognizance of the process. 
Nisbet's argument focuses on the technological utility of invention (which Seneca does indeed observe), but it misses the essence of Seneca's real line of reasoning. Progress (in terms of technological invention) is recognized by Seneca, but contrary to Nisbet's reading, it is certainly not celebrated, an ethos has not yet been based on it, and it is not driven by human agency.

As we shall see shortly in the cases of Epictetus and Marcus Aurelius, agency figures heavily in ancient spiritual practices, but it was of a very different sort and occupied a very different place than modern agency. In an analysis of Seneca's $O n$ Consolation, Foucault argues that for the Stoics, there was no real possibility of choice, that "nothing can be chosen without choosing the rest" (The Hermeneutics of the Subject 284). Altering the course of one's life was not up to us. All that was up to us was to accept the challenge of life, to make the soundest judgments possible, and to choose how to respond to those things not up to us. Agency occupied an external position. Marcus Aurelius' descriptions of fate are also quite instructive, and help foreground the differing sites of agency. Fate involved an individual "welcoming with his whole heart all that comes about and is allotted to him," and the acceptance on the part of an individual "that whatever is allotted to him is good; for the fate assigned to each person accompanies him through life and is only to his benefit" (Aurelius 18). In short, fate dictates that all events happen as they should, and that everything is part of a larger plan. The site of agency here is external to humanity.

It is at this point that the concept of agency becomes murky and problematic, for if we choose to work on the self, as the stoics tell us we must, does this mean that agency does lie within the individual? Perhaps after a fashion, but only to a limited extent, as any 
- what we would call - individual agency is in this instance more of an outgrowth or an expression of external agency that works towards aligning the individual with the whole. As individuals, we only have the power to affect that which is up to us, and all that is up to us is how we choose to respond to the world. Recall the proclamation of Epictetus, for whom not even the gods could affect this initial individual choice. The only choice that is up to us is how to respond to that which is not up to us. In order to make spiritual headway, we must decide to treat indifferents indifferently. In other words, if we are to follow the will of nature, we must choose to work on the self and through this benefit the whole. This initial choice, to either follow the will of nature and work on the self by engaging in spiritual practices, or not, must be made by the individual. This is the extent of human agency. While it may appear that agency resides in the individual, this agency is only cursory: agency ultimately resides in the cosmos. This matter of exercising a preliminary choice is what we might call an initial spark of agency, and while this spark (and the willed pursuit of the requisite spiritual practices that flow from it) lies with us, its purpose is to awaken us to our ultimate lack of agency. It is when we realize our weakness and accept the will of nature (that agency is external to us, and resides in the harmonious cosmos) that we will be allowed to progress towards the Good.

Stoic agency involves engaging in spiritual exercises, and consciously moving towards wisdom while accepting the vicissitudes of fate. Here we see something of a paradox, as we must vigorously engage the entirety of our being in áskēsis in order to accept our ultimate lack of agency. We must will before we can accept our lack of will, we must exercise our limited agency (by choosing to treat indifferents indifferently) before we can accept that agency ultimately lies in the cosmos. Modern agency on the 
other hand, involves a disavowal of destiny, as we are thought to be responsible for making and shaping our own lives, selves, society, world, meaning, etc. Broadly speaking, for moderns, agency does not lie in the gods or fate: it lies within us. Thus, in a move that clearly marks an epochal shift, moderns have rejected fate and internalized agency. We might also think of this in terms of scale of affect, and patterns of localization. As Ronald Wright observes, we are now shaped moreso by culture than by nature (30). Wright's description of culture as a "collective personality" is quite striking and is applicable here, as modern progress does occur on a mass scale. While moderns have internalized agency, it has been internalized collectively. Such a mass internalization of agency is necessary for technological progress, as such progress occurs incrementally and on the scale of culture. The modern sense of agency is diminutive yet bombastic when compared to that of the ancients, as ours is an agency which is thought to lay within humanity as a whole, and which is designed to bring about total collective change. While Stoic agency resided in the cosmos, the individual was impelled to act and work on the self, and through such work fulfill her purpose as part of the whole. For the Stoics,

all spiritual exercises are, fundamentally, a return to the self, in which the self is liberated from the state of alienation into which it has been plunged by worries, passions, and desires. The "self" liberated in this way is no longer merely our egoistic, passionate individuality: it is our moral person, open to universality and objectivity, and participating in universal nature or thought (Philosophy as a Way of Life 103).

While the ancient "return to the self" is ultimately a social gesture intended to beget concordance, the modern desire to design and produce a perfect world takes on a collective form, yet ends with the atomization of that collective. Ancient agency ultimately resides in the cosmos: modern agency has been taken up by the individual. 
Through this discussion of agency and progress, I have endeavoured to make apparent the understated relationship that exists between the site of agency, the object and trajectory of progress, and the implications for the self. Ancient progress was something deeply personal and was performed by the individual in order to foster concordance with the whole, while modern progress is performed by the culture as a whole and ends up alienating the individual.

In his $90^{\text {th }}$ letter, Seneca writes explicitly of two very different views of progress: one of the personal and spiritual variety, the other what we have come to call technoscientific progress. This letter runs counter to Nisbet's claim that Seneca advocated a material view of progress, and enriches the work of Bury, providing a new distinction by which we can better understand progress. Nisbet (who would have been wise to cite Posidonius in his argument for the ubiquity of technological Progress) is both cognizant and dismissive of the distinction drawn by Seneca, and while Bury adroitly captures the spirit of modern Progress, he neglects the wholly different tenor of ancient progress as something both personal and spiritual. Seneca presents us with two distinct notions of movement: one spiritual (viewed as advance), and one material (viewed as regress). For Seneca, technological and economic progress is not the product of philosophy; true progress must be spiritual rather than material.

Seneca refutes the claim of the Stoic Posidonius that philosophers are responsible for technological innovation. ${ }^{10}$ For Seneca however, technology and the busy urban life it spawns is not the result of wisdom, but of avarice and the practical demands that arise from avarice. Technology comes not from the sage, but from regular men, and is of the

\footnotetext{
${ }^{10}$ In a broad move that obliquely anticipates McLuhan, Posidonius proffers the idea that technology imitates nature, or is what we might call an extension of man. He provides the example of the grist mill as emulating teeth and the stomach.
} 
order of the body, whereas wisdom is of the order of the mind: "Wisdom's seat is higher; she does not train hands but is mistress of souls" (The Stoic Philosophy of Seneca, Letter 90, 233). Writing of the move from a "primitive" and natural way of living to construction and urban dwelling, Posidonius attributes technological invention to philosophy. Seneca on the other hand, credits avarice:

I cannot believe that philosophy contrived these intricate structures rising floor upon floor and cities nudging cities any more than it did the fishponds enclosed to protect the gullet against the risk of storm, so that luxury should have safe havens in which to fatten assorted schools of fish, however fierce the raging sea. What say you? Philosophy taught men bolts and keys? They but put the seal on avarice

(The Stoic Philosophy of Seneca, Letter 90, 228).

Clearly Seneca views the pursuit of technological invention as a move in the wrong direction, as a move away from the "golden age." Seneca describes various other technological practices and inventions, from metallurgy to carpentry to shipbuilding to trapping, and notes that "It was practical shrewdness, not philosophy, that contrived these things" (The Stoic Philosophy of Seneca, Letter 90, 228). Avarice and luxury, not philosophy, are the sires of technological "progress." Seneca is the first to admit that invention comes from acute minds, but he applies the following caveat which Nisbet neglects: that it is not the product of lofty or great minds. He holds up Diogenes and Daedalus as examples, asking "Which do you consider a sage, the man who thought up the saw, or the man who took his cup from his wallet and smashed it as soon as he saw a boy drinking out of the hollow of his hand?" (The Stoic Philosophy of Seneca, Letter 90, 229). He proceeds with this line of questioning, examining the trade of engineers who make elaborate fountains and structures, and he comes to the conclusion that "The men whose physical needs were simple were sages or very like sages. Necessities require little care; it is luxury that costs labor" (The Stoic Philosophy of Seneca, Letter 90, 229). Here 
Seneca alludes to the importance of awareness when he makes the subtle distinction between the sage-proper and the sage-like. The "primitive" who lived a simple life was indeed sage-like, but he could not properly be called a sage, as becoming a sage requires dedication, effort, and an awareness of one's spiritual progress. Seneca does glorify the primitive state of being, yet he also acknowledges the necessity of culture in any sort of spiritual progress. Without cognizance of ourselves and our move towards the Good, progress cannot occur. Progress, for Seneca, ought to be of the spiritual variety, which is to say, it ought to be a move back towards the lifestyle of the primitive, but with our symbolically acquired self-consciousness intact. Paradoxically this move back to the golden age can only be realized by moving forward through culture. While Seneca acknowledges the movement of culture, he is certainly not advocating technological progress. His is primarily a progress of the spirit, and though we do need culture (the symbolic) for this, Seneca is aware of the paradox and frequently wrestles with this contradiction, as when he writes on the relationship between the sage and "the mechanic arts," noting that the sage "never touched them at all. The sage would never have esteemed an invention worth making if it was not likely to merit permanent use" (The Stoic Philosophy of Seneca, Letter 90, 234). The sage is not interested in the incremental and instrumental progress of technology, but rather in progress towards a permanent spiritual state. It is only after we choose not to pursue wisdom (as connection to the Good) that we move toward incremental technological progress. Writing on the primitive Seneca observes, "Those were not wise men even if they behaved as wise men should" (The Stoic Philosophy of Seneca, Letter 90, 235). Though actions may be noble, they mean little without effort, awareness, and without that initial act of choice. Innate nobility 
or loftiness of spirit is not enough, "For virtue is not Nature's gift; to become good is an art” (The Stoic Philosophy of Seneca, Letter 90, 237).

Despite his recognition of the necessity of culture, Seneca offers a scathing critique of civilization, beginning with agriculture and private property: "But avarice invaded this happy system, and in its desire to withdraw property to subvert to its own uses it alienated the whole and reduced itself to narrowly delimited instead of undefined resources. It was avarice that introduced poverty; by craving much it lost all" (The Stoic Philosophy of Seneca, Letter 90, 236). Noteworthy here is Seneca's subtle return to the importance of the symbolic, which, while granting an awareness of our condition in the world (our alienation from immediate apprehension), establishes that very condition. Seneca's comments on delimiting nature raise an interesting problem which accompanies the act of defining. To define is to limit and to place within boundaries; definitions give knowledge of and power over, which is to say, they grant control. I refer here to knowledge divorced from care, or knowledge disconnected from any transformative component. To know, in this instance, is to have gained an understanding of the inner workings of some natural force, which may then be harnessed for our own ends (consider the conversion of mechanical to electrical energy in hydro-electric dams, energy which can be stored and transmitted). Seneca is obviously describing physical resources here, but this discussion echoes his thoughts on the symbolic itself and the danger that accompanies acts of defining and knowing rather than fostering awareness through care. This distinction between caring and knowing is vital, particularly once we begin to probe the historical conditions which permitted modern apathy and the modern distance from the Good (but to this I shall return later). Seneca proceeds to refer to technological 
innovators (the pioneers of technical progress) as "low-grade slaves" (The Stoic Philosophy of Seneca, Letter 90, 233), and claims that philosophy on the other hand "fosters peace and summons the human race to concord" (The Stoic Philosophy of Seneca, Letter 90, 233). Philosophy is responsible for (and is the very act of) spiritual movement, and this is the only necessary kind of progress. Seneca is clearly privileging the spiritual over the material. Spiritual progress (a move toward concordance carried out by way of work on the self) is only possible once we have been alienated from nature by language and culture. Recall Seneca's claim that primitive peoples were not sages, and can at best be thought of as sage-like, as they lack awareness of their condition, and as it was won not through effort but gifted through ignorance. In order to become a sageproper, and in order for this process of self care to be possible and meaningful, we must be aware of the process and its difficulties and implications. Awareness requires language and culture. By culture, Seneca is referring to our use of language and the abstractions, interactions and associations which emerge as a result of language, and while language is responsible for our present alienation, it is the only tool at our disposal for returning to that natural sage-like state.

Ancient philosophy involved spiritual movement, and not only movement, but also awareness and choice. Áskēsis must be deliberate, and must be constantly reflected upon (we need only consider the content and repetitive style of Aurelius' meditations for an example of this). In his examination of the primitive state of being, Seneca notes the "great difference between not willing to sin and not knowing how. They [the primitive] knew nothing of justice, of prudence, of temperance and courage. Their uncultivated life did possess qualities analogous to these virtues, but virtue can only occur in a soul trained 
and taught and raised to its height by assiduous exercise" (The Stoic Philosophy of Seneca, Letter 90, 237-8). For Seneca intent and reflection are crucial. "[N]ot willing to sin" equates to choosing not to will sinful actions, and to make this choice means first being aware of what constitutes sin, and then deciding not to partake. Simply acting in accordance with Nature is not enough. For one's actions to possess meaning, they must be deliberate, and must be accompanied by an awareness of said actions and motivations. Through this reading of Seneca, it becomes clear that while critical of culture (the symbolic, our ability to reason abstractly), culture is absolutely vital if spiritual progress is to occur, and if it is to have meaning. Here we see a link between a longstanding concern with the problems accompanying the symbolic and modern aesthetic exercises, many of which are meant to weld the sensual and rational into fleeting instances of beingin-the-moment, which are experienced as self transcendence. Such threads (upon which I will tug in subsequent chapters) run back to antiquity, and are picked up by various modern thinkers who explore the possibility of staging a re-orientation towards the Good.

As Nisbet observes, Seneca is aware of the move from the primitive to the civilized mode of living, but he is certainly not enamoured with all aspects of technological development. On the contrary, he recognizes in culture the tools needed to return to a state of virtue that has been earned, and that we are made conscious of (these are the truly valuable tools culture affords: not the hammer or chisel, but awareness). Combining Seneca's thoughts on technological progress and the primitive, and Epictetus' assertion on our inescapable weakness, ${ }^{11}$ it would seem that culture generates weakness, and this weakness is essential, as it is only after we are weak that we can gain an

\footnotetext{
${ }^{11}$ He writes that the beginning of philosophy is "a consciousness of our own weakness"(Epictetus p. 98 : II,11,1).
} 
awareness of our weakness (and through this awareness work on the self and progress spiritually - weakness as the foundation of sagehood). Without this initial condition, the progress towards sagehood cannot begin, and it is this deliberate progress that matters.

Seneca and Epictetus both touch on what I will call the Stoic paradox of culture and language: the fact that culture ${ }^{12}$ is what initially alienates us from Nature/the Good, and yet in order to return to Nature (to align oneself with the Good) in a meaningful way, we must use language - one of the essential attributes of culture. A point made by Susan Sontag is helpful here, as she identifies our "notorious first fall into alienation" with our initial use of writing (and I think we can extend this beyond the written, as Zerzan does, to include the symbolic itself), and associates this "leeching out the world" and rendering it a mental object to control, with domination and a move away from the Good (On photography 4). If language and culture alienate but it is only through language that we can become aware of our plight, would we not have been better off living as the primitive does, with no awareness of our weakness? For the Stoics, the answer must be a resounding no. Seneca appreciates the irony of culture, that it is the source of alienation, inequality, and a move away from the Good, and yet it is also necessary if we are to become sages and return to the Good in a meaningful way. Culture grants us consciousness of our weakness, and consciousness of our progress towards virtue. Borrowing from Bacon, McLuhan finds an example of this in the fall of Adam, and proposes a possible response: "To him [Adam] the whole of nature was a book which he could read with ease. He lost his ability to read the language of nature as a result of his

\footnotetext{
${ }^{12}$ Rather than risk sliding too far off topic and engaging in an exploration of "culture," for our purposes I'll limit the idea of "culture" (which can, as Raymond Williams observed, so easily degenerate into "a vague and baggy monster") to the use of symbols and abstraction (which of course imply community, communication, politics, interactions with nature/self/other, construction of meanings, etc.)
} 
fall... The business of art is, however, to recover the knowledge of that language which once man held by nature" (The Classical Trivium 16). By "language of nature" McLuhan is referring to instant apprehension, to unified faculties of sense and reason. McLuhan writes not of mimetic art aimed at matching the essence of the world, but rather an art of disruption aimed at manifesting human creativity. This art of "inner making" has the potential to shock us into awareness, and through such shock open us to the uncertainty that is our lot. Enduring this uncertainty is the best way for moderns to move towards a meaningful and conscious experience of the Good. This is a different way to the Good, and it reveals that while following the logic of self care, modern áskēsis (arising out of the modern milieu) can take a different form than its ancient counterpart.

For Seneca "Wisdom is the perfect good of the human mind; philosophy, love of wisdom and progress towards it" (The Stoic Philosophy of Seneca, Letter 89, 220). Here we see the Stoic understanding of progress as something intensely spiritual, something deeply personal, and something meant to bring one closer to apprehending (and living in line with) the Good. Like Seneca, Epictetus asserts that this act of becoming good must be considered a process, as it demands constant movement and progress (towards virtue) via care for the self. This task of becoming a good person is never complete, as "No great thing comes into being all of a sudden; not even a bunch of grapes or a fig does" (The Discourses of Epictetus p38: I,15,7). Likewise, "Wisdom is never a windfall," writes Seneca; it must be earned through constant work on the self, or through spiritual movement and exercise, as "virtue is not an accident" (The Stoic Philosophy of Seneca, Letter 76, 209). We are all born with the capacity for virtue, but not virtue itself. Interestingly enough, this is rather like language. We are born with the innate ability to 
use language, but it must be learned, acquired, and practiced (through culture). Seneca continues, claiming that "Even knowing virtue is no light or offhand task" (The Stoic Philosophy of Seneca, Letter 76, 209). Knowing virtue is no light or offhand task precisely because it means actually becoming virtuous. The wording here implies that virtue can be known, yet this is misleading, as in order to actually know virtue, one must have actually become (through caring for the self) virtuous. To know of something rather than to know it outright signals sensitivity or awareness, and as it is unlikely that anyone will ever actually know virtue (be entirely virtuous), awareness is perhaps a more accurate term. This semantic exercise highlights the distinction between the ancient conflation of caring and knowledge (which radically alter one's very being), and the modern understanding of knowledge as elevation above and power over. We may hold an idea of what it means to be virtuous, and yet still not be virtuous ourselves. The only way to know virtue, is to become one with it. As Hadot observes, real wisdom doesn't just let us know, "it makes us "be” in a different way" (Philosophy as a Way of Life 265).

For the ancients, the purpose of language and culture is to foster a move away from the consequences of language and culture. That is, language and culture are necessary, but only insofar as they generate awareness. The price that must be paid is the alienation that language and culture also generate, but it is a necessary price as this is the only way that our spiritual progress (a return to nature, or the state unconsciously occupied by the "primitive") can have any meaning.

Foucault makes the important observation that "there is no right age for attending to oneself" ("The Cultivation of the Self" 48), an idea also championed by the Stoics, as Lucilius (the recipient of many of Seneca's instructive letters) was only a few years 
younger than Seneca himself ("The Cultivation of the Self" 49). Foucault notes that Seneca "asked people to transform their existence into a kind of permanent exercise," and that "while it is good to begin early, it is important never to let up" ("The Cultivation of the Self' 49). Matthew Arnold echoes this notion, as for him the writings of Aurelius contain "modern applicability and living interest" (Arnold 160). Weaving ancient thought into his own philosophy, Arnold suggests that these sorts of living exercises are not only for the young, but for people of all ages, as we are all students of life. Hadot shares this awareness of the difference between ancient and modern education, and puts it in no uncertain terms:

It must be admitted that there is a radical opposition between the ancient philosophical school, which addressed individuals in order to transform their entire personality, and the university, whose mission is to give out diplomas which correspond to a certain level of objectifiable knowledge (What is Ancient Philosophy? 260).

Differences in pedagogy emphasize the epochal epistemological change which occurred between antiquity and modernity, yet the fact that thinkers like Arnold, as well as recent proponents of critical pedagogy, endorse a more holistic sort of education meant to encourage the overall development of the individual suggests a residual connection with antiquity.

While conceding that modern philosophy has at times rediscovered some of the experiential and spiritual aspects that connect us to a larger world and that formed the basis of ancient philosophy, Hadot claims that beginning in the Middle Ages, "Education was thus no longer directed toward people who were to be educated with a view to becoming fully developed human beings, but to specialists" (Philosophy as a Way of Life 270). Following a shift in emphasis whereby care was sundered from knowledge, 
education was transformed from something lived and practiced to something institutional, just as the practice of philosophy has shifted from a way of life to a discourse located within the university. Philosophy is (by and large) now exegetical rather than lived, and where it used to facilitate lifelong spiritual growth, education has been instrumentalized, and now cuts us off from connection to a wider world. For the ancients education was ideally the act of using culture to return to nature, while modern education (as proponents of critical pedagogy tell us) has become instrumental, and is (if we are thinking in terms of general ethos) limited to certain stages of life.

In a passage from his $124^{\text {th }}$ Letter, Seneca outlines the path leading towards the good life, and makes it clear that this good cannot be reached quickly, and that striving after this good cannot be confined to certain phases of life:

And what is this good? I will tell you: It is a free and upstanding mind which subjects other things to itself and itself to nothing. So far is infancy from being capable of this good that even boyhood cannot hope for it and young manhood is wrong to hope for it; old age can be thankful if it attains it after long study and application. By this definition the good is a matter of intellect

(The Stoic Philosophy of Seneca, Letter 124, 258).

Philosophy, that art of becoming a good person, that art of using symbols to return to nature and align oneself with the will of the cosmos with self consciousness intact, takes a lifetime of effort and self-reflection (and even then it may remain unfinished). This description of the Good as coming from long study and application over the course of one's entire life reveals quite clearly Seneca's thinking on progress: it is something individual, spiritual, and as its object is likely always deferred, it is to be pursued in perpetuity. Stoic education was not limited to a distinct phase of life; it was an ongoing process. And while ancient progress is performed on the self, it is nonetheless aimed toward the whole, toward aligning the self with virtue in order to better serve the whole, 
for recall that, despite an initial choice, agency ultimately resided in the cosmos, and the only thing up to us was to make sound judgments in order to re-align ourselves with the Absolute. In antiquity, fate had not been internalized. Hadot claims that :

The Stoic experience consists in becoming sharply aware of the tragic situation of human beings, who are conditioned by fate. It would seem that we are not free at all, for it is not up to us to be beautiful, strong, healthy, or rich, to feel pleasure, or to escape suffering. All these things depend on causes which are external to us (What is Ancient Philosophy? 127).

Hadot's point corroborates the fact that for the Stoics, agency was something external, and the only thing in our power was to decide how to respond to this grand agency. But for moderns, things such as (agreed upon notions of) beauty, strength, wealth, etc., are to an extent (or are at least thought to be) now up to us. The body can be moulded or remade through surgical procedures, body building, pharmaceuticals, etc., while one's station in life is seen as something to be chosen rather than something that is dictated by larger forces. The meritocratic ideal now prevails, and the body is seen as a site of contestation, meaning making, and identity construction. Moderns are thought to have a certain measure of influence in shaping (might we even say control over) their fate, whereas for the ancients, fate was something to be accepted, hence the ideal of apatheia as contentment derived from the exercise of right judgments and consequent divorce from the passions. At first glance the doctrine of apatheia and the stoic understanding of fate may appear to be at odds with one another, for while apatheia involves realizing contentment, it is also a form of refusal - refusal to allow oneself to be affected - and thus a deliberate exercise of will. This is best explained in the following way: the individual will is exercised in order to turn the self towards the absolute of which it is a part. "[T]he special characteristic of a good person," writes Aurelius, is "to love and 
welcome all that befalls him and is spun for him as his fate" (22). As everything that transpires does so in accordance with nature, why should we let the will of nature affect us negatively? The passions must not lead us, we must either lead the passions, or free ourselves from them by making sound judgments which are in line with universal reason. Recall the words of Marcus Aurelius, who writes that one must keep oneself "beyond the reach of passion" (48), and that you must "No longer allow your passions to pull you around like a puppet" (61). The ability to make correct judgments can only come about through spiritual practices, which is to say through a life which is constantly changing, moving, or a life lived as an ongoing work of art.

As a staunch believer in the value of repetition as a spiritual practice, Marcus Aurelius frequently reiterates his thoughts. Once again Marcus Aurelius tells us there is a "power that governs all" (46), but even if there weren't, Aurelius argues that we should still be content and care only for that which is up to us, as in the end, all is either the dispersal of atoms, or unity and order:

Either a hotchpotch and the entangling of atoms and their dispersal, or unity, order, and providence. If the first thought is true, why should I even wish to linger in such a random assemblage and chaotic disarray? Why should I be concerned about anything else than how one day I shall 'turn again to earth'? And why, indeed, should that trouble me? For dispersal will be my lot whatever I do. But if the latter thought be true, I submit reverently, I stand secure, I place my trust in the power that governs all (46).

In either case (though Marcus Aurelius favours the latter: unity, order), contentment with and submission to the will of nature is the only option. Altering the will of nature is beyond us; the only thing not beyond us is making the choice to act in accordance with virtue. Apatheia is thus grounded in the metaphysical view that there is a power that governs all and the exercises of Aurelius are geared towards constantly reminding us of 
our smallness, of our position in relation to the rest of the cosmos, of our nature as part of the whole, and of the essential character of all things.

Progress obviously implies movement through time, but ancients and moderns view time rather differently. Meyer observes that for moderns, one event produces another, while "The Stoics, by contrast, conceive of causes as bodies that act on other bodies" (76). We can think of this in the following way: the modern understanding of fate can be described in terms of chronological causal chains, with each cause being traced back to the cause directly preceding it, whereas the Stoic conception of fate must be thought of as a causal web of ubiquitous and simultaneous interactions, with each cause being traceable back to God or the cosmos. When something affects one strand of the web, the vibrations are experienced simultaneously on all parts of the web. This flows from the Stoic understanding of nature, in which everything is part of a self-contained system that interacts with and affects other systems, and all are guided by Reason. The universe is a self-contained system with smaller self-contained systems existing within it (universe, galaxy, solar system, planet, biosphere, animals, bacteria, atoms...), and all are governed by divine will. Stoic fate does not involve "sequences of causes producing other causes," but rather "causes acting on each other" (Meyer 78). Meyer refers to this as "relations of mutual influence" (78), and one of her main points is that we should not be so quick to interpret the metaphor "chain of causes" from a modern perspective (as a sequence of cause and effect). The ancient conception of fate then, is one of complete exteriority and is identified with the Absolute. A passage from the Meditations reminding us to "Reflect again and again on how all things in the universe are bound up together and interrelated" (Aurelius 52), demonstrates Meyer's point quite well. Aurelius 
describes the complete and utter unity and connectivity of all things; he does not describe a causal sequence, but rather writes of a grand bound-uped-ness or "cosmic sympathy."

For the stoics fate was ubiquitous and external, while for moderns fate has been subsumed under the category of the self, and is thus seen as something that lies within our power to affect, alter, modify, and even control. This understanding of fate has a direct effect on how progress is viewed. If fate is external and ubiquitous, as it was for the ancients, then the only way for us to progress is by working to align ourselves with this fate, which means refusing to allow those things which are not up to us to affect us, and in so doing, foster a contentedness with all that comes to pass. Conversely, the internalization of fate by humanity alters the form and object of progress. Where progress was about fostering concordance through work on the self, it becomes a process of collectively moving towards an imagined ideal end, an end both imagined by us, and generated by us through the only means available to us - our technology.

I hope the preceding pages have provided an adequate sense of what progress meant to the ancients: what form it took, what it involved, and what its aims were. While Wright, and Nisbet demonstrate that humanity has always progressed, the forms assumed by progress and the ways in which we have interpreted said progress have changed and taken various shapes. This says something of the ethos of an age, as well as the direction of its striving. As I have endeavored to demonstrate through an examination of several late Stoic texts, the ancient understanding of progress was wholly distinct from and foreign to the modern narrative of Progress. As evidenced in the texts of Epictetus, Seneca and Marcus Aurelius, progress in antiquity was primarily personal and spiritual, 
and as such, it was closely bound up with philosophy. To progress was to engage in áskēsis and move towards virtue.

Ancient progress is deeply spiritual and intensely personal (though with a view to benefit the whole, as in order to best serve nature, one first had to cultivate oneself), while as Bury and others illustrate, modern Progress is something altogether different; it is connected to knowing and controlling, rather than awareness of and caring for. This difference in idiom is profound, and carries serious implications. Knowledge (divorced from care) elevates, and it divides participants into roles of dominance and subordination. Awareness is more of a shared experience, or a recognition of presence, both of the observer and observed. Further, one is aware of both oneself and others, aware of a shared sphere of being and experience. One is immersed within something larger than oneself, rather than sitting upon and presiding over a narrow and static plane of knowledge.

For all of the freedoms it won, the advantages it delivered, and for all of its munificence, modernity can still benefit from the study of antiquity, as its ideas and approaches can help temper our excesses and inspire us to care in our own ways and to seek awareness rather than certain knowledge, and perhaps steer us away from the pitfalls of unchecked material progress (what Ronald Wright calls "progress traps"). The ancients viewed spiritual exercises as "a prerequisite for spiritual progress" (Philosophy as a Way of Life 100), and saw this progress in terms of "cosmic sympathy" (Meyer), or becoming synonymous with virtue (Philosophy as a Way of Life 101). As Ferry reminds us, "for the Stoic the individual self is destined to merge into the totality of the cosmos" (Ferry 86). 
This reappraisal of ancient progress has been in effort to justify my turning to antiquity for inspiration ${ }^{13}$ and to illustrate the fact that the modern understanding of progress is but one interpretation, and one that has emphasized instrumental knowledge at the expense of care and a connection to the Good. It is but one interpretation, and therefore not inevitable. It is my hope that an awareness of the Hellenistic idea of progress (as something both personal and spiritual), which now lacks the prominence it once enjoyed, could help lend awareness to modern spiritual practices in order to give us a chance of once again touching the Good.

\footnotetext{
${ }^{13}$ I am interested in using the ancients as a source of inspiration and a means of gaining perspective rather than as a model to rigidly emulate. I am more interested in the logic of áskēsis, of "care of the self" (epimēleia heauton) which was supplanted by the dictum "know oneself" (gnōthi seauton), than in specific tactics.
} 


\section{Chapter 3-Modern Progress: Collective and Technical Movement}

In a discussion with Toronto high school students, Marshall McLuhan claimed that the idea of progress no longer exists except in the minds of developers, and that such talk of progress is the product of nineteenth century minds. ${ }^{14}$ The idea of progress, for McLuhan, came to a halt with the electronic age and the sense of immediacy it inaugurated. The visual mechanical age understands the world in terms of linear causality (much like the linearity of print, with singular author, objective reader, flowing linear text), while in the aural electronic age this causal chain is broken, and becomes something present which ensconces us. While this sounds rather similar to the cosmic web of sympathy understood by the ancients, there are (despite the aural character of the digital) some glaring differences between the oral and electric ages. Where orality coincided with a view of cosmic sympathy, the print age was one of linear progress (and fragmentation, or a kind of universal Taylorism ${ }^{15}$ extended to all spheres of life), and the electronic age is the age of discord, shortness, and confusion (as opposed to the eternal unity of the ancients, or the causal chain culminating in a deferred telos of moderns). The world is changing with such rapidity that having a singular point of view (as of a reader's relation to a text) is becoming increasingly difficult. Such a stable point of view depends upon fixity, or a stable point of origin (which under modernity was the self, the "I" of Descartes cogito principle), and on a stable object upon which we gaze (in the case of modernity, the world as standing reserve).

\footnotetext{
14 This discussion was part of the CBC radio program "Ideas," with Alan Anderson (c. 1960's).

15 Taylorism (named after Fredrick Taylor 1856-1915) refers to the economic/production theory of scientific management meant to improve efficiency, productivity, and profit. Taylor published The Principles of Scientific Management in 1911, and shortly thereafter Henry Ford would begin producing automobiles via assembly line production.
} 
I am not interested in giving a comprehensive account of either modernity or progress (as others have already provided thorough accounts of each ${ }^{16}$ ), but rather to expand upon the relationship between ancient and modern progress begun in the last chapter with the aim of demonstrating that modern progress can only exist once an attitude of forgetfulness concerning care of the self has taken hold. This type of progress elevates knowledge over care, and sees a language of will privileged over a language of good. I offer a potted history of the idea of modern progress as filtered through the thought of a number of thinkers. In citing an eclectic group of modern thinkers attuned to the idea of progress in its various forms, I hope to let past centuries speak for themselves. Following this history of the idea of modern progress, I will then, through a reading of Descartes' principles of philosophy, investigate changes to modern subjectivity, and the relationship between care and knowledge under modernity.

I have argued that ancient progress is deeply personal and strives to unite the self with the Good, while modern progress is instrumental and looks to impress human ingenuity upon a horizon. For the former, knowledge is viewed in terms of personal exercise and training, and is in fact subordinate to and dependent upon care of the self, which means ancient knowledge could only occur as a result of a change in one's very being (modern knowledge carries no such stipulation). For the latter, by and large,

\footnotetext{
${ }^{16}$ This is contentious ground, as there is still some disagreement, but see for example: J.B. Bury's The Idea of Progress, Robert Nisbet's History of the Idea of Progress, Karl Lowith's Meaning in History, Hans Blumenberg's The Legitimacy of the Modern Age, Ronald Wright's A Short History of Progress.
} 
knowledge has been broken away from the idea of care, and is seen in terms of accumulation. ${ }^{17}$

I do not wish for this chapter to degenerate into a total condemnation of modernity, for such a stance would be unfair. While responsible for our spiritual malaise, modernity has also allowed for unique opportunities to respond to these malaises. Despite its many sunderings and the attendant dearth of spiritual awareness, modernity has granted an ability to "step back" as it were, to acquire context enough to perform an autocritique, and it also gave rise to a number of tools of estrangement. Through the objectivity it grants, and through the forms of estrangement it makes permissible, we can perform work on the self in new ways.

Admittedly, terms like "moderns" and "modernity" are sweeping and likely to elicit allegations of cloudy vagueness. When I use the term "moderns," I am referring to those with a visual orientation, those who, whether knowingly or not, experience and understand the world through a Cartesian subjective position, and those who occupy a milieu shaped by this way of thinking. This way of thinking allowed for the development of the technological system, and the idea of progress as defined by Bury. In short (and acknowledging that there are different stages of modernity), approximately the last five hundred years of the west have been modern.

In the electronic age we are ensconced by a cacophony of aural quality, and herein lies the primary difference between the electric experience and that of ancient cosmic sympathy: the electric age is non-linear, yet it is cacophonous. The ancients, on the other hand, also lacked a sense of linear causality, and yet their whole was sung in

\footnotetext{
${ }^{17}$ This is not to say that there are none who engage in spiritual exercises under modernity. The type of knowledge which characterizes our culture has been divorced from care, but there are still those who work on the self. Examples will be discussed in chapter 5 .
} 
harmony. There has been a loss of faith in progress coinciding with the electronic age (the postmodern moment), but regardless, the idea of progress remains a part of our institutions, which are propelled by the mechanical logic of the nineteenth century, and it is chiefly on this sense of modern progress that I would like to dwell in the following pages. Modern progress, born of calculative thinking, is synonymous with technological advance, and here, I follow Ellul's understanding of technological progress as laid out in The Technological System (in which he describes its central features: self-augmentation, automatism, causal progression and absence of finality, and acceleration).

e.e. cummins gives us insight into this nineteenth century logic, and the beginnings of its end, in his poem 'pity this busy monster, manunkind':

pity this busy monster, manunkind,

not. Progress is a comfortable disease:

your victim (death and life safely beyond)

plays with the bigness of his littleness

--- electrons deify one razorblade

into a mountainrange; lenses extend

unwish through curving wherewhen till unwish returns on its unself.

A world of made

is not a world of born --- pity poor flesh

and trees, poor stars and stones, but never this

fine specimen of hypermagical

ultraomnipotence. We doctors know

a hopeless case if --- listen: there's a hell

of a good universe next door; let's go

e. e. cummings 
Progress, in a general sense, may be thought of as the optimistic name for the process of change (Bury 231), but beyond some vague inkling of positive change, what is meant by the term progress? Progress, in its contemporary doctrinal sense, has been imbued with an ethical judgment (something good and in the best interests of all), and yet cummings refers to progress as a "comfortable disease:" something to be treated, and yet something that placates want; something that enhances the material conditions of life, and yet is also a sickness which afflicts those modern "busy monsters."

Man afflicted by progress is both unkind, and un-of-a-kind, which is to say, no longer properly part of human kind. People have become completely autonomous, floating apart from the larger human community and nature, and it is this atomization, this separation from a larger world, which is one of the consequences of a forgetting to care for the self. In this, cummings follows de Tocqueville's observation that modern individualism has an isolating effect which causes people to withdraw into themselves and their private lives, whereas in ages preceding modernity, people tended to be "closely involved with something outside themselves" (507). Twentieth century thinkers have commented on this alienation, on what they describe as the dehumanizing conditions begotten by progress. Jacques Ellul for example, claims that technique, or the logic of efficiency and drive to order which has co-opted all activities, leads to conditions which are less than human, and ultimately meaningless, "Yet we call this progress" (The Technological Society 5).

cummings reminds us that while the material achievements of progress are indeed grand in a way, in the larger scheme of things, they are trite and insignificant, as the price we paid was the sundering of part from whole. "A world of made" is where we now find 
ourselves, or rather, it is where we have placed ourselves. We are vain enough to believe that we can, with impunity, claim total agency, and in so doing, we attempt to reshape all of nature to suit our designs and reshape even ourselves. For Luc Ferry "The new vision of the world forged by modern science had almost nothing in common with that of the Ancients." Ferry continues: "We might say that modern thought puts mankind in the place of cosmos and divinity... It was up to man to introduce, by means of his intellectual labour, sense and coherence into a world which seemed no longer to possess meaning" (Ferry 102). With this apparent centering of agency, identity becomes a task to be carried out rather than a given to be accepted. A consequence of this is that we imagine ourselves to be separate from nature, separate from the cosmos, separate from the whole. As beings who think themselves separate, we neglect fulfilling our purpose as part of something larger.

Connectivity is atomized, as we focus on the made object rather than the whole. Our telescopes (the primary instruments for peering through space and back through time) extend "unwish." By "unwish," cummings is referring to the modern critical consciousness responsible for demystifying the world; in other words, the logic of modern doubt initiated by the likes of Descartes, and carried to new extremes by Marx, Nietzsche, and Freud. cummings uses the word "unself" in a completely different way than Iris Murdoch, who treats "unself" as a verb. For cummings, "unself” is a noun that refers to a self without a self.

cummings' use of amplificatory prefixes is also noteworthy. If omnipotence signals supreme power, then how can one be ultra-omnipotent? The prefix "ultra" works well to qualify conditional states, but not categorical states. Is it possible to be ultra-dead? 
This qualifier seems rather excessive and redundant, perhaps nearly as redundant and excessive as our efforts to elevate ourselves to such a position. ${ }^{18}$

Modern Man has striven to master nature and know with certainty, which is to say, acquire knowledge beyond any doubt (ironic, as this very inquisitiveness stems from doubt itself), but certain knowledge is hard to come by and is likely illusory. At the risk of presenting these ideas prematurely (though I think cummings' poem does presage them), in order to recover from the logic of technique and to once again experience the wonder of things (which marks, of course, the beginnings of philosophy), we must give up on the possibility of certain knowledge, or at least be courageous enough to live with uncertainty. Through áskēsis, we can condition ourselves to wait, and be at least open to enduring uncertainty. Such action is necessary if we wish to once again orient ourselves towards the Good. I will return to and elaborate on this point in later chapters, but for now, I will only say that by giving up on certainty, I am certainly not advocating that we bring all striving and thought to a halt. Quite the contrary actually, as the fortitude to endure uncertainty will demand constant attention and effort. For now though, let us return to cummings' poetic assessment of modern ills. cummings' hopeless case speaks to a lack of real or completed agency, a lack of certain knowledge regarding an outcome, and a lack of faith in something larger or a disenchanted world. We might also describe disenchantment as "neutralizing the cosmos, because the cosmos is no longer seen as the embodiment of meaningful order which can define the good for us" (Sources of the Self 148). This is a consequence of our objectifying and mechanistic view of the world. "Gaining insight into the world as mechanism is inseparable from seeing it as a domain

\footnotetext{
${ }^{18}$ Must we, as Nietzsche observed, not become gods ourselves to appear worthy of the feat of disenchantment?
} 
of potential instrumental control" (Sources of the Self 149). cummings then, is pointing to the grandest failings of modernity and its drive to certainty, mastery and technique.

cummings' poem suggests that modern internalized agency has less potency than we think, it acts as a call to re-evaluate modern progress and its implications, and it also indicates that faith in progress is waning. Within this short poem cummings raises the central character of, and debates surrounding modern progress. Namely, that what has been variously called the idea, theory, dogma, myth, presupposition, or disease of modern progress (as it now operates in the twenty-first century) is primarily technical and material, is connected with the perception of an internalized agency, and is accompanied by a desire for certain knowledge and the exercise of control which promises to banish uncomfortable uncertainty. Despite its benefits (a new potential for material freedom, a potential for auto critique, a new political authority that saw power placed - at least in theory - in the hands of the people, new opportunities for aesthetic exercises), modern progress, which grew out of an objectifying way of viewing the world that followed the "Cartesian moment,"19 resulted in a disengaged or interiorized subject.

The primacy of the visual and the privileging of knowing over caring (cemented into the modern consciousness by Descartes) is what allowed this type of technical progress to unfold, and while modern progress has been characterized in a number of ways, I would like to consider it primarily in terms of a number of sunderings or fragmentations, including the cleft hewn between sense and reason by Descartes, the sundering of care and knowledge, and the sundering of individuals from the Good. While the one who most ably expressed this shift from care to knowledge, Descartes cannot be

\footnotetext{
${ }^{19}$ This "Cartesian moment" saw the idea of "care of the self" (epimēleia heauton) supplanted by the dictum "know oneself" (gnōthi seauton). It was this forgetfulness concerning the care of the self and the subsequent move away from concern with the Good which lead to apathy in its modern form.
} 
held personally responsible, as these changes began before him, and as his own meditations read as a personal spiritual exercise. At most, Descartes can be labeled a herald of the move from care to knowledge. Modern progress demands a centering of the self and the division of parts from whole in the pursuit of knowledge and mastery, while ancient progress involved caring for and orienting the self towards unity and seeing parts flourish as emanations of something larger. Another way of understanding modern progress, then, is as the movement of securing freedom through the imposition of our will upon nature (and this, through technique).

In the last chapter I alluded to some of the features of modern progress, yet I don't want to oversimplify the narrative which undergirds modernity. I fear that without elaboration such a brief description risks belying the complexity of this guiding ethos. Perhaps the most obvious question (and one addressed obliquely in the last chapter), is what exactly does modern movement look like, and why has the change from ancient to modern progress occurred? The Cartesian moment was not a line in the sand; it was not a horizon dividing modernity and what came before. Modernity cannot be said to start with Descartes; it has earlier roots, with the printing press for example, for as McLuhan notes, "With Gutenberg Europe enters the technological phase of progress, when change itself becomes the archetypal norm of social life" (Gutenberg Galaxy 155). And while a look back at the early unbalancing and realignment of the sense ratio coinciding with paradigm shifts in communications technology can offer insight into the contours of the modern self and modern progress, Descartes is a convenient epistemological index fossil and his work marks the zenith and perhaps clearest expression of this way of thinking. It was Descartes who inaugurated this idea of collective technical progress by way of his 
new ground of knowledge (the self), and this change (the shift from care to knowledge) and the subsequent disconnect from the Good, would provide the necessary precondition for a modern apathy experienced as carelessness. I will return to Descartes shortly, but for now, I would like to (in a rudimentary fashion) chart the direction of the progress narrative, or the progress of progress.

With the disenchantment of the world, one belief has lost credulity, while another has arisen in its wake: the site of agency was now thought to be entirely internal, and with agency internalized, we experienced, for the first time, a belief in the real possibility of creating and fulfilling our own wish images. Aspirations for the future, it was thought, could no longer be left up to fate, but had to be planned, made, and brought into being by us. While optimism or faith in progress was the norm for quite some time, this faith later moved towards ambivalence, and for some, outright rejection. In sketching the basic contours of modern progress, I will now briefly return to Bury:

The spectacular results of the advance of science and mechanical technique brought home to the mind of the average man the conception of an indefinite increase of man's power over nature as his brain penetrated her secrets. This evident material progress which has continued incessantly ever since has been a mainstay of the general belief in Progress which is prevalent to-day

(Bury 213-4)

Progress then, at least in "the mind of the average man," stems from science and technique, and signals a propulsive movement into a future of our own making, or what cummings calls a "world of made." Bury notes three distinct phases of modern progress, each spurred on by a "degradation," or a kind of confrontation wherein Man was thrown back on his own efforts and forced to change (221). Among these "degradations" Bury notes the positing of a heliocentric universe, which decentred humanity and forced it to take stock of its position in the cosmos; the French Revolution (while not technically 
what we might call a degradation, it had the same effect), which unseated a system of authority and saw Enlightenment values of liberty, fraternity, and equality taken up en mass; and the theory of evolution, which again, decentred Man, revealing him to be the progeny of primates rather than a being cast in God's likeness. Each phase of progress extends disenchantment, and sees doubt aimed in different directions. Others have framed the idea of degradation and decentering differently and cited different skeptics, ${ }^{20}$ but the premise remains the same. These decenterings or degradations forced us to look inwards, so that we no longer relied on an external providential order, but worked to create meaning from within.

Prior to the French Revolution, Bury observes that progress was a taken for granted fact that was casually accepted. Following the Revolution progress was imbued with a new energy and universal laws of progress were fervently sought, but it was, for Bury, only after Darwin's Origin of Species that the dogma of progress attained the near ubiquity it has since enjoyed. Had Bury been alive today and given the opportunity to assess the idea of progress as it unfolded in the twentieth century, he would have seen a shift in attitude - a shift which he presciently predicted. Progress was to be about liberation, emancipation, humanity leaving behind the old and oppressive; however, as critics (perhaps most notably Horkheimer and Adorno) have pointed out, history has not lead us to a golden age. For them, the Enlightenment has resulted in its opposite. In its quest for liberation, progress abandoned its ends and elevated its means (technology, instrumental rationality). A project bent on universal emancipation, the institution of universal Reason, and individual autonomy, had for them, resulted in domination (of

\footnotetext{
${ }^{20}$ For example, Althusser's "narcissistic wounds inflicted on humanity" by Galileo, Darwin, and Freud (104-5), or Ricoeur's “masters of suspicion," Marx, Nietzsche, and Freud.
} 
nature and man), instrumental reason, and mass conformity. As progress in its most basic sense is an optimistic idea of change, Bury was aware that the very logic of this idea would one day turn back on itself, and "submit to its own negation of finality," compelling progress to fall from its position "as the directing idea of humanity" (231).

While Bury's stages of progress are basically apt, I would like to amend the second phase, which he describes as brimming with optimism. While there was certainly an abundance of optimism, I would like to suggest (following Postman and Berman) that in certain circles it was restrained, and in fact grew into a nervous ambivalence. In addition, I would also like to spend some time discussing the loss of faith in progress, which Bury predicted but was unable to witness. Let us now proceed with a brief overview of the phases of modern progress.

For moderns, progress tends to be synonymous with economic growth and technological innovation. As a collective endeavour, growth and improvement are, and of course must be measured on a large scale. Herein lies one of the primary differences between ancient and modern progress. For the ancients, whose world had solid metaphysical moorings, to progress was to align oneself with the cosmos. Thus, all movement could be measured on an individual level. In a mass society where the adoption of a general ethos of doubt lead to a receding bed of foundational meaning, the only way "progress" can be measured is through the economy and technological innovation, which are both mass efforts. Descartes himself realized that the task of knowing and mastering nature was beyond him, and would require the efforts of others. The question of scale is important, as for the ancients, progress was far more intimate than it is today; it was personal and spiritual, and yet the agency which allowed for this 
type of progress was vast and external. And while we ought not rigidly emulate the ancients, we can look back to them for inspiration, and to gain a measure of perspective on our own practices.

The eighteenth and nineteenth centuries saw a number of staunch supporters of the doctrine of progress. We need only consider H.G. Wells and his overwhelmingly optimistic account of progress, or Benjamin Franklin's reverence for “the power of Man over Matter" $(230) .^{21}$ And while Franklin is enamored with scientific progress and its potential (to the point that he sometimes regretted being born so soon), he does, after showering scientific progress with praise, raise concerns about the future of moral progress. In a letter written in 1780, Franklin laments the one-sidedness of modern progress: "O that moral Science were in as fair a way of Improvement, that Men would cease to be Wolves to one another, and that human Beings would at length learn what they now improperly call Humanity!" (230). It is this emphasis on meaning and morality that, as Marshal Berman points out, lead the greatest thinkers of the modern era to view modernity and its promises with a keen ambivalence, a nervousness occasioned by hope and fear. I link thinkers like Franklin and Wells, who we might not otherwise think of connecting, because their very different social backgrounds (geographical location, personal life, occupation, historical period, etc.) considered alongside the parallels in their thinking demonstrates just how pervasive ideas of progress were.

Perhaps predictably, H. G. Wells' A Short History of the World can be read as a vindication of the modern view of progress as ineluctable technical mastery of nature. ${ }^{22}$

\footnotetext{
${ }^{21}$ A printer, journalist, inventor, and politician, polymath Benjamin Franklin (1706-1790) is perhaps best known for his role in authoring the American Declaration of Independence.

${ }^{22}$ A British teacher, writer, and journalist, H. G. Wells (1866-1946) is best known for his imaginative works of science fiction which are typically imbued with an utopian spirit.
} 
This utopian analysis of progress is brimming with a fervent optimism, as Wells views history as the process of the "steadfast upward struggle of life towards vision and control" (308). Wells concludes with a call to clean the canvas of outmoded moral and political beliefs, in order to make room for a grand experiment, namely, "what the human will can do with material possibilities" (308). The scale of his study, his adoption of a language of will (rather than language of Good), and the way he sets up his text (with the inclusion of a chronological table whose stages are demarcated by wars and technological difference), speaks to an idea of technologically determined, gradually realized, absolutely necessary universal advancement, and while triumphal, gung-ho and rather totalizing, his approach bears the semblance of subtlety, as it is admitted that advancement is variegated with occasional setbacks, errors, etc. This assurance that we are indeed marching forward demonstrates confidence in our abilities and optimism in the results of our efforts, two features which for Bury are integral to modern progress.

Wells describes the ancient world as one where no man designed and no man foresaw (262), which suggests deliberate planning along a linear arc and the large scale progress this entailed, are, as Bury attests, recent developments. Of the eighteenth and nineteenth centuries Wells observes "Technical knowledge and skill were developing with an extraordinary rapidity and to an extraordinary extent, measured by the progress of any previous age" (254). Progress of previous ages is thus measured in terms of technical knowledge and its exercise, rather than any other attributes. The technological society does not permit any other frame of reference; it does not permit an external position from which it may be critiqued. In an idea that will later become a touchstone for George Grant, Ellul observes, "man in our society has no intellectual, moral, or spiritual 
reference point for judging and criticizing technology" (Ellul The Technological System 318). Grant takes up this idea, paying special attention to our language, claiming that the language of the Good has dissipated, and that we have left to us only the language of freedom and willing. This language of willing is the result of a progress that has been broken apart from personal care, and extended to the mass of atomized individuals.

Wells places great weight on humanity's ability to manipulate and rework materials, recasting them into new forms, capturing, changing, and coercing matter, and bending it to our collective will. He contrasts this directly with the inability of the ancients to achieve such technical heights, but he ignores the completely different ethos which guided the ancients, and he is unable to extricate himself from the modern technological milieu. Wells stands as one in awe of our technical mastery over nature (cummings would have accused him of celebrating the "bigness of his littleness"), and even condemns those who sneer at technical progress.

Despite the fact that its overall logic was technological/material (though certain keen thinkers did view it with a mixture of optimism and trepidation), as Berman and Postman point out, it is primarily during the twentieth century that progress lost all sense of its spiritual dimension and was thought of in totalizing, rather than ambivalent terms. Thus, it was primarily in the twentieth century that faith in progress was lost, hence the recent attacks on this thing that was once lauded, or at least met with ambivalence.

The idea of progress (filtered through Kant, Hegel, and Marx) as inevitable collective movement toward an utopian end is often described as the dominating idea of modernity. Nisbet for example, calls progress a central idea that serves as a context for all other ideas under the umbrella of modernity (171), and likewise for Bury, progress 
(though a blip on the radar) is a controlling idea. "The experience of four hundred years, in which the surface of nature has been successfully tapped, can hardly be said to warrant conclusions as to the prospect of operations extending over four hundred or four thousand centuries" (Bury 6). This sentiment is echoed by Ronald Wright, who notes that in the West, we tend to view the past two centuries of affluence as inevitable, but in reality, it is an anomaly (117).

"The idea of human Progress then is a theory which involves a synthesis of the past and a prophecy of the future. It is based on an interpretation of history which regards men as slowly advancing..." (Bury 6). Bury's use of the word interpretation is revealing, as it signifies that the modern Progress narrative (technological, universal...) is only one of many potential ways of reading history. ${ }^{23}$

Daniel Bell's thesis on the end of ideology and Fukuyama's reading of Hegel mark a variation (progress realized) of the dominant view of modern progress, in which Western democracy - under-girded by consumer capitalism - is seen as the ideological endpoint in human evolution. This is a potent example of what various thinkers and critics have described as the myth of progress, but this is of course only one (celebratory) view of progress, and one which Ronald Wright refers to as "naïve triumphalism" (6). Wright refers to progress as myth and ideology, and while he readily admits that progress has served some of us (the relatively small number from the privileged classes) well in the past, he claims that "it has become dangerous. Progress has an internal logic that can lead beyond reason to catastrophe" (Wright 5). Continuing cummings' apt physical ailment metaphor, Wright also comments on the addictive properties of technology,

\footnotetext{
${ }^{23}$ Likewise, I should note that my view of antiquity is also one interpretation of history, and I concede that others may have other views, but given the spiritual interest of my work, I think my reading of ancient progress as personal, spiritual, and based on care is apt.
} 
noting its cyclic and self perpetuating character (what Ellul describes as selfaugmentation and automatism): technology seeks to address problems that are produced by technology, and in so doing, it creates further (often unforeseen) problems, which (of course) can only be attended to by additional technological progress. To my mind those who only seek to apply new technology to old problems miss the point. Technology is paradigm altering, and as such it reconstitutes problems in new and unpredictable ways, also generating new problems with it. As McLuhan, Heidegger, Ellul, and Grant have each argued, we must seek to understand the essence of technology.

Ellul locates the origin of technical progress in the eighteenth century, and of course by technical, he is referring to technique, or, the impulsion towards efficiency in all spheres of life. For Ellul, technique could only properly erupt in the eighteenth century because it required modern science in order to proliferate (Technological Society 42). Postman also notes that eighteenth and nineteenth century thinkers went to great lengths to consider the connection between technological and moral progress - a task we have let slide. Novelists and poets of these centuries noted a "spiritual emptiness that a culture obsessed with progress produces" (Postman 36). This is an important point: that as our proclivity for and profundity of invention increased, the types of questions we posed began to change. We became more interested in the question of how to invent than the formerly important question of why we were inventing. Philosophy was supplanted by practicality, and this in turn speaks to a lack of care.

As Bury surmised, despite its current economic bias and its apparent universality, modernity gave rise to the conditions necessary for its own critique. Only under the auspices of modernity could an ethos be established which generated doubt of its own 
precepts. Such doubt has been taken up by various thinkers, from existentialists, critical theorists, and postmodernists, to environmentalists and anarcho-primitivists, and a number of other "ists."

While one of modernity's central features is a skepticism which leads to progressive technical overcoming, the inherent rightness of these presuppositions has been elevated beyond that doubt, at least until recently. Late modernity saw the doubt of doubt, and the doubt of progress; not doubt as in the ambivalence or skepticism of Marshal Berman's celebrated nineteenth century moderns, but a supreme doubt culminating in a loss of faith in the modern project. We can think of this lack of faith in terms of hyperbolic doubt turned in on itself, or disillusionment not only with past traditions and authority, but disillusionment with our contemporary doctrine of progress which grew out of an original modern skepticism. There is no solid measurement for apathy (no apathetical index as it were), yet it is felt (as a kind of carelessness), and has been observed by various social critics. Apathy is intimately connected to late modernity, for it is at this moment (when we have come to question the modern presuppositions) that we have finally become aware of a crisis of meaning occasioned by the modern shift in epistemology and subjectivity.

During the nineteenth century the idea of progress was naturalized; however, in the twentieth century, "the idea that progress is real, humane, and inevitable died" (Postman 40). The shift from the literate visual age to the electronic aural age, which roughly coincided with critiques of modernity (postmodernity and its immediate predecessors), allowed us to experience what Grant called intimations of deprival. For the first time, we were able to feel some of the consequences of modernity. Doubt of doubt, 
or a loss of faith in the progress narrative has lead to what I will simply refer to as late modernity ${ }^{24}$ which can be thought of in basic terms as the exhaustion of modernity and the petering out of its optimism. And while in the twentieth century progress is, according to Postman, no longer thought of as natural historical imperative, its logic persists. As Bauman asserts, "The modern romance with progress - with life that can be 'worked out', to be more satisfactory than it is and bound to be so improved - is not over, though, and is unlikely to end soon" (Liquid Modernity 134). In fact, progress has taken on an entirely technical hue, shedding any former concern for moral, social, psychological progress. George Grant speaks to the deprivation of the moral and social dimensions of progress when he writes "something has been lost. Call them what you will superstitions or systems of meaning, taboos or sacred restraints - it is true that most Western men have been deprived of them" ("A Platitude" 449). It is interesting and apt that Grant frames this as a problem of deprivation - something has indeed been lost, for in forgetting to care for the self we have alienated ourselves from our fellows and have lost contact with the Good. Grant continues, wondering if the old systems of meaning have simply been supplanted and exchanged for a new one: "The enchantment of our souls by myth, philosophy, or revelation has been replaced by a more immediate meaning - the building of the society of free and equal men by the overcoming of chance" ("A Platitude" 449). On certain levels progress is still limping along, yet its exhaustion is palpable. And while widespread optimism in progress may be fading, the logic of technological progress is accelerating. Progress is progressing towards more (and ever accelerated) progress. Technological progress has become a kind of contemporary good,

\footnotetext{
${ }^{24}$ Though there have been a number of other prefixes used to describe this phase of late modernity, including post, liquid, hyper, digi.
} 
and due to the emptying of larger meanings, progress is now undertaken for its own sake - it is self-augmenting and automatic. Progress has been "liberated from any purpose beyond itself” (Grant, “A Platitude” 449).

For Berman, the relationship between the material and spiritual orders of progress must contain a measure of subtlety, as the two orders of progress are linked, and can never really be separated. Material progress alters the conditions of our existence in space and time, our relations with ourselves and others, and as such, it affects the ways in which we experience and engage with the world. As the conditions of existence are altered, and as our experience of the world and self changes, so too must the practices and modifications which we bring to bear on them (self, world, others). As Marx and Engels famously put it, "Does it require deep insight to understand that with changes in man's material conditions in life, social relations and social system, his ideas, views, and conceptions, in one word his consciousness, also changes?" (Communist Manifesto 140). Thus, in order to understand the mental and spiritual dimensions of modernity, we must know something of technological progress, we must be aware of what our technology does to us.

While it is now synonymous with technological advance and economic growth, progress was once a term imbued with paradox, at the same time suggesting optimism and distrust, temerity and reservation, and conjuring enthusiasm and fear. Progress was (with a wink at Marx) pregnant with its contrary. With this brief history complete, I would like now to turn to the deleterious effects of a purely technical progress, namely, the fracturing of the self, and sundering from the Good. 
Modernity is often associated with the Cartesian moment, its key traits being a logic of doubt (and a desire to overcome said doubt) which saw the world disenchanted, an understanding of history as constant technological progress and overcoming, and an exacerbation of the separation between the rational and sensual, all of which roughly coincided with the mass circulation of the printed word. This move towards a print culture saw a guild economy recede and make way for capitalism and the rise of a new middle class, and consequent new notions of a less stable self. Print culture altered the sense ratio in favour of the visual, which, as Ong notes, is a dissecting sense, a taking apart that is dependant on clarity and distinctness (Ong 71).

As in all other fields of enquiry, the self is opened up to critique and skepticism, and Descartes answers this skepticism by claiming that the self is nothing other than a thinking thing. Through doubt, Descartes claimed that one could properly know the self, so long as by self we are referring to mind only. Ferry views this from another perspective, claiming that under modernity, "It was not only man who 'lost his place' in the world, as is often said, but the cosmos itself - the enclosed and harmonious frame of human existence since antiquity - quite simply evaporated" (Ferry 94). In the place of such vacuum, Man had nothing to fall back on except himself.

The cogito argument becomes Descartes' first principle of philosophy, and from this he outlines several precepts. The four precepts which govern Descartes' thought sum up his position (and that of modernity) quite nicely. I will recount them here in brief. The first principle deals with certainty, in that one must not accept as true anything except that which excludes all ground of doubt. The second principle is that of division, or of breaking apart a problem into its smallest component parts, so as to render it more 
manageable. The third principle follows from the second, and suggests progress, as the division of complex problems will lead to a gradual accretion of knowledge. The fourth principle outlines the need for rigor, through which omniscience might result. While it would be naïve to claim that these features of modernity owe their existence solely to Descartes, they are, nonetheless, set out most clearly in his work.

The first feature, the difficulty of being in uncertainties, carries a compulsion to know with certainty, and a fear of the unknown. Such compulsion fuels the drive of continuous progress, and reinforces the need to fracture all things. The second feature, or the act of sundering, demands breaking things apart to know them with certainty. This means that in order to know a thing, it must be disassembled or dissected. A comment by Erich Fromm seems germane, as for him, western sciences "seek the truth by means of dismembering life" (To Have or to Be 14). To know a thing we must kill it. Take for example a tree. In order to know the age of a tree it must first be felled; only then can we count its rings. To know the biological functions of an animal, it must be dissected. Also implied in this second feature is the fact that everything outside of the self becomes an object to be known. The act of sundering also describes our relation to the cosmos, as we are now left with only parts. The third feature, that of infinite progress, suggests that through knowing the parts of things (it is hoped) we can continuously progress to ever greater understanding. Such emphasis on technological progress also creates a hierarchy (as in the case of Wells' history), suggesting that less technologically advanced peoples are less worthy. We can perhaps be thankful for the rigor demanded by Descartes in his fourth precept, though it comes with a hearty supply of hubris, as in exercising rigor, it is hoped that we may one day become omniscient. Descartes describes the practice of 
stripping oneself of all past beliefs - a practice which implies a rejection of authority, and a belief in continuous progress (though it should be stressed that he cautioned that not everyone was up to this challenge).

Descartes provides some justification for his Discourse on Method when he describes how the experiments necessary for bringing about knowledge of (and thus control over) nature, and the consequent elevation of humanity "are such and so numerous, that neither my hands nor my income, though it were a thousand times larger than it is, would be sufficient for them all" (Discourse on Method 48). In dispensing his processes to the public in the hope that they will take up his method and pursue experiments that he himself cannot, Descartes treats progress as something collective and ongoing, and as primarily concerned with technical and material ends, culminating in a better future for humanity.

What Descartes sought was "the certainty of a consciousness that had withdrawn from all sense experience" (Arendt, The Life of the Mind 48). This attempted withdrawal marks for Foucault the defining moment in the shift of attitudes towards the self. More specifically, it is the "reason why this precept of the care of the self has been forgotten, the reason why the place occupied by this principle in ancient culture for nigh on one thousand years has been obliterated" (Hermeneutics of the Subject 14). Foucault continues, claiming that the "Cartesian moment" involved nothing less than "putting the self-evidence of the subject's own existence at the very source of access to being" (Hermeneutics of the Subject 14). Such action removed the requirement of conversion, of work and transformation which would alter the subject's being and his/her relation to truth. To know the self (and by self Descartes means disengaged reason, or mind only) 
requires interiority and sundering, whereas to properly care for the self requires both mental and bodily exercises and practices. Caring entails a more rounded understanding of being. As George Grant claims, "technology is the ontology of the age. Western peoples... take themselves as subjects confronting otherness as objects - objects lying as raw material at the disposal of knowing and making subjects" (Technology and Justice 32). Technology and our subjective inwardness separate us from the whole. They snip the multiplicity of filaments comprising the cosmic web of sympathy enjoyed by the ancients, replacing it with a chain of one-off causality, and in so doing, set us apart from the "objects" which constitute the standing reserve of the physical world. "Literate man, civilized man, tends to restrict and enclose space and to separate functions, whereas tribal man had freely extended the form of his body to include the universe. Acting as an organ of the cosmos, tribal man accepted his bodily functions as modes of participation in the divine energies" (McLuhan, Understanding Media 117). What was once connected with and a part of, has become something sundered from and external to.

We can see something of the logic of modern progress, or, the influence of the Cartesian sensibility, in ways of understanding communication. Building on the work of Harold Innis, communications theorist James Carey points out that our engagements and interactions with others and the world transform in step with changes in communication technology and also in the very ways we interpret communication. In Communication as Culture, Carey describes two views of communication: the transmission view of communication and the ritual view of communication. Stemming from a geographical or transportation metaphor, the transmission view of communication dominates industrial (read Western) cultures, and the "center of this idea of communication is the transmission 
of signals or messages over distance for the purpose of control" (Carey 12). This model of communication seeks to eclipse time and transcend space so as to control the "objective" world. Such a metaphor demands an understanding of the world as something that can be separated into constituent elements, as mastery of time and space leads to control of sundered parts. ${ }^{25}$ As these changes in communication are experienced collectively, on the level of culture, a widespread change in how we experience the effects of our relationships occurs. Modern progress can be thought of as the experience of collective technological change, which isolates and separates the individual from collective contexts in which meaning-making occurs. Under the transmission view of communication, the "meaning" of the world may appear muted, thinned, distant, or hollow, and the act of sending messages efficiently becomes more important than the content.

In a ritual view of communication, maintenance in time and the representation of common values (rather than rapid transmission in space for purposes of control) are paramount. An understanding of communication as transmission will always be bent on control, whereas an understanding of communication as ritual will be interested in maintaining fellowship and connection. The former depends upon decreasing time, on continual technological change, and on a constant transgression and domination of physical boundaries, while the latter demands a stationary permanence, or what Penty refers to as the fixity of social foundations. Alexandre Dumas' famous line from The Three Musketeers encapsulates the demands on the subject made by the different views of communication. In the transmission view it really is "all for one," in that collective

\footnotetext{
${ }^{25}$ In other words, in emphasizing bureaucratic power and economic relations, the transmission model of communication functions as an instrument of technique.
} 
effort (technological movement) is thought to liberate the subject from the bonds of tradition and grant a measure of freedom, whereas the ritual view takes a "one for all" stance, where work on the self benefits the whole and sees the individual fulfill her purpose as a part of the cosmos. Viewed as transmission, communication becomes an instrument in extending control over space. Viewed as ritual, communication is something collaborative, which corroborates a view of the world and stabilizes meaning. The ritual view is representative of oral (pre-modern) cultures, while modernity is a culture of transmission. ${ }^{26}$ To restate this in no uncertain terms, technology acts on our consciousness. If the unconscious is structured like a language, then the conscious mind moulds itself to the form of the dominant medium. This is to say, the conscious mind takes on the traits of the dominant communication medium; consciousness develops in tandem with the medium in which it is immersed.

This chapter sought neither to propound a comprehensive assessment of modernity nor to extol an absolute definition of modern progress. Its purpose was to continue the history of the idea of progress, and demonstrate that modern progress can only exist once we've forgotten to care for the self. Modern progress reveals the primacy of knowledge over care, and bears witness to the fact that a language of will has been privileged over a language of Good.

The doctrine of progress, permitted by the change from a life of caring to a life of knowing and arising out of the literate-visual age, took as its starting point the logic of doubt and internalization of agency. Through the exercise of our own reason, it was

\footnotetext{
${ }^{26}$ McLuhan provides yet a third view of communication - as transformation - in which technology acts on our consciousness in ways that we fail to grasp. This view demands awareness.
} 
hoped that in the future humanity would conduct itself humanely and rationally, and would progress towards universal emancipation. At this point, progress was not completely bound to the technological and economic, and it still contained an interest in self development (though in a way entirely different from the ancient care of the self). After centuries this logic of doubt was extended and directed towards God, meaning, and value, and with this application of doubt to previously untouchable subjects, modern optimism recoils somewhat, and becomes critical ambivalence. Following the assault on the sacred by various "masters of suspicion," the critical faculties and keen ambivalence of many commentators on modernity became dulled. It is at this point (what we might call the totalizing point in the history of modern progress) that progress became synonymous with technique, and it is at this point where technology displaced all other categories of measuring movement. Modern apathy is a consequence of an epistemological and subjective shift, which saw the act of caring for the self disconnected from knowledge of the self, yet insight into the problem (which is to say the feeling of apathy) only arises when this interiority is subjected to scrutiny.

Where ancient progress was initiated on an individual level and its effects felt by the surrounding world and community, collective technological progress sees the individual broken off from the larger world. The ancients fortified themselves in order to approach the Good, while moderns forfeit such care and are broken apart from such connections by their compulsion to know. Requirements of this type of technological progress include the forfeiting of connections to a larger world (as on an individual level, in order to exist as a disengaged subject the world must be viewed as mere extended object, and as on a collective level, technological progress demands division of labour 
and specialization), and the expectation that individuals are to be the governors of their own fate.

Modernity brings with it what Arendt calls the "loss of the world," or a loss of something larger, something which transcends the self, and something (through its feature of connectivity) that offers the possibility of grounding meaning in the Good, the unity of the cosmos and acceptance of our place within and as part of it. The challenge before us is to re-orient ourselves toward the Good, but this cannot be accomplished simply by readopting past traditions, as they have been stripped of their legitimacy. In our isolation, in our sundered state, we have ceased to experience meaning in the ways we once did. What we can do, is to allow ourselves to be inspired by the logic behind ancient spiritual exercises, and in so doing work to cultivate new ways of seeing which emerge from the modern milieu, and yet that afford greater connectivity with others, the world, and the Good.

"I will gladly concede to you that, little as individuals could derive any profit from this dismemberment of their being, yet the race could have made progress in no other way" (Schiller 43). For Schiller too, modern progress occurs en mass, and its consequence is the dismemberment of being. Modern progress is based on separation of wholes into constituent parts: it is a progress of discombobulation. The fruits of modern progress have been won through sundering, division and specialization, and when such is the temperament of life, how can we not expect consciousness to follow suit? Modern progress was a consequence of the visual-literate orientation, the attendant mechanization and sundering of wholes into more easily managed parts, and of our forgetting to care for 
the self. This forgetfulness (and the creeping metaphysical hunger it inflicts) is the subject of the next chapter. 


\section{Chapter 4-Modern Apathy: A Self not Cared for}

"What is the secret of the apathy of the present day? The immediate cause is, doubtless, disillusionment. For centuries society has worshipped at the shrine of mammon, science, and mechanism. Men saw the immediate advantages which followed their surrender to them, while they concealed from themselves their evil side, which was tolerated, nay, justified, as incidental to the cause of progress"

Penty 81

While Penty is correct after a fashion, his account leaves a great deal unsaid. Modernity is a time of many sunderings. Among these are the intensification of the visual, the rift between philosophy and life, the subject/object division between mind and world, and the division between culture and nature. Modern apathy owes its birth, at least in part, to the diminution of philosophy during the Middle Ages (where philosophy became a technical discipline rather than something lived), and the exacerbation of this trend under modernity. Such sunderings accompanied the change from a mode of being focused on caring, to one focused on knowing with certainty. Descartes formalized this shift, and through his writing this new attitude was cemented into the newly minted modern consciousness.

We now lack stable or fixed ethical standards and shared moral sources, and the fact that modernity did not usher in the promised age of peace, leisure, and equality has lead to disillusionment. And while Penty is quite correct in locating apathy within modernity, there is more at work here than disillusionment alone. It was the waning of faith in progress (coinciding with the intense movement from a visual-print culture to an auditory-electric culture) experienced in the twentieth century that allowed us to feel more fully the effects of the Cartesian moment. This moment radically altered how we approach the self, as it became something to know rather than care for. A consequence of 
this shift from caring to knowing is the cordoning off of an idea of something beyond the self (which is to mark a change in aspirations: from openness to the Good, to mastery of nature). Apathy is a problem of "care."

While there are a limited number of late nineteenth and early twentieth century works that explore the matter of political apathy (such as Speed Mosby's short paper “The Danger of Political Apathy” published in 1898), the bulk of such scholarship began in the 1940's and 1950's. ${ }^{27}$ By the 1980's a concern with apathy in another forum opened. Studies began to focus on the North American family and school experience. ${ }^{28}$ In the 1990's consideration of apathy in other forums emerged, including explorations of apathy in the media. ${ }^{29}$ The millennium saw apathy addressed in yet another forum; this time the business self-help world began to produce anti-apathy guides for the managerial class.

Despite the continued interest in apathy, studies focus on effects in specific forums, rather than on the roots of the problem. Nina Eliasoph comes close to a concern with sources, as for her, political apathy (and politics is her focus) is caused by a lack of

\footnotetext{
${ }^{27}$ For examples we need only consider Joseph Schumpeter's Capitalism, Socialism, and Democracy (1942), Dwight G. Dean's “Alienation and Political Apathy" (1960), Morris Rosenberg's "Some Determinants of Political Apathy" (1954) and his "The Meaning of Politics in Mass Society" (1951), Herbert J. Gans' Political Participation and Apathy (1952), and E.P. Thompson's "Out of Apathy" (1960). This concern with apathy and its implications for democracy persists to the present, with, for example, Carole Pateman's Participation and Democratic Theory (1976), Tom DeLuca's The Two Faces of Political Apathy (1995), Nina Eliasoph's Avoiding Politics: How Americans Produce Apathy in Everyday Life (1999), Steve Davis, Larry Elin and Grant Reeher's Click on Democracy (2002), Cliff Zukin et al's A New Engagement? (2006), and Eric J. Wilson and R. Justen Collins's We Surround Them: Our Journey From Apathy to Action (2010).

${ }^{28}$ Consider Randle W. Nelson's "Books, Boredom, and behind Bars: An Explanation of Apathy and Hostility in Our Schools" (1985), Paul Rogat Loeb's Generation at the Crossroads: Apathy and Action on the American Campus (1995), Jeff C. Marshall's Overcoming Student Apathy: Motivating Students for Academic Success (2008), Danny Hill and Dr. Jayson Nave's The Power of ICU: The End of Student Apathy...Reviving Engagement and Responsibility (2009), and T. J. Sullivan's Motivating the Middle: Fighting Apathy in College Student Organizations (2012).

${ }^{29}$ Kenneth Newton's "Mass Media Effects: Mobilization or Media Malaise?” (1999), William A. Gamson et. al's "Media Images and the Social Construction of Reality" (1992), and Kenneth Quade's Apathy and the Media (2007).
} 
public contexts/dialogues. Likewise, Russell Jacoby approaches the source of apathy, and his work serves as a bridge between these previous studies of apathy in specific forums and my own work. Jacoby seems to expand upon E.P. Thompson's claim that apathy is a form of decay (though it should be noted Thompson was concerned with the failure of a British Socialism). For Jacoby apathy is a result of the failure of modernity, and of our skepticism of modern values following the horrors of the Second World War. ${ }^{30}$

While it does have political and social implications, apathy is not primarily a political or social problem - it is a set of philosophical problems, namely, problems of subjectivity, technology, aesthetics, and epistemology. Apathy is a problem of subjectivity, in that during the Middle Ages philosophy became the tool of theology, a change which meant that while once being the way of moving the self towards truth (through áskēsis and a life lived as art), philosophy was now on its way to becoming an exegetical discipline or a set of logical exercises used to shore up theological reasoning. This forgetting of the importance of the epimeleia heauton would eventually be cemented into the modern consciousness by Descartes, whose work would see knowledge become more important than care. Apathy is also a problem of technology. Typographic mechanization was a precondition which allowed for the modern subject position, as well as an understanding of time and progress in terms of linear causality. In addition, typography and the literate culture it gave rise to coincided with a realignment of the sense ratio, which is what leads me to claim that apathy is, in part, also a problem of aesthetics. With the realignment of the sense ratio and the intensification of the visual

\footnotetext{
${ }^{30}$ In his 1997 MA thesis Towards a Politics of Apathy: Baudrillard, Bartleby, and Adorno, John D. Sawicki approaches apathy in a novel way. Drawing primarily on the work of Baudrillard and Adorno, and using the example of Melville's famous scrivener, Sawicki makes a case for apathy as a means of political resistance. Though still centered on politics, Sawicki's reading of apathy as subversive is refreshing.
} 
(that most divisive sense), modern consciousness was forever altered. It was now standard to view parts in isolation from the whole, and to sunder in the interests of manageability and control. In this sense, apathy is also an epistemological problem. With the adoption of a visual orientation and a self that could only be sure of its own existence came a problem of knowledge. Following the Cartesian moment, the ground of knowledge was brought inwards, and fate became something to manipulate and control. A self to be known, a mechanistic mindset, and a distancing and objective view (viewer versus thing viewed) of the cosmos demanded that we elevate ourselves in order to control, and that we use our extensions (predicated on visual experience of the world) to break-apart and know rather than care for the self and enter into concord with the cosmos.

What follows is an exploration of how these philosophical problems are interconnected. By listing these philosophical problems in a specific order, I am not suggesting a linear causal relationship (to do so would be to err - I am simply limited by the typographic medium). It is enough to say that many things act on many other things, and these philosophical problems act on each other.

While his immediate concern is not apathy, Foucault's discussions of the consequences of the Cartesian moment bring us to the very heart of the matter: "There has been an inversion in the hierarchy of the two principles of antiquity, "Take care of yourself” and "Know yourself." In Greco-Roman culture, knowledge of oneself appeared as the consequence of the care of the self. In the modern world, knowledge of oneself constitutes the fundamental principle" ("Technologies of the Self" 228). I would like to characterize apathy as a kind of carelessness, and by this I mean a failure to care for the self, which in turn leads to an inability to care for others or orient oneself towards the 
Good. We might also think of apathy as a case of self neglect or forgetfulness, for in neglecting the self we fail to fulfill our obligations to the whole. Admittedly, the claim that apathy must be thought of as a failure to care for the self seems almost counterintuitive, as after the Guttenberg Revolution and the meditations of Descartes, moderns experienced a turn inwards. Yet despite such an inward turn, the self became an object of neglect.

I am here standing on the shoulders of Foucault, Hadot, Ferry, and McLuhan among others. Without their groundwork my hypotheses would have been impossible. Before proceeding further, I feel obliged to recall a comment made by Foucault concerning the Cartesian moment. While a convenient historical watermark, the Cartesian moment does not indicate a clean break with the ancient conception of philosophy as something lived. The "break" began during the middle ages, and was in fact a gradual process. The Cartesian moment formalized this break, putting it in no uncertain terms. This division resulted from the encounter between philosophy and theology. Theology, with its

omniscient God and subjects capable of knowledge... is undoubtedly one of the main elements that led Western thought - or its principal forms of reflection - and philosophical thought in particular, to extricate itself, to free itself, and separate itself from the conditions of spirituality that had previously accompanied it and for which the epimeleia heautou was the most general expression (Foucault Hermeneutics of the Subject 26-7).

The disengagement of philosophy (as spiritual practice) from life was a gradual process whose beginnings lie in the relationship between theology and philosophy. Luc Ferry also locates this disengagement in the interaction between (what Hadot refers to as the mutual contamination of) theology and philosophy, as does historian of medieval thought Gordon Leff. Medieval thinkers "sought to explain the natural and the human by 
reference to such tenets of faith as God, creation, the Incarnation, using philosophical and logical argument to do so" (Leff 11). In such action philosophy was stripped of what had formerly been its most central feature - the epimeleia heautou, or care of the self. Stoic influence is present in the writing of Christian theologian Clement of Alexandria, who, in the latter part of the second century promoted a version of the Stoic doctrine of apatheia, but where the Stoics sought to align themselves with virtue and fulfill their purpose as part of the cosmos, Clement of Alexandria sought salvation through the power of God. "Salvation" writes Clement, "is the privilege of pure and passionless souls" (46). Here "passionless" refers not to an utter lack of feeling, but to a soul turned away from what the Stoics would have called externals (in this case, anything disconnected from salvation - wealth, status, etc.). Clement also emphasizes an idea that Simone Weil would later describe as a stance of attentiveness, or a kind of objectless waiting, when he writes "a man by himself working and toiling at freedom from passion achieves nothing. But if he plainly shows himself very desirous and earnest about this, he attains it by the addition of the power of God. For God conspires with willing souls" (46). In the work of the early Christian, apatheia can not be achieved solely through an act of will; it still demands submission or openness to something beyond the self. While I admire his advocacy of attentiveness, already, in the writings of Clement of Alexandria are contained intimations of what is to come - early whisperings of a philosophy that is used to support theological reasoning. Stripped of its spiritual status, philosophy became "the handmaid of theology" (Leff 31). Building on these observations, John Cooper chooses to emphasize the necessary unity of ancient philosophy over the role of spiritual exercise. Cooper focuses on the fact that "ancient philosophies insisted on the complete unification and 
interlocking, mutually self-supporting, character of ethics, physics, and dialectic (or however else one might divide up the totality of philosophical discourse)" (Cooper 15). It is this unity, rather than áskēsis, that for Cooper constitutes the defining characteristic of philosophy as something lived. Contrary to such unity, modern philosophy (with few exceptions) tends to be divisive, addressing problems and branches of philosophy in isolation, and as theoretical puzzles rather than spiritual exercises. Despite his emphasis on unity over áskēsis Cooper still marks the distinction observed by the aforementioned thinkers: that "philosophy after antiquity, and ever since, is no longer widely conceived as a way of life" (Cooper 10).

A necessary condition of apathy was the move away from a stance of caring to a desire for certain knowledge. A self not cared for cannot care for others, as empathy and the ability to connect with others and the world becomes diminished. The realignment of the senses prompted by the Guttenberg revolution also played its part by intensifying the privileging of the visual (that divisive sense, which encourages an understanding of time based on linear causality, as well as unique and separate subject positions - as in author and reader). It is only during the twentieth century (with the stirrings of the electronic age), that we could begin to perceive the fallout from the diminution of philosophy and the consequences of the Guttenberg revolution and the Cartesian moment. While only properly begun in the mid twentieth century,

the technological extension of our central nervous system that we call the electric media began more than a century ago, subliminally. Subliminal have been the effects. Subliminal they remain. At no period in human culture have men understood the psychic mechanisms involved in invention and technology (Understanding Media 305). 
McLuhan's observation helps explain why apathy appeared on the critical radar almost a century ago.

While responsible for modern objectivity and detachment (which McLuhan credits as the chief benefits of the typographic age), the privileging of the visual bears a measure of culpability for our disconnection from the Good. The intensification of the visual orientation made it increasingly difficult to care for the self, and the failure to care for the self (and the consequent inability to care for the world) is another way of describing apathy. Apathy is typically understood as a lack of concern for others, and it is. But, this carelessness, this general lack of concern for others and the world begins with forgetting to care for the self.

If apatheia involves a preclusion of reactive passions, and is both end and process without end, then the term apathy, as used in the following pages, designates a forgetting to care for the self, which results in an inability to fulfill our purpose and function as part of the whole. I think it fair to describe apathy as a kind of general carelessness which coincided with the many sunderings of modernity, and which was experienced most sharply once the modern project stalled, once faith modern progress waned, once the sense ratio was on the verge of another recombination. For, to paraphrase McLuhan, it is only when we have begun to pass an era by that we can begin to view its contours:

Cultures like ours, poised at the point of transformation, engender both tragic and comic awareness in great abundance. It is the maximal interplay of diverse forms of perception and experience that makes great the cultures of the fifth century B.C., the sixteenth century, and the twentieth century. But few people have enjoyed living in these intense periods when all that ensures familiarity and security dissolves and is reconfigured in a few decades (Understanding Media 143). 
The paradigm shift from typography to electronic communication allows us to finally feel the apathy which attends modernity. ${ }^{31}$ It is only after the literary age began to dissipate (and the electric age began to proliferate) that we were actually able to feel the condition of apathy. In other words, the move from explosion to implosion let us perceive apathy, or let us finally feel the unhealthy organ (the disconnect from the Good and the attempt to know rather than care for the self).

Apathy appears on the critical radar during the twentieth century. At this time a new media paradigm was experienced, and postmodern critics challenged the "metanarratives" of modernity. The events of the twentieth century also contributed to a loss of faith in the modern project, and in so doing facilitated an awareness of modern apathy. Numerous critiques emerged during the twentieth century, from Adorno and Horkheimer's seminal critique of Enlightenment, to Alisdair MacIntyre's claim that modern groundlessness stems from the failures of the Enlightenment, to examinations of the modern origins of the Holocaust by Hannah Arendt, Zygmunt Bauman, and others.

During late modernity, the modern project itself is subjected to scathing critique, and such critique finally permits a questioning of the Cartesian shift from caring to knowing. Social historian Russell Jacoby attributes apathy to a similar loss of faith in the modern project, and vindicates and calls for the revival of a utopian (read modern progressive) impulse. ${ }^{32}$ To Jacoby, we are no longer capable of conceiving any alternatives to the status quo (consumer capitalism). This is partially due to the failure of

\footnotetext{
${ }^{31}$ As evidenced in McLuhan's claim that "the twentieth century has worked to free itself from the conditions of passivity, which is to say, from the Gutenberg heritage itself" (McLuhan Gutenberg Galaxy 278).

${ }^{32}$ Is it any wonder that the dystopian genre is a product of the twentieth century? The term itself, though coined in the late nineteenth century by JS Mill, was given its contemporary meaning and significance by J. Max Patrick in 1953. The optimism of/in modernity which (though sometimes fluctuating or tempered by caution) reigned from the time of Thomas More to the early twentieth century, seems to have in large part dried up.
} 
communism and the shortcomings of Marxism, and Jacoby calls this elimination of optimism in the future, the end of utopia. Here Jacoby uses the term utopia in its barest form, stripping it of any complexity or sinister connotations, describing it as "a belief that the future could fundamentally surpass the present" (The End of Utopia xi). For Jacoby, this alleged lack of optimism has lead to a culture of apathy, a culture in which "radical critique" doesn't so much critique and offer new possibilities, as seek pithy reform, or tweak existing economic policy. History, for Jacoby, "contains possibilities of freedom and pleasure hardly tapped," however, this optimism seems to have perished. In its place, "A new alternative has emerged: there are no alternatives" (The End of Utopia xii). And while we must applaud his optimism, I think adding some of McLuhan's insights to Jacoby's grievances will see us further ahead. Jacoby seems obliquely aware of the consequences of McLuhan's distinction between a visual goal oriented world and an amorphous roleplaying auditory world, yet he doesn't use this awareness to his advantage. It was not a lack of optimism which lead to a culture of apathy, but the roots of this optimistic project itself which lead to apathy. MacIntyre's claim in After Virtue that modern groundlessness is due to the failure of the Enlightenment is surely relevant here. The lack of optimism, or loss of faith in the modern project, plays a role in granting a sensation of this consequence of print culture and the Cartesian moment, but it is not in itself the cause.

Jacoby's language is steeped in the bias of a visually oriented literate culture; history is described as linear causal chain, with a lone viewer looking to a horizon in the future. Jacoby is however correct in claiming that we are now unable to envision anything other than the present society; as Ellul reminds us, the technological system 
does not grant any perspective. From this reading, it would seem that the future does not last forever, nor has it been reached (as per Fukuyama's famous claim); the future has effectively been eliminated, which may signal a shift from a goal oriented linear visual world to an electric-aural world - we are fast becoming digital peasants. ${ }^{33}$ And yet, critics like Penty continue to affirm that "the future may only be discovered in the past" (67). While I am not calling for a return, especially a return to Catholicism as advocated by Penty, his remark is provocative, as in a sense, the future can only be discovered in the past where we had not yet been disconnected from the Good and where progress was viewed as personal transformative exercise.

It seems that we can no longer properly care for the self, and care of the self is necessary if one is to transform the self so as to gain access to truth or to experience a renewed sense of wonder. We of course have specific, banal, or instrumental cares as we go about our daily lives, but care of the self and the resultant ability to care for something larger, or care in a grander sense continues to recede. I would like to spend some time addressing the following question: with our divisive visual orientation and our instrumental view of self and world as things to know in certain terms, how can we care about the harmonious whole when we have forgotten to care for ourselves?

While apathy is often cited as a political problem (and as such this chapter will be peppered with brief discussions of political apathy), I am interested in apathy more as a

\footnotetext{
${ }^{33}$ I don't (necessarily) mean this in a derogatory sense. I only mean to suggest that the aural quality of digital technology has conjured an experience of the world that somewhat mimics (albeit on a much grander, global scale) medieval experience: a world without critical self awareness, a world not caught between past and future, a world without a desire to overcome and escape tradition. The crucial difference between the ancient/medieval and digital worlds is that the ancient and medieval worlds saw themselves as part of a harmonious order, while in the digital world, a kind of dissonance (prompted by an overabundance of information divorced from any context) is the norm.
} 
general phenomena bound up with the modern experience of groundlessness and the invention of the modern self. Again, I understand apathy as a failure to care for the self, and thus an inability to properly care for others or experience the harmony of the cosmos. Weber ponders the question of groundlessness and the divisive character of modern knowledge, asking if there is now any meaning beyond the technical and practical, a concern which speaks to Taylor's alarm at the loss of connection to a larger world. For Weber, modern man will never again be sated with life, for (thanks to the narrative of infinite progress) there will always be more to know, and we will never arrive at any solid, stable, readily graspable meaning. All that is open to us is fatigue or exhaustion at the fluidity of our condition. "And today?" writes Weber, who "still believes that the findings of astronomy, biology, physics, or chemistry could teach us anything about the meaning of the world? If there is any such 'meaning"' (142).

Weber's concerns (which would be expanded upon by Ellul years later), describe a condition vastly different from anything experienced during antiquity. Once again, ancient apatheia can be thought of as a preclusion of the pathé, or a taking charge of one's faculties (through care of the self or spiritual exercises) so as to always exercise right judgments. Apathy can be thought of as an inability to care (for the self), or as a forgetfulness regarding care. In other words, apatheia involves preclusion and transcendence; apathy involves forgetfulness and isolation. 
Edmund Burke's thoughts on the sublime are indicative of an early shift in our relationship to the cosmos. ${ }^{34}$ Formerly something to fall into accord with through spiritual practice, the cosmos became something to fear, know, and master. Without recapping his entire argument, Burke describes various sources of the sublime (including nature and infinity), claiming they incite passion. The sublime is the larger whole, the ungraspable, the unfathomably deep, and it is awareness of these qualities in nature or infinity which incites the passions. Recall that Stoic apatheia consists of a refusal to be lead by the passions, while Burkean terror or awe, derived from awareness of the immensity of nature or the irreconcilability of the idea of infinity, involves nothing less than being led first by certain passions, by a visceral reaction to the massive and ungraspable. As his pathé-centric treatise demonstrates, for Burke, meaning grows out of awe at the apprehension of something larger than the self. Herein lies the connection between the rise of modern apathy and a move away from awe or wonder inspired by unknowable vastness. Modernity altered our relationship to the sublime. The sublime became something to fear and (more importantly) something to know and master, rather than something to align ourselves with. While Burke is still interested in feeling the sublime, the direction of his work - the fact that the sublime inspires terror - speaks to the modern fear of (and subsequent need to control) the unknown. While still a part of the tradition which seeks a relationship with the sublime, Burke is sensitive to the changes occurring around him, and his work is indicative of the direction of modern epistemology. But what effect does the modern drive to know have on our experience of the sublime? The idea that the world can be known objectively through disengaged

\footnotetext{
${ }^{34}$ Edmund Burke (1729-1797) looks to understand how nature incites the passions, and to learn the origin of the beautiful and sublime in his 1757 work A Philosophical Enquiry into the Origin of our Ideas of the Sublime and Beautiful.
} 
reason, and attempts at securing such objective knowledge, appear to denude the sublime of its power, or at the very least, distance us from the wonder it previously inspired. While a thing known may elicit respect, it does not evoke awe.

Burke's description of the "delightful terror" and the attendant uncertainty that accompany the experience of vastness marks a movement away from the ancient understanding of the cosmos as something to be contented with and entered into concordance with. Acceptance became delightful terror, and while such joyous terror (awe) is still connected to something larger, this understanding of the cosmos indicates the beginnings of a new episteme, and the disenchanting of the world. Apatheia is something deliberate, emanating as it does from personal spiritual practices, while modern apathy is in part a by-product of fear (rather than acceptance) of the unknown. This fear is visible in the work of Descartes and in the language of Burke. In our role as pretenders claiming to strip fate of its power, we diminish our ability to feel the sublime. We move from acceptance and concordance to fear and anxiety, and then in our desire to know with certainty, we lose the ability to feel awe or experience wonder. Everything thus becomes (potentially) objectively knowable, and we can (apparently) gain mastery over it. In this sense, we might also think of apathy as an inability to feel awe.

Let us now, in what I promise will be a brief digression on politics (specifically, modern representative democracy), turn our attention to those who exhibit what Nietzsche describes as an involuntary spasmodic counter movement. What is described as participation in culture or politics is quite often a hollow, pseudo, semblance of participation. We don't so much actively participate as simply follow a crowd, or 
synchronize our movements with those of the herd. True participation can only occur when individuals have begun to care for themselves, which suggests that apathy (even if we limit our discussion to the political arena), cannot simply be legislated away, or banished by way of media campaigns; apathy is a more fundamental problem. This concern for true participation versus the mere semblance of participation has implications for the democratic process, and such implications are examined by Carol Pateman, a critic of the minimalist conception of democracy, which holds that a measure of apathy is necessary for modern democracy in consumer capitalist states in order to maintain stability and an artificial consensus. Contemporary democracy involves elites competing for votes (and in this way it mirrors the market - consider the expression, "voting with one's pocket book"). Equality refers to the equal opportunity to vote, and the equal opportunity to consume. A century ago this would have been considered very antidemocratic (Pateman 104), and yet now, formal participation in contemporary democracy is limited to voting and consuming. Pateman critiques the likes of Joseph Schumpeter, for whom a level of political apathy is desirable and in fact necessary if stability in modern states is to be maintained. People should not take an active interest in decision making, and must be minimally engaged in the process (i.e. voting for representatives, or the exercise of taste via consumption). For Schumpeter the ideal form of democracy was representative, rather than direct (Schumpeter 269-272). In such an arrangement, citizens would, to paraphrase de Tocqueville, only emerge from their state of dependence once every few years, and then only to select a leader. Citizens would not participate in the actual decision making process, and would be persuaded by a widespread "manufactured will. ${ }^{35}$

\footnotetext{
${ }^{35}$ To avoid making this idea seem completely sinister, it should be noted that Schumpeter is attempting to
} 
For Schumpeter, contemporary democracy, as opposed to classical or direct democracy, ought to minimize active participation and critical thought. Pateman's exploration of mid twentieth century theories of democracy reveals a revision of classical democracy, one which drastically limits participation of the citizenry, which follows the model of the market, and which sees the emergence of a small representative group of leaders. For these revisionists of democracy, an "increase in participation by the apathetic would weaken the consensus on the norms of the democratic method" (Pateman 14). The limited form of "participation" championed by the revisionists is really not participation at all, as it distances people from what has been called a politics of polarization (Taylor), a politics of conflict (Barber), or a politics of friction (Eliasoph). Such an "ideal" of tolerance and consensus is a "cloying, unconflictual simulacrum of community" (Eliasoph 244), and such spurious engagement limits the ability to truly participate in the decision making process.

Though focusing on taste and pop culture, in The Empire of Fashion, Gilles Lipovetsky argues that banality can serve a moral purpose, in that superficial consensus is not likely to promote conflict. Those who view the world through the optic of consumer culture (fashion, advertising) feel little connection to or interest in that world. Selves constituted under such a disinterested milieu tend to be indifferent to all but the superficial and fashionable surfaces which surround them. Banality, understood in this way, would seem to have a consoling effect. Interestingly, such pop cultural analgesia is

address the problems of scale, lack of time, and overabundance of information that beset modern citizens. With the centralized power of the modern state, the diffusion of citizens across vast areas, the temporal demands of working life, the number of issues at stake (and the expertise needed to navigate such diverse issues), arriving at any informed consensus is indeed a formidable task, and voting for experts who manufacture mass will is Schumpeter's solution. In recent years some thinkers have suggested that rising digital technologies could potentially address issues of centralization and scale, but this is a debate for another time. 
exactly what Eliasoph condemns, and while a novel point, I think it can be countered by the arguments of Eliasoph, Barber, and Taylor described above. Such a lack of friction is inimical to real community. A consensus won through superficiality seems like a rather empty form of consensus, one unknowingly foisted on people from above. Though his observations may be apt, should such triviality, such political and social evanescence, be celebrated? Lipovetsky seems to be describing yet one more way the current (pop) cultural milieu facilitates apathy (as carelessness). And while Lipovetsky celebrates this form of consensus, as it does, in a sense, draw upon a common background and thus potentially limit conflict, the kind of self he describes, concerned with surfaces, shares something with Seneca's description of the primitive we encountered earlier. The primitive lives in an (ostensibly anyway) harmonious state, just as those selves formed under a flattening or uniformity of desire live harmoniously, but both groups lack awareness. Fashion and popular culture become the common backdrop, and while Lipovetsky's argument is indeed provocative, I am skeptical about the worth of such a contingent and trivial backdrop to human activity. While this form of subjectivity (and politics) may dissuade conflict, it also limits awareness, and this does not seem like a fair trade. There may be equilibrium here, but it was not won, nor pondered - it happened to people. I link the thought of Lipovetsky, Pateman, and Eliasoph, as their discussions of political consensus lead rather nicely into the thought of Siegfried Kracauer and his descriptions of the spiritual stances available under modernity.

The condition of modernity has been described as "metaphysical suffering from the lack of a higher meaning in the world, a suffering due to an existence in an empty space," or an alienation from the absolute, and for German sociologist and cultural critic 
Siegfried Kracauer (1889-1966), this condition links all moderns as "companions in misfortune" (129). In what I read as an acknowledgment of the consequences of the Cartesian moment, Kracauer points to a loss of experience or feeling, and the privileging of a distancing intellectualization in which life shifts from lived experience to abstraction. Such is also the case for Pierre Hadot, who describes the difference between ancient and modern philosophy in similar terms. Ancient philosophy proposed an art of living, was focused on the whole human being, and offered a guiding principle for a life well lived, whereas modern philosophy "appears above all as the construction of a technical jargon reserved for specialists" (Philosophy as a Way of Life 272).

For Kracauer, three possible spiritual stances exist within modernity. The first is that of the skeptic without hope. The hopeless skeptic is aware of the modern gravitas but feels unable to "wrest" himself free. This is a stance on which Weber theorizes and which Kafka's writing emotes, where one feels the iron bars closing in, where life is not determined by God but by culture, and where the individual lacks the will to escape or effect change. People have fought for the disenchantment of the world, doubt has been extended to all realms of thought, God is dead... but now what? Doubt has been extended and agency exercised, yet the consequence of this erasure of authority has been a recession of meaning and disconnection from the Absolute. This Weberian condition is born of a kind of heroism; its central problem however, is that it makes no appeal to meaning. In their attempt to disenchant all facets of existence, the skeptics never touch on the meaning of meaning.

The second possible spiritual stance produced by modernity involves a fear of uncertainty felt by those "short-circuit" people who flee into a world of baubles and 
distractions. Driven by a tacit despair at the vacuity which penetrates and surrounds them, the short-circuit crowd tries to force themselves upon any form of faith in order to prevent the reality of disenchantment from entering their consciousness. For Kracauer theirs is primarily a spurious religious return, but these short-circuit types also retreat into other beliefs and practices. It is a faith forced upon the self out of desperation, an act Kracauer refers to as metaphysical cowardice - a desperate fortification erected not out of true permeating belief, but out of self defense and a turning away from uncertainty. The vast majority today occupy these defensive ramparts. Vacillating between artificial faiths (they desperately want to believe, but they cannot entirely submit to something larger), they wear consumerist blinkers, gazing at the ephemerality of the mall rather than towards matters of spirit or the Good. Kracauer writes that "uncertainty leads them to underscore their certainty," a comment which speaks to desperation, as they exert a great deal of effort advocating their forced belief, whereas belief for a true believer encompasses the very being of the adherent and requires no effort (Kracauer 137). This need not necessarily be religious faith; it might also take the form of a faith in progress, science, consumer capitalism, etc. Within this stance Kracauer observes the oft illusory and self-deceptive nature of profound certainty. Certainty is vigorously asserted only when on a deep level one is experiencing doubt. Profound certainty in this case becomes a defense against doubts which may lead to an uncomfortable uncertainty. This observation seems to explain the modern drive for control, particularly if we look back to Descartes, who was deeply troubled by the fact that there were things he did not know. Modernity is characterized by (among other things) the ability (and obligation) to doubt; when one doubts of meaning, one can react, as Kracauer observes, by denying all 
meaning, by vigorously pursuing certain meaning, or by enduring discomfort and waiting amidst uncertainty.

The only remaining attitude is one of waiting. Of those who wait, Kracauer writes: "By committing oneself to waiting, one neither blocks one's path towards faith (like those who defiantly affirm the void) nor besieges this faith (like those whose yearning is so strong, it makes them lose all restraint). One waits, and one's waiting is a hesitant openness" (138). Those who wait share with the skeptics a measure of doubt, yet theirs is a keen and highly discerning doubt, rather than a skepticism on principle. When he writes of openness, Kracauer is referring to an openness to faith that is not forced, but that is rather experienced and genuinely believed. It is an openness to faith born not of impatient desperation, but of a "ripening" of the self, or a gradual alignment of the self with something larger. Kracauer's idea of hesitant openness is indeed provocative, but Heidegger places far greater weight on this idea in his discussion of the "openness to Being."

The history of western thought is one of forgetting the openness to Being: "the truth of Being has remained concealed from metaphysics during its long history" (Heidegger "The Way back into the Ground of Metaphysics." 268). The forgetfulness of Being has long dogged our steps, and Heidegger wonders if this problem has "determined the entire modern age? What if the absence of Being abandoned man more and more exclusively to beings, leaving him forsaken and far from any involvement of Being in his nature, while this forsakenness itself remained veiled?" ("The Way back into the Ground of Metaphysics" 269). Heidegger is concerned with "the Being of those beings who stand open for the openness of Being in which they stand, by standing it. This "standing it," 
this "enduring," is experienced under the name of "care" " "The Way back into the Ground of Metaphysics" 271). "Standing it," or endurance is crucial here, and it is this idea which Kracauer arrives at, if in a rather less lively fashion. To stand open, to resist either positing or running headlong into some dogma or narrative, and to endure the uncertainty which besets us is the task to which moderns must apply themselves. Interestingly, Heidegger links endurance and care, and likewise for Kracauer, in a striking similarity to the stoic spiritual stance (awareness, exertion, effort), the act of waiting “consists of tense activity and engaged self-preparation" (Kracauer 139), or what we might describe as care of the self. Waiting then, is not a passive act; to refrain from activity demands a degree of exertion. Nietzsche describes something similar, when he discusses the "forbearance from reaction" that characterizes those with strong constitutions. "A strong nature," writes Nietzsche, "manifests itself by waiting and postponing any reaction: it is as much characterized by a certain adiaphoria as weakness is by an involuntary counter movement and the suddenness and inevitability of "action", (Will to Power 28). Here too waiting marks a hesitant openness. Those who wait do not slip into despair, nor do they feel compelled to vacillate between banal pleasures in order to alleviate disorientation. Their decision to wait is deliberate and comes with a carefully won awareness, whereas the weak nature, the short-circuit type, feels an involuntary and unconscious compulsion to react (a spasmodic counter movement). Their pursuit of certainty is a knee-jerk reaction to a world that has been rendered groundless. The task before us then, is to wait.

Kracauer continues, writing, "what is at stake for the people under discussion here [those who wait] is an attempt to shift the focus from the theoretical self to the self of the 
entire human being, and to move out of the atomized unreal world of shapeless powers and figures devoid of meaning and into the world of reality and the domains it encompasses" (139). In his final word on those who wait, Kracauer quite admirably moves towards that ancient problem which occupied Seneca and Marcus Aurelius: how are we, we alienated individuals, to once again become synonymous with virtue? Kracauer is approaching the problem of alienation caused by language and all acts of representation (the overemphasis on theoretical thinking as he calls it), and intensified by modernity (specifically the Cartesian moment, which articulated the move toward a theoretical self and elevated knowing over caring) and its move away from absolute moral sources to relationships motivated by material and economic relations, which see humanity and nature objectified and made interchangeable with symbols (money, that real abstraction) in a so-called culture of authenticity.

Though I am not interested in focusing on the effects of apathy in the forums mentioned earlier, I would now like to turn to some specific expressions of modern apathy, or towards the kind of individual that grows out of the shift from a life based on caring for and thus transcending the self, to one based on knowing with certainty and through such knowledge gaining mastery over. Both Simmel and McLuhan ably describe manifestations of this shift from caring to knowing. Writing on culture's effects on the soul, Simmel argues that the most serious problems of modernity arise out of the individual's struggle to retain some measure of autonomy amidst the vast pressures of social and cultural life. Here, the desire for autonomy and authenticity, and the modern desire to elevate oneself above the world so as to know and master it, is at the heart of the 
problem, as such desires see us at a remove from others and the world, whereas care of the self actually brings us closer to others, the world, and the Good. For Simmel, such desires are best viewed in the arena of urban life. The urban individual is confronted with "the intensification of emotional life due to the swift and continuous shift of external and internal stimuli" (Simmel 325). With "every crossing of the street" the metropolitan individual experiences a rush of stimuli, and as such, the individual "creates a protective organ for itself against the profound disruption with which the fluctuations and discontinuities of the external milieu threaten it" (Simmel 326). This is strikingly similar to McLuhan's interpretation of our response to our technological extensions. Here too, numbness, or what Simmel refers to as the urban blasé attitude, is an unconscious psychological defense mechanism, and this defense mechanism is spawned by the desire for autonomy, or the modern desire for freedom, and such a defense mechanism is only necessary in a technological society. As George Grant points out, the problem of meaninglessness is caused by the very desire for freedom. The assertion of radical freedom, of our separation from the world, and the consequent groundlessness of value, have given us a world in which things appear without inherent value.

Modern progress (begotten by the shift from self care to self knowledge) is technical progress. As Ellul reminds us, technology is not a mere means, nor is it benign. Technology obeys an internal logic. Those living within the technological system are subject to certain conditions, including hectic urban life and the shift from a visual to electric privileging. In addition to changing the way we approach the self and establishing a new episteme, the effects of the shift from care to knowledge are compounded by the technological system intertwined with these changes in consciousness and episteme. 
Analyses performed by Simmel and McLuhan suggest that the nervous strain experienced under a technological society is a fertile growth medium for apathy.

"There is perhaps no psychic phenomenon which is so unconditionally reserved to the city as the blasé outlook" (Simmel 329). This blasé attitude descends upon urban folk as a response to one of two types of excessive nervous stimulation. The first, Simmel describes as an immoderate sensuality which "stimulates the nerves to their utmost reactivity until they finally can no longer produce any reaction at all," the second, and that which Simmel trains his acumen upon, we can think of as successions of rapid banality. These everyday stimuli, experienced in the full sway of their rapidity and contradictoriness, put such strain on the nervous system that after enduring intense vicissitudes, it effectively shuts down. I would like to suggest that the challenge is to endure contradictions, as such enduring may leave us open to encounters with the Good. As Seneca was so keenly aware, there is a tremendous irony in using narratives to confront the disconcerting ambiguity of life. We tell stories to make sense of the world (by overlaying meaning atop complexity), and yet the symbolic is what separates us from the world. For Postman, the collapse of narratives is intimately connected with the problem of meaninglessness, as "when people do not have a satisfactory narrative to generate a sense of purpose and continuity, a kind of psychic disorientation takes hold, followed by a frantic search for something to believe in, or, probably worse, a resigned conclusion that there is nothing to find" (10). Here we have a hurried description of Kracauer's short-circuit type and his skeptic without hope, yet Postman's claim neglects the fact that the narrative form misrepresents experience. Narrative smoothes over the roughness of the unknown, the disconcerting ambiguities, and presents the world as 
something wholly graspable, something that can be known with certainty. While this may not be true of all narrative content, it is a trait of the narrative form. This is to say, the content of some narratives works to accentuate ambiguity, but the narrative form itself tends to connect events, to smooth over uncertainty, to align and order, to organize events/ideas into a sequential framework. Narrative, and its compulsion to know, to control and preclude the unknown and mysterious, is, as Elder tells us, "the artistic structure of technocracy" (The Cinema We Need 265). A fitting comment, as McLuhan too links narrative to the typographic (technological) age (Medium is the Massage 126).

For Simmel the nervous system is shut down; for McLuhan, it is extended and numbed. Both descriptions speak to a loss of feeling, and both thinkers connect this loss to the modern city and more generally, to the technological society. While McLuhan moves beyond the mere local urban in his observation that with rapid transit, the "urb orbs," he does dwell on localized urban space, specifically the high rise apartment complex. According to McLuhan's High-rise apartment tetrad (Laws of Media 138), the apartment enhances solitude, reverses the slum, obsolesces community, and retrieves the catacomb. ${ }^{36}$ Despite cramming hundreds (perhaps even thousands) into a relatively small urban footprint, such close quartered living is actually inimical to community and fraternity. This mode of living is an example of modern sundering, and is evidence that despite being pushed into close proximity, a collection of atomized selves not cared for does not a community make. As with modern progress, efficiency is the central advantage here.

\footnotetext{
${ }^{36}$ In a discussion with Toronto high school students (on the CBC radio program "Ideas," with Alan Anderson c. 1960's), McLuhan claimed that high-rises are vertical cemeteries. It appears then that Mumford's "castles in the sky" have become repositories of the dead.
} 
Simmel characterizes the blasé attitude as an inability to respond to stimuli. This is a very specific claim: the blasé attitude is not forbearance from response, but an inability to respond. This fits with an understanding of apathy as a withering of care and feeling due to the move from epimeleia heautou (care of the self) to gnothi seauton (know yourself) and the resultant relation to the cosmos, which became something to fear and know (freedom was to have resulted from such knowledge and control). Apathy is both a problem of meaning and of care. It is a problem of meaning in that, with a self understood as disengaged reason, meaning is truncated and disconnected from something larger than the self. It is a problem of care, as in an objectified world that can be known through disengaged reason, knowledge has been disconnected from care and consequently, that transformative requirement, or an understanding of knowledge as a change in one's very being won through a program of care, has been lost. If we don't properly care for the self, which is to say, if philosophy is treated as a detached discipline rather than a way of life, how can we properly care for anything beyond the self? For Simmel, the urban culture of rapid banality is responsible for nervous exhaustion, while for McLuhan, it is a lack of awareness and misunderstanding of our technological extensions that leaves us in a state of numbness. The content of these examples owes its existence to the Cartesian moment, to the mind/body division which posited a knowable interiorized self (that no longer required care in the ancient sense), an objectified world to be known and controlled (rather than wondered at and entered into a relationship with), and a consequent distancing from the Good (as harmony).

Simmel describes the urban blasé as nervous exhaustion and as a form of psychic preservation. McLuhan will later observe the same symptoms as Simmel, however he 
cites slightly different causes. For McLuhan, technology is an extension of some sense or faculty, thus for him, the environment in which we live is made, built, a product of techne, or human arts. These "modern" extensions (dependant on the intensification of visual privileging), ${ }^{37}$ which could only occur under a technological society that views our environment as objective fodder, work to parse out life into easily digestible portions and categories, which is to say, our own extensions serve to sever us from a larger world. The blasé attitude is precisely what modern aesthetic operators seek to expunge. By using aesthetic practices, they seek to revivify that which has been taken for granted; they seek to defamiliarize the prosaic, and expose the strangeness of the world, thus making it worthy of contemplation and attention. These thinkers attempt to recover a sense of awe at the apparently banal, or to make the commonplace strange so that it once again demands thought. They suggest living in a state of diminutive confusion or mild uncertainty, thus eliminating inattentional blindness and forcing the smallest details into the center of our awareness. In short, they vie for a hesitant openness.

For Simmel the blasé attitude amounts to an unconscious act of self preservation. Note his language, preservation rather than care - this distinction is significant. To preserve is to maintain one's ego, to uphold a perceived authentic self, while to care for the self demands movement, or a transformation bent on aligning oneself with the Good and thus acting in the interests of the whole. Care of the self is ultimately about others; self preservation is about maintaining the ego in the face of oppressive forces. Further, this attitude "is obtained at the cost of devaluing the entire objective world, ending inevitably in dragging the personality downward into a feeling of its own valuelessness"

\footnotetext{
${ }^{37}$ I am careful to specify "modern" extensions here, as even "primitive" humans extended their faculties (sticks, flint arrows, levers, animal hides, etc.).
} 
(Simmel 330). Such an attitude could only have taken shape in a world that has been objectified, in a world divested of authority, in a world that has been treated as a separate realm of objects rather than as a constitutive part of the harmony of the cosmos, in a world afraid of uncertainty, and in a world of knowing rather than caring.

For McLuhan, each extension of the human senses, or each new form of media, generates a numbness in the individual and society. Technology is not innocuous, nor is it born in a vacuum - it affects our consciousness, and it alienates: "significant technological change always involves a re-ordering of our moral presuppositions, of social life, of psychic habits, of political practices" (Postman 96). This is the central problem with which communication studies grapples. The problem of how technology affects our consciousness, and more specifically, how technology alters our relations with (or alienates us from) the world, the self, and others, is a spiritual endeavour. Another way of describing communication studies then, is as a discipline which traces the effects of material progress on the spirit.

Communications mediums which extend the nervous system in specific ways and privilege one sense at the expense of the others enable and encourage a turning away of the sort experienced by Kracauer's short-circuit types. When we extend a sense through technology, we delegate the work that would have been performed by that sense, which is to say, we allow our technological extension to act, think, feel, etc., on our behalf. In each instance of technological extension (which is accompanied by an auto-amputation), we lose the ability to feel/experience something directly. In order to cope with the stress caused by this auto-amputation, the nervous system responds with "a generalized 
numbness or shock that declines recognition" (McLuhan Understanding Media 52). Once adapted to our technology, we become numb, and this numbness extends to the vibrations of the resonant interval which are no longer felt. "Shock induces a generalized numbness or an increased threshold to all types of perception. The victim seems immune to pain or sense" (McLuhan Understanding Media 53). McLuhan does several important things here. First, he observes that auto-amputation forbids recognition, which is to say, this process occurs unconsciously. Second, he refers to the numb as victims, implying that this state of numbness happens to people, and is not something willed or decided. McLuhan continues his musings: "It could well be that the successive mechanizations of the various physical organs since the invention of printing have made too violent and superstimulated a social experience for the central nervous system to endure" (Understanding Media 53). Both McLuhan and Simmel point to the connection between overstimulation and numbness or the blasé attitude, and though each cites a different source of said stimulation, the result in both cases is an unconscious or unrecognized numbness. Both Simmel and McLuhan are actually describing modern technological society, specifically the changes in social life begotten by typography, and the move away from a self well cared for to a self (and world) to be known objectively, and thus, the numbness they observe is part of a history going back to the middle ages and early modernity.

Typography instigated the intensification of the visual sensorium, an intensification necessary for the formation of the Cartesian self which formalized the shift from caring to knowing, a shift that was in turn necessary for technical progress and the technological system. This form of progress would eventually lead to a shift from the 
visual-literate to the aural-electric. With electric technology, we have extended the entire nervous system in an act which McLuhan describes as suicidal. Ironically, each additional extension signifies an increased level of interiorization, which sees us more forgetful of the need to care for the self, and consequently the world. To be interior in this sense is not to work on the self; it is to close ourselves off from anything beyond the self. We have extended ourselves to the point that losing an extension feels like losing a limb. "Today the mass media are inescapable and people feel slightly less alive when unhooked from long lines of news and entertainment" (Carey 1). We may have more relationships now, but what of their quality, duration, depth, and motive? We typically fail to ask these sorts of qualitative questions.

A. A. Milne's Eeyore character (the apathetic ass) is perhaps one of the most iconic symbols of disenchantment, but we can also think of him as one of Kracauer's skeptics. Where a misguided heroism leads the skeptic to a life resigned to meaninglessness, existential suffering caused by an inability to endure uncertainty leads to a short-circuit of sorts, or what we might describe as an unconscious retreat into apathy. Neither Burke, Kracauer, Simmel, nor McLuhan set out to explain the source of apathy; rather, they are thoughtful observers of modernity, and in their work we can glimpse apathy as it exists in various spheres of life. Their respective work points to the fact that modern apathy arises out of a failure to care for the self, a consequent forgetfulness concerning the care for others, and an inability to orient ourselves toward the Good as harmony. This apathy is the result of the reduction of philosophy to mere method in the Middle Ages, the intensification of the visual sense (and the attendant 
changes in consciousness) wrought by the development of typography, as well as a tragic Cartesian irony, whereby Descartes' own spiritual exercises diminished the spiritual act of caring in favour of the instrumental act of knowing. Where the ancients decided to judge certain things indifferent, the modern state of not caring is not directed or consciously entered into. Modern apathy sees a world emptied of meaning where one does not care (not by choice - this lack of care happens to people), and in this way apathy can be thought of as feelinglessness or carelessness.

If a consequence of apathy is the inability to feel awe, then how might we rekindle a sense of awe, or an ability to endure and even experience wonder and marvel at uncertainty? The next chapter is devoted to such questions, and will turn its attention towards modern aesthetic exercises which encourage the experience of wonder in the everyday. How can we care about the world when we have forgotten to care for ourselves? The short answer is, we cannot. Thus, we need to re-learn to take care of ourselves. If the self has not been cared for, it is ill equipped to make right judgments regarding others and the world. A self not cared for is not fulfilling its purpose, and in not fulfilling its purpose, it is not contributing as well as it might to the harmony of the whole.

In a "world of made" (which implies a world of known), what room is there for wonder? The ability to endure or stand for uncertainty, brought about by way of aesthetic practices designed to allow for awareness may grant us a way back to the Good. The task before us is to "stand for," or endure uncertainty, for in enduring we may rekindle wonder at the fact that there is something rather than nothing. 
To reiterate, at its heart, apathy is not a political or social problem (though its effects are certainly felt in the political and social spheres). It is better thought of as a set of philosophical problems. Apathy is a problem of modern subjectivity, as a sundered self, and one not cared for, cannot participate in the harmony of the cosmos. It is a problem of modern progress and the technological system, as in a move away from the ancient understanding of progress, the modern iteration demands specialized collective movement for the benefit of the isolated individual. It is a problem of modern aesthetics, as in the typographic age the primacy of the visual has been further intensified. And apathy is a problem of modern epistemology, as the ground of knowledge was brought inwards and the world became something uncertain that had to be mastered and known in order to secure an apparent freedom. Apathy can be thought of as a failure to properly care for the self (and also a failure to care for the world and an inability to touch the Good). This may sound counterintuitive at first (as apathy is generally thought of as a lack of care in general, specifically a lack of care for others), until we recall the Stoic position: care of the self as the way to care for others and participate in the harmony of the cosmos. 


\section{Chapter 5-Art and Estrangement: Modern Áskēsis and the Rekindling of Awe}

Foucault poses questions regarding modern attempts at forging an ethics and aesthetics of self, claiming "The theme of return to the self has never been dominant for us as it was possible for it to be in the Hellenistic and Roman epoch" (Hermeneutics of the Subject 251). While the idea of caring for the self no longer enjoys its former prominence, "a whole section of nineteenth century thought can be reread as an attempt, a series of difficult attempts, to reconstitute an ethics and aesthetics of the self' (Hermeneutics of the Subject 251). Foucault offers the examples of Nietzsche, Schopenhauer, Baudelaire, anarchism, dandyism, and to this list I would add certain theorists who study communication from transformation (McLuhan), ritual (Carey), or reconciliation (Peters) perspectives, rather than a transmission perspective. ${ }^{38}$ Approached in this way, Communication Studies is primarily a spiritual matter, concerned with relationships and the authentic unfolding of being. ${ }^{39}$

It is not my intent to suggest that the ancients were spiritual and moderns are not, as such a distinction is totalizing and misses the mark. The first four chapters (focusing on a history of ideas) were meant to establish our proximal distance to antiquity, and to provide perspective thus granting awareness of and inspiration for our own áskēsis. As Foucault points out, there is a modern tradition which appeals to aesthetics in order to perform work on the self (though we tend not to think of such work in terms of áskēsis), and in this chapter, I will perform a re-reading of this tradition, for as Peters observes,

\footnotetext{
${ }^{38}$ In brief, the transformation perspective works to secure awareness of the effects our technological extensions exert over the self. The ritual perspective is an effort to secure shared meaning. The reconciliation perspective performs a kind of de-objectifying, in order to reveal a unity which exists between self and others - it is not a sending (as in the transmission perspective) but a revealing. ${ }^{39}$ By this I am referring to an ethical orientation which encourages us to develop our possibilities in relation to something larger than the self, and something beyond technique.
} 
"Re-reading can retroactively enrich texts (Peters:2011 228). Tracing a number of modern examples which highlight our distant closeness with antiquity, this chapter will explore the artist's role as a facilitator of openness through practices of modern estrangement, and will then go on to claim that under modernity, openness to uncertainty (won through estrangement) is the best way available to us to approach the Good. By artist, I do not mean only those who (with a nod to Elder's excellent example of symbolic deflation) splash goo on canvas, or work with some physical/visual medium. Although these are the forms of art which most readily spring to mind, as Granata points out, we may consider any "aesthetic operator," or anyone who grasps the implications of extending the senses, an artist. Whether art is designed to inspire and impel us towards a gradual congruence with higher forms, or whether its purpose is to jolt or jar us into awareness via estrangement (and allow us to hover in the newly opened interval), it is, ultimately, concerned with reconnecting us with the Good. The artist is a facilitator of openness, one who forces us to endure the discomfort of encountering the unknown. Before discussing the role of the artist, I would like to say a few words about Marshall McLuhan, one who dedicated the better part of his life to understanding the consequences of contemporary culture. Because McLuhan was deeply inspired by the ancient grammarians, and because he understood aesthetics in the old sense, his work is especially important for my project. He grasped, perhaps better than anyone, the importance of understanding our technological extensions.

John Durham Peters (2011) focuses on McLuhan's aversion to dialectic (in favour of a poetic or grammatical stance), a position he observes in McLuhan's thesis on the Trivium and throughout the rest of his work, and it is with this observation that I would 
like to begin probing the spiritual and aesthetic implications of McLuhan's grammatical method (which as Peters points out, sought "immediate intuition," or, an "all-at-once vision"). This all-at-once vision is another way of describing the commingling of sense and reason, 'a way of being aspired to' since antiquity, and into the present. McLuhan's grammatical approach to understanding contemporary culture can be read as part of the same spiritual tradition as the Stoics. McLuhan's probes are a form of áskēsis based on an aesthetics of awareness, ${ }^{40}$ which demonstrate an interest in clarification, and yet which force us into a state of perpetual contemplation due to their poetic and estranging nature. McLuhan's work seeks clarity through uncertainty.

I would like to suggest that McLuhan's probes are best understood as a form of áskēsis bent on generating awareness. That said, there have been a number of critics who read McLuhan's work rather differently. I would like to take a moment and respond to some of these alternate readings. Raymond Gozzi Jr., for example, claims that McLuhan had his metaphors backwards. Media are not extensions, contends Gozzi, but rather, media are intrusions upon our senses. Gozzi's view comes from concern over the effects of our media, yet rather than understand, he wishes to turn away from media.

In order to understand the effects of our media, we must open a space within which to wait, for only through careful observation can we survive the effects of our extensions. If media are intrusions, then leaving openness enough for awareness is counter productive, and instead, we must, ostrich-like, bury our heads in the sand. The course of action we choose depends on our understanding of media. While turning our attention away from media and their effects would undoubtedly be less traumatic than the

${ }^{40}$ Peters points out that others (Theall (2001); Cavell (2002)) also identify McLuhan's later work with aesthetic concerns. 
alternative, this flight from trauma would end up being more harmful than the trauma itself. Furthermore, turning away does not require any effort or exertion, as does understanding and weathering the storm. This is one reason why McLuhan's work should be understood as an example of modern áskēsis - it demands careful attention and exertion, and it is a task that will likely never end. By changing McLuhan's metaphor from extension to intrusion, Gozzi smoothes over the problem by removing the need to understand and deal with changes in consciousness. Denial and retreat are far easier than observing patterns and facing the unknown.

Other critics (like Wertime for example) have mistaken prescience for optimism, when they characterize McLuhan's writings as utopian (utopian in the sense of naïve and uncritical enthusiasm). While Donald A. Fishman rightly perceives McLuhan's skepticism of electronic technology (specifically his mistrust of television content), he seems to miss the point of McLuhan's style, or his grammatical method. McLuhan's "elliptical style of writing, and his heavy reliance on "probes" hurts the ability to understand his ideas" (567), claims Fishman, but of course, McLuhan's style itself works to cause a rupture, to force contemplation and a dwelling on. McLuhan's writing demonstrates that the medium is the message. Fishman's grievance with McLuhan's "limitations" is centered on his unstructured style. "There is a stream-of-consciousness style of writing to McLuhan's work that is interesting but distinctly offputting. It is not an argumentative or scholarly approach to discourse" (Fishman 573). While for Fishman McLuhan's stylistic tendencies (namely his non-scholarly prose) are an off-putting drawback, I find them to be integral to his purpose, as they demand effort on the part of the reader. McLuhan's writing does, in a way, bear some resemblance to that of 
Heidegger, as his probes, aphorisms, and elliptical style work to prevent the easy absorption of his thought. Such tactics also make his work comparable to the Meditations of Marcus Aurelius, which often take the form of stream-of-consciousness "probes," and which are often fragmentary, disconnected, repetitive and rambling. The Meditations, like McLuhan's various grammatical probes, are an exercise, both for the writer and his readers.

In his thoughtful and wide ranging history of communication, John Durham Peters counts McLuhan among the ranks of what he calls the technicians of communication, those who "think the imperfections of human interchange can be redressed by improved technology or techniques" (Peters:1999 29). ${ }^{41}$ The inclusion of McLuhan within this group implies that there is a technological optimism in his work, and this is simply not the case. If there was an optimistic side to McLuhan, it was more delicate and understated than this. ${ }^{42}$ McLuhan's is an aesthetic theory, and art is, for McLuhan, a survival tactic, necessary in the face of supreme ignorance about the effects of our media, and while survival does imply "making it," it also implies just barely "making it." As with the sailor in Poe's short story, to weather a maelstrom is to endure privation, not to serenely sail into the future. Peters is correct that McLuhan does create universal formula in his laws of media, but to claim that McLuhan wishes to "mimic the angels by mechanical or electronic means" (Peters:1999 29) is to downplay his stance of estrangement. While McLuhan considered himself an observer and was loath to inject

\footnotetext{
${ }^{41}$ I should make it clear that here, Peters does not focus on McLuhan, but rather treats him in passing.

${ }^{42}$ To elaborate, McLuhan is pessimistic about the immediate "upheavals" wrought by technology, but like Grant and Ellul, his faith commitments permit a long term optimism in humanity's ability to eventually understand these changes. For a more explicit description of where McLuhan positions himself on the optimism/pessimism spectrum, see the last few pages of his famous "Playboy Interview" in The Essential McLuhan, Ed. Eric McLuhan and Frank Zingrone (1995).
} 
personal sentiment into his analysis, ${ }^{43}$ on the occasions when he allowed intimations of his feelings to surface, they turn out to be anything but optimistic or congratulatory. On the contrary, the term global village (and all of McLuhan's work) is loaded with trepidation. After all, McLuhan was quick to remind us that he was first and foremost a teacher of literature. While attentive to the maelstrom of electric technology and often critical of modernity and print culture, McLuhan was firmly rooted in the Gutenberg age, and was certainly not a champion of the changes wrought by the electric. McLuhan is better characterized as a sleuth than an optimistic technician. He was a private eye in the world of the ear, doing a job and trying to avoid expressing a direct judgment. His was an aesthetic of awareness, or a desire to understand transformative processes that act on our consciousness, and in this way, his "probes" and "explorations" are rather like various Stoic exercises, which attempted to generate an awareness of one's place in the world and lead the self toward virtue. And while he saw himself this way, we can, if we look carefully, discern a subtle ambivalence in McLuhan. Intellectually, as a scholar of media and a participant in Western culture, McLuhan was indeed pessimistic about the consequences of our lack of awareness. And yet, his faith commitments (he was a devout Catholic) would have obviated any total and deeply entrenched pessimism. While he may have been pessimistic about the immediate consequences of electric technology (and our resounding lack of awareness), he had faith in the harmony and order of God's plan.

In a way, McLuhan's thought shares something with that of Peters, for whom the problems of communication "are fundamentally intractable" (Peters:1999 29). Where McLuhan differs is in his suggestion of stable laws that can be used to garner some measure of awareness of the electric vortex in whose pull we are caught. For Peters, such

\footnotetext{
${ }^{43}$ A “problem” Peters later terms McLuhan's “suspension of the ethical” (Peters:2011 240).
} 
structural approaches miss the mark and oversimplify. McLuhan is concerned with understanding processes, rather than with judging these processes, but if he were to judge, the verdict would be condemnation. While he was resolutely opposed to much technological change ${ }^{44}$ McLuhan was quick to caution against reactionary resistance, as this exacerbates the problem (perhaps this is why Peters counts McLuhan among the technicians of communication - his lack of resistance is read as acceptance). We might also read this lack of resistance as a consequence of his faith. There is, then, a certain amount of turmoil within McLuhan. As a media scholar, he was leery of the changes wrought by electric technology, while as a Catholic, he accepted his place within the cosmos created by God. Recall his allusion to Poe's "Descent into the Maelstrom," where to resist the maelstrom is to vainly work against insurmountable forces; it is to court doom. To accept our place within the swirl of implacable forces, and then to observe, and garner awareness so as to weather the storm, was, for McLuhan, our only option. His apparent lack of action then, should not be read as inaction. His is an aesthetic of awareness and anticipation, as such attitudes may allow us to understand the trauma that accompany our extensions, and provide us with insight into ourselves. McLuhan was not optimistic about our media, but he was hopeful that we might gain some awareness of it, and thus of ourselves.

In an article published over a decade after Speaking into the Air, Peters provides a much more detailed reading of McLuhan, in which he expertly plots the "multiple McLuhans" in their various forms, and then amends this list with one more re-read of McLuhan. The existence of these "multiple McLuhans" and their various approaches (English professor and moral critic, Canadian techno determinist, modernist literary

\footnotetext{
${ }^{44}$ As he makes clear in various interviews (see McLuhan's Wake).
} 
critic, Catholic critic of print culture, etc.) is what so vexed Fishman. McLuhan was anything but a traditional academic. His entire corpus reads more like an exploratory collage than a solid, stable, staked-out position. The very presence of these "multiple McLuhans" sets up his work as a kind of public áskēsis as he struggled for awareness and encouraged others to do the same.

For Peters, McLuhan is best thought of as a grammatical theologian, one who interprets the world and draws connections between life and language (we might also think of this as part Stoic and part Catholic humanist). Peters reminds us that "Ancient grammarians took grammar to be the art of interpretation in general, extending beyond literature to the universe, the book of nature, itself" (Peters:2011 229), and proceeds to trace the lines of connection between the Stoic understanding of "a cosmic logos that informed everything and that could be best read allegorically" (Peters:2011 230), and McLuhan's own grammatical tendencies. McLuhan was interested in understanding the whole. His work is bent on generating awareness, and can be read as a form of áskēsis in the tradition of the Stoics.

McLuhan was both critic (as evidenced by his early fealty to Chesterton) and defender of modernity (as evidenced by his love of the written word and the modern subjectivity it contributed to, and for the possibility of estrangement which it granted). Far from diminishing his credibility, this delicious ambiguity places McLuhan squarely in step with those whom Berman has called modernity's greatest thinkers. McLuhan's interdisciplinarity (like much of contemporary Culture Studies) is, in a sense, a return to the ancient grammarians. Here, the sensibility of a teacher of English (one who interprets 
texts and language) is extended and applied to the world in order to tease out the connections that exist between words, things, and consciousness.

Like McLuhan, Viktor Shklovsky is also a grammarian of sorts, engaging in something similar to probes in order to wrestle with the relationship between language and the world. Not always organized in a clear linear fashion, his work (particularly in Bowstring: On the Dissimilarity of the Similar) is rather a collage or a montage of thoughts and examples, and in reading through said montage, a sense or a feeling begins to emerge. Of McLuhan's work on the Trivium, Marchand writes:

Grammatica, or the study of words, was based on the belief that all human knowledge inhered in language. To the ancient Stoics, who developed this science, the universe itself was the Logos, or divine word; the order of human language and the order of reality were closely related... To crack the secrets of language would be to penetrate deep into the heart of the universe (Marchand 55).

Such was certainly true for Seneca and Aurelius, and, I would suggest, is also true for Shklovsky and McLuhan. Shklovsky spent much time dwelling on the importance of ostranenie or estrangement, and he observed that as a thing "becomes habitual, it also becomes automatic. So eventually all of our skills and experiences function unconsciously - automatically" (Shklovsky 4-5). Shklovsky continues:

in order to return sensation to our limbs, in order to make us feel objects, to make a stone feel stony, man has been given the tool of art. The purpose of art, then, is to lead us to a knowledge of a thing through the organ of sight instead of recognition. By "estranging" objects and complicating form, the device of art makes perception long and "laborious." The perceptual process in art has a purpose all its own and ought to be extended to the fullest. Art is a means of experiencing the process of creativity. The artifact itself is quite unimportant (Shklovsky 6).

The effects of art then, are psychological and physical. Art dredges up and unsettles that which has been instantly recognized, it de-habitualizes and forces a dwelling on. And, as Elder points out, art is perlocutional, which is to say, its meaning comes from what it 
does to us (Harmony and Dissent 440). And in the case of McLuhan (as Fishman lamented), his probes (dare we say, his art?), made apprehension somewhat laborious, even while it aimed at generating awareness. In estranging or causing a rupture, McLuhan's probes (regardless of which of the multiple McLuhan's launched them) perform spiritual work.

As well as being central to the work of Shklovsky and McLuhan, defamiliarization is contained within the thought of such diverse thinkers as Brecht, Orwell, and Heidegger (among others). As Heidegger rightly observes, "Only when the strangeness of beings oppresses us does it arouse and evoke wonder. Only on the ground of wonder - the revelation of the nothing - does the "why?" loom before us" ("What is Metaphysics" 109). This strangeness is what the artist attempts to foreground, and such strangeness also marks the beginnings of philosophy, which Arendt describes as "the surprised wonder at everything that is as it is. More than anything else, Greek "theory" is the prolongation, and Greek philosophy the articulation and conceptualization, of this initial wonder" (Between Past and Future 115). We see this in the Hellenistic Stoics, specifically in the symbolic deflation of Aurelius, and similar tactics have been employed by moderns in an attempt at unseating the common place, and forcing a critical confrontation with the apparently banal in order to disrupt the urban blasé experience described by Simmel. While sharing a great deal with Hellenistic practices, the exercises (or rather, the logic which underlies them) which are the focus of this chapter, revel in indeterminacy, and in fact work to cultivate a sense of uncertainty, which in turn demands constant attention and thought. 
James Carey writes, "A wise man once defined the purpose of art as 'making the phenomenon strange.' Things can become so familiar that we no longer perceive them at all. Art, however, can... wrench these ordinary phenomena out of the backdrop of existence and force them into the foreground of consideration" (Carey 19). The artist attempts to "induce in us a capacity for wonder and awe" (Carey 19), or a curious eye, which was for Plato the necessary precondition of philosophy, and this renewed sense of wonder is what the artist works to cultivate. "What's needed" writes Georges Perec, "perhaps is finally to found our own anthropology, one that will speak about us, will look in ourselves for what for so long we've been pillaging from others. Not the exotic any more, but the endotic" ("Approaches to What" 210). Perec's anthropology of the endotic amounts to an anthropology turned in on itself, leading us to be (to borrow a phrase from Certeau) foreigners at home. This anthropology of the endotic involves distancing or estranging ourselves from what Clifford Geertz called "experience near concepts," or all those aspects of daily life we pass over or take for granted. Whereas in traditional anthropology the object culture automatically appears strange by virtue of the fact that the observer is not and has never been immersed within it, an inverted anthropology seeks to de-naturalize one's native culture. Thus, efforts must be made to make strange, to gain distance from the habitual. "Whereas dominant ideologies define and sanction certain patterns of life as 'natural' or 'inevitable'... transgressive moments problematize, 'make strange', and thereby subvert the ideological and bureaucratic structuring of everyday life" (Gardiner 19). The artist, the cultural critic, and the philosopher each work to spark such transgressive moments. 
I will now connect these initial remarks on estrangement with the importance of modern aesthetic exercises. We tend to be at our best when "in-the-moment." If we slip out of the moment, if we begin to reflect or reason after the fact, we stumble. This is perhaps most applicable to music and acts of physical prowess. Intense (and transformative) training is of course required, but eventually, the motions will be internalized, and one immediately feels rather than reasons after the fact; one ceases to evaluate the past (notes/movements) or to envision future consequences, one simply feels, one simply is. In one view, after returning from "being-in-the-moment" back to the "after-the-fact-ness" of abstract thought, assessment and awareness of the moment and its significance is vitally important. Living in the moment is one thing (and a fine thing at that), but without awareness of this experience, it can have no meaning. Thus, it would seem that meaning can only exist alongside of language and culture. The corollary is that culture can only be meaning $f u l$ if we at least attempt to transform the self and experience the world in the moment - if only for an instant. And while this is a promising start to the project of allowing the sensuous and rational to touch, it still insists upon the essential fragmentation of these faculties. Schiller calls for a return to a more ancient sense of wholeness, but we may well ask, is Schiller's project of reuniting the sensuous and rational dimensions feasible, or must these realms remain separate?

In The Aesthetic Dimension, Marcuse shifts his focus from the classical notion of aesthetics to the role of art in allowing for praxis, and critiques orthodox Marxist readings in which all art is "conditioned by the relations of production" (Marcuse Aesthetic Dimension 14). For Marcuse, art is intimately connected to the possibility of freedom, in that it negates the common-senseness of the established order. The necessity of such 
negations (whether artistic or philosophical) is a prevalent theme in much of Marcuse's work. The established reality smoothes over contradiction, whereas philosophy (at its best) and art negate or contradict the common-senseness of the established order, thereby forcing us to confront its untruth. Art then, carries an emancipatory potential, and it updates sensibilities. "One of the functions of the artist... is, above all, to prevent us from becoming adjusted to our environments" (McLuhan "Art as Survival in the Electric Age" 223). In other words, the artist's real product is ostranenie; she pulls out the connections between things (this is especially true in the case of abstract art, as narrative - or, "the artistic structure of technocracy" - is ruptured), and thus disrupts the commonsense, or "dislocates our sensibilities." For Marcuse the logic of negation was present within the origins of philosophic thought. It is important to understand that such negation is not a singular one-off event, but rather a process that must be sustained. The established reality must always be contradicted - it must always be exposed and experienced as untruth, lest it calcify into rigid dogma. (Marcuse One Dimensional Man 140). Any two-dimensional thought ${ }^{45}$ will be critical and negative, whereas one dimensional thought ${ }^{46}$ will be complacent. One dimensional thinking is not conducive to freedom.

Marcuse notes that "Schiller's Letters on the Aesthetic Education of Man... aim at a remaking of civilization by virtue of the liberating force of the aesthetic function" (Eros and Civilization 180). Despite the inconsistencies in Schiller's letters, ${ }^{47}$ there is much to be learned from his work on aesthetic education. His letters ought to be read as an

\footnotetext{
${ }^{45}$ And by this Marcuse simply means the ability to estrange, to negate or subvert the established order and reveal its contradictions.

${ }^{46}$ One dimensional thought is that which conforms to existing patterns of thought/behaviour, and describes the absence of a critical faculty from which to negate and transcend the existing society. One dimensional man is incapable of making strange and therefore incapable of performing any sort of critique.

${ }^{47}$ Schiller presents two very different models of aesthetic development: transitory (where Beauty and Nature are means of approaching the Good) and holistic (where Beauty and nature are synonymous with the Good).
} 
intuition (rather than a blueprint) of aesthetic education, as his ultimate goal was the concatenation of abstraction and sensuousness that would lead to freedom in the form of a new society. T. S. Eliot levies a similar critique against the modern sundering of the sensuous from the rational in his essay "The Metaphysical Poets," in which he describes their "direct sensuous apprehension of thought," or their attempt at "a re-creation of thought into feeling” (Eliot "The Metaphysical Poets" 116). While for Schiller this disjunction between the sensuous and rational has its roots in late antiquity, Eliot views it as something modern, and locates it in the seventeenth century, when "a dissociation of sensibility set in, from which we have never recovered" (Eliot "The Metaphysical Poets" 117). In a sense, both are correct. Building on the comments of Sontag and Zerzan, and drawing on the thought of McLuhan, I think this disjunction actually began with our first foray into the symbolic (this is to say, the earliest examples of human language). Abstract thought, that defining trait which makes us human, actually distanced us from the Good, or saw us separated from nature. This disjunction was exacerbated with the adoption of the phonetic alphabet, and then drastically intensified again during the Gutenberg age, and so while it was certainly felt during antiquity, it became far more serious and noticeable under modernity. Taking Donne as his example, Eliot describes a harmony of thought and feeling: "A thought to Donne was an experience; it modified his sensibility" (Eliot "The Metaphysical Poets" 117). Here Eliot points to the difficulty moderns seem to have being-in-the-moment. The reflective poet is, for Eliot, always "forming new wholes." In uniting things and forming new wholes (as when a poet unites such diverse things as the softness of velvet with the smell of motor oil), the poet is briefly estranging those things from common experience before uniting them into a new whole which both 
demands thought and elicits immediate feeling. Elder notes a similar tendency when he writes of

the Romantic antipathy toward language, which the Romantics accused of reducing perceptual vivacity by turning thinking toward abstraction; of transforming (or tending to transform) thinking into chains of logical deductions; and of reinforcing thereby the divorce of the subject of experience from the experienced object that only the imagination - the faculty that produces not language, but images - could possible heal (Elder Harmony and Dissent 61-2).

There is in the Romantics a desire to reunify sensibility with reason, but for Eliot this project remains incomplete. McLuhan incorporates a kind of Romanticism into his work, and in this he bears a striking resemblance to Schiller, interested as he is in recombining the senses in a new unity reminiscent of an older time. Commenting on the spiritual tenor of McLuhan's work, Peters writes “McLuhan awaited - or tried to provoke - an experience of bypassed temporal process. He was a medieval modernist who was quite opposed to modern thought's obsession with time. He wanted another mode - the poetic (grammatical) process, in which the totality is apprehended all at once" (Peters:2011 235). This is an apt description of a spiritual encounter, where the senses commingle (if only briefly) with the abstraction of reason. Eliot would call this the transmutation of ideas into sensations, and such a transmutation involves nothing less than transcending a fixed Cartesian subject position. The difference between a visual and an aural orientation is a difference between linear chains of logical connections versus an all encompassing resonance, or an in-tune-ness with the cosmos where everything vibrates in harmony. The visual orientation is the Cartesian subject position, while the aural orientation demands transcending the visual subject; it is total and all involving, and is experienced as simultaneity. Of the "multiple McLuhan's" noted earlier, this affinity for the resonant interval comes from the Catholic critic of the visual age. The idea of resonance is total, 
and this idea is, for McLuhan, analogous to his faith commitments. Resonance surrounds us, and moves through us, and while I prefer to speak of the Absolute or the cosmos, McLuhan links the idea of the resonating interval which surrounds and moves through us to God. $^{48}$

While I am fond of Foucault's understanding of spirituality as transformative exercises that alter our relation to truth, I think this definition could benefit from a description of how such transformations make us feel, as such description acknowledges the aesthetic dimension. In modifying the self and altering its relation to truth, transformative practices engender feelings of connectivity to something beyond the self, feelings of presentness (being "in the moment"), and feelings of oneness. Each of these "feelings" is connected to immediate experience. The spiritual encounter is one in which the symbolic and the sensual are absorbed back into a whole, and this encounter, this simultaneous absorption is another way of describing a brush with the Good.

When compared to Foucault's understanding of spirituality, McLuhan's definition appears rather constrained, bound as it is to his religious beliefs. The early McLuhan claims that "the merit... of spiritual acts is derivative. It is derived from Christ" (Media and the Light "Spiritual Acts" 25). In other words, without the sacrifice of Christ, all spiritual acts become meaningless. We need not necessarily subscribe to his underlying Catholicism or his understanding of spiritual acts as "derivative" in order to be struck by the significance of this statement. To claim that all spiritual exercises are derivative in

\footnotetext{
${ }^{48}$ McLuhan elaborates on the connection between what he calls the resonant interval (Laws of Media 102) and his faith commitments in an interview with Fr. Patrick Peyton on an episode of Peyton's Television show "Family Theater" (c.1970's).
} 
this way is to offer a ground for his work, and to suggest that McLuhan's entire project can be read as a set of spiritual encounters - a project all too uncommon in our time.

When engaging in such diverse acts as creating or experiencing art (regardless of medium - writing, visual art, performance art, auditory art, etc.), the rational and sensuous may briefly be wed, allowing us to feel thought or think feeling. These sorts of practices have the potential to recombine the experience of the world with the faculty of reason, and thus return to us a sense of being in-the-moment. When in-the-moment, "time flies," which is to say, we briefly stop taking stock of the passing of an abstract measurement. Consider the examples of trance (induced physiologically or chemically, or via sensory deprivation), or of being engaged in a collective experience (at a concert, or at a religious ceremony chanting a hymn with a thousand other people): in each of these cases, one simply experiences without the delayed filter of abstraction. Such, what I'll call in-tuneness with the world on a sensory level, is what transformative acts can feel like while in the moment. And yet, in order to have value, the spiritual experience must commingle with the rational. This is to say, unity or harmony of the sensuous and rational is a far more powerful condition than feeling, and then attempting to reflect after the fact. In what we might read as an affirmation of his faith commitment, McLuhan was supremely confident that things were intelligible (Peters:2011 231), and yet his method was steeped in indeterminacy, suggesting that while things are knowable, they may not be knowable for us at present, and thus the best thing to do is to leave space. McLuhan's religious convictions reveal a tension between his later desire to use laws to uncover the order of things and his appreciation for mystery, as "a mystery is, strictly, not something queer or hidden, but something unfathomably and inexhaustibly rich in meanings" 
(Media and the Light "Spiritual Acts" 25). The limitless depth of mystery demands constant work, or a kind of perpetual spiritual engagement and this constant engagement advocated by McLuhan and other thinkers here surveyed can also be thought of in terms of a philosophical life. In an interview with Michael Chase, Pierre Hadot speaks out against the purely exegetical and institutional direction taken by modern philosophy when he explains that he "always believed that philosophy was a concrete act, which changed our perception of the world, and our life: not the construction of a system. It is a life, not a discourse" (Philosophy as a Way of Life 279). The lived and transformative nature of this act seems rather like McLuhan's study of media. And of course (as Granata explains), the study of media is really the study of ourselves. McLuhan's probes were designed to grant an awareness of the self; they are not meant as conclusions, but as explorations, and ought to be considered as part of the ancient tradition of áskēsis.

But if there are already modern aesthetic exercises, then why look to the Stoics? Quite simply, we tend not to think of these modern practices as áskēsis, and so I think it helpful to look back to the Stoics to gain perspective on the present. I am not necessarily interested in their specific exercises (though some are quite good - symbolic deflation, repetition, writing, negative visualization), but definitely their ethos - care of the self in order to move beyond the self (for in moving beyond the self, we move towards an acceptance of uncertainty, which may allow us to once again touch the Good). The ancients, as Schiller claims, were more adept at wedding the sensuous and rational, or at feeling thinking and thinking feeling. I wish to present these modern exercises as Stoic type áskēsis, which through prompting a caring for the self and a Romantic transmutation of ideas into sensibilities (to use Eliot's term), encourage awareness of a wider world. 
It is here that we again touch upon the Stoic understanding of progress, where progress refers to a deliberate individual spiritual movement (via áskēsis) bent on aligning the self with virtue, and in so doing, fulfilling one's part in the whole. Such exercises are possible under modernity, and have in fact been attempted, though they are not often recognized for what they are: áskēsis. Hadot claims that "spiritual exercises are still being practiced in our day and age. Spiritual exercises do not correspond to specific social structures or material conditions. They have been, and continue to be, practiced in every age, in the most widely diverse milieus" (Philosophy as a Way of Life 282). This comment emphasizes the familiar difference which binds us to and separates us from antiquity; there are indeed modern attempts at leading spiritual lives, though the types of exercises (mimetic versus creative) are different.

Let us now (by way of Schiller and Marcuse) turn our attention to art as an example of modern áskēsis. Schiller claims that a revolution in consciousness must precede any political revolution, and that the way to ennoble one's character is through art. In Schiller's metaphysics, art leads us back to truth: "give the world on which you are acting the direction towards the good, and the quiet rhythm of time will bring about its development" (Schiller 53). Art, created by those sensitive souls open to what George Grant called intimations of deprival, has the potential to overcome the base impulses of the present, the "coarseness... enervation and perversity" which besets us (Schiller 55). I agree art has the potential to put us back into contact with the Good, though perhaps not in as direct a way as Schiller would hope. Modern art does not lead back to any stable truth. What it can do, is jolt us (to use McLuhan's language), and generate distance enough for uncertainty, for a fount of wonder, for space enough for questions, and while 
such space does not guarantee an encounter with the Good, it allows for the possibility. The artist does address the "coarseness" of the present, but for McLuhan, this can only be accomplished by upsetting the senses, and forcing us to realign ourselves to the changes occurring around us ("Art as Survival in the Electric Age" 223).

On the revelatory power of art, Marcuse writes "As fictitious world, as illusion (Schein), it [art] contains more truth than does everyday reality. For the latter is mystified in its institutions and relationships" (The Aesthetic Dimension 54). The representation of the sensuous reflects the world as it appears prior to institutional mystification. "If the established society manages all normal communication, validating or invalidating it in accordance with social requirements, then the values alien to these requirements may perhaps have no other medium of communication than the abnormal one of fiction" (One Dimensional Man 247). This is just one more way of understanding the worth of the sensuous forms (art, comedy, fiction): as they are thought to fall under the purview of the imaginative realm (as opposed to reality), they are not subject to the same ideological restrictions, and hence have the ability to describe society as it truly is. "[T]he encounter with the fictitious world restructures consciousness and gives sensual representation to a counter-societal experience" (Marcuse The Aesthetic Dimension 44). Acts of negation function "to break down the self-assurance and self-contentment of common sense, to undermine the sinister confidence in the power and language of facts, to demonstrate that unfreedom is so much at the core of things that the development of their internal contradictions leads necessarily to qualitative change" (Marcuse Reason and Revolution "Preface" ix). The power of facts is the power of domination, and the established order is one of unfreedom. Marcuse describes the link between dialectical thought and avant- 
garde literature (though this description is equally applicable to all forms of avant-garde art): it is "the effort to break the power of facts over the word, and to speak a language which is not the language of those who establish, enforce, and benefit from the facts" (Marcuse Reason and Revolution "Preface" $\mathrm{x}$ ). This is to speak the language of contradiction, or to practice negation. Negation involves contradicting the simple falsity of the established reality and thereby revealing its contradictory nature. This is the truth of the world - it is contradictory, irreconcilable, and ungraspable.

In an idea that seems to take its inspiration from Schiller (and that presages McLuhan's concerns about the end of (visual) civilization at the hands of the electronic age), Arthur Penty worries that "If the arts should disappear, then, as far as I can see, our civilization must perish with them" (42). Penty elaborates: "when I speak of the arts I must be understood to mean everything into which the aesthetic element enters" (43). Here Penty is not only speaking of high culture and fine arts (sculpture, painting, architecture, etc.), but of all acts of what we can think of as authentic creations. He is primarily opposed to pre-fab design, or what he calls "cheap-jack" methods of design and building. Penty's ideas correspond to Schopenhauer's Kantian reading of aesthetics, of the importance of the senses in connecting to the realm of Ideas, and the role of art in this connection, and yet Penty's sense of art also parallels Marcuse's, where the authentic work is not something mass produced (we might say, to use Benjamin's terminology, that Penty is registering the loss of Aura).

In "On Lying in Bed" (one of his many charming essays mocking the triumphs of modernity), conservative critic G. K. Chesterton uses the bed as a staging ground for a vitriolic assault on modern mass culture. Musing on the interior of the modern home, 
Chesterton notes the absence of any uncluttered surface save the ceiling. While bearing the semblance of expressivity, these cluttered, patterned surfaces (such as wallpaper) thwart any attempt at authentic artistic expression, which, depending on our point of view, must either facilitate concord with the Good, or jolt us into awareness. They are "childish and barbaric" mass produced patterns, devoid of any originality or meaning, resembling a kind of "smallpox" infecting the walls. Moderns, claims Chesterton, tend to elevate petty and secondary matters of conduct at the expense of great, primary, and eternal ones. "If there is one thing worse than the modern weakening of major morals it is the modern strengthening of minor morals. Thus it is considered more withering to accuse a man of bad taste than of bad ethics" (Chesterton 104). Even in his earliest published work (“G. K. Chesterton: A Practical Mystic”), McLuhan had a pressing interest in the need for awareness. McLuhan finds in Chesterton an artist, one "full of that child-like surprise and enjoyment which a sophisticated age supposes to be able to exist only in children" (“G. K. Chesterton: A Practical Mystic" 4-5).

While Chesterton was concerned with authentic art's propensity to elevate, McLuhan also notes a more modern tendency within his anti-modern idol: "A little attention shows how he [Chesterton] consciously causes a clash between appearances in order to attract attention to a real truth..." (“G. K. Chesterton: A Practical Mystic" 5). We need only consider such Chesterton essays as "On Lying in Bed" or "A Piece of Chalk" to see the truth in this. Such an observation sheds light on McLuhan's metaphysics, for while he practices estrangement, McLuhan's is a quest for truth. His tactics, like the artist's estranging jolts, are intended to generate space enough for a reconnection of sorts, 
and while his method is more abrasive than Schiller's, both seek concord with the Good, and both see aesthetic practice as the way to achieve this end.

Marcuse attempts to revive the importance of aesthetics from the "cultural repression" to which it has been subjected under modernity. His first step is to remind us of the depth and multifarious character which the term aesthetics gives rise to. The original term aesthetic "aims at a realm which preserves the truth of the senses and reconciles, in the reality of freedom, the "lower" and the "higher" faculties of man, sensuousness and intellect" (Eros and Civilization 172). Art offers the possibility of such reconciliation, it is one possible bridge between the sensual and the abstract. Art allows the sensual and the abstract to touch, it sits at the crossroads of sensation and reflection (spiritual practice and spiritual feeling), it allows both the feeling, and the opportunity for reflection and awareness.

How is modern art uniquely equipped to deal with the consequences of disengaged reason? Ancient art forms tended to be mimetic, to be seen as copies or attempts at approximating the Good, the Beautiful, the world as it "really is." Ancient art was seen as a reflection of Truth. Modern art also speaks of a truth, but its truth is different. Admitting that we have lost touch with the Good, modern art revels in indeterminacy and uncertainty. It engages in estrangement not in order to put us into contact with an essence (as in the symbolic deflation of Aurelius), but to encourage a diminutive confusion or uncertainty which demands constant contemplation of the world as it appears. And yet, this is similar to ancient philosophy in a way. If philosophy (the love of wisdom and concern with the Good) springs from wonder, then art is one way of encouraging wonder, or the inaugural "why?" of philosophy. Much art in the twentieth 
century "moved from outer matching to inner making" (Understanding Media 174). It stopped trying to replicate the world, and instead moved to explicate the process of making and creativity. This is to say, modern art tends toward the abstract, toward removing connections and destabilizing smooth narratives. "The encounter with the truth of art happens in the estranging language and images which make perceptible, visible, and audible that which is no longer, or not yet, perceived, said, and heard in everyday life" (Marcuse The Aesthetic Dimension 72). Art ought to jar us out of commonsenseness in order to illuminate. The authentic work of art must have something to say, or it must seek to expose something to view, for, to paraphrase Blake, there is no use lighting a lamp if we do not wish to see ("English Encouragement of Art" 509).

McLuhan characterizes the artist as sleuth, as one who sharpens perception and grants awareness (The Medium is the Massage 88), and this sleuth is rarely well adjusted. In fact, the cultural sleuth must of necessity be somewhat maladjusted, for in order to pick up (and indeed even begin to scour culture for) clues, the artist-sleuth must begin from a place of estrangement. Drawing his central metaphor for our current predicament from Poe's "A Descent into the Maelstrom,” McLuhan claims that "A whirling phantasmagoria can be grasped only when arrested for contemplation" (The Mechanical Bride "Preface" v). Detachment from and awareness of our own situation is crucial if we are to survive the electric maelstrom. The Mechanical Bride is precisely such an attempt at arresting a swatch of the swirling swath of print culture, to prevent it from simply washing over us, and to understand something of what it does to us. In his repetitive Aurelean form, McLuhan reminds us that "The voice of reason is audible only to the detached observer" (The Mechanical Bride 3). The Mechanical Bride is an example of 
áskēsis in which McLuhan asks questions not so that they will be answered, but so that they will be pondered. In The Mechanical Bride, we are given a representative selection of advertisements and comics (to be read in no particular order) which would have been circulating in the popular media of the 1940's - 1950's. By this time the psychoanalytic influence of Edward Bernays had been extended throughout the mass media, and in The Mechanical Bride McLuhan subjects the standard fare of adverts to playful scrutiny in an effort to grant awareness of the complexity of our situation. Each critical vignette freezes its object, thus allowing us to view it from afar, and view it afresh. The Mechanical Bride is a personal exercise for McLuhan, and an example of how we might perform our own exercises.

Marcuse claims "Art cannot change the world, but it can contribute to changing the consciousness and drives of the men and women who could change the world" (The Aesthetic Dimension 32-3). Modern art makes strange, it contradicts, it allows a vision other than that of the established reality to surface, and it subverts stable narrative truth. Art upsets the established order, and forces contemplation. A life lived as art, which is to say a philosophical life, might accomplish something similar. In chapter three we considered the idea of progress as it has been expressed over the past several centuries, and for Marcuse, "art militates against the notion of an iron progress, against blind confidence in a humanity which will eventually assert itself" (The Aesthetic Dimension 47). And while art is grounded in the real conditions of life and keeps in check unbridled faith in technological progress, it offers (it seems to me) hope in a broader sort of progress, one more akin to that experienced by the ancients. McLuhan would describe this in terms of reading the maelstrom, and the understanding of the media's effects this 
reading engenders opens the way for spiritual growth. Modern art offers not a return, but a uniquely modern way toward a spiritual existence.

In a very McLuhanesque fashion, Zerzan critiques symbolic thought, arguing that "Symbolic culture inhibits human communication by blocking and otherwise suppressing channels of sensory awareness. An increasingly technological existence compels us to tune out most of what we could experience" (6). Zerzan's critique challenges the effects of the phonetic alphabet and of the Guttenberg technology which extended and privileged the modern visual sense. The visual is privileged at the cost of all other senses and experiences, thus modern culture has sundered the senses and eclipsed any synaesthetic potential. Things are isolated, defined, delimited, placed neatly in their own sphere, and subordinated to the visual. This mechanization of man and the attendant specialization and fragmentation observed by Zerzan, effects what McLuhan calls a "metaphysical hunger," and such hunger is an apt way of thinking about apathy. Recall that in chapter four I approached apathy as a philosophical problem (bound up with matters of subjectivity, aesthetics, technology, and epistemology, and resulting in a disconnect from the Good). This metaphysical hunger is experienced as emptiness, or as a dearth of purpose and meaning, things which would normally spring from unified sensory experience. Zerzan points to Blake's "Marriage of Heaven and Hell” as an exemplar of this point:

If the doors of perception were cleansed, everything would appear to man as it is, infinite. For man has closed himself up, 'till he sees all things through narrow chinks of his cavern.

(Blake, qtd. in Zerzan, 6). 
In recounting an event from Prince Modupe's autobiography I Was a Savage,${ }^{49}$ McLuhan reveals how abstraction works to diminish the awe of direct sensual experience. Modupe's father found his son's grand talk of representing the world as a map injurious, as such an "airy and easy sweep of map-traced staggering distances belittled the journeys he had measured on tired feet" (Qtd. in Understanding Media 146). While Zerzan suggests the benefits of a more synaesthetic experience, he is unable to suggest how we might get there. For him, the task of critique is to "help us see what it will take to reach a place in which we are truly present to each other and to the world" (Zerzan 8). McLuhan's work is not as nostalgic as Zerzan's anarcho-primitivistic return to synaesthesia or balanced sense ratio. ${ }^{50}$ McLuhan's is primarily an aesthetic of awareness. While as a man who taught literature from morning till night McLuhan was pessimistic about the effects of electric media (to the point where he was often opposed to technological "innovation"), he made it his mission to understand such effects. In this sense, McLuhan and the ancients are kindred spirits, as both prized awareness over certain knowledge. McLuhan aims to show us that we don't really know what we think we know. In other words, he wants to make strange that which we take for granted, and in so doing, force us to bear witness, to be attentive and aware.

McLuhan is not interested in outright condemnation or celebration of technology. Rather, he argues that "the unconsciousness of the effect of any force is a disaster, especially a force that we have made ourselves" (Gutenberg Galaxy 248). What has variously been called estrangement, defamiliarization, ostranenie, etc., is one way of

\footnotetext{
${ }^{49}$ Autobiographical account of Prince Modupe's (b. 1901) efforts to reconcile his tribal African childhood with his literate Western adulthood.

${ }^{50}$ Synaesthesia (from the Greek prefix sýn - "together," and aisthēsis - "perception") refers to a unity of the senses in which none are privileged and all function harmoniously.
} 
rendering the unconscious conscious, or of cultivating the awareness of the world and self so crucial to McLuhan.

While central to McLuhan's project, the cultivation of awareness is not unique to him; it has a provenance running back through modernity and antiquity. Such proximal distance grants perspective, and can be recognized by tracing the idea of estrangement as it appears in a number of thinkers. Marcus Aurelius and Brecht both called for estrangement, but they each sought different ends. This difference is akin to the difference between the two types of authentic art discussed earlier: Schiller's Kantian notion of art as bridge between the sensuous and abstract, versus Marcuse's and McLuhan's understanding of art as disruption. One seeks smooth congruence, the other seeks disruption and openness, yet both seek to put us in touch with the Good. Foucault points out another thinker in this tradition when he claims that "Montaigne should be reread ... as an attempt to reconstitute an aesthetics and an ethics of the self" (Hermeneutics of the Subject 251), while for Hadot "Montaigne's Essays... show the philosopher trying to practice the various modes of life proposed by ancient philosophy" (What is Ancient Philosophy? 263). As is true of the authentic work of art, one of the ways Montaigne returns to ancient philosophy, or one of his tactics in reconstituting an aesthetics of self, involves his emphasis on estrangement. Following Lucretius, Montaigne notes that not knowledge, but proximity and habit remove strangeness, the implication being that a measure of imposed distance and newness can lead us towards strangeness, and thus force contemplation. "What makes us seek the cause of anything is 
not size but novelty" (Montaigne 76). The commonplace dulls the critical faculty, and prevents the wonder which gives rise to philosophy.

Such is also among the chief lessons to be learned from Xavier de Maistre's 1790 novel A Journey Around My Room, and its sequel, A Nocturnal Expedition Around my Room. While in part a jejune homage to travel narratives, and in part a response to his being placed under house arrest, de Maistre's domestic travel narratives force a confrontation with that which has become banal through proximity and habit, for "even the most beautiful vista soon wearies you when you see it too often; your eye gets used to it, and you don't appreciate it any more" (de Maistre 81). de Maistre sets out on a fortytwo day journey around his flat in which he dwells on the common and habitual. At each stop on his pilgrimage, whether at the corner of his desk or the pink stripes on his bedding, de Maistre's careful attention forces him to consider his condition in the world, and then the condition of others. His work is very much an effort at caring for the self through estrangement.

In a similar fashion, Georges Perec (1936-1982), that "unassuming laureate of the everyday" (Sturrock 190), focuses on the seemingly trivial in order to make strange and facilitate wonder, and he and the OuLiPo ${ }^{51}$ utilized formal constraints in order to force new creative approaches to problems. In his novel $A$ Void, Perec imposes upon himself the almost unfathomable restriction of avoiding the use of the letter "e." In $A$ Void we find a Pynchon-esque ${ }^{52}$ murder mystery whose ludic quality is undercut only by the sense of paranoia it inspires. As the bodies pile up, so to do the absurdities. From death by

\footnotetext{
${ }^{51}$ OUvroir de LIttérature POtentielle ("workshop for potential literature"), founded in 1960, was a collective of poets and mathematicians (of which Perec was a member) interested in how the imposition of formal constraints might generate creativity. Perec then, is primarily interested in form.

${ }^{52}$ In reference to Postmodern novelist Thomas Pynchon, whose work often inspires a sense of paranoia. It has been said that in order to appreciate a Pynchon novel, one must be paranoid, educated, or stoned.
} 
enshroudment in plaster, to electrocuted duck ponds, to exploding beastial suppositories, no topic is too morbid to be made the subject of fun. And despite its ludic qualities, this three-hundred page lipogram is really interested in very serious questions of knowledge, certainty, fate, and the possibility of perceiving and rightly interpreting the vast amounts of information that surround us. We are made aware of what appears to be a deeply interconnected world which operates just beyond our perception. The characters grapple with their inability (and the frustration this inspires) to sort all of the information they uncover into a meaningful narrative framework. Perec uses this self imposed lipographic restriction to force creativity, and the content of his lipogram forces us to confront what passes for certain knowledge. The question Perec's work inspires is, are all actions interconnected in a cosmic sympathy, as the apparent web of coincidence implies, or, is this interconnectivity simply a product of the mind, an effort to sort the random into a graspable narrative (no matter how ultimately bizarre)?

In “Approaches to What?" Perec gives us a more direct explication of his thought, as he sketches his annoyance at the tendency to only focus on "the big event," and asks: "How should we take account of, question, describe what happens everyday and recurs every day: the banal, the quotidian, the obvious, the common, the ordinary, the infraordinary, the background noise, the habitual?" (“Approaches to What?” 210). The problem of how to question the habitual is what Perec wrestles with here. As Sturrock notes of Perec's work, he gives us the structure without the event itself (Sturrock 190). In other words, for Perec too, the medium is the message. In asking us to question "bricks, concrete, glass, our table manners, our utensils, our tools, the way we spend our time, our 
rhythms," and all "that which seems to have ceased forever to astonish us," Perec is calling for a specific type of enquiry into culture (“Approaches to What?" 210).

Noting a lack of awareness, Perec claims that "We sleep through our lives in a dreamless sleep. But where is our life? Where is our body? Where is our space?" (“Approaches to What?" 210). Estrangement from the everyday can rekindle wonder that things are the way they are, and grant an awareness of the tenuous ground on which our knowledge rests. "How are we to speak of these 'common things', how to track them down rather, flush them out, wrest them from the dross in which they remain mired, how to give them a meaning, a tongue, to let them, finally, speak of what is, of what we are" (Perec “Approaches to What?" 210). To question the habitual, to rediscover astonishment and awe in the seat of the commonplace, this is Perec's ambition. Of his seemingly banal questions, Perec writes:

It matters little to me that these questions should be fragmentary, barely indicative of a method, at most of a project. It matters a lot to me that they should seem trivial and futile: that's exactly what makes them just as essential, if not more so, as all the other questions by which we've tried in vain to lay hold on our truth (“Approaches to What?" 211).

In posing apparently trivial questions concerned with seemingly trivial things, we generate various levels of awareness; awareness of the fact that we gloss over the commonplace, and awareness of the instability of our truth(s). Perec encourages us to sit within the interval, to occupy the interstices, to wait. In a similar fashion, McLuhan's work looks for truth, but it uses as its method a fostering of estrangement and a dwellingon in order to get there, and the result is no less than a standing for uncertainty.

There is at present a need to make strange: "it is only on those terms, standing aside from any structure or medium, that its principles and lines of force can be 
discerned. For any medium has the power of imposing its own assumption on the unwary" (McLuhan Understanding Media 30). Modern writers have often used their art to promote just such a "standing aside.” In a rather Brechtian maneuver, Donald Barthelme's postmodern re-imagining of Snow White (1967) utilizes such a disruption or "standing aside" in the most overt of ways. Halfway though his novel, Barthelme confronts the reader with a questionnaire, posing such questions as "Are the seven men, in your view, adequately characterized as Individuals?" and "In your opinion, should human beings have more shoulders?" (83). Such a direct affront to the suspension of disbelief makes it impossible to become lost in the text. One observes, and is aware of observing. This "standing aside" and the distance it grants are important themes in Edwin A. Abbott's short mathematical novel Flatland (1884), where the protagonist, A. Square, an occupant of a two-dimensional world, is confronted with a three dimensional sphere and given the opportunity to experience three dimensions. Until granted access to the world of three dimensions, A. Square lacks the ability to comprehend both the idea of the sphere (as it falls wholly outside of his frame of reference), and also of the two dimensional world in which he is immersed. Upon his return to Flatland, A. Square is unable to explain the idea of three dimensions to any satisfaction, precisely because his fellow two-dimensional beings lack the capacity for such thought. Flatland is a tale of cultural, sensual, and spatial incommensurability. It foregrounds the challenge of communicating or fully understanding something which lies beyond ones own frame of reference, and about the difficulty that comes from critiquing or even properly understanding something within which one is immersed. To transcend such immersion requires a Brechtian act of estrangement, or a standing aside, and such estrangement is 
necessary if we are to gain awareness of ourselves and our cultural milieu. Like A.

Square in Abbott's Flatland, it is difficult to gain perspective of that in which we are immersed.

Estrangement is thus a useful tool in allowing space, and in generating perspective. When we consider our own culture, we must cultivate this strangeness in order to pierce the common sense appearance which has taken hold. McLuhan expresses this idea in another way, noting "when some previously opaque area becomes translucent, it is because we have moved into another phase from which we can contemplate the contours of the preceding situation with ease and clarity" (Gutenberg Galaxy 275). It is tremendously difficult to view the contours of something in which we are immersed, and this explains our ability to perceive the problem of apathy during the twentieth century, as we began moving beyond the Gutenberg era. "As we move out of the Gutenberg era of our own culture, we can more readily discern its primary features..." (Understanding Media 89). McLuhan reminds us that any attempt at understanding a form demands a stepping back, as it is difficult to observe something within which one is immersed (Understanding Media 162). "[T] he best way to get to the core of a form is to study its effect in some unfamiliar setting," as to do so is to wrest the form from its habitual context and thus render it strange (Understanding Media 257).

George Orwell's famous essay on "Politics and the English Language" also exhorts the practice of defamiliariztion or estrangement, specifically with regards to metaphors. The purpose of a metaphor is to aid thought by evoking a vivid image, or to force contemplation. We use what Orwell calls "dying metaphors" out of laziness, as they require no thought, and no longer evoke any image. Such metaphors are commonplace 
and cliché. Through habit, we simply know when they are appropriate to use, and thus they do nothing to aid thought. One of the remedy's Orwell suggests is the creation of fresh or live metaphors which we are not accustomed to seeing in print. These living metaphors have not had time to curdle into cliché, and so there is still a vivacity about them. To rely on dying metaphors is to allow these ready-made (what Penty might call "cheap jack") bits of speech to think for us (or rather, to prevent us from thinking). This explains why Orwell encourages us to craft our own unique metaphors, so as to force thought and disrupt commonsense readings of culture and politics. "When such disruptions of daily routines occur, and actors can no longer rely on commonsensical notions and typified behaviour responses, we are able to examine critically prevailing traditions and received ideas, and our receptivity to alternative modes of being... is heightened dramatically" (Gardiner 20). While Orwell seems interested in the transmission aspect of communication here (his goal is clarity of transmission), the vivid metaphors which he advocates work to slow down thought and ensure that the mind is actually active. In this case then, his interest in transmission promotes a view of transformation, and can be thought of as a spiritual exercise. These excursions through such diverse modern authors as deMaistre, Perec, Barthelme, Abbott, and Orwell reveal that estrangement (as rupture, as opening of possibilities) is a thoroughly modern spiritual practice, though as I claimed earlier, it tends not to be viewed as such. The practice of estrangement, as theorized by McLuhan and Marcuse, and as seen in the literary excursions above, both binds us to and separates us from antiquity. These eclectic literary examples are meant to illustrate the prevalence of the modern spiritual practice of estrangement, and to shore up claims made by Marcuse and McLuhan, that modern art (in 
this case literature) is part of a tradition which seeks to disrupt the commonsense and force contemplation of the commonplace.

Orwell is not alone in advocating estrangement through language, but while he calls for us to be conscientious writers, Heidegger works to make us careful readers. Orwell and Heidegger are both interested in estrangement, though with a distinct difference: Orwell wishes to clarify thoughts and ease transmission (by forcing the work of contemplation), while Heidegger's writing is rather poetic, in the sense that Shklovsky describes as impediment, or what Eliot would describe as difficult. Ellen Grabiner relates a personal anecdote of her early encounters with Heidegger, and of the frustration she met until she began feeling his language in a "visceral way" rather than interpreting it in a "linear, rational way." "Heidegger's excessively particular use of language was rooted in a hope that his out-of-the-ordinary constructions would cause us to stop and abandon our everyday, habitual way of reading - abandon the imposition of what we already know so that his meaning could be uncovered" (26). Apart from revealing the inability of language to completely and truthfully represent its subject, Heidegger's unique turns of phrase (for example, the worlding of world, or the thing's thingly character, etc.), force us to suspend assumptions, to slow down, and to consciously think over (and over again) each word, and to simultaneously, as Grabiner notes, feel the meaning. Grabiner describes the attitude of contemplation found in many modern artists (an attitude which was also present in the Stoics - most notably in Marcus Aurelius) as "disruption of our habitual, everyday tendency to short-cut our understanding of our experience..." and something which "confuses, disrupts, redirects and returns us to our everydayness so that we might see it anew" (27). Bauman notes a similar intent in the work of Heidegger when he writes 
"you tend to notice things and put them into the focus of your scrutiny and contemplation only when they vanish, go bust, start to behave oddly or otherwise let you down" (Bauman Identity 17). In other words, it is by making strange that we can force ourselves to be attentive and to wrestle with ideas which are commonly passed over.

In "The Origin of the Work of Art” Heidegger comments on Van Gogh's “A Pair of Shoes." Through an exploration of both the shoes as they are unconsciously used by the peasant, and the artist's representation of the shoes, Heidegger raises the idea of estrangement. In the case of the peasant's shoes, as art makes strange it distances us from use, and in so doing, foregrounds and forces us to contemplate the character of that use. The peasant woman who uses the shoes is unaware of the character of the shoes, as she simply uses without lending a second thought to said use: "But perhaps it is only in the picture that we notice all this about the shoes. The peasant woman, on the other hand, simply wears them" (Heidegger "The Origin of the Work of Art." 160).

The character of things cannot be found solely in the things themselves, but rather in the way things are used or performed in the world, and to apprehend this character, things must be made strange. "As long as we only imagine a pair of shoes in general, or simply look at the empty, unused shoes as they merely stand there in the picture, we shall never discover what the equipmental being of the equipment in truth is" (Heidegger "The Origin of the Work of Art.” 159). Heidegger's essay fascinated McLuhan, who commented that "the artist translates the hardware or equipment into another mode for contemplation" (Understanding Me, "Man and Media" 291). Likewise, McLuhan's very style is designed to "provoke the reader, to jar the sensibilities into a form of awareness" (Eric McLuhan Laws of Media "Preface" viii). His style is rather Heideggerean in its 
effect. McLuhan's writing is itself a work of art, as his probes, his tetrads, his mosaic rather than linear approach (all of which pull out the connections between things, and then force us to reassemble the pieces in new ways), attempt to peer ahead through the windscreen rather than glance into the rearview mirror.

"Is it possible to constitute, or reconstitute, an aesthetics of the self?"

(Hermeneutics of the Subject 251). I believe it is, and I believe that modern methods of estrangement, whether practiced by communication theorists, philosophers, scholars, poets, or any other type of artist, partake in such a project, even if they are not always recognized as partners in such an endeavour. As Foucault and Hadot make clear, there have been modern attempts at living spiritually. The problem, it seems to me, is that such attempts are not often thought of in terms of áskēsis. Aesthetic works which ought to be understood as part of that ancient tradition, and which ought to be held in as high esteem as the Stoics held their spiritual exercises, are too often discounted as "mere" art. Like the very faculties which they try to jolt into cohesion, modern aesthetic practices are seen as discrete events, rather than as part of a continuous project. As emphasized by both the ancient Stoics and McLuhan, awareness is crucial if our endeavours are to have meaning, and if we are to survive. Reflection must coincide with the immediacy of the spiritual experience.

Spiritual exercises involve "the putting in action of all kinds of means, intended to act upon one's self" (Hadot, Philosophy as a Way of Life 284). Hadot continues, noting that "Imagination and affectivity play a capital role here: we must represent to ourselves in vivid colors the danger of such-and-such a passion, and use striking formulations of ideas in order to exhort ourselves" (Philosophy as a Way of Life 284). Might we take 
these "striking formulations" to be works of art which jar us out of commonsenseness?

Might we take them to be the living metaphors of Orwell, the grammatical probes of McLuhan, the collage of Shklovsky, or the poetic language of Heidegger? These modern exercises seek to form the habit of upsetting the habitual, and through such an upset to rekindle awe that comes from standing in the resonant interval.

Hadot considers communication as relationship and alludes to the importance of aesthetic estrangement:

[E]verything that touches the domain of the existential - which is what is most important for human beings - for instance, our feeling of existence, our impressions when faced by death, our perception of nature, our sensations, and a fortiori the mystical experience, is not directly communicable. The phrases we use to describe them are conventional and banal; we realize this when we try to console someone over the loss of a loved one. That's why it often happens that a poem or a biography are more philosophical than a philosophical treatise, simply because they allow us to glimpse this unsayable in an indirect way (Philosophy as a Way of Life 285).

Here Hadot refers to an experience unhindered by abstract thought, a pure connection between self and world, mediated by sensation but without the restrictions and delays imposed by reflection. He writes of the conjoining of the sensual and rational, and notes the importance of poetry and other artistic forms. McLuhan makes a similar assertion, noting "Whereas the philosopher teaches and the historian gives examples of philosophical principle, only the poet applies the whole matter to the correction of the human will and the erection of the human spirit" (Gutenberg Galaxy 155-6). Eliot too discerns a distinction between these roles, as poetry does not serve as replacement for philosophy, but has the emotional function of providing "strange consolation" ("Poetry and Philosophy" 56). Authentic art can serve as bridge between sensual experience and abstraction, and it can also act to disrupt the habitual and thereby force a dwelling in 
uncertainty. Although modern art, with its emphasis on estrangement, won't directly connect us to the Good, it can at least help us to leave room for the Good. Luc Ferry describes the beginning of transcendence in terms of uprooting ourselves from our egocentrism (Ferry 251), and this is another way of describing estrangement. One must uproot oneself in order to gain perspective and awareness, and art provides one way of uprooting. The task of the present art is to estrange, impede, defamiliarize. The ruptures caused by such estrangement open a hesitant standing room in which to wait. They open the resonant interval, in which we are free to experience uncertainty, and such experience offers the best possibility of again brushing up against the Good. 


\section{Chapter 6 - The Good, Harmony, and Modernity}

In the last chapter I suggested that estrangement through an art of disruption might allow transcendence of the modern subject position (or what we might call a temporary re-engagement of the disengaged subject), but I would like to offer a point of clarification. By transcendence I am referring to a commingling of sense and reason this is the shape of transcendence. Thus, estrangement may permit transcendence of not only the Cartesian subject, but of symbolic Man himself. The Cartesian subject is simply the most sundered expression of symbol using Man. I do not wish to imply that under modernity we were suddenly cut off from synaesthetic experience. This break began when, to use Seneca's term, "primitive" humans began using symbols. ${ }^{53}$ The break was then exaggerated by the development of the phonetic alphabet, and dramatically intensified with mechanical reproduction. That said, prior to the intensification of the visual and the disengaged reason of Descartes, ancient thinkers were better able to register the loss of this simultaneity, of a connection to the Absolute. This becomes clear when viewing ancient progress, which was, as I've argued, personal and spiritual. In antiquity, technological progress (such as it was), was understood as regress, and there are and have been modern thinkers who follow this same logic, and whose work can also be read as áskēsis. It is to these moderns that I look to in this chapter.

The split between sense and reason has been the subject of intense debate, and has occupied a central place in the thought of such diverse thinkers as Plato, Seneca, Sontag, Zerzan, McLuhan, and Arnheim. From the intensification of this split came the idea that the senses are not able to accurately report the nature of reality and this in turn lead to a

\footnotetext{
${ }^{53}$ This break is millennia old, perhaps dating back to early cave paintings like those found at Chauvet or Lascaux.
} 
new doubt, which brought with it a profound sense of uncertainty. The mistrust of the senses has origins in antiquity, but it is not until modernity that such skepticism becomes the norm. This type of sensual fragmentation is but one example of the many sunderings emblematic of modernity, and it is these sunderings which, while allowing the many achievements and benefits of the modern era, have also resulted in our spiritual malaise. Perhaps just as central as aesthetic sundering is the language of will and freedom (reflective of the modern belief - a kind of technical hubris - in the supreme agency of man), which has become dominant under modernity. The ability to do what one wants has become the ideal of freedom, while to submit or remain open to the Good has become abnormal.

The frantic quest to escape from authority has lead to a forgetting of the Good. When ancient philosophers (or those concerned with or influenced by antiquity) talk about the Good they are concerned with the "perfect order and harmony of the ideal realm" (Lodge 473). Our sense of such a Good has withered under modernity. By this I mean that there is now a tendency to see only parts, to break parts away from a sense of the whole. In a sense, the ideal mixture as presented in the Philebus has been atomized. When compared to the ancient ideal of harmony, modern relativistic goods, whether egotistic or hedonistic, read as a cacophony, as a collection of parts sundered from the whole.

With modern progress and the resultant aggrandizement of the self, we have forgotten that selves cannot exist in isolation. This is the other side of Arendt's philosophy, for while excited by the possibilities she saw accompanying the loss of authority, Arendt was also concerned that such loss would leave people without any 
common ground whatsoever, and this lack of common ground "threatens to weaken or cut the bonds between men" (Norberg 139). The question of the Good in the modern world is really a question of selfhood. This is to say, if, as Iris Murdoch affirms, the path towards the Good is tantamount to an act of "unselfing," then modern subjectivity (individual, objective, internal) has made an experience of the Good untenable.

The question before us is not how to create a new good, but how to reorient ourselves toward the Good without forgoing the advantages of modernity. This also seems to be the crux of the problem of apathy. I view apathy as a problem of carelessness, or, more specifically, as a failure to care for the self, which in turn precludes transcendence of self and participation in the harmony of the cosmos. I argue that what is needed is an orientation toward the Good, and the way to enact such an orientation under modernity is through art, estrangement, and the ability to be in a state of uncertainty.

The point of this chapter is to once again call attention to one of the most crucial questions ever posed: what does it mean to lead a good life? This chapter will map out the Platonic conception of the Good and some of the ways in which it has been understood (such as through mathematics, beauty, and metaphor), and will then assess the relevance of the idea of the Good for modernity by juxtaposing the work of George Grant, Simone Weil, and Iris Murdoch - twentieth-century thinkers who attempt to affirm the superiority of classical thought over modern - with that of Hannah Arendt, a thinker who while cognizant of the crisis suffered under modernity, sees in such crisis the potential for political renewal. In looking to both ancient and modern conceptions of the good, certain themes become apparent. Namely, that the ancient understanding of the 
Good requires of us a submission to a grand harmonious order, while under modernity the good has come to be associated with freedom won through the exercise of will.

I would like to begin with a discussion of some of the dangers that accompany a "looking back" to antiquity in order to gain perspective. We shall have to tread carefully here. Of the Greeks, and specifically Plato, Arnheim notes that "attempts to adapt the Greek philosopher to the tidy alternatives of modern thinking can only obscure our understanding of this complex figure" (Arnheim 7-8). Likewise, Alasdair MacIntyre, in his Short History of Ethics puts the difficulty of translating words, and transmuting concepts from one cultural context to another in no uncertain terms. This potential stumbling block is obvious when attempting to translate a word such as "good" from the ancient Greek to the modern context. In antiquity, "good" meant something rather different than it does to most moderns. MacIntyre notes that "what Greek achieves by a single word English needs periphrasis to achieve," and goes on to point out that the occurrence of certain concepts in ancient Greek discourse and others in modern English marks a difference between two forms of social life. To understand a concept, to grasp the meaning of words which express it, is always at least to learn what the rules are which govern the use of such words and so to grasp the role of the concept in language and social life (MacIntyre:1966 2).

Adequate translation requires an understanding of the host language's context and social life. In the case of the of the ancient word "óyatós" (agathos, good), the meaning is connected "completely to fulfillment of function" (MacIntyre:1966 8). Words such as "good" and "happiness" (among others) have been "overgrown with a millennium and a half of connotation that not even the most determined can completely strip away" (Peters Greek Philosophical Terms, preface v). There is a degree of incommensurability of which 
we must be aware. As is the case with apatheia versus apathy, the ancient and modern conceptions of good differ radically. What then did the ancients mean by the Good?

The Good for the ancients is harmony, or connection with something larger than the self. To experience such connection (or such transcendence of the ego) is to fulfill one's purpose. Failure to care for the self (and thereby failure to care for others and align oneself with the whole) is to live a discordant and unbalanced life.

The good life, Aristotle tells us, can be summarized in the word "happiness." Happiness is an intrinsic good, and end in itself, if anything is; indeed, Aristotle tells us that the very word "happiness" (eudaimonia) is nothing but the name of the ultimate good in life, its highest end, the summum bonum toward which all our activities and hopes are aimed (Solomon Ethics 63).

And yet, we must be clear on exactly what Aristotle meant by happiness. He certainly did not mean individual happiness, or the fleeting pleasure wrought by egoism or hedonism. Erich Fromm condemns contemporary attempts at securing "happiness" when he writes "man's happiness today consists in "having fun." Having fun lies in the satisfaction of consuming and "taking in" commodities, sights, food, drinks, cigarettes, people, lectures, books, movies - all are consumed, swallowed" (Fromm Art of Loving 80). The difference then, is of the overwhelming good-feeling of eudaimonia versus the fleeting diversion offered by entertainment. Fromm's assessment of modern hedonistic "happiness" makes rather a nice counterpoint to Aristotle's notion of eudaimonia, and Solomon is quick to point out that a modern reader's understanding of the term happiness is likely vastly different from Aristotle's meaning: "Happiness, however, designates two very different features of the good life, which we might distinguish as feeling happy and as flourishing (or "doing well," a more literal translation of eudaimonia)" (Solomon Ethics 66). Happiness, as eudaimonia, is a life lived according to higher principles (an end in itself 
that requires no further striving after ends), a life of harmony, a life which partakes in the general good, in short, a life that flourishes. Epicurus too, as both Hadot and Fromm point out, is often grossly misread, his name being erroneously tied to radical hedonism. Happiness for Epicurus had little to do with individual gratification; it was more about being in-tune with nature and tranquility of soul (ataraxia). Happiness would be better served by sitting in a meadow on a spring day and apprehending the beauty and wonder of nature than by imbibing drink and partaking in orgies.

The form of the Good refers to an ideal of harmony in which the individual element fulfills its role as part of the whole, which is to say, it acts in accordance with the cosmos. In human terms, this can only occur if the self cares for itself, for in caring for the self, one puts one's self in a better position to move into conscious alignment with the whole. The "highest good for the universe," writes R. C. Lodge, "consists in the ideal functioning of the whole so as to realize the maximum of value-potentiality inherent in its elements, and that the highest good for a particular human being consists in so living as to constitute a consciously organic portion of this whole, and, in so living, to realize his own deepest happiness and well-being” (Lodge 477). Lodge is an interesting case, for while holding classical attitudes (in spirit anyway), his language (for example, talk of "maximum of value-potentiality") betrays his grounding in modernity, and does not adequately reflect the ancient world voice. Regardless of his reliance on modern language, Lodge raises the issue of awareness that was so important for the Stoics. It is not enough to live in concord with the whole; one must be conscious of such concordance. If we consider Eliot's comments or Schiller's Romanticism (concerning the attempt to conflate the sensuous and abstract into an all-at-onceness, what McLuhan 
would describe as a recombination or balancing of the sense ratio), we get a sense of moderns trying to bestow upon us a sense of the Good as unity. I mention this to make it clear that while distanced from the Good, we are not entirely divorced from it; there are still moderns concerned with the ancient sense of the Good.

Plato used mathematical and geometrical analogies to describe this good, in addition to numerous metaphors. ${ }^{54}$ The most famous of these is Plato's simile of the sun in book six of The Republic, and it offers the earliest and perhaps most lucid description of the Good. Where the sun illuminates objects in the visible world and allows the eyes to see, the Good is the cause of knowledge and truth and grants the knowledge and awareness of absolute forms or categories. The sun is responsible for visibility and the sense of sight, without actually being those things. It allows for them, but is above them. Likewise, the Good allows reality and truth to exist, and yet it is beyond these things. Here, in translation, is an excerpt from Plato's famous simile: "The good therefore may be said to be the source not only of the intelligibility of the objects of knowledge, but also of their being and reality; yet it is not itself that reality, but is beyond it, and superior to it in dignity and power" (Plato The Republic 509c). ${ }^{55}$ The point of Plato's simile is that the cosmos can be best apprehended if viewed as a good and harmonious arrangement, and so "the highest Idea becomes the complete unity of all that is known and of all that has being" (Jones 39).

The phrase from the Philebus, translated as "the well mixed life," is perhaps the best way of summing up the idea of a life well lived. ${ }^{56}$ Neither pleasure nor knowledge

\footnotetext{
${ }^{54}$ The significance of mathematics as it relates to the notion of harmony between parts and whole was also emphasized by Plutarch (Moralia vol. XIII, part 1, p 39), one of Plato's earliest commentators.

${ }_{55}^{55}$ Desmond Lee translation.

${ }^{56} \mathrm{H}$. N. Fowler translation.
} 
on its own is adequate to ensure a good life in and of itself. Harmonious mixture is paramount. But a mixture of pleasure and knowledge is insufficient. Rather, the idea of mixture itself is what matters. Whether using the example of music, weather, or health, parts commingling to form an harmonious whole is the central idea behind the Philebus. Gadamer offers additional remarks on the incorporation of parts to form music and language, some of the examples Plato uses to expound upon the relationship between parts and wholes:

out of the rushing flood of the audible, the numerically determinate relationship of the "pure tones" comes to the fore - harmony in music. Or, in their function as letters, determinate lines of script emerge from the whole of the visible, and phonemes from the rest of what is to be heard, each as the special articulation of meaning that it is. Similarly, that which lives is brought forth as an organic body (Philebus 29d), and the entire universe as a harmonic order (Gadamer:1986 117).

Such metaphors deal with things fitting together as one, or parts coming together as a whole. This very mindset is foreign to us moderns, who work to separate, to parse out and classify parts. We have worked to disassemble unity, a stance that can be seen in terms of specialization, and in Cartesian mind/body dualism. For Plato:

mathematical conceptions are not "opinions," they are eternally so, whether you like them or not. They are "above" caprice, above contingent happenings, above subjective seemings. They are in their scope and compulsion "beyond" the mind and will of the individual thinker. They are absolute. They compel assent. They rule the mind in their own right. They are "transcendent" in the sense that they deal with objects which lie entirely beyond the range of any possible experience of sense (Jones 30).

Plato's "enigmatic" lecture on mathematics is best read (as is the case with the rest of his work) as analogy, and for Rosemary DesJardins it marks "a serious effort to explain in the most luminous terms his core belief about the nature and role of the Good" (DesJardins 120). The relationship between parts and whole as unity "can be observed most clearly in the field of mathematics. Arithmetic, geometry, harmonics, astronomy, all 
incorporate and reveal certain rules which show how unity passes into indefinite plurality" (Gaiser 13). For Plato, mathematics (whether used to identify harmonious relationships between musical notes, or the motions of the cosmos) was an ideal expression of parts and wholes functioning together in unity. Gaiser observes that for

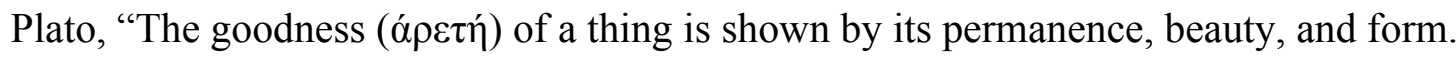
These qualities depend on order ( $\tau \dot{\alpha} \xi 1 \varsigma, \chi 0$ ovos); that is, on a well-proportioned arrangement of parts within the whole. The basis of order therefore is unity, and thence unity or one-ness is the cause of all good, or good in itself" (Gaiser 12). Gadamer offers a further insight on the relationship between mathematics and the Good: "Plato is emphatic in always justifying exercises in the mathematical sciences by their single essential preparatory function: they ready us for knowledge of the good" (Gadamer:1986 83). Gadamer's comment goes a long way towards explaining and making particularly poignant the dictum written over the doorway of the Academy: Let no one unversed in geometry enter.

For DesJardins:

the creation of harmony and beauty - whether mathematical, linguistic, ethical, epistemological, ontological, or political - rest on our response (explicit or implicit) to the appeal of this ultimate imperative of Unity. Powerfully attractive at every level of our being, it is this very principle of Unity in Wholeness that Plato calls the Good (DesJardins 126-7).

The Good then, is the idea of harmony, the idea of unity, the idea of wholeness, and it is applicable to every enterprise undertaken by Man, and every part of nature. What matters is not knowing the Good (as such final knowledge is impossible); what matters is how we respond to, or orient ourselves toward the imperative of the Good (unity, harmony). Mathematical practice, and the understanding of ideals and unity it brings, prepares us for 
an encounter with harmony, and for the necessary reorientation of the self demanded by such an encounter.

“The question of good," affirms DesJardins, "and Plato's response to it, provides the drumbeat of the whole Platonic corpus" (DesJardins 17). And while goodness and harmony pervade all of Plato's work, these ideas are fleshed out most lucidly and compellingly in the Philebus, a dialogue in which "the universal question about the good is woven completely into the plot of discussion" (Gadamer:1986 105). In the Philebus, we are introduced to the importance of proportion or harmonious measure, as neither pleasure nor knowledge alone can guarantee a fulfilling and meaningful life. It is the combination of these two things, properly balanced, which leads to a good life. Moreover, this idea of harmonious measure is applicable to all things, and to the general relation between parts and the whole. The state of goodness then, is one of order, harmony, balance - when parts fulfill their purpose, and thus contribute to the overall fulfillment of the whole of which they are a part. For DesJardins, the answer to the question of the Good as laid out in the opening pages of the Philebus is not as straightforward as it seems. We ought to take the idea of a mixture of knowledge and pleasure not as the answer to the problem of what it means to lead a good life, but rather as the starting point. What is important is the relationship between parts and the whole.

The central question in the Philebus has to do with whether pleasure or thought is the highest good, and as DesJardins rightly points out, the tension between these two goods is used as a way into an even deeper understanding of the Good as harmonious union of parts and whole. Once it has been established that neither pleasure nor knowledge on its own constitutes the good life, the task becomes one of combining an 
appropriate mixture of elements. This is not a mixture of separate things, as pleasure and knowledge are in fact inseparable. Gadamer asks, "Would pleasure be anything at all without consciousness, without our being aware of it?" (Gadamer:1986 111). Further, would a life completely devoted to contemplation, one devoid of pleasure (even of the pleasure that comes from breaking new ground in thought), be any sort of life at all? For Gadamer, the mixture metaphor is one way of expressing the need for human selfawareness. Plato's discussion of measurement and mixture is meant to bring us closer to an understanding of what it means to lead "fitting" lives. What Gadamer describes as "fitting" or fittedness is referred to as the "mixed" in the Philebus, and Gadamer, quite rightly I believe, asserts that the Philebus offers "the ideal of a life harmonized rightly" (Gadamer:1986 121).

Plato is interested in reconciling "opposites by combining them within a more comprehensive whole" (DesJardins 21). This mixture is begun very early in the dialogue, which means the emphasis is not on ideas of pleasure versus knowledge, but rather on the process of combining itself, and all of the attendant implications. The Philebus, read in this way, is not merely interested in the content of the good life (pleasure versus knowledge), but in the act of living the good life, which includes how parts relate to the whole, how the many are tied to the one, and how the one is present within the many. For DesJardins, "it is the relating of the one and many, the making, producing, or generating of a whole - and the condition of so doing - that the dialogue is primarily about" (DesJardins 22). In the Philebus, the central question is: "what does it mean, and how is it possible, to combine many (elements, parts, or components) into one (system or whole)?" (DesJardins 36). The answer to this question will determine the answer to the question of 
what it means to lead a good life, and following DesJardins, I argue that such questions are still relevant (perhaps now more than ever) in the modern world:

The good can be equated with harmony, or the unity of parts and wholes: Translated into the context of human life and happiness, the question becomes: how can we avoid fragmented lives in which we find ourselves "falling apart" or "going to pieces", in which we cannot "get it together", in which we are split between, say, Monday, Wednesday, Friday devoted to professional research, and Tuesday, Thursday, and Saturday spent on a pleasure binge? How, in other words, can we make out of the multiplicity of our days and the variety of our doings, a human life which, genuinely integrating pleasure and knowledge, will be whole and happy? (DesJardins 40).

DesJardins has here identified the crux of the matter. The Philebus (and indeed, the notion of the Good) goes beyond positing a balanced ratio or mixture of knowledge and pleasure, and is instead attuned to the notion of a harmonious relationship between parts and whole more generally. DesJardins does an excellent job raising what (it seems to me) is perhaps the central problem faced by moderns: fragmentation.

The modern epithet "work hard play hard" is just one example of an attitude of pervasive divisiveness. Here knowledge and pleasure have been completely sundered from one another. If our professional lives are so unfulfilling as to demand an entirely different sphere in which to practice catharsis, diversion, or forgetting, then perhaps the "working hard" fragment of our lives needs to be rethought. Is it not possible for work and play to coexist? If we follow Arnheim, then whisperings of this fragmentation began in antiquity, but it was not until the literary age, the privileging of the visual, and the discomfort with uncertainty (a split given new vigor in Descartes' cogito argument), and by this I mean not until modernity, that the sense ratios were drastically unbalanced and lives tremendously fractured. Such unbalancing opens the way for the disengaged reason 
characteristic of the modern self, and establishes the subject/object divisions between Man and nature, Man and Man, Man and self.

Plato uses the example of language to demonstrate the mutual dependence between parts and the whole. It is only by way of words and letters (morphemes and phonemes) that complete ideas are allowed to circulate, that language (and culture) can exist. Yet, in order to make sense of individual words or letters (to be able to identify them, or find them at all meaningful), they require a larger context, they require a whole (the system of language). This reciprocity between parts and whole is applicable to anything and everything (whether it be the playing of music, the weaving cloth, the practice of politics, etc.). Through separation and combination, we are able to transform each set of basic units into something more, a sum that is greater than (yet which is also reflected in) its constituent parts, be it notes into a symphony, fibers into a tapestry, or individuals into a polis (DesJardins 47).

In order to know something of the Good, we must have the capacity for abstract thought. This is why the "primitive" is, in a sense, farther from the Good (despite the fact that he may be living in harmony with the whole) than the man of abstraction, for the man of abstraction is aware of the fact that he is but a part (even if such awareness actually precludes him from experiencing complete harmony). This is the paradox, the tragedy, and the blessing of being human: our reason grants awareness, yet at the same time prevents us from becoming one with the very thing of which we are granted awareness.

According to Rufus M. Jones' reading of Plato, "the Idea of the Good is the absolute unity of being and knowing, the common, inclusive principle in the world that is 
known and in the mind that knows - the complete organism of all that is truly real, one living unity" (Jones 40). The Good, in short, can be thought of as the harmonious ordering of all things, so that the whole and all of its constituent parts exist in perfect unity. Lodge describes this concept in full completeness:

It is the vision of an ideal system of elements, each with a definite and positive function, so arranged that, while each realizes, as completely as possible, its own function, these functions are so adapted to one another that all, taken together, are co-operating to realize a single, all comprehending, systematic totality of value (Lodge 471).

Lodge continues:

The interpenetration of the whole and its parts is thought of as so complete that each element, while preserving its distinctness from each other element, is permeated by the spirit of the whole, and represents the concentration of all the forces of the ideal totality in some particular direction; while the whole is entirely realized in the ideal functioning of all its particular manifestations, its parts or elements, and indeed the spirit of the whole is completely realized in the ideal functioning of any one of its elements (Lodge 471).

Thus, in fulfilling its function, a constituent part realizes its own highest good. When the ancients refer to the Good, they are describing the act of fulfilling one's purpose and contributing to the harmony of the whole. For George Grant the good of a being can be thought of in terms of "what it is distinctively fitted for. Human beings are fitted to live well together in communities and to try to think openly about the nature of the whole... Good is what is present in the fulfillment of our given purposes" (Grant "Faith and the Multiversity" 466). Gadamer too (appealing to the idea of mixing in the Philebus), describes the Good in terms of fittedness. ${ }^{57}$

The Good is best understood in terms of unity or harmony, and under modernity, such harmony has largely been forgotten. Individuals are fractured (psychological issues are evidence of this, as are pervasive problems like apathy), values are fractured and

\footnotetext{
${ }^{57}$ Interestingly, like Grant, Gadamer too occasionally taught at McMaster University.
} 
askew (as the modern trend of technological progress illustrates), and culture is generally out of balance (environmental destruction, disposable consumer culture). Modern sunderings (of care and knowledge, of philosophy from life, of a unified sensorium) have distanced us from the ideal of harmony, and this distance from the Good is the source of our various malaises. DesJardins sums the matter up quite nicely, claiming that "ultimately the Good is to be understood as Unity itself. For, whether we recognize it or not, this Good in fact underlies all that we do and are" (DesJardins 111). This relationship between parts and whole can also be discerned in the beautiful. As Gadamer (Truth and Method) and Warry both point out, goodness and beauty are closely aligned, for a thing that is good (existing in a state of harmony) is also beautiful. This relationship also applies to action, for a good or decent act could be said to possess beauty (kállos). Gadamer notes a likeness between ideas of beauty and the Good, as both are chosen for their own sake. These ideas spill over into one another, or overlap, and yet are ultimately distinguishable. "Platonic philosophy exhibits a close connection, and sometimes even a confusion, between the idea of the good and the idea of the beautiful. Both transcend everything that is conditional and multiform" (Gadamer:2006 473). Both the beautiful and the Good can also be described in terms of measure, or appropriate proportion, which again signals the importance of mathematics: "the close connection between the mathematical orders of the beautiful and the order of the heavens means that the cosmos, the model of all visible harmony, is at the same time the supreme example of beauty in the visible sphere. Harmonious proportion, symmetry, is the decisive condition of all beauty" (Gadamer:2006 474). And such is also of course true of the Good. 
Gadamer continues his comparison of the Good and the beautiful with the observation that:

the intangibility of the good finds an analogue in the beautiful - i.e., in the harmony between the thing and its attendant disclosure (aletheia) - in that it too has an ultimate effulgence. But Plato can say, moreover, that in the attempt to grasp the good itself, the good takes flight into the beautiful. Thus the beautiful is distinguished from the absolutely intangible good in that it can be grasped. It is part of its own nature to be something that is visibly manifest. The beautiful reveals itself in the search for the good (Gadamer:2006 475).

And so, despite their parallels, the intangible good (and it is ultimately intangible) is distinguishable from the perceivable beautiful: "what distinguishes the beautiful from the good is that the beautiful of itself presents itself, that its being is such that it makes itself immediately evident" (Gadamer:2006 476). Gadamer understands beauty as that which mediates between the idea and appearance, and he calls recognition of this the “metaphysical crux of Platonism" (Gadamer:2006 476). The beautiful is the Good made manifest, which is to say, we can discern the Good (as harmony) in the beautiful. Beauty and goodness depend upon unity and wholeness, and for Plato, our response to beauty is what leads us to the "threshold" of the Good (DesJardins 106). And while we may approach this threshold, actually crossing it and knowing the Good is far more problematic.

For some, Plato's discussions of the Good are unsatisfactory, presented as they are in a mythical poetic style. As Santas observes, Plato's claims about the form of the good "have been found so obscure that in the last century and a half a whole series of eminent commentators... have told us there is nothing to them" (Santas 168). Karl Popper is one of the aforementioned commentators, and in The Open Society, he is put off by Plato's treatment of the Good. Popper comments on what he describes as the 
"empty formalism" of the Philebus, and is also dissatisfied with Plato's lecture on the Good and on its treatment in the Republic (Popper 146). What Popper fails to grasp is that the Good is not something to be firmly known with certainty; it is something whose presence we can feel, something of which we can be aware. As Gadamer is so fond of reminding us, we must not make the mistake of reading Plato literally, a mistake Popper seems to border on. As Rufus M. Jones notes with regard to Plato, "The literalist as interpreter of a poet is always wrong" (Jones 32). When reading Plato's allegories, we must "abandon all attempts at an exact interpretation" (Gadamer:1986 74). Concern with the Good is not about actually knowing the Good, so much as learning to orient oneself toward it. It is not about "learning" some specific thing, but rather about "turning" or reorienting one's soul. The Good cannot be known except by way of metaphor, and the metaphor Plato uses is the sun. While we cannot wholly know the Good, we can certainly orient ourselves toward it, which is to say, we can work to align ourselves with the Good, to fulfill our purpose, to do our best to amply participate in the cosmic mixture, to realize the presence of the Good in ourselves and thus act (as parts) in accordance with the whole. Consider the following famous passage from The Republic, where Plato has Socrates discuss education:

Then this turning around of the mind itself might be made a subject of professional skill, which would effect the conversion as easily and effectively as possible. It would not be concerned to implant sight, but to ensure that someone who had it already was not either turned in the wrong direction or looking the wrong way (Plato Republic 518d). ${ }^{58}$

Platonic myths are not meant to be authoritative. On the contrary, they are meant to open a space for the performance of self-analysis. Socrates "makes no claim that what he says

\footnotetext{
${ }^{58}$ Desmond Lee translation.
} 
is authoritative. Rather, he sets the listener free once again to recognize himself in what is said" (Gadamer:1986 109). Jones notes that Plato

was a poet, a genius, a supremely great writer of prose, but he left no system, no well organized and carefully matured conclusions; only debates magnificently handled, endless questions tentatively answered and then again reopened for new answers, myth, dreams, high hopes, visions and withal logical insight of the highest order, unsurpassed moral fervor and humor of the rarest quality (Jones 26).

Plato never produced a complete, systematic, all encompassing theory. Plato poses questions and offers wise speculation, but never claims to have created a comprehensive system.

As a prelude to the twentieth century modern thinkers who will be considered shortly, I would like to stage a brief encounter with Spinoza (that modern Stoic), who can be read as a transitional figure, as his work is concerned with the Good, and also with the burgeoning early modern science. Spinoza begins his "On the Improvement of the Understanding" in a very Stoic fashion, dealing as he does with the "vain and futile" affectations of social life, or what the Stoics referred to as indifferents. He then quickly decides that self transformation (what I have hitherto been calling spirituality) is necessary if one is to approach a sense of the Good. I use the phrase "sense of" because Spinoza (unlike Popper, but very much like DesJardins) seems to realize that to approach the Good, we must forego certain knowledge and take a plunge into uncertainty. This is to say, the Good cannot be delimited in a precise fashion. The good life for Spinoza can be thought of as "knowledge of the union existing between the mind and the whole of nature" (Spinoza 6). This is the shape of his metaphysical naturalism - a mind that experiences harmony, which is working towards concord with the Good. In Spinoza's view, nature possesses a unity, an overarching order; and yet, he accepts the fact that to 
firmly know this order may be unrealistic, for to do so "would far surpass the powers of human understanding" (Spinoza 37). Understanding all things and actions through a cause and effect schema is too simple, as the unity of nature exists in brilliant simultaneity. That said, while Spinoza does suspect that ultimate and complete knowledge of God or nature (in its infinite attributes) surpasses human understanding, he does propose a deductive structure to know the order of things. Like Descartes, Spinoza found that "the deductive method is the truest avenue to certainty" (Perry 89). Thus, while ultimate knowledge may be beyond human understanding, human reason is still the way toward certain knowledge of nature.

While Kisner (in his chapter "The good") focuses on that which is good for us (that is, to use Spinoza's terminology, whatever contributes to man's power), he does observe that for Spinoza "nature itself is a fixed causal order, which has no interest or concern in human needs and desires" (Kisner 96). Nature is not a conscious willing thing; it does not act with a goal in mind. If I may be allowed to dwell on Spinoza's language for a moment, the "contribution to Man's power" is an interesting turn of phrase, in that it connotes both an affinity for the ancients, and a modern divergence from them. Man's power suggests control, or at least the ability to know (through reason), and yet also implies a "doing well," whereas flourishing suggests doing well within and as part of nature. Through the expression "man's power," we are privy to the early sundering of Man from nature (and centering of Man), and this even in the writing of one who drew heavily on antiquity for inspiration. Spinoza is a fine example of a bridging figure, one who carries an ancient sensibility into the modern context. "Philosophy, for Plato, is a kind of vision, the 'vision of truth'. It is not purely intellectual; it is not merely wisdom, 
but love of wisdom, Spinoza's 'intellectual love of God' is much the same intimate union of thought and feeling" (Russell 124). This unity of thought and feeling, discussed in the last chapter, is an apt description of a brush with the Good, of self transcendence which is the result of a process of áskēsis. Also like Plato, Spinoza held mathematics in high regard, as he understood nature in terms of mathematical laws:

For Spinoza, God was not a transcendent creator or miracle maker; he was not a superhuman being who possessed an intellect and free will; he was not a personal being, a loving father who cared for each individual and heeded prayers. Inspired by the new science, Spinoza identified God with the order of nature: nature, a single all-inclusive system of unchangeable, universal laws in which all things have a determinate place... God and nature are indistinguishable (Perry 89).

As nature is a unified system it becomes possible to understand something of the harmony of nature's dynamic order through reason. And because for Spinoza, the harmony of nature is synonymous with God, to know something of nature's order is also to approach the Good. Spinoza is a modern who operates in the tradition of the ancients, and so while sundered and possessed of a different attitude (one which privileges knowledge over care and which takes the self to be the ground of that knowledge) than the ancients, we are not wholly separate. As Hadot observes, "Spinoza's discourse, nourished on ancient philosophy, teaches man how to transform, radically and concretely, his own being" (Philosophy as a Way of Life 271). We see in Spinoza, as in the ancients, advocacy of a program of caring for the self. Likewise, Foucault claims that "in formulating the problem of access to the truth Spinoza linked the problem to a series of requirements concerning the subject's very being" (Foucault Hermeneutics of the Subject 27). His inquiries are a form of áskēsis, and the language he uses sheds light on his approach. Consider the way Spinoza claims to have "compelled" himself, and how he sought with all of his "strength" for a remedy regarding the problem of leading a good 
life. This highly engaged and tense stance is one of the reasons that Spinoza is generally referred to as a modern Stoic. As such, rather than chasing transitory goods, Spinoza retains an ancient interest in a more permanent good: "All these [desire for reputation, pleasure, wealth, etc.] arise from the love of what is perishable... But love towards a thing eternal and infinite feeds the mind wholly with joy" (Spinoza 5).

In his article "The Concept of the Good Life," Steve Smith calls attention to the fact that living a good life results from developing the self (Smith 28), and in so doing, touches on an idea modeled by Spinoza and later stressed by Hadot: that in order to transcend the self and exist in harmony with the whole, one must first care for (or develop, to use Smith's terminology) the self. It is in this way that the sundering of caring from knowing, and the distance from the Good are related under modernity.

Having made these remarks about the Good, I would like to pose the following question: how might we, using modern methods, work to re-orient ourselves towards the Good? Of the thinkers here assessed, George Grant and Simone Weil affirm the worth the Good as understood in antiquity, while Hannah Arendt, though cognizant of the problem of worldlessness and groundlessness, understands the loss of traditional authority as an opportunity to forge a new politics.

The balancing of the sense ratio, Schiller's concatenation of the rational and sensuous, or Arnheim's "thinking through perceiving" are other ways of describing an approach to the Good. These examples represent aesthetic approaches to decreation, or divesting oneself of ego. But of course, to do this means fundamentally altering the self, and moving beyond the "I" of the cogito. This requires a tremendous amount of care. As 
we've established, to take care of the self is to perform work or exercises on the self designed to alter one's relation to truth, and thus one's very being. Care of the self is intended to open the self to the possibility of living virtuously. In this sense, caring for the self is like chipping away at the ego. Caring for the self is meant to lead one to the realization that they are but a part of an infinitely large whole. One can assert the ego and attempt to secure freedom via an exercise of will (and so resist playing a part in the unity of nature), or one can attempt to open oneself to the possibility of alignment with the whole (which means to annul - if only briefly - the ego). In this way the ancient practice of caring for the self works to turn us towards that which is beyond the self and which thus undoes the self. Caring for the self is thus the first step in self transcendence and opening the self to an encounter with the Absolute.

Erich Fromm is one recent modern thinker for whom the good is a pressing concern. Fromm is, for the most part, a supporter of the modern project, but a supporter who applies certain qualifications. In the midst of our progress and freedom from past authority, we have neglected essential ethical questions. What does it mean to be human? How ought we to live? How can we harness our energies responsibly and lead fulfilling lives? Fromm is an interesting case, but one which I will treat only in passing. His ambitions are noble, but his notion of goodness is beleaguered by the modern claim to authenticity (his work is unabashedly Cartesian in this sense, and exhorts what we might call - borrowing from Taylor - an inauthentic authenticity). And while he clings to modern ideas of authenticity and internalized agency, his motives are gallant, and his critique of modern culture is sound. 
In To Have or to Be, Fromm claims (quite rightly I think) that the promise of modern progress (universal emancipation, contentment, control of nature, an utopian telos, etc.) was not fulfilled because of failures that were built into modernity itself. Fromm identifies two underlying psychological assumptions (perhaps better thought of as misunderstandings) of humanity responsible for the current malaise in which we find ourselves: the belief that the aim of life is happiness (happiness as radical hedonism, not happiness in the Aristotelian sense of eudaimonia or harmonious flourishing), and the idea that unlimited egoism leads to harmony (Fromm To Have or to Be 2-3). We have in many ways surpassed past ages, and yet in a crucial sense, we have fallen behind. During the eighteenth century Enlightenment, the Renaissance, the early Christian era, and antiquity, the problem of fulfillment, the problem of living a good and meaningful life which so plagues us had been largely overcome (Fromm Man for Himself 5). In a world as fragmented as ours, living a good life (which is to say, an harmonious life, a life of virtue, a life according to general principles) becomes exceedingly difficult. Any attempt at mending modernity must not come from specialized, truncated disciplines, or from the language of will and freedom which emerged out of the technological landscape, but from the realization that ethical considerations are indissolubly linked with philosophy and self awareness.

Weil and Grant are two modern thinkers who reject the language of authenticity and individuality exhorted by Fromm. Commenting on Grant, Robertson makes reference to such modern turns of phrase:

Our technological fate is especially evident in the language of "values" or "quality of life" that is everywhere present in our culture, eclipsing the older language of the "good." The older language implies a given order or set of purposes, and with this, a sense of "nature" as an ordered whole (Robertson 78). 
Shaped as it is by the work of Ellul, in Grant's thought "the technological standpoint is joined to the very being of modernity, which in turn is joined to a conception of the essence of humanity as freedom or as will" (Robertson 77). The technological society, its tendency to objectify, and its demands of mastery see humanity placed at a remove from the rest of nature. Technology is (as Grant tells us) the ontology of the age, and this way of being determines that humans exercise their wills, and attempt to enact their designs (which are really technological in nature - we have become servos) upon nature in order to free themselves from its imperatives. Grant's use of the word freedom is vastly different from the modern sense of freedom, which is tied to either political liberty or technical mastery and control over (and thus extrication from) the order of nature. For Grant, freedom is connected to truth, and he asks us to work to open spaces within the technological system in which human excellence can flourish (Grant "A Critique of the New Left (1966)" 89-90).

Modernity of course, is not entirely reprehensible, and "Grant was too honest not to recognize that technology had greatly liberated human beings from suffering and the slavery of work - especially women" (Robertson 79). Despite this recognition, Robertson affirms that "for Grant, to live in the midst of technology is to live in the midst of deprival. The very way of being that liberates us from necessity and suffering brings with it a more profound suffering - the suffering of spiritual deprivation" (Robertson 79). Intimations of deprival, while painful, may also be thought of as a gift. Such intimation is necessary if we are to question the ontology of the age. "To find our way out of modern, technological ontology we need first to know of its deprivations," and "for Grant, most of us can only have access to such positive intimations in recollection, by receiving in 
tradition an encounter with a world that is pre-technological" (Robertson 80). I'm taking my cue from Grant, for "recollections" offer perspective, they allow us to gain a measure of critical distance from the present ontology, and thereby suggest a way out. This is why antiquity is such an important reference, and why allowing ourselves to be inspired by antiquity is so important.

Likewise, Iris Murdoch (who, like Grant, was greatly influenced by the thought of Weil) critiques the modern sense of "good." Under modernity, the idea of good has, in Murdoch's estimation, been tied too closely to the individual will or human agency. This understanding of good is identified with behaviourist, existentialist, and utilitarian thought, and for Murdoch, such a view of humanity leaves "something vital" missing. Murdoch vehemently rejects the existentialist view of solitary agents exercising freedom. Contrary to the existentialist emphasis on will, moral life goes on continuously. It is not “switched off” in between explicit moral choices (Murdoch 37). Right living involves more than specific acts of will or choice. It involves paying "attention," as Murdoch (who borrows the phrase from Simone Weil) ${ }^{59}$ puts it. This sort of attention is necessary if we wish to counter illusions about the world (for example, the illusion of complete agency and autonomy), and if we hope to unself or decreate the ego, and thus accept our position as part of the cosmos.

Murdoch offers a worthwhile (though on the surface contradictory) account of a modern good influenced by Platonism and (despite her claims to the contrary) a smattering of existentialism. Contrary to her claims, Murdoch does not actually seem to reject existentialism outright. Rather, she engages with it, prising it open, discarding its

\footnotetext{
${ }^{59}$ Weil tells us that "We have to try to cure our faults by attention and not by will" (Gravity and Grace 116). This is to say, touching the Good cannot be willed. Rather, we must condition ourselves to be receptive to the Good.
} 
self aggrandizing tendencies, but retaining its humanism. Murdoch offers a summary of her position on existentialism when she writes "most existentialist thinking seems to me either optimistic romancing or else something positively Luciferian. (Possibly Heidegger is Lucifer in person)" (Murdoch 71-2). I am forced to disagree with this total indictment of Heidegger. Granted, his political affiliations were (to put it mildly) dubious, but this doesn't change the fact that Heidegger had many worthwhile things to say. His estranging style alone merits careful consideration, and while perhaps not heavenly, he is certainly not Luciferian. That said, Murdoch is correct when she claims that there is an excess of optimism and self aggrandizement in much existential philosophy. And while Murdoch critiques existentialist egoism and internalization of agency, she does seem to subscribe to some of their other conclusions, as when she claims "there is, in my view, no God in the traditional sense of the term." Murdoch continues:

the various metaphysical substitutes for God - Reason, Science, History - are false deities. Our destiny can be examined but it cannot be justified or totally explained. We are simply here. And if there is any kind of sense or unity in human life, and the dream of this does not cease to haunt us, it is of some other kind and must be sought within a human experience which has nothing outside it (Murdoch 79).

Contrary to what she sees as the existential impulse to "fill" the void left by the death of God (with human will), Murdoch would have us experience that openness. She would have us, like McLuhan, stand in the resonant interval. A measure of ambiguity (even contradictoriness) then, is a necessary part of approaching the Good. F. B. A. Asiedu works to highlight the "confounding" tendency and the contradictions present in Murdoch's understanding of the Good. "One often gets the impression that Murdoch has an insight that resists theorizing, as she seems almost unsure just where the sense of value is supposed to come from." (Asiedu 37). Contrary to what Asiedu thinks, this is entirely 
fitting, as the Good itself resists theorizing. Although contradictions exist within Murdoch's polemic on the Good, Asiedu's consternation with vagueness is precisely where his analysis falls short. Asiedu's frustration is palpable, as he is unable to stand the mysteriousness which must accompany the idea of the Good. As we've seen, the Good cannot be known in any definite way. We can and do have a sense of it, as we understand it to be an experience of harmony, unity, and oneness, but having a sense of what constitutes the Good is not the same as actually knowing the Good.

Asiedu craves something firm. This is not to say that in the Judeo-Christian tradition God can be known, but it is nonetheless comforting to put a name and a face to the idea of Good. "In place of God as a single, perfect, transcendent non-representable and necessarily real object of attention, she proposes the Good, which she has already pointed out is difficult to define and mysterious" (Asiedu 41). God only took the place of the Good (as centre) during the Middle Ages, in what Jones called a "bungling" concern with final ends. With this in mind, it is unfair of Asiedu to present Murdoch's positioning of the Good as unjustified. Capitani offers a more favorable appraisal of Murdoch's secular yet objective and universal ethics: "Struggling with her need to find a way to live in a world where traditional God-images no longer worked, Murdoch formulated her theory of the power of Good as an alternative" (Capitani 101). We can, I think, forgive any inconsistencies (or, even better, appreciate them for what they represent: an affirmation that the Good is not something to be known with certainty), as such alternatives are sorely needed.

Another modern thinker painfully aware of the emptiness of the modern experience and who affirms the need for a sense of harmony and unity is philologist J. R. 
R. Tolkien, most famous for his high fantasy series The Lord of the Rings. Tolkien was keenly aware of the modern deprivations observed by Grant and experienced by Weil, and his work is in many ways an attempt at making such deprivations felt (the enduring popularity of his work is a testament to his insight and to the current need for such ideas). While order and harmony are taken up in The Lord of the Rings and The Hobbit, these themes are nowhere more apparent than in the first two chapters of The Silmarillion. Here, Tolkien presents a creation myth which beautifully describes the unity of all that is, and the suffering that arises when that harmony is challenged. In his own words, in The Silmarillion, Tolkien created a "body of more or less connected legend, ranging from the large and cosmogonic, to the level of romantic fairy-story - the larger founded on the lesser in contact with the earth, the lesser drawing splendour from the vast backcloths" (Tolkien xii). Tolkien's entire mythology is concerned with falls from grace, the folly and blasphemy of attempts at reworking creation into our own image, the hubris that comes with sub-creation, and the dangers of "the machine" (or magic - Tolkien uses these terms interchangeably). Everything in Tolkien's universe fulfills a purpose and participates within an harmonious whole. The various quests all work toward restoring the harmony which has been (in a sense) unbalanced by the dominating logic of the machine. While Tolkien abhorred allegory, ${ }^{60}$ his stories are certainly relevant for those living in a technological society, sundered from the Good, and quite proud of the "bigness of our littleness." In much the same way as Grant, Tolkien describes the importance of reflection on the Good, and "the preservation in reverent memory of all tradition concerning the good, wise, and beautiful" (Tolkien xxi footnote). Reflection and

\footnotetext{
${ }^{60}$ While a Catholic, Tolkien is careful to avoid explicit traces of Christianity in his mythology, as such bald allegory is for him, fatal.
} 
preservation are different than calls for a return, and they also differ from the egoistic desire to mold the world in our image. There have been a number of modern thinkers concerned with the Good, and Tolkien's work represents one more example of proximate distance. Through such work we can critique our culture, gain awareness of ourselves, and recollect something of the ancient sensibility.

Unlike Postman, Berman, and Jacoby, who each claim that we have not lived up to the demands of the Enlightenment, I align myself with MacIntyre, who suggests that our current moral predicament (groundlessness) is owing precisely to the internal and inherent failures of the Enlightenment, namely, the failure to justify or provide stable ground for a humanistic ethics. This failure permitted the many "goods" in circulation under modernity. In other words, the common background of ethical activity which was a part of ancient everyday life, and which was for a time provided by religion, had, under modernity evaporated.

In the Middle Ages theology displaced philosophy as the way towards truth. In the nascent stages of modernity, burgeoning print culture saw the beginning of modern subjectivity, and in an ironic turn, the Cartesian moment effectively altered the necessary conditions for approaching truth. Where transformative exercises were once the way towards virtue, the way towards wisdom, the way towards a philosophical life lived in harmony with the whole, after Descartes' own meditations, a rational scientific method became the way to approach truth as knowledge (rather than wisdom). In a culture where the self has been thrown out of cosmic accord and where it appears to be separate from the rest of nature, the shared moral framework which had hitherto existed began to wither. With this malaise, Enlightenment philosophers began a project of inventing an 
ethical ground. But of course, as MacIntyre makes clear, without a teleological framework, and without an understanding of essential human features, the character of morality (if it remains at all) will be radically altered.

Such is also true for Weil who, like MacIntyre, understands there to be essential human traits, and an external ground for morality. All humans, writes Weil, have within the depths of their hearts, a longing for the absolute good which exists beyond this world. In directing the attention towards such ends, we have the potential to brush up against the Good. ${ }^{61}$ Weil's "Draft for a Statement of Human Obligations" explicitly presents such ideas, and its language is also noteworthy. Where rights (the idea to which Weil responds in her essay) describe something owing to the individual (a stance of entitlement, taking, deserving - something egoistic), an obligation describes something which an individual owes (a stance of responsibility, of giving - something un-egoistic). The latter speaks to selflessness and connection to something larger than the self - the Good beyond this world to which we are not granted full apprehension. The former takes the self as its ground, demanding that others and the world recognize the individual's inherent worth and merit. The idea of an obligation describes submission to something beyond the self, while the idea of rights asserts that freedom (which is deserved) must come from an exercise of will. The very idea of "rights" is uniquely modern, relying on a culture of atomized individual selves for its currency. The radical alteration of morality saw the centering of the self, and the opening of a number of relative goods, each just as viable as the next.

\footnotetext{
${ }^{61}$ I should make it clear that for Weil there is a distinction between attention and will: attention is akin to objectless waiting or openness to the Absolute, whereas will is the assertion of the ego.
} 
George Grant owes a debt to Simone Weil, as her attention to modern affliction impressed upon him the importance of intimations of deprival suffered under modernity. Though born into a Jewish family, Weil has been described as a secular saint, as she embodied the lessons of the Gospels, and yet did not actively participate in organized religion. Intellectually, Weil positioned herself somewhere between Judaism and Christianity (specifically Catholicism), yet formally, she was allied to neither. Weil was one who, in the spirit of the ancients, lived her philosophy. Weil, whom Grant describes as a Gnostic saint, ${ }^{62}$ is perhaps one of the finest examples of one who lived a truly philosophic life. Weil "taught that desire which has not passed through the flesh by means of appropriate action remains a sentimental phantom" (Grant "Simone Weil" 254). Understanding comes through a life lived philosophically. Theoretical knowledge is not enough; one must live truthfully.

Intellectual pursuits had always been a part of Weil's life, and her reading of ancient texts (especially Plato and the Gospels) was what opened her to receptivity (Grant "Simone Weil" 243), and I would suggest that such intellectual pursuits can be read as spiritual work. Weil was not merely a philosopher in the theoretical sense. On the contrary, "she was incarnate in the twentieth century - that is, she knew it not only as an observer, but its affliction became her flesh" (Grant "Simone Weil" 251). Weil had experienced first hand the horror of war, the crushing drudgery of industrial work, and the general "uprootedness" (alienation) of modern culture.

Viewing the unity in Weil's thought is difficult, as much of her writing comes to us in the form of posthumous letters and essays which were never intended for

\footnotetext{
${ }^{62}$ By saint, Grant means someone who gives themselves away, or who lives unegoistically ("Simone Weil" 257).
} 
publication. Bearing this in mind, let us look to a line from Plato to which she repeatedly returned: "How great is the real difference between necessity and the good" (Republic 493c). The fundamental contradiction of the human condition here expressed by Plato served as a touchstone for Weil, who "waited upon that contradiction with ceaseless attention" (Grant "Simone Weil" 264). Weil reminds us that:

As Plato said, an infinite distance separates the good from necessity - the essential contradiction in human life is that man, with a straining after the good constituting his very being, is at the same time subject in his entire being, both in mind and in flesh, to a blind force, to a necessity completely indifferent to the good (Weil, Oppression and Liberty, qtd in Grant "Simone Weil" 248).

As Grant makes clear, it is through such contradiction that the mind is lead to truth, but the dwelling in such contradiction often requires "too great an attention" for an accelerated technological society (Grant "Simone Weil" 263). This is where aesthetic exercises are so important, as they can grant us distance from our accelerated technological culture, and allow us space. This is particularly true of modern art, which, as McLuhan claims, aims at creating ruptures or shocking us into awareness. The practice of making strange (in a modern context) opens up a space from which we may feel intimations of deprival and reorient ourselves toward the Good. As we saw in chapter five, "at the heart of the aesthetic way of life... is the attempt to lose the self in the immediacy of present experience" (MacIntyre After Virtue 40). Loosing the self is precisely what Weil and Murdoch advocate in their respective programs of care, and it is also what Schiller, Eliot, and McLuhan envision as the consequence of the concatenation of sense and reason.

Linking art and morality through the act of what she calls "unselfing," Murdoch claims that "art is an excellent analogy of morals, or indeed that it is in this respect a case 
of morals. We cease to be in order to attend to the existence of something else, a natural object, a person in need" (Murdoch 59). Beautiful art then, whether meant (as in the ancient mimetic sense) to mirror the world, or (in the modern sense of estrangement) to disrupt it, does have a universal quality - it has something timeless to say. What Murdoch would label "good art" has the potential to allow us (if only briefly) to transcend the self, to fuse perception and reason and experience all-at-once-ness. Murdoch describes the practice of "unselfing" as the silencing and expulsion of self through contemplation of art or nature (Murdoch 64). This practice is in the same tradition as ancient áskēsis. While Murdoch tends to view art as mimetic rather than as disruptive, her concept of "unselfing" does leave room for an art of ostranenie - for an art of disruption, a force which jolts us out of complacency, compels us to ask questions, and encourages us to experience openness. In Murdoch’s Platonism (which is so very much like Weil's), beauty offers a way towards the Good. "Murdoch's theory is that through art we lose ourselves and that in unselfish love the same thing happens" (Capitani 101-2). For Capitani, what Murdoch "attempted to find in her metaphysical writings as well as her fiction is a plan for life in a secular time" (Capitani 108).

Murdoch shares a great deal in common with McLuhan, as for her, "Art indeed, so far from being a playful diversion of the human race, is the place of its most fundamental insight, and the centre to which the more uncertain steps of metaphysics must constantly return" (Murdoch 73). Murdoch continues: "For both the collective and the individual salvation of the human race, art is doubtless more important than philosophy" (Murdoch 76). Though she approaches the matter rather differently, Murdoch comes to the same conclusion as McLuhan. Recall that for McLuhan, the artist 
is a sleuth and art a way of disrupting the commonplace, and such disruption can open an interval from which to remain open to the Good. For Murdoch, contemplation of art (or nature) can put us back into contact with the Good, with a sense of unity that pervades all things and in which we all participate. Following Weil, for whom attention to the beauty of the world is the most straightforward way to approach the Good (Weil Waiting for God 103), Murdoch writes, "The appreciation of beauty in art or nature is not only (for all its difficulties) the easiest available spiritual exercise; it is also a completely adequate entry into (and not just analogy of) the good life, since it is the checking of selfishness in the interest of seeing the real" (Murdoch 64-5). Beauty has the potential to put us into contact with the Good, as through the experience of beauty, we can perceive something of the order and harmony of nature and thereby submit ourselves to the cosmos, or open ourselves to something beyond the self. Beauty is of course not the Good itself, but only a way toward the Good. The apprehension and contemplation of beauty can (if only briefly) return us to a state of being where sense and reason are united, where we experience the all-at-onceness of the world, where we endure (again, if only briefly) that quality Arendt calls "speechless wonder." ${ }^{, 63}$ If consideration of beauty in nature or art which allows transcendence of self is an apt way of thinking about a path toward the Good (and I feel it is), then this helps to explain the modern difficulty with experiencing harmony. Modernity has been described as an age of the self, and this intensive focus on the self has risen out of numerous sunderings. It will be tremendously difficult, if not impossible, to open oneself to contact with the Good without engaging in áskēsis, for

\footnotetext{
${ }^{63}$ Arendt too appreciates the need for such speechless wonder, and yet she takes issue with Plato's treatment of this idea. "Plato proposed to prolong indefinitely the speechless wonder which is at the beginning and end of philosophy. He tried to develop a way of life (the bios theōrētikos) what can be only a fleeting moment" (Arendt Promise of Politics 36-7). There is truth in this observation, and yet there is an inherent nobility in Plato's attempt.
} 
through áskêsis we prepare ourselves for decreation, for putting aside or surrendering our individual self in order to align ourselves (bring ourselves into harmony) with the cosmos. As Weil reminds us, we cannot simply "will” an orientation toward the Good (in her "Spiritual Autobiography" letter, Weil is careful to remind us that she has never actively "sought" God), and as the egoistic language of will/agency is dominant under modernity, looking back to ancient attitudes might inspire a rethinking of this language and reveal that there are alternatives. In a culture of many sunderings, the Good (as harmony/unity) can only be touched by re-orienting the self through spiritual exercises and thus preparing the self to participate (un-egoistically) in the harmony of the whole. True being is not found in the self, true being is being towards others.

For Weil, touching the Good is not a matter of willing or deliberate choice, "but of intellect and attention" (Grant "Simone Weil" 251). Grant's religious commitments (his understanding of faith as something that cannot be willed) mirror Weil's, for whom touching the Good was not a question of will, but of waiting and receptivity. In this sense, both Weil and Grant fit into Kracauer's category of "those who wait." And yet, it seems to me that the way to receptivity, the way to this Wordsworthian "wise passiveness," is through áskēsis. Transcendence cannot simply be willed, God or the Good cannot be reached by means of a unitary egoistic assertion. The self must first be prepared for such openness, for such a stance of receptive waiting. It is in this way that self care and self transcendence are linked. No one arrives on this earth immediately prepared for transcendence - the stance of openness necessary for an encounter with the Good is something that must be cultivated. We must exert effort in order to arrive at that point of objectless waiting. Any direct and active pursuit of the Good is bound to fail, for 
"if a person wants to cross that distance on his/her own, or by the sole force of his/her will, instead of finding God at the end of that pursuit, he/she will reach only his/her own ego" (Estelrich 246). We must wait, and open ourselves to being carried up. The encounter with the Good cannot be forced; in order to prepare for waiting, we must first work on and condition the self, we must think meditatively, we must live philosophically.

One of Grant's most incisive indictments of modernity is expressed in his understanding of the modern language of will and freedom:

all languages of good except the language of the drive to freedom have disintegrated, so it is just to pass some antique wind to speak of goods that belong to man as man. Yet the answer is also the same: if we cannot so speak, then we can either only celebrate or stand in silence before that drive. Only in listening for the intimations of deprival can we live critically in the dynamo

(Grant, "A Platitude" 451).

Grant is highly critical of the language of values, will, and freedom which is so central to modernity. He writes, "All coherent languages beyond these which serve the drive to unlimited freedom through technique have been broken up in the coming to be of what we are" ("A Platitude" 449). Kroker comments on this same passage, noting that the "frenzied drive to "freedom through technique" is, in a word, the horizon of modern culture" (Kroker 29). As this frenzied logic and its language of freedom and will ensconce us, it becomes terribly difficult to "think against and beyond the horizon of technical reason" (Kroker 29). We have been, Kroker tells us, dispossessed of any "language of the good." This is precisely Grant's point: without such language, it is exceedingly difficult to respond to the current predicament. We can bear witness to the loss of the language of the Good in the sundering of knowing from caring, and in the isolation and elevation of knowledge over care. These are of course the conditions which 
gave rise to apathy, and so the distance from the Good is made visible by, or is incarnate in the problem of modern apathy.

Commenting on the role of philosophy under modernity, Grant affirms that "thought is not the servant of psycho-analysis or sociology; but a straining for purification has the authority of the Delphic 'know thyself,' " ("A Platitude" 450). In true Heideggerian form, Grant seeks to restore the eminence of thought; thought not as a system for validating the hard or social sciences (which seems to be the lot of philosophy in late modernity), but rather as a kind of work on the self, in order that the self be permitted to move closer to knowing the Good. Grant quietly recognizes the relationship between care and knowledge. Care, in this instance, is straining for purification, and the knowledge that results is knowledge of oneself as a part of the whole (rather than an instrumental knowledge bent on mastery and freedom as exercise of will). As Foucault states in no uncertain terms, care and knowledge were, in antiquity, bound together. In order to "know thyself," one first had to care for the self. This is to say that while knowledge has become the modern instrument in controlling nature and thereby securing a sense of freedom, it has an ancient provenance and was in fact connected to áskēsis and the Good.

In a rather Nietzschean turn of phrase in which he expresses the modern idea of freedom as "will to will," Grant calls for a recollection of the language of good: "The language of good is not then a dead language, but one that must, even in its present disintegration, be re-collected, even as we publicly let our freedom become ever more increasingly the pure will to will" ("A Platitude" 452). Grant is a staunch critic of the language of willing which has come to dominate, and which is in fact representative of 
the technological society. In fact, "Grant is unrelenting in his insistence that all aspects of technological society are reducible to a common source, the language of will" (Kroker 39). Kroker goes on to explain that any language or way of thinking not supportive of the modern idea of freedom through willing, is consequently hindered (not in a deliberate sense, but simply through the vast momentum of technological progress). This is apparent in the distinction Heidegger draws between calculative and meditative thinking, and in the way he defends the idea of meditative thought. Meditative thinking is surely a fine example of an orientation which contravenes the logic of willing and the modern idea of freedom (freedom to do, rather than be). Modern thoughts on subjectivity, aesthetics, epistemology, and technology (those fundamental categories through which we might try to understand something of the modern experience, and that are, for our purposes, noteworthy, bound up as they are with the problem of care), are for Grant "derivative expressions of... the language of willing" (Kroker 40).

For Grant, the way out of the present malaise, the way to resist the language of willing, is to wait, to stand in silence before the drive to mastery:

When technique is thought and lived as a dependency relation fully integral to the human personality; that is, when "we" are technique, then Grant instructs us that any movement which seeks to transcend the horizon of the technocratic imperative must begin, and can only begin, with a reformation of human identity (Kroker 31).

We must condition ourselves to think meditatively (to again borrow Heidegger's term). Arendt, on the other hand, would have us act. In her essay on "Socrates" in The Promise of Politics, Arendt charts the gulf between philosophy and politics, a gulf which, for her, opened with the trial of Socrates, and which did not begin to close until Marx's theses on Feuerbach. 
Arendt argues that the abyss between philosophy and politics (foreshadowed in the figure of Socrates himself) has grown out of Plato's response to the death of his teacher. Socrates was one in whom thought and action were mingled, but this mingling collapsed in the work of Plato. Arendt reacts to the idea of Plato's philosopher ruler by looking to Socrates and claiming that the role of the philosopher, in a Socratic sense, "is not to rule the city but to be its "gadfly," not to tell philosophical truths but to make citizens more truthful" (The Promise of Politics 15).

Arendt is deeply concerned about the spread of worldlessness, which she also describes as the modern desert, and yet, she sees in worldlessness the possibility of forging a common humanity (and thus merging philosophy and politics), if, that is, we can endure the desert. Arendt critiques the modern practice of adjusting to the desert, and in the course of her critique condemns modern psychology (and we might add to this the modern pharmaceutical industry), as it allows us to continue living productively in the desert, rather than questioning the nature of the desert itself which causes our malaise. Arendt critiques these modern adjustments, under which, she claims, "we lose the faculty of suffering and with it the virtue of endurance. Only those who can endure the passion of living under desert conditions can be trusted to summon up in themselves the courage that lies at the root of action, of becoming an active being" (The Promise of Politics 202). Suffering and endurance are (though for different reasons) central to both Arendt and Grant. For Arendt we must be aware of the desert in order to move beyond it: "precisely because we suffer under desert conditions we are still human and still intact; the danger lies in becoming true inhabitants of the desert and feeling at home in it" (The Promise of Politics 201). Grant of course also notes the importance of what he calls intimations of 
deprival, for such intimations will prevent us from becoming, to use Arendt's phrase, "reconciled to the desert." Intimations of deprival will, for Grant, awaken us to the need to endure uncertainty in order to leave room for an encounter with the Good (in other words, to sustain speechless wonder). For Arendt, we must endure the desert not to leave space for a reorientation toward the Good, but so that we may come together as a community and forge a real politics.

While both Grant and Arendt would have us endure the desert, each views the desert differently. Arendt describes the spread of the desert as the "modern growth of worldlessness, the withering away of everything between us" (The Promise of Politics 201). Based on her understanding of politics as the "coexistence and association of different men" (Arendt The Promise of Politics 93) ${ }^{64}$, we can see that for Arendt the desert is political. Grant on the other hand, would describe the modern desert as philosophical, in that we have lost touch with, and disposed of any language of the Good. Both counsel enduring, but do so for different reasons. Grant counsels endurance in order to leave space enough for an encounter with the Good, while Arendt advocates endurance in order to prompt action. While I do tend to follow Grant's understanding of the desert (and thus also his understanding of what it means to endure), what we can take from both of these thinkers is the need for endurance: we must not allow ourselves to become acclimated to the desert of our time.

Again, Arendt views politics as the arena in which worldlessness can be overcome. While drawing on antiquity, her look back to the ancients differs from both Grant and Weil, as Arendt honed in on what she saw as an ideal political arrangement in

\footnotetext{
${ }^{64}$ For Arendt philosophy is concerned with Man (the category), whereas politics is concerned with the relationships between different (individual) men.
} 
pre-Socratic Greece, rather than an ideal spiritual existence as exhorted by Plato. While Grant wishes to preserve tradition, Arendt wishes to move beyond it: "With the loss of tradition we have lost the thread which safely guided us through the vast realms of the past, but this thread was also the chain fettering each successive generation to a predetermined aspect of the past" (Between Past and Future 94). Euben considers Arendt's debt to, divergence from, and occasional misreading of the ancients (specifically Plato), in an effort to present her view of politics. Noting that ancient Greece is a recurrent point of inspiration and reference for Arendt, Euben points out that while "other theorists understand and judge the polis in terms of a philosophical tradition largely hostile to it, she inverts that reading, condemning the tradition for effacing the originary and in some respects still quintessential expression of freedom and power present in the practices and literature of classical Greece" (Euben 151). Euben summarizes Arendt's take on politics quite nicely:

Politics, which is what gives meaning to human life, is a world of appearances. Politically speaking, what appears is the world, not some pale imitation of another world beyond it. The political does not lack firmer ground or more efficient organization, and it is not, as Plato's parable of the cave seems to indicate, a shadowy place lacking splendor and beauty. It is, rather, a world rich with tone and texture (Euben 157).

Against the ancient philosophical notion of an harmonious and ordered cosmos bound together in unity, "Arendt sides with politics and drama, the world of appearance and opinion, with truth as negotiation among competing viewpoints" (Euben 158). Euben understands Arendt as a political educator, one interested in deepening our understanding of problems rather than necessarily solving them. It is in this light that Arendt's debt to the ancients becomes apparent. "For Arendt, a political community as opposed to the ersatz politics of a Platonic city or a liberal state requires the contentiousness of strong- 
willed individuals who also appreciate how the world they share makes their individualism possible" (Euben 156). The Arendt who understands politics as the coming together of individuals with diverse views, is also the Arendt who admires "episodic revivals of political freedom" (Euben 161). But there is another Arendt, the Arendt concerned with worldlessness which marks the periods of crisis which in turn permit episodic revivals of freedom, and which allow individuals to attempt to re-order their society and sort things out for themselves. Although ultimately interested in the coming together of individuals, her concern with worldlessness connects her (at least obliquely) to the ancient wisdom espoused by Weil and Grant.

There is, in Arendt, something similar to what was discussed in the last chapter, something which follows the thinking of Shklovsky, and aims at the (specifically political) end sought by Orwell. Arendt seeks "to make the everyday seem anomalous, thereby opening up the present for real thinking if not real political struggles. We have come to talk in clichés... and no one can think in clichés" (Euben 163). This impulse toward thinking must be applauded, even if the ultimate goal in this case (a modern individualistic politics) does not bring us any closer to the Good (as understood in antiquity). In the midst of "crisis, Arendt contends, politics as a particular discourse and practice becomes unavoidable for all. Crisis is not just a synonym for disaster, but names the moment in which we are forced to become political beings" (Norberg 132). The worldlessness experienced under modernity is for Arendt an opportunity, it is the moment when we must become political actors. Crisis compels us to ask questions, to wrestle with what was once taken for granted. This is, for Arendt, precisely the value of the modern crisis of authority. As Norberg observes, "criticism and reflection tend to arise when we 
are knocked off balance" (Norberg 134-5). Crisis compels critique and contemplation of that which has been taken for granted, and yet it also signals a loss and a possible disruption of meaningful communication and shared values. This is the other side of crisis, the disintegration of a common backdrop to human activity, "the erosion of what we have in common or the loss of the very notion of the common" (Norberg 136). Norberg attends the idea of crisis in Arendt's thought, and observes that "crisis can trigger an exercise in political thought, but it also threatens to rob this exercise of its foundation" (Norberg 137). Thus we see two Arendt's, one optimistic about the potential for critique and renewed political discourse, the other carrying reservations about the loss of shared experience. While she is, in one sense, troubled by the condition she calls worldlessness, she is not (like Grant and other conservatives) calling for a reinstatement of traditional authority (read Platonism). Rather, she uses the crisis of authority as an opportunity to challenge common sense understanding and force a taking stock of the present. Norberg puts this in no uncertain terms:

The essay "What is Authority?," is thus not a learned article that lovingly uncovers the past to save it from imminent forgetting but rather an attempt to understand the exhaustion of the tradition and then also to grasp the moment as a possibility for confronting the problem of living together, which is the fundamental problem of politics (Norberg 138).

Continuing, Norberg cautions us that while

Arendt may welcome the decline of authority and its powers of prescription as the emancipation of politics from transcendent sources of absolute rules: in accordance with her vision of the autonomy and integrity of politics, genuine political activity only flares up when dominant social and philosophical authorities have been subverted, but this vision is combined with a historical perspective that identifies the crisis of old authorities as the backdrop to the massive destabilizations of the twentieth century (Norberg 139). 
According to Arendt, the vacuum of authority presents us with the opportunity to reshape society. Rather than a revival of Platonism as advocated by Grant and Weil, for Arendt, judgment is the only response to crisis, and "Judgment is brought into Between Past and Future as a way to reconstitute a human community at the point of dissolution, and to hold together a work about to disintegrate into discrete and contradictory narratives" (Norberg 144). Judgment is important in Arendt's thinking (she borrows from Kant here), but unlike the Stoics (whose right judgments are un-egoistic and seek to move one closer to the whole), Arendt's is an individualistic form of judgment (interested in the human community, rather than the whole). Arendt's judgment refers to a political plurality that comes together in order to collectively shape a "common world" rendered meaningful by this political act.

For Arendt, moderns live without a common world, and are either alienated and alone, or pressed into a solid mass. Rather than counsel a return to a world of traditional authority (a world with an external ground of meaning as called for by Grant and Weil), Arendt looks for an answer to the crisis of authority in politics, in the coming together of individuals, each aware of their role in the constitution of meaning. In such arrangement, Arendt aspires to plurality without relativism, and common ground that is not transcendent.

While not blind to the consequences of the "loss of the groundwork of the world" and the attendant crisis, Arendt is cautiously optimistic that the loss of authority (and by this she is really referring to modernity), "does not entail, at least not necessarily, the loss of the human capacity for building, preserving, and caring for a world that can survive us and remain a place fit to live in for those who come after us" (Between Past and Future 
95). Arendt's language is interesting here. Where Grant and Gadamer would describe flourishing or alignment with the Good in terms of fittedness (that is, a person aligning themselves with the whole in order to better fulfill their role as part of the cosmos), Arendt describes the molding of the world to fit our needs. Hers then is a very modern position, and one which centers Man. Common meaning used to be granted by authority (something external to humanity), but for Arendt, under modernity, it must now be created politically.

Arendt is correct in claiming that in traditional social arrangements the source of authority is always external to the body in question and that it must always transcend the political realm (Between Past and Future 97), but what she neglects to comment on is that problems arise when we think we know (with certainty) the nature of said transcendent authority. An external essence (for my purposes, the idea of an harmonious and benign nature or cosmos) is not the problem. We go astray when we try to know (when we try to will knowledge of, and thus force ourselves upon) rather than orient ourselves toward the Good.

I fall somewhere in between Grant and Arendt. I appreciate Arendt's need to render the familiar strange and thus open it to critique, and yet, I do not follow her progressive impulse and her individualism. Both Grant and Arendt rightly admonish attempts to acclimate us to the desert of the present, but they do so for different reasons. Grant's endurance leads to stillness and openness, while Arendt's leads to action. For her, rather than sustain wonder at the cosmos, we ought to experience wonder at the realm of human affairs. Arendt turns away from the eternal, and toward the plurality of men, or the common world. 
Grant and Weil are right in placing so much emphasis on the Good, for we have truly lost something under modernity. It seems to me that the primary problem is philosophical, rather than political. I am not calling for a return per se, but for a "looking back" to gain perspective. Pure return or revival is impossible and undesirable, but we can look back to antiquity for inspiration and perspective on the present deprival. This is where Grant's conservatism (the idea that we have lost something under modernity, and must look back to antiquity for inspiration) and his critiques of the modern language of freedom and "will to will" representative of the technological society are so refreshing. MacIntyre is one of many thinkers who claim we must look to the past in order to understand the predicament of the present. In order to assess and address the problems of the present (a task which modernity, locked as it is within the confines of the language of willing, is itself ill-equipped to manage), a way of life informed by the ancients and expressed through their concepts is needed. MacIntyre does not call for a return but for a new perspective on the present, and subtly suggests that a kind of jolt is needed, something to shock us into awareness so that the catastrophic consequences of modernity (groundlessness, fragmentation, specialization) are felt. As I've attempted to show, the ancients understood the Good as harmony, and alignment with such harmony demands an openness on our part. While ancient schools of thought certainly did not agree on all matters, there was general consensus regarding the shape of the Good. Not so for moderns. Modernity saw various philosophers wrestling with disagreements and fragmented views, as they tried (and failed) to implement a stable ethical ground based on gaining knowledge and mastery over nature, and thus securing freedom through the 
exercise of will. To put this another way, the ancient Good demands of us submission, while the modern good asserts itself through submitting nature to our wills.

With the invention of the electric light, we effectively veiled the cosmos, and thereby removed the idea of the whole from everyday experience. With the invention of the mechanical clock, we objectified and quantified experience in general, allowing the rhythms of life to be parsed out, divided, and managed. With the disengaged reason that accompanied literate culture and its solidification in the Cartesian moment, we were distanced from the Good. The idea of good became tied to a kind of subjective nonAristotelian happiness (pleasure) to be won by human agency, and the language which grew alongside the technological society came to reflect this view. The good became an infinite number of vessels to be filled by whatever we saw fit, and as an expression of human freedom. The task of the present is to rekindle the Good as understood by the ancients, as harmonia and hen, for the Good "is the One; the Good is Unity" (DesJardins 9). Further, "It is our response to the irresistible attraction of Unity as Wholeness that shapes our fundamentally human activity" (DesJardins 111). Through modern sunderings, we have lost an orientation toward such things. We have lost a permanent backdrop to human activity. MacIntyre calls ours "a time of waiting for new and unpredictable possibilities of renewal. It is also a time for resisting as prudently and courageously and justly and temperately as possible the dominant social, economic, and political order of advanced modernity" (MacIntyre After Virtue xvi). I support this assessment, and following the likes of Heidegger, Grant, and McLuhan, I suggest what is needed is space (resonant interval) in which to reorient ourselves to the pulse of the cosmos, and a willingness to endure the uncertainty that comes from standing in such a 
space. Murdoch, McLuhan, and others, point to the role of art in this endeavour.

Consideration of art (and other spiritual exercises) can estrange us from the present. It can grant awareness, an intimation of deprival of all that has been lost through modern sunderings, and thus encourage us to stand in the interval and orient ourselves toward the Good. 


\section{Chapter 7 - Áskēsis and Uncertainty}

"The only means of strengthening one's intellect is to make up one's mind about nothing - to let the mind be a thoroughfare for all thoughts" (Keats, Letters, Vol II, Sept 241819 , p 121).

While necessarily potted and incomplete, the history of modernity I have attempted to sketch has been one of many sunderings, where despite its numerous advantages, we have lost something vitally human. In chapter three I discussed modernity's drive to certainty and order, and the implications for the self. I would now like to carry this discussion further and ask, is an orientation towards the Good possible under modernity? Further, what might happen if the desperate grasping after certainty emblematic of modernity were calmed, and uncertainty endured? Such is the scope of this chapter. The modern quest for certainty and mastery has resulted in deprivations, or spiritual privations. I have, following McLuhan and others, suggested that art is one means of shocking us into awareness, thus allowing us to feel an "intimation of deprival." Such intimations are necessary if we are to close the fissures opened by modernity. We must first feel that something is missing (even if only indistinctly) before we can assess or respond to the problem.

A number of the thinkers I have engaged with to this point have argued that transcendence requires a measure of openness, or a willingness to endure the uncertainty that is our lot. Heidegger described this as a "standing for," while to Kracauer it meant a stance of waiting. To McLuhan standing for uncertainty meant occupying a place within a "resonant interval" that could be minted by an art of disruption, and to Nietzsche such openness requires a strong constitution. In similar fashion, Simone Weil affirmed a stance of attention rather than the exertion of will. Looking back to antiquity we find an 
ambiguity at work within the thought of Plato, as he does not seek to resolve, but rather to encourage questions, wonder, and thought. His corpus is not aimed at resolution, but rather at provocation. Plato is one who sits in uncertainty, and it is from this position that he asks us to turn toward the Good. Likewise, modern attempts at estrangement seek to push us into unknown territory, for this is the best position to occupy if we wish to avoid complacency, if we wish to force ourselves to evaluate (and re-evaluate) where we stand. This is the act of waiting, of being in a state of hesitant openness. To transcend the self is to move beyond egoism; it is to disassemble and exteriorize the cogito. We must transcend the self, if only briefly, in order to re-orient ourselves toward the Good. Áskesis is necessary if one is to decreate, and the stance of openness, or the acceptance of uncertainty, is only possible if one has engaged in decreation. Modern arts of estrangement, meant to unsettle the commonplace and foreground contradiction also work toward this end; they encourage simultaneous feeling/thinking, an experience tremendously difficult for symbol using beings generally, and made even more difficult by the intensification of the visual which lead to the modern disengaged subject. Unselfing, decreation, openness to the Good; these are ways of describing a state of allat-once-ness, of feeling-thinking, of a commingling of sense and reason, a simultaneity of aesthetic and abstract apprehension whereby the harmony of nature is intuited.

Critique requires estrangement, orientation toward the Good requires openness, and áskēsis leads us into nearness with both conditions. Any attempt at re-orienting ourselves toward the Good must come as the result of áskēsis - not necessarily the specific exercises practiced by the ancients, but exercises which follow a similar logic 
(philosophy as something lived), yet which are attuned to and arise from the conditions of contemporary culture.

I would like to begin with an investigation of the motives behind Descartes' compulsion for certitude, before considering a Romantic response - the ability to "stand for" uncertainty, specifically the Keatsian version of this doctrine called negative capability. Where Descartes' own áskēsis ironically discouraged spiritual practice, Keats conception of negative capability actually demands áskēsis. I will also draw a comparison between negative capability and apatheia in attempt to illustrate that the ancient impetus is with us still. In this Latour was correct - there has never been a clean and total break with the past. While the specifics differ, the structural features and overall logic are strikingly similar, as both demand consistent effort/engagement, both demand áskēsis, and both permit an orientation toward the Good.

To paraphrase Ferry, the central distinction between the cosmological ethics of the ancients and the individualist ethics of the moderns has to do with the form of virtue. In antiquity, a virtuous life was one lived in harmony with nature. To be virtuous was to fulfill one's role in the cosmos. Under modernity this sense of order evaporated, leading to a sense of virtue tied to the individual's ability to move beyond his natural limitations (Ferry 125). In a word, humanity itself became something sacred, which is to say, the location of agency was brought inwards. "For the Ancients, the cosmos is infinitely more significant than its constituent parts... For the Moderns, there is no longer anything sacred about the All, since there is no longer any divinely ordained and harmonious cosmos within which we must find our place. Only the individual counts" (Ferry 126). While not solely the product of one lone thinker, these changes in the perceived location 
of agency and the form of virtue are perhaps most clearly established in the work of Descartes. For Descartes, philosophy was an inadequate discipline, based as it was on "infirm" foundations, a fact demonstrable by the lack of resolution and apparently perpetual disagreement between philosophers. The study of "letters" (what we might now more generally refer to as the humanities), was for Descartes, somewhat of a disappointment, as it lead to no certitude and left him floundering amidst doubt. The study of mathematics on the other hand delighted him, "on account of the certitude and evidence of their reasonings" (Descartes Discourse on Method 7). Based on what he saw as the shortcomings of philosophy, Descartes came to the conclusion that the only thing of which one could be absolutely certain, was that the self existed. "What is there, then, that can be esteemed true? Perhaps this only, that there is absolutely nothing certain" (Descartes Meditations 79). Nothing that is, except the fact that because I doubt, I must exist.

Descartes sought certainty in an age of tremendous uncertainty. In such an age, he could be certain of only one thing: that his individual reason must exist. This has lead Ferry to claim that "the true rupture with antiquity occurred in the seventeenth century, specifically with Descartes" (Ferry 127). Foucault calls this the Cartesian moment, meaning "the event by which "care of the self" (epimēleia heauton) is finally displaced by the imperative to "know oneself" (gnōthi seauton)" (McGushin 178). Following this moment, the truth is no longer to be approached through áskesis, through a concerted ethical-poetic effort, but rather by the disengaged reason of the subject alone. McLuhan expands on this in an astringent critique:

When Descartes surveyed the philosophical scene at the beginning of the seventeenth century, he was appalled at the confusion of tongues and began to 
strive toward a reduction of philosophy to precise mathematical form. This striving for an irrelevant precision served only to exclude from philosophy most of the questions of philosophy; and that great kingdom of philosophy was soon parceled out into the wide range of uncommunicating sciences and specialties we know today (Understanding Media 148-9).

This "irrelevant precision" is another way of describing the move away from a philosophy that is lived, or a philosophy that demands care of the self. Like Descartes, Epictetus writes of the value in achieving certainty, ${ }^{65}$ but the certainty of which the stoic speaks is incompatible with that modern variety sought after by Descartes. Descartes' desire for certainty saw the invention of a new ground of knowledge, namely the self, and established a new relationship between self and self, self and other, and self and nature. Epictetus on the other hand speaks of a certainty which guarantees that the lessons of a philosophical life, lessons learned through constant spiritual labours, lessons so thoroughly practiced as to have been internalized, will leave no room for any sort of spiritual dalliance. In other words, Epictetus is not desperately craving certainty in the wake of a collapse of systems of meaning (cosmos, divinity); his certainty (which might be better described as fortitude or confidence tempered by humility) is more modest, and, like the ancient understanding of progress, more personal, in that it is meant to sustain the philosophical life on the path toward virtue, and the participation in the grand order to which one belongs. And so while the quest is personal, it ends in unity.

Descartes' apprehension is a response to the epistemological problems posed by the new science and the consequences for the individual, society, and life in general. Descartes sought knowledge that was to be "highly useful in life;" or knowledge that would guarantee mastery. Through certain knowledge of all natural processes, Descartes

${ }^{65}$ Epictetus, Discourses: III,2,5 
hoped to render us "the lords and possessors of nature" (Descartes Discourse on Method 46). Such mastery was also to be extended to the human body, offering us control over life and death itself.

Descartes' was a desperate grasping after certitude, and in his philosophy "The uncertainty and unfreedom of the external world is countered by the certainty and freedom of thought as the individual's only remaining power base" (Marcuse Negations 50). The Cartesian moment is one of disquiet, and thus, the modern self was born out of an inability to endure uncertainties, or a desire to overcome doubt and provide thought with a stable foundation, for as Descartes himself claims, his "design was singly to find ground of assurance, and cast aside the loose earth and sand, that I might reach the rock or the clay" (Descartes Discourse on Method 22). And yet, modern subjectivity was also, paradoxically, given life by way of an ancient type áskēsis. This being so, is it possible for the modern self to endure uncertainty, if its very existence is predicated upon an overwhelming desire for certainty?

We must be careful not to view Descartes philosophy too narrowly, and the work of Michel Foucault can aid in broadening our understanding. Edward F. McGushin provides a genealogy of Foucault's overall project, which he in turn describes as a genealogy of philosophical discourse, and as a diagnosis and poetics of the present. Foucault's long term project can be read as a form of áskēsis aimed at transformation, but perhaps most importantly, Foucault's work reveals a "modern philosophical neglect of self" (McGushin 283). Our current philosophical position (or more accurately, our predicament) "begins to take shape at the moment when the ancient philosophical project of care was displaced by the modern scientific project of knowledge; the moment when 
the ancient imperative, take care of yourself, was displaced by the modern imperative, know yourself' (McGushin 282). The Meditations marks this moment, being itself a response to past discourses and forms of subjectivity which Descartes found untenable and pernicious. And while his efforts succeeded in transforming subjectivity and our relation to knowledge, this new episteme, which McGushin calls the sedimentation of past arts of resistance, has generated a new set of challenges. ${ }^{66}$ Descartes encouraged the shift toward modern subjectivity (disengaged reason) ${ }^{67}$, and also participated in the refocusing of philosophy from a practice whereby care lead to knowledge to a doctrine of certain knowledge, and yet, oddly enough, he does this by way of spiritual exercise. Far from being simply an inquiry into the relationship between the subject and truth and the desire for a firm ground and method by which to lay hold on certain knowledge, Descartes' Meditations was also a spiritual act. This is to say, for Foucault, and also for Hadot, Descartes was engaged in áskesis: "Each Meditation is indeed a spiritual exercise - that is, work by oneself and upon oneself which must be finished before one can move to the next stage" (Hadot, What is Ancient Philosophy? 264). ${ }^{68}$

It seems almost anomalous that the Cartesian moment, which impelled the displacement of self care by self knowledge, should itself be the product of an exercise, of a form of care. Foucault implies that "the ascetic aspect of the Meditations is obscured

\footnotetext{
${ }^{66}$ Challenges which have been the subject of this dissertation: the flattening of experience, a culture of many sunderings (body/mind, the senses), philosophy not as lived practice but as dry discipline(s), spiritual malaise...

${ }^{67}$ While I am critical of many of the consequences of this shift, it should be said that the modern subject position also permitted objectivity, the ability to stand back from one's environment, to estrange and thereby gain perspective on the present. In other words, the modern subject position establishes the conditions necessary for its own dissolution.

${ }^{68}$ Foucault and Hadot differ slightly in how they situate the shift from a philosophy that is lived, to one that is theorized (the project of care versus the project of knowledge). While admitting its medieval roots, Foucault locates this moment in Descartes, while Hadot (like Ferry) places it in the Middle Ages. I feel that both are correct, in that Christian theology began to supplant philosophy in the Middle Ages, but the resulting changes were not cemented into the collective consciousness until the Cartesian moment.
} 
by the very tradition it inaugurates" (McGushin 191). In other words, the results of Descartes' exercise are unique, in that they caused a philosophical rupture which "allowed the "knowledge" model to displace spirituality as the structure of philosophical truth" (McGushin 192). It is in this ironic way that Descartes arrives at his position of certain knowledge - through áskēsis, through the practice of meditation.

Elaborating on Foucault's work, McGushin claims that "the Meditations are part of that event by which the subject is detached from spiritual practice as the ground of its access to the truth. As a result of this event, access to the truth no longer requires ascetic self-transformation; rather, it requires employing the proper method of reasoning" (McGushin 192). In short, Descartes' own spiritual exercise de-legitimated spiritual exercises. Descartes' meditations are a practice of self, and yet they inaugurate a subject who no longer needs áskēsis. After Descartes, “one arrives at knowledge by following the proper method of thought, not by living the proper kind of life" (McGushin 193). McGushin makes it clear that this way of being, this ethos (which for us is now commonplace) guided by a desire for certain knowledge and arrived at through rational method, is an historical construct and therefore not inevitable. The naturalization of the "know thyself" dictum over the last few centuries has obscured the spiritual dimensions of Descartes' Meditations. Our historical position as Cartesian subjects has obscured a sufficiently full reading of Descartes' text. Our philosophical tradition has, for Foucault, overemphasized the dictum "know thyself" and in the process relegated the doctrine of "care for the self" (Foucault "Technologies of Self" 226). To appreciate its full complexity, we ought to consider the Meditations in both of its aspects - as a method for securing certainty, and as áskēsis. If we understand Descartes' work not only in terms of 
its consequences, but as áskēsis, might this open the possibility of challenging our own philosophical position, including the many sunderings (namely, the reduction of philosophy to a series of specialized disciplines rather than a way of life patterned on care and transcendence) endemic of modernity? Might recognition of this paradox soften the ground which Descartes sought to make firm (thus revealing his clay to be silty loam)? The potential to soften Descartes' ground justifies my effort to locate modern aesthetic exercises within the ancient tradition of áskēsis. Recognition of this paradox (that modern certainty was won by spiritual exercise) opens a wonderful ambiguity, and encourages a rethinking of the desire for certitude in favour of negative capability.

I would now like to turn toward Keatsian negative capability, as perhaps nowhere else is the stance of uncertainty that I here advocate as the end of áskēsis and beginning of transcendence so admirably expressed. In a letter to his brothers, Keats introduces what he calls "Negative Capability, that is, when man is capable of being in uncertainties, Mysteries, doubts, without any irritable reaching after fact and reason" (Keats Letters vol I 50). Walter Bate suggests that we can paraphrase Keats' famous description of negative capability, of being content with half knowledge, as follows: "In our life of uncertainties, where no one system or formula can explain everything - where even a word is at best, in Bacon's phrase, a "wager of thought" - what is needed is an imaginative openness of mind and heightened receptivity to reality in its full and diverse concreteness" (Bate 56). In Keats and Negative Capability, Li Ou gives perhaps the fullest appraisal of the concept to date, taking it to mean

being able to resist the instinctive clinging to certitude, resolution and closure in the firm belief that great poetry is marked by its allowance for a full-scale human experience that is too copious and diverse to be reduced to a neatly unified or conceptualized system. To be negatively capable is to be open to the actual 
vastness and complexity of experience, and one cannot possess this openness unless one can abandon the comfortable enclosure of doctrinaire knowledge, safely guarding the self's identity, for a more truthful view of the world which is necessarily more disturbing or even agonizing for the self $(\mathrm{Ou} 2)$.

Áskesis is one way of moving towards negative capability. By engaging in spiritual exercises we prepare the self for transcendence, we open the self to openness, we condition ourselves for decreation. Adding to the anatomy of negative capability, $\mathrm{Ou}$ suggests "the idea, with its core of receptive openness, is composed of many other elements: the primacy of feeling and imagination, the mind's ability to contain discordant or even contradictory ideas, and the embrace of experiential life and artistic intensity" (Ou 5). The Romantic tendency to move away from the Cartesian primacy of reason shines through in Keats' concept. ${ }^{69}$

Wordsworth's notion of "wise passiveness" is sometimes compared with Keastsian negative capability, ${ }^{70}$ and while it is a fruitful comparison, the ideas are not interchangeable. In "Expostulation and Reply," a lone thinker sits upon a stone and, through his senses (which cannot be switched off), thinks through perceiving. This thinker (William) is confronted by one who suggests the benefits of exegetical learning, rather than direct thinking-feeling. In his reply, William claims that the mind can be amply fed by a condition which he calls "wise passiveness," or a stillness of sense and reason which allows for a receptivity. While not as bold as negative capability (as wise passiveness does not directly claim to exist in uncertainties and the attendant discomfort), the ideas of openness, stillness of soul, preclusion of desperate grasping after of facts, and conjoining of sense and reason, are still raised in this poem about a dreamer whose wise

\footnotetext{
${ }^{69}$ The existence of the "multiple McLuhan's" observed by John Durham Peters reveals McLuhan as a negatively capable artist-thinker.

${ }^{70}$ See: Garrod, H. W. Keats, 2nd ed. Oxford University P, 1939.
} 
passiveness allows him to intuit the harmony of the cosmos. The preclusion of desperate reaching after fact and reason is - in its logic if not its specific aim - reminiscent of apatheia. Negative capability seeks the same end as wise passiveness, but not through passivity; to be negatively capable is to be engaged.

Philosophy tends no longer to be a thing lived, a practice with spiritual effects. This is, in part, due to the influence of Christianity, an influence which saw philosophy relegated to a dry discipline. Such relegation would continue into modernity, where this discipline would undergo further sundering following Descartes' new ground of knowledge. "[P]hilosophy has become essentially the history of ideas, a purely 'discursive' apprenticeship, contrary to what it had been in ancient Greece” (Ferry 70). Philosophy was denuded; it went from a way of life to an exegetical discipline, and this is precisely what thinkers such as Wordsworth attempt to raise. This is a recurring thread in Ferry's work (a thread he shares with Hadot), and one which I find heartening, as he clearly laments the Apollonian turn philosophy has taken. Philosophy (and any and all scholarship for that matter), should not be practiced in the service of technique. "Everything and anything" writes Ferry, "can become an object of erudition, bottle tops as much as concepts, so that technical specialization produces forms of expertise that are closely allied to the most arid absence of meaning" (Ferry 221).

In his critique of Garrod, who equates negative capability with wise passiveness, Wigod claims that the two ideas are in fact "poles apart," particularly in terms of Wordsworth's egoism, versus Keats' claim that the poet must be without identity. To stand without an identity is to be without a central position, whereas egoism precludes the possibility of transcendence. There are also other minor differences worth noting. 
Wordsworth exhibits an openness to nature, while "Keats is thinking of the world of men and the problems of men, of struggling humanity on a darkling plain, when he speaks of the "uncertainties, mysteries, doubts."' (Wigod 383). Negative capability was for Keats "the maintaining of an open mind, a capacity for change, and an aversion to forming comfortable - but in reality unsatisfying - resolutions and philosophies” (Wigod 384). Far from making up one's mind about nothing, Wigod sees in Wordsworth's notion of receptivity and his anti-exegetical stance one who has indeed made up his mind about everything. The cornerstone of Keatsian negative capability is "objectivity and universality of outlook," and for Wigod, Wordsworth is possessed of a moralizing and didactic egoism which prevents this (Wigod 384). Despite Wordsworth's egoism, his idea is at least animated by a parallel spirit. We oughtn't be too quick to dismiss Wordsworth's wise passiveness, as it looks to unite sense and reason, and at least offers the desire for transcendence through contemplation of nature. To dismiss offhand this idea of wise passiveness would be to close the mind to certain thoroughfares of thought. Negative capability implies a move away from the purely rational faculty of consecutive reason towards "an intense aesthetic experience that embodies the actual human life that is full of "disagreeables"” (Ou 3). In this at least, negative capability and wise passiveness are aligned.

Following Bate, Ou draws a brief comparison between negative capability and Heidegger's notion of Gelassenheit (translated as "releasement"), which "refers to a spirit of availability to what-is (Bate, 1964), on that basis that in our life of uncertainties, in the absence of any ultimate explanation, what is required is an imaginative openness of mind and heightened receptivity to reality in its full and diverse concreteness." (Voller 345). In 
his "Conversation on a Country Path about Thinking," Heidegger sets up a dialogue between a scientist, a teacher, and a scholar, on the question of what it means to think. It is noteworthy that this dialogue occurs outdoors on a country path, and that their most profound insights are realized when night begins to fall. The scientist observes that "without forcing,",71 night "compels concentration" ("Conversation on a Country Path about Thinking" 60). Darkness, that which impedes vision and shrouds the known demands attentiveness. The scholar then remarks that night (impediment, the unknown) also slows their pace and thus grants time for meditation. The very setting of this dialogue is a metaphor for that which is uncertain and beyond the din of civilization, and the staging provides an example of slow and careful thought prompted by such impediment. Philosophy is here being lived.

One must be "awake for releasement," which is to say, one must be aware in order to release the will. Gelassenheit amounts to a letting-in of releasement, or, an openness to not-willing which we might describe as transcendence of self. To let-in releasement is to allow for transcendence of self, but this letting-in is not, as the scientist tells us, "a matter of weakly allowing things to slide and drift along." ("Conversation on a Country Path about Thinking" 61). And yet, as the scholar makes clear, "what we have called releasement evidently does not mean casting off sinful selfishness and letting selfwill go in favor of the divine will" ("Conversation on a Country Path about Thinking" 62). Gelassenheit involves more than a simple substitution; it is not itself transcendence, but rather the openness which allows for the possibility of transcendence. This openness requires a strong constitution, and a deliberateness. As Ou reminds us, negative capability

${ }^{71}$ As the teacher tells us, representation attempts to force objective truth (83). 
is also typified by "the deliberate refusal of resolution, the inclusion of both sides of the opposition and the exploration of their paradoxical interdependence and irreconcilable conflict" (Ou 108). Belitt explains that Keats did not advance a program of surrender, rather, his negations demonstrate epistemological engagement. Keats' project involved "multiplying doubts to enhance, rather than dispel, 'mystery,' in an ongoing dynamics of uncertainty--to all of which he gave the misleading name of "Negative Capability." (Belitt 165). It is those "who insist on the shortest distance between two lexical points; terminal answers to probabilities and uncertainties, conclusive returns; whose stance is pugnacious, acquisitive, categorical, and demand an end to possibility in the name of "knowledge"' that Keats repudiates (Belitt 164). This is yet one more way that negative capability is similar to apatheia (in its form at any rate); apatheia was not a retreat, but was rather the conscious end of a process of care. Through numerous exercises, one worked to form right judgments, which would ensure that pathé were never permitted to "lead one like a puppet." Negative capability is not a passive retreat from knowledge, but an acceptance of uncertainty hard won by exercises meant to annul the ego.

As Heidegger's dialogue proceeds, all certain ground seems to be slipping away, a fact which troubles the scientist (who knows less and less what they are talking about) more so than the others. As was the case for Kracauer's open individual, the teacher in this dialogue suggests that their response should be "to do nothing but wait" (62). This stance of waiting, of openness to possibility, can also be thought of in terms of acceptance of uncertainty. Consider the scholar, who, in gradually unraveling his thought, says, "if I understand correctly, we are to view what we call releasement in connection with the nature of thinking as talked about, even though we hardly know it and above all 
are unable to place it properly" (63). Certain knowledge is illusory, and in order to avoid stifling receptivity, we must maintain openness.

Nothing can be known with certainty. Language falls short. Re-presentation is always a stab in the dark. This fact troubles the scientist, who makes efforts to represent the ideas being discussed in stable terms. And of course, Heidegger uses language which demands re-reading and which resists stable understanding, if by understand we mean to represent a thing in stable terms. Heidegger foregrounds and yet sidesteps the problem of language and representation by (as the scholar puts it) moving "freely in the realm of words" (“Conversation on a Country Path about Thinking” 69). Openness, or waiting, can lead to releasement, but the teacher makes a careful distinction between waiting and awaiting. Waiting implies pure openness, while awaiting implies an object after which one waits. One can wait in general (waiting "has no object"), but if one awaits, one must await something (some re-presentation, and by re-presentation, Heidegger just means a stable "known" idea - which is of course illusory). We wait for something, though we know not what, and in such objectless waiting, we allow space for releasement. The teacher suggests that "In waiting we leave open what we are waiting for" ("Conversation on a Country Path about Thinking" 68). To wait is to be open, as waiting entails no representation, only space. Waiting marks an emptiness, but an emptiness rich in contingencies (“Conversation on a Country Path about Thinking” 82).

The Greek word A $\gamma \chi ß \alpha \sigma i ́ \eta$ (roughly translated as "going toward") is used to describe scientific knowledge (the basis of modern progress), and the scientist admits that "scientific research is a kind of attack on nature" ("Conversation on a Country Path about Thinking" 88). Further, "going toward" is almost the opposite of waiting; and yet, when 
translated literally as "going near," it seems to the teacher to suggest a "moving-intonearness," which fits much better with the idea of waiting. In exposing this mistranslation, the teacher reveals scientific progress (and its consequences) to be the result of a misreading (of nature, and of what it means to think). So to "move-intonearness" is clearly preferable than "going toward." To go toward implies an endpoint in the future, while to move-into-nearness suggests an experience of oneness with that which surrounds. Perhaps in "going toward" for the past several centuries, we've misdirected progress? Perhaps progress ought to involve waiting and moving-intonearness? The nighttime walk along the country path which allowed both the time and the impediment necessary for the dialogue is then itself described as a "moving-intonearness," and what they move into nearness with seems to be the cosmos. As the trio conclude their walk and once again near civilization, their conversation winds down, and it is only at this point that their attention lands once again on their surroundings. On this country lane night surrounds them; it impedes, it brings them nearer to the stars, it prompts wonder, and wondering and waiting allow the possibility of transcendence.

Like the bird in Keats" "Ode to a Nightingale," which, as Voller reminds us, only sings in the stillness and silence of night, here, the trio are only able to approach oneness, only able to properly meditate on thinking and releasment, while impeded by darkness. Likewise, there is a kind of 'watchfulness' "against certitude and closure" at work in Keats' poetry (Ou 108), particularly in “Ode to a Nightingale." This poem sees Keats "unself" and become as one (if only briefly) with nature. B. I. Evans suggests that there is an implied egoism in Keats' earliest work, but then admits that this egoism broadens "out into a genuine social sense" (Evans 57). Evans points to the fact (albeit in a restrained 
fashion) that Keats was working towards transcendence of the self, a fact corroborated by Ou, who points to Keats' "non-egotistical nature" (Ou 188). "[N]egating one's own ego" is of critical importance to the negatively capable (Bate 56). This negation of ego is precisely what Weil and Murdoch advocate; it amounts to an act of decreation, or a transcendence of the Cartesian self. Bate describes an "openness to amplitude" in the work of Keats (Bate 55), and goes on to claim that "To be dissatisfied with such insights as one may attain through this openness, to reject them unless they can be wrenched into a part of a systematic structure of one's own making, is an egoistic assertion of one's own identity" (Bate 57). An inability, or unwillingness to endure uncertainty can also be read as a positing of the self above the whole, or an understanding of self as mind that is distinct and separate from the external and objective world. Keats' openness to amplitude, his negative capability, calls for self care and a "moving-into-nearness with," rather than an ego that imposes itself on nature.

Echoing T.S. Eliot, Bate claims that "Greatness in art, philosophy, moral action the 'heroic' in any sense - involves losing the sense of 'our personal identity in some object dearer to us than ourselves"' (Bate 65). Negative capability then demands a divestment of ego, and the fostering of a connection with the whole. It "emphasizes a full expression of experience rather than a 'consequitive' resolution, and the transfiguration of the self into a vaster otherness instead of self-expressiveness" (Ou 186). Rather than self(ish) expression, negative capability demands self-transcendence, or "opening the self to the multifarious otherness of the world and human beings" (Ou 8). Elsewhere, Bate provides a concise explanation of negative capability as it applies to transcendence of self: "the ability to negate or lose one's identity in something larger than oneself - a 
sympathetic openness to the concrete reality without, an imaginative identification, a relishing and understanding of it" (from Walter J. Bate's Criticism: The Major Texts, qtd. in $\mathrm{Ou}$ 16).

In order to transcend the self, we must first care for the self. It takes a self well cared for to move beyond the self and experience unity. Thus, the stance of negative capability must be the result of a long process of áskēsis. And far from being a static position, negative capability is both aim and continuous process, involving a constant "ripening, the very openness within itself nourishing its constant growth" (Ou 4). Ou sees negative capability as "an organic conception that is itself growing all the time" (Ou 13). In this way is it a process, and the very antithesis of dogmatism. Negative capability is like apatheia in that it is an open project with no end.

In this light, poetry can be read as spiritual exercise, as its end is sometimes described in terms of transcendence. In Eliot's "Tradition and the Individual Talent" poetry is seen as an escape from personality, which Eliot calls "depersonalization." Eliot insists that the poet must develop consciousness of the past, and in so doing, "What happens [to the artist] is a continual surrender of himself as he is at the moment to something which is more valuable. The progress of an artist is continual self-sacrifice, a continual extinction of personality" (Eliot "Tradition and the Individual Talent" 26). For Eliot, and for Keats, art is not about self expression, but self transcendence and being in the moment (or being privy to a fleeting sensation of eternity). Ou traces the legacy of negative capability through the idea of impersonality expounded by Eliot, and goes so far as to suggest that something comparable to negative capability (though not directly borrowed from Keats) lies at the very heart of Eliot's The Waste Land. And while this 
may be, it seems to me that Keats' idea is itself an expression of a more ancient type of acceptance. As Ou admits, the idea, while honed in on and nobly expressed by Romantic poets, is not unique to these poets, but is part of a larger tradition. Though described differently, this concept is also found in ancient Greek philosophy, Christianity, Hinduism, Buddhism, and Taoism, which leads Ou to claim that negative capability is "part of our oldest heritage" (Ou 182). This realization is what I am attempting to foreground with my comparison between negative capability and apatheia - though separated by culture, location, and era, they are part of a common human project which works to orient us toward the Good and allow a marriage of sense and reason.

While the acceptance of uncertainty is part of our cultural heritage, this inheritance is often forgotten. The Cartesian impulsion to know and thereby gain mastery over nature established a precedent which would last for several centuries. Modern culture is still, on the whole, technocratic. As Elder passionately argues in his polemic on cinema:

in technocracy nothing can be left uncontrolled, for technocracy is the will to mastery. Narrative is the artistic structure of technocracy. The cinema we need, the cinema that combats technocracy, will, therefore, be non-narrative. It will not be animated by a rage for order - and order's concomitant, concealment. It will accept that every discovery involves dissimulation. It will accept error and lingering mystery, for its maker's negative capability will afford him the strength to accept what Keats terms the "Penetraium of Mystery" (Elder "The Cinema We Need" 265).

Here, avant-garde cinema (both making and viewing) is a kind of áskēsis, a way of combating the drive to order, a way of allowing complexity to daunt us, rather than concealing complexity through narrative. Negative capability involves opening oneself to the world as it is, without imposing a governing conceptual system. To view the world in terms of cause and effect is far too limiting and simple (as we are doubtless only aware of 
a fraction of the causes and their relation to their effects). Elder makes this clear in his observations on our perception of temporal processes: "it is not true to say that one thing follows another. It is only true to say that many things follow many" (Elder "The Cinema We Need" 271). Such thinking distances itself from a linear narrative understanding of time (which though neat, tidy, comfortable, and readily graspable, is tremendously limiting) and moves into concord with a more ancient understanding of time as cosmic sympathy. Although timelines may be represented in various ways and with varying degrees of complexity, ${ }^{72}$ they follow from the same basic assumption, that cause A leads to event $\mathrm{B}$. Such is also how narrative and ideologies function:

Given our present cultural imperatives, narratives pose a problem because they misrepresent experience. Narrative misrepresents because, in order to organize the past into comprehensible structures, it eliminates unmanageable ambiguities and the painful contradictions inherent in experience. Only in fictions can we be certain of anything. Narrative explains how events lead up to the final event in order to clarify the past but the notion of causality on which narrative is based is all too simple and serves only to cover over mysteries (Elder "The Cinema We Need" 264-5).

Edward T. Hall notes something similar in recent scholarship, following as it does a narrative format, which works to impose the illusion of certainty. Hall is interested in integrating seemingly disparate viewpoints and theories, and as such, provides a tangible example of negative capability. Drawing on the personal account of noted physiologist and Nobel laureate Albert Szent-Györgyi ${ }^{73}$ Hall discusses two modes of thought: the Apollonian and Dionysian. Szent-Györgyi describes the difficulty he had securing research grants, and attributes this difficulty to his Dionysian thought process. The Apollonian thinker is able to clearly envision his project from beginning to end, whereas

\footnotetext{
${ }^{72}$ See for example, Rosenberg and Grafton's excellent book, Cartographies of Time: A History of the Timeline.

${ }^{73}$ Set out in Szent-Györgyi’s essay on “Apollonian and Dionysian” research styles.
} 
the Dionysian thinker has only a vague intimation of his research trajectory. Perhaps understandably (though mistakenly), the agencies responsible for awarding grants tend to favour the Apollonian approach, and as such, Szent-Györgyi only succeeded in securing grants when he concocted spurious projects. Of these two approaches, Szent-Györgyi writes:

sitting in an easy chair I can cook up anytime a project which must seem quite attractive, clear, and logical. But if I go out into nature, into the unknown, to the fringes of knowledge, everything seems mixed up and contradictory, illogical and incoherent. This is what research does; it smoothes out contradiction, makes things simple, logical, and coherent. So when I bring reality into my projects, they seem hazy and rejected (Szent-Györgyi, qtd in Hall 125).

The universe is imponderably vast, and so while attempts at reducing contradiction and imposing limits may allow us (as set out in Descartes' method) to view constituent parts, they also neglect a sense of the whole, as well as stifle imaginative potential. Hall finds in Szent-Györgyi one who sees through "the fallacy of the usual, Apollonian procedures," and calls for us to embrace both methods (Hall 125), reminding us that "The essence of living substance is uncertainty" (Hall 126). In allying ourselves solely with Apollonian methodology, we smooth over contradiction, and impose a readily graspable order atop the unknown. ${ }^{74}$

Citing the likes of Werner Heisenberg and Niels Bohr, Ben Belitt links Keatsian negative capability with the uncertainty apparent in the world of quantum mechanics. Richard Feynman, in his lecture "Probability and Uncertainty," begins by encouraging the audience to be open, to refrain from incredulously exclaiming, "how can it be like that?" The quantum world defies everything we've experienced, and so in order to make

\footnotetext{
${ }^{74}$ Although he does not fully reach the condition of negative capability, Richard Feynman cautions against the imposition of "pompous preconditions," (of the Apollonian type described by Hall) and claims that we "should not be sure ahead of time about what must be."
} 
some sense of it, we must not grasp after certitude. We must accept that the quantum universe is "screwy" to use Feynman's term. Openness is critical here. Quantum mechanics asks us to consider the "paradoxes, and mysteries, and peculiarities of nature" (Feynman). In a sense then, the study of elementary particles asks the scientist to consider the world from the perspective of the poet, as within each subatomic particle is contained the vastness and mystery of nature, just as for the poet, within each moment, each object, each gesture, we may catch a fleeting glimpse of eternity.

Quantum mechanics also informed McLuhan's notion of the resonant interval. In an interview with Fr. Patrick Peyton (on the television show "Family Theater" c.1970's) McLuhan describes the resonant interval in terms of chemistry, and immediately (in the same breath) equates chemistry with quantum mechanics. The resonant interval suggests that there are no connections between matter as previously understood. Instead, there are vast spaces between particles, spaces bound together by energy. McLuhan offers what we might now consider an older reading of quantum mechanics (popular in the field's early days), where it is associated with the breakup, or complete dematerialization of matter. McLuhan's use of the term fits with the popular reading of his day - atoms were thought to be pure space. ${ }^{75}$ This metaphor of disembodiment, of dissolution of matter, is what McLuhan is after. While he does at times describe the interval in terms of chemistry, this calls to mind glowing liquids and beakers, and this is not the image McLuhan wished to cultivate. At the level of elementary particles, there is actually more space than matter. In this sense, there are no physical connections, but there is a resonating interval between

\footnotetext{
${ }^{75}$ This also fits with McLuhan's talk of "Angelization" or "discarnate being," of not merely sending messages through the phone line, but sending one's CNS as disembodied energy through the ether.
} 
and among particles, and this interval of resonance that surrounds and binds matter is the source of McLuhan's metaphor.

I would now like to turn to modern literary examples which explore and celebrate the idea of uncertainty. I turn to recent literary examples to highlight the prevalence of these ideas and the variety of ways in which they have been expressed. Following Ou's claim, I would like to emphasize the fact that while often overlooked, negative capability is part of our cultural heritage.

John Ralston Saul critiques the modern "slavish devotion to the rational certitude that there are absolute answers to all questions and problems" (237), as such rational certitude closes off the space necessary for an encounter with the order of the cosmos. In Melville's Moby Dick, Captain Ahab is ensnared by a similar devotion, and his constitution bears a striking resemblance to that of Descartes, as both are frustrated by their desire (and inability) to gain mastery over nature. Consider one of Ahab's rants on Moby Dick:

He tasks me; he heaps me; I see in him outrageous strength, with an inscrutable malice sinewing it. That inscrutable thing is chiefly what I hate; and be the white whale agent, or be the white whale principal, I will wreak that hate upon him. Talk not to me of blasphemy, man; I'd strike the sun if it insulted me (Melville 181).

Ahab is a modern subject bent on conquering the inscrutable cosmos. It maddens him, and ultimately destroys him, but not before he is able to reflect on all that he has foregone:

Forty years of continual whaling! Forty years of privation, and peril, and stormtime! Forty years on the pitiless sea! For forty years has Ahab forsaken the peaceful land, for forty years to make war on the horrors of the deep! ... When I think of this life I have led; the desolation of solitude it has been; the masoned, walled-town of a Captain's exclusiveness, which admits but small entrance to any sympathy from the green country without - oh, weariness! heaviness! ... when I 
think of all this; only half-suspected, not so keenly known to me before - and how for forty years I have fed upon dry salted fare - fit emblem of the dry nourishment of my soul! ... what a forty years' fool - fool - old fool, has old Ahab been! (Melville 596-97).

Ahab is unable to stand for uncertainty, and this inability leads to the squandering of forty years of his life, the loss of his leg and unbalancing of his character (the loss of his leg being a warning he chose to ignore), the loss of his sanity, the loss of his ship and all hands save one. His is a life not lived. The obsessive (and impossible) task of asserting the ego to master the cosmos has withered his soul. Ahab's fate is tragic, and relatable to us moderns. In positing the ego against the cosmos, in vying for final knowledge and control, he has effectively cordoned himself off from others and the world.

Ferry comments on the process by which, "Scientific progress became merged with the progressive eradication of the mystery that, in the Middle Ages, was believed to be part and parcel of nature" (Ferry 209). Just such a process is elaborated by Melville in Moby Dick, and

if nature is no longer mysterious or sacred but on the contrary can be reduced to an inventory of merely physical phenomena entirely devoid of meaning or value, then there is [it is sometimes thought] nothing to prevent us from harnessing nature in whichever way seems appropriate for our ends (Ferry 209).

In this light, we might consider Ahab a caricature of Descartes central precepts. Ahab hates Moby Dick because of what he represents - the unknown, the vastness of the cosmos. This is why the white whale must die, for as the cetacean taxonomy reveals, only the lifeless can be known. Classification amounts to dissection. To know a thing completely demands that we place it in stasis; we can only arrive at a solid definition through autopsy. 
The need to classify and take inventories of all things is taken up by Melville, and is presented most explicitly in the chapter "Cetology." The subject matter of this chapter is nothing less than the "classification of the constituents of a chaos" (Melville 144). Here is an attempt to bring order to a seeming chaos, to bracket the cosmos within limits comprehensible to us, to take an inventory of all parts, and write a stable narrative. The sperm whale, the deepest diving and most enigmatic of the cetacea, is an apt metaphor for the vastness of the cosmos. Melville borrows the opinions of contemporary experts in the field of cetology in order to confront us with our lack of understanding. He describes one expert's account of our "Unfitness to pursue our research in the unfathomable waters," and another expert's claim regarding the "Impenetrable veil covering our knowledge of the cetacea" (Melville 144). The aforementioned naturalists find such incomplete knowledge "torturous." Given the lack of knowledge, Ishmael offers his own brief classification but with the qualification that he makes no promise as to the completion and finality of his definition, as "any human thing supposed to be complete, must for that very reason infallibly be faulty" (Melville 146). Human knowledge is ever incomplete. That is perhaps its chief characteristic. According to Camile Paglia's reading, "MobyDick aspires to epistemology, organizing the known, if only to dramatize what cannot be known" (Paglia 584). While Paglia is primarily interested in the consequences this poses for gender in Moby Dick, her observation also highlights a much broader problem of knowledge. Melville's whale (and the obsessive need to categorize and inventorize - a feat which amounts to a symbolic dissection) represents an epistemological problem, a problem concerning the limits and accessibility of knowledge, and the fear that 
accompanies the realization of these limits. The whale is that which we seek, but can never capture.

Stan Fögel (with a nod to Roland Barthes) notes, the act of defining tends to truncate that which is being defined in the very act of attempting to incorporate it (Fögel 143). ${ }^{76}$ Defining is often a violent act, and one bent on mastery. A place of ambiguity or diminutive confusion foregoes attempts at mastery, and is instead content with communion. Further, as soon as one defines a thing, it is relegated to irrelevance and no longer demands contemplation. Definition, in this light, is akin to dissection, which nothing can survive. In order to know a thing, firmly, with certainty, we must tear it asunder, reducing it to its constituent parts.

The desperate reaching after fact and reason is ever present in Moby Dick. The incessant compulsion to classify parallels Ahab's drive to impose his will upon and thus conquer nature, an ambition that is ultimately shrugged off, and that leads to his demise. Some of the more superstitious sailors exercised "the unearthly conceit that Moby Dick was ubiquitous" (Melville 199). And if we read Moby Dick as a representation of the vastness of the cosmos, then he is indeed ubiquitous. In the chapter "Whiteness of the Whale," Melville describes the depths of mystery and awe (Burkean awe, sublime terror at the magnitude of nature) for which Moby Dick stands:

Is it that by its indefiniteness it shadows forth the heartless voids and immensities of the universe, and thus stabs us from behind with the thought of annihilation, when beholding the white depths of the milky way? Or is it, that as in essence whiteness is not so much a color as the visible absence of color, and at the same time the concrete of all colors; is it for these reasons that there is such a dumb blankness, full of meaning, in a wide landscape of snows - a colorless, all-color of atheism from which we shrink? ... of all these things the Albino whale was the symbol (Melville 216-17).

\footnotetext{
${ }^{76}$ Fögel is specifically engaged in highlighting the perversity that accompanies attempts at defining postmodernity, but his observation is applicable more generally and in the present context.
} 
Moby Dick reads as a rumination on the unfeasibility of the modern project (read as certitude and mastery), and stands as a challenge to modern hubris. The white whale is likened to many amorphous things that modern knowledge seeks to disenchant: death, ghosts, God, Angels, exotic animals at the ends of the earth, etc. All are unknown (we might say borderline mythic, or operating outside the boundaries of linear time), and beyond the scope of modern knowledge. As such, they are frightening, and pose a threat to the modern conviction that we can know and govern all. It is here that the colour of the whale becomes significant. These things to which the whale is likened are ethereal, which, as Wittgenstein remarks, is also true of colour. Any consideration of colour must speak to its subtler qualities (translucence, opaqueness, etc.), and for Wittgenstein, white is an opaque colour. We cannot see into it, or past it, or through it. It baffles and rejects all attempts at intuiting. From the perspective of physics whiteness is an ultimate conflation of everything (all colours). Whiteness is the simultaneous rendering of the entire spectrum of colour, and in this way we may think of it as a blinding overabundance of information. The whiteness of the whale represents at the same time infinity and void, absolute presence and absence, life and mortality, the ungraspable and awe inspiring vastness of the cosmos and our smallness and finitude in relation to it. To look into the whiteness and do nothing is to stand for uncertainty; to assault the whiteness with the aim of mastery is to assert the ego, and (to ultimately) forfeit life.

Ahab desperately seeks control, and Melville makes us aware of the monumental impossibility of such a task. Attempts at claiming firm knowledge by conquering the unfathomable forces of nature represent a desire to overcome (rather than stand for) uncertainty. Moby Dick foregrounds the desperate compulsion to inventorize the natural 
world in an attempt to know it and thereby become its master. Such irritable grasping after fact and reason may be comforting for a time, but is in the end futile. Ahab attempts such grasping, and is overcome by his compulsion for certain knowledge. The task before us is not to assert the ego and know with certainty, but to stand for uncertainty and orient ourselves toward the cosmos rather than aspire to mastery.

While a Cartesian desire for certainty fuels Ahab's rage in Moby Dick, uncertainty is the driving revolutionary force in Yevgeny Zamyatin's dystopian novel $W e$, a fact underscored by virtually every aspect of the novel, from the plot and character descriptions, to the very punctuation itself. ${ }^{77}$

The protagonist, called D-503, staunchly defends the merits of reason and systems that delimit and attempt to control nature, almost, it seems, in an effort to sustain his faith in reason. In an early encomium of certitude and limits, D-503 exclaims, "Oh, great, divinely bounding wisdom of walls and barriers! They are, perhaps, the greatest of man's inventions. Man ceased to be a wild animal only when he built the first wall. Man ceased to be a savage only when we had built the Green Wall, when we had isolated our perfect mechanical world from the irrational, hideous world of trees, birds, animals..." (93). Initially then, for D-503, to be human is to aspire to certitude and to construct stable narratives. As the novel progresses and his infatuation with I-330 (and all that she represents) grows, he begins to doubt his defense of reason. In $W e$, the desire to place

\footnotetext{
${ }^{77}$ Set in a Taylorist future, individuals in $W e$ are assigned numbers rather than names, and occupy a society where the motions of life are rigidly regimented and scheduled, and where all activities are, quite literally, completely transparent, as all walls are of glass. The protagonist, the rather soft and pliant D-503, is torn between his lifelong acceptance of the uncluttered rational order imposed by the One State, and the allure of mystery inspired by his love interest, the sharp featured and revolutionary I-330. Eventually, in an effort to forever banish uncertainty, the One State lobotomizes its citizens in an effort to eradicate all imagination. And while such background is necessary, rather than focus on the social and political response to problems of knowledge, I would like to dwell on We's central epistemological questions themselves.
} 
limits on life, thought, imagination, and emotion, is the result of a deep resounding fear of the unknown.

This sense of the unknown, of the unpredictability of life, of the interconnectedness and ultimate incomprehensibility of the cosmos in its entirety (and our inability to control it), in other words, the state of being in uncertainties, is described by D-503 as the irrational root (the maddening equation that cannot be solved). D-503 calls it frightening, claiming the idea devours him as it cannot be comprehended. For D503, "it is unnatural for a thinking, seeing being to live amidst irregulars, unknowns, X's... As if you were blindfolded and forced to walk, feeling your way, stumbling, and knowing that somewhere - just near-by, is the edge" (176-7). I-330, the manifestation of uncertainty, the algebraic unknown "X," critiques the vainglorious quest for control and certainty. Infinity cannot be understood precisely because it is infinite and we are not. In a pivotal passage, I-330 asks D-503 to name the final number, and of course he cannot (an impossible task). Elsewhere, another character, R-13, confronts D-503's idea of “knowledge! This knowledge of yours is only cowardice. Don't argue, it's true. You're simply trying to enclose infinity behind a wall, and you are terrified to glance outside the wall" (40-1). Circumscription and control of the unknown is crucial for D-503, who sums up the modern epistemological position quite nicely: "The function of man's highest faculty, his reason, consists precisely of the continuous limitation of infinity, the breaking up of infinity into convenient, easily digestible portions - differentials" (65). This is of course what the cetacea taxonomies in Moby Dick attempt.

Just prior to the surgical excision of his imagination and the renewal of his "faith" in certainty (his return to dogmatism), D-503 approaches a moment of clarity, and by this 
I mean he approaches a state of negative capability. He has learned too much to be certain of anything any longer. It is at this point (of diminutive confusion) that he teeters on the brink of a Socratic understanding - awareness that he does not know much. D-503 does approach a stance of negative capability, however the strain is too great and his imagination (a vital component in Keats' philosophy) is excised. In the end, the novel argues against the irritable reaching after of fact and reason so condemned by Keats. To circumscribe infinity (represented in this case by the surgical excision of the imagination) is to limit something vitally human.

The punctuation (particularly ellipses) in $W e$ also works to emphasize the importance of uncertainty. Ellipses leave thoughts open. They leave room for choices, interpretations, and infinity... "I was about to put the final period to these notes, just as the ancients put crosses over the pits where they had thrown their dead" (230). For Zamyatin a full stop indicates a dead or exhausted idea, one with no room to grow. A full stop closes thought by resolving it fully. Ellipses on the other hand trail off; they allow (and demand) ‘what ifs?’ Ellipses reject resolution and signal an openness... D-503 uses ellipses when he is on the verge of some revelation, some epiphany, or when he is wrestling with a deep or troubling thought, a thought which remains forever elusive. The frequent ellipses can be thought of as a punctuational incarnation of Kracauer's hesitant openness, in that they allow a space for Being. Punctuation suggests that uncertainty is exceedingly troubling for the protagonist, as we see in his discussion of the "question hook," his term for the "squirming, torturing, nagging question mark" (207). Punctuation also reveals something of D-503's reckoning of knowledge and Being: "Not to mention the fact that all unknowns are organically inimical to man, and homo sapiens is human in 
the full sense of the word only when his grammar is entirely free of question marks, when it has nothing but exclamation points, periods, and commas" $(118-19){ }^{78}$ The claim that Man is only fully Man when he ceases to question is antithetical to the current of western philosophy. From Plato, to the Stoics, to the Romantic poets, to modern philosophers like Arendt, humans are humans precisely because they are question asking beings.

Philosophy itself begins with questions, its starting point is awe:

It is from the actual experience of not-knowing, in which one of the basic aspects of the human condition on earth reveals itself, that the ultimate questions arise not from the rationalized, demonstrable fact that there are things man does not know, which believers in progress hope to see fully amended one day, or which positivists may discard as irrelevant. In asking the ultimate, unanswerable questions, man establishes himself as a question-asking being (Arendt The Promise of Politics 34).

Both Moby Dick and We subject the modern desire to know and impose limits on infinity to scrutiny, and demonstrate such attempts at knowing with certainty demand objectification and destruction, and are in the end, unattainable.

In his challenge to the modern quest for certitude, Zamyatin alludes to Notes

from Underground, when he has D-503 claim "There is only one truth, and only one true way; this truth is two times two, and the true way - four" (67). But for Dostoevsky's underground man, such a truth can only end in death:

perhaps the only goal toward which mankind is striving on earth consists of nothing but the continuity of the process of achieving - in other words, of life itself, and not the goal proper, which, naturally, must be nothing but two times two is four - in other words, a formula; and two times two, gentlemen, is no longer life, but the beginning of death (Dostoevsky 33).

Dostoevsky sees a paradox in the modern quest for certain knowledge. Despite creating increasingly elaborate blueprints, edifices, systems of classification, and narratives to shore up meaning, certain knowledge would severely limit something fundamentally

\footnotetext{
${ }^{78}$ An ironic and desperate comment, as D-503's writing makes copious and unrestrained use of ellipses.
} 
human. The underground man continues: "After two times two, there would be nothing left, not only to do, but even to learn. The only thing possible then would be to stop up your five senses and submerge yourself in contemplation" (Dostoevsky 34). There is no point to life if everything is (as Descartes wished) known with certainty, or if everything is reduced to a formula, as this would effectively eradicate the aesthetic dimension, and with it, any chance of uniting sense and reason and touching the Good. Dostoevsky's narrator appreciates the value of uncertainty, and yet seems tortured by it. This is, as Ferry reminds us, Man's philosophical condition in the world, and what the underground man is standing for is nothing less than this condition, an awareness of the fact that we are both apart from and a part of nature. For Dostoevsky, "suffering is the sole root of consciousness" (Dostoevsky 34). Suffering here refers to an acute awareness of the structural contradictions of existence, of the painful encounter with uncertainty.

The narrator is riddled with self doubt by the "conscious intelligence" won through reason; hence his need to wrestle and play with paradox and the contradictions and inconsistencies of existence. And despite the pain this causes, despite the uncertainty, he wouldn't have it any other way. This is the condition of the underground man, the man of "conscious intelligence," as opposed to the average man or the man of action, the man who simply responds to a stimulus, the short-circuit type who reacts without thinking. And while dissatisfied with easy answers and consequently unhinged, he tells us quite plainly, "Though I have said that I envy the normal man to the point of the bitterest gall, yet, under the conditions in which I see him, I do not want to be one (Though, all the same, I shall not cease to envy him)" (37). The normal man is not compelled to wrestle with paradox, he does not stand for uncertainty, and therefore, his life must seem stable, 
well-ordered, and built on a ground of clay or stone. And while such comfort and such obliviousness is by far the easier way to live, it narrows and barricades the thoroughfare of thought.

"[T]he best thing," writes the underground man, "is to do nothing!" (Dostoevsky 37). This is not to advocate a course of enervated renunciation. When he writes of nothing, Dostoevsky is asking us to avoid getting involved in the construction of "absolute" edifices, in the building of classification systems meant to offer certain knowledge. Here, very much as in the work of Kracauer and Heidegger, "Nothing" does not imply total absence, but rather, demands engagement with the paradoxes and uncertainties of existence. "Nothing" does not suggest turning away from the suffering which attends consciousness. This "nothing” is, like negative capability and like Stoic apatheia, something active, and something which requires engagement. To do "nothing" is to stand for uncertainty, and what better word to use than nothing - a term which is ultimately impossible to represent or visualize, a term (along with its antithesis, infinity) which defies any solid understanding, and as such, a term which precludes the possibility of resolved thought. To do nothing is to stand for openness, or to wait. The decision to do nothing, to refrain from reaction, to wait, or to stand for, comes not from a skittishness or numbness wrought by modern sundering, but from consciousness of the complexity of the universe and an awareness of the artificial shape of our technocratic narratives. I mention these literary examples to underscore the fact that resistance to the modern desire for certitude has a history, and is ongoing. There is a tradition, as Ou claims, which exhorts a standing for of uncertainty, and in this tradition various modern thinkers take hold of threads spun in antiquity, weaving them into modern aesthetic forms. 
As Berman notes in his analysis of such eminent thinkers as Marx, Nietzsche, Dostoevsky, and Baudelaire, modernity, at its best, offers an awareness of the contradictory nature of our existence, as seen in the exhilaration and enthusiasm which existed along side of the alarm and reservation within the corpus of their works. Rather than embrace this uncertainty, rather than maintain tension and expand the horizon of potentialities, the trajectory of modern culture attempts to limit infinity, to punctuate the cosmos with full stops, and thus exclude uncomfortable uncertainties. While seeking to overcome the "enchanted" world of antiquity, modernity, fixated on certainty, establishes its own variety of dogmatism.

The scientist in Heidegger's dialogue comes to understand something of the historical character of the ego, and the fact that sundering, instrumentality, and objectification are inherent in modern subjectivity: "The program of mathematics and the experiment are grounded in the relation of man as ego to the thing as object" (Heidegger "Conversation on a Country Path about Thinking" 79). Self transcendence means giving up a stable subject position. To decreate is to forego the possibility of certain knowledge offered by the cogito. It is to once again exteriorize the modern self, that invention which allows all other certainties to exist, and which begins a process of sundering (as the whole is torn into constituent parts in order to be known and mastered), and which establishes the subject/object relationship between self and other, self and nature, and self and self. To decreate is to stand in the interval, or to experience the world in a negatively capable fashion. From here, we may, if we're careful, re-orient ourselves toward the Good. Heidegger's teacher describes a kind of objectless waiting (Weil calls this desiring 
without an object), which amounts to openness to the void - not desiring or pursuing the void, but not turning away from it either. And so we wait... 


\section{Conclusion}

Releasement toward things and openness to the mystery belong together. They grant us the possibility of dwelling in the world in a totally different way. They promise us a new ground and foundation upon which we can stand and endure in the world of technology without being imperiled by it. - Heidegger, "Memorial Address," p 55

After presenting a history of the idea of apathy, and after revealing the lingering connection with antiquity in the form of modern spiritual practices, and after making a case for the Good under modernity, and after assessing the value of uncertainty in leaving space enough to touch the Good, I will now conclude by restating the initial question: what allowed for the possibility of apathy, and why has it thrived under modernity? The answer to this question opens the door to larger concerns pertaining to attitudes of unity and discord. In antiquity there was an understanding of the universe as an harmonious whole, while under modernity, such a sense of harmony has largely evaporated; in its place are many sunderings. The first half of this project presented a history of the ideas of apatheia and apathy, and worked to trace the contours of the problems which accompany modern sunderings. Forgetting to care for the self alters the shape of progress, shifts our language from one of good to one of will, and distances us from the Absolute. Building on this, the final three chapters suggested a possible response to said sunderings.

During the twentieth century a number of admirable studies sought to examine apathy in the realms of politics, pedagogy, family, and media. And yet, such studies neglect the history of the phenomenon and the larger implications. Apathy is a problem of care/lessness, yet studies have asked the following sorts of questions: how do we encourage students to care? How do we move citizens to care about their democracy? Or alternately (for the likes of Schumpeter and his ilk), how do we prevent citizens from 
caring too much? Following a typically modern modus operandi (in which we dwell on and treat symptoms, as we are unable to estrange ourselves from the technological milieu), such questions beg for a response without fully understanding the problem. The bulk of scholarship on apathy focuses not on the preconditions of carelessness, but rather on its manifestations and effects in specific forums. Contrary to this approach, I have asserted that apathy is not simply a political problem; rather, it must be understood first and foremost as a set of philosophical problems - specifically, problems of epistemology, technology, aesthetics, and subjectivity. As such, the problem of apathy cannot be addressed in political terms - it is not something that can be legislated or willed away. Apathy (as a philosophical problem) was sparked during the middle ages, and under Descartes' inadvertent tutelage became an essential feature of the modern landscape. It was only during the twentieth century and the shift from typographic to electronic media that we began to observe and feel the effects of apathy (on political, social, cultural fronts). Eliot is aware not only of the shift from typography to electric media, but also of many of the modern problems discussed in the preceding pages. In a selection from "Choruses from the Rock" Eliot asks:

Where is the life we have lost in living? Where is the wisdom we have lost in knowledge? Where is the knowledge we have lost in information?

(Eliot "Choruses from the Rock" I, 147).

In these three lines Eliot manages to confront us with the problems here assessed, and to highlight the metaphysical hunger that accompanies modern progress. The idea of wisdom lost to knowledge speaks of a vanishing backcloth, and a lack of awareness concerning the self in a technical milieu. Such a lack of awareness is one of the central problems of our time, and a problem which modern aesthetic operators - including Eliot 
- have worked to foreground. The final line presciently predicts the electronic age, and the discordance caused by an overabundance of information without context. Together, the three lines reposition modern progress as regress. As McLuhan claimed, artists have their thumb on the pulse of their age, and through their work, we can gain awareness of the present.

I am indebted to a number of thinkers, but perhaps none more so than Foucault and McLuhan, as an engagement with the spiritual side of their work has provided the methodological scaffolding for my research. Through engaging with Foucault's work on the care of the self and McLuhan's thought on arts of estrangement (coupled with the fact that both actually perform their own áskēsis), I have claimed that apathy may be addressed by way of áskēsis, by caring for and transcending the modern subject position and thus renewing an experience of connection to the Absolute. The effort on the parts of McLuhan and Foucault (and other moderns) to perform their own áskesis marks a regaining of Descartes' displacement of spiritual exercise. The tradition of performing work on the self is still being practiced under modernity (though without the widespread circulation it enjoyed in antiquity), but it is not often visible to us. Thinkers like Foucault and McLuhan work to bring these practices to our attention, and to emphasize their importance - we need such practices in order to estrange ourselves from the present, and turn ourselves toward the Good.

Schiller suggests that beautiful forms will call the social world into alignment with themselves, McLuhan sees in art powerful disruptions that have the potential to grant awareness of our milieu, Marcuse finds in art powerful forces of negation which make visible the contradictions of the social world, and Heidegger's very style works to 
jar us out of commonsense thoughtlessness. What unites these thinkers is the shared belief that aesthetic exercises encourage awareness of the present, and that they offer a chance at exposing and enduring the contradiction and mystery which inhere in life. It is in this way that care, endurance, and openness to uncertainty are linked.

I am not offering a complete condemnation of modernity, but I am highly critical of its spiritual consequences, hence my refocusing in the second half of the project from a history of the problem, to potential responses. We can look back to the ancients to remind us how to live life as art, or how to lead philosophical lives. While in antiquity care of the self was paramount, I have tried to avoid suggesting that modernity is completely devoid of spiritual exercises. There are among modern artists and scholars those whose work must certainly be read as part of that ancient tradition concerned with áskêsis. Artists who work to jolt us into awareness, philosophers who attempt to render the familiar strange and thus arrest attention, and thinkers who understand communication as transformation, ritual, or reconciliation are but a few examples of those actively engaged in spiritual exercises under modernity. And while such methods of reading communication, such aesthetic practices aimed at awareness, and such intellectual efforts to estrange exist under modernity, they tend not to be viewed as áskēsis. This, it seems to me, is a mistake. In viewing these exercises as discrete one-off acts of scholarship or entertainment, we neglect the potential which they offer, and diminish their final worth and necessity. Such aesthetic and intellectual exercises allow us to once again feel the strangeness of the world, and this experience of strangeness is necessary if we are to rekindle a sense of awe that was extinguished through the long process of disenchantment. 
When entered into with awareness, aesthetic exercises (including but not limited to contemplation of nature, making/reception of art, acts of estrangement) may allow us to lead lives which transcend the disengaged reason of the modern interiorized self. My reading of thinkers such as Weil, Murdoch, Eliot, and McLuhan (among others) suggests that spiritual exercises are the precondition of decreation, and sustained openness or waiting can only arise once we've begun to shed the ego. It is from this stance of waiting that, if we're attentive, we may brush up against the Good, or experience something of the harmony of the cosmos. While áskēsis requires effort and awareness, touching the Good cannot be forced or willed. What can and must be willed are our efforts (áskēsis) to orient ourselves toward the Good, our efforts to open ourselves to objectless waiting. We must learn to leave space enough to dwell in uncertainty. Accepting and sustaining mystery demands constant effort, and this is what I have described as an orientation toward the Good. This project has been a personal attempt at re-reading a number of modern aesthetic and intellectual exercises, one which has (I hope) revealed them to be part of a long tradition of áskēsis. Ancient and modern spiritual practices, though separated by culture, location, and era, are part of a common human project that seeks concordance with the Absolute and conflation of sense and reason into immediate and unmediated intuition. The Good need not be lost to the past. While it is not at the centre of the modern ethos, there is still hope for us, hope that we may encourage receptivity enough for encounters with the Good.

This project should not be read as a call for a return. I have not been looking for a normative foundation in antiquity. I have looked back for inspiration, and to garner a sense of familiar difference or proximal distance so as to prompt a rethinking of the 
present. I am suggesting that a kind of care is needed, but our care will necessarily differ from the care of our ancient counterparts. Modern art tends to be non-mimetic; it does not aim at reflecting a providential order, but rather at shocking us into awareness and encouraging us to stand for uncertainty. I have sought to decontextualize modernity (to render it strange) by looking back to antiquity. This has, I hope, granted some perspective on the present. Just as Mr. A. Square from Abbott's interdimensional romance partakes in a Foucauldian exercise of foregrounding familiar difference, my turn to antiquity has been in effort to grant us perspective on the present. We cannot enact a return, and so we must therefore create conditions favorable to wonder, conditions in which modern hubris has been allowed to dissipate, and in which enchantment is recognized. These conditions can emerge through the exercises of contemporary artists and thinkers, and more generally, through philosophical lives lived as art, but they may be enriched by always keeping in memory the ethos and practices of antiquity prior to the diminution of philosophy in the middle ages. In the preceding pages I have tried to avoid a program of re-enchantment. I am interested in recollection; recollection that despite our attempts at disenchantment, the world has ever been a realm of enchantment.

While this work should not be read as a call for a return, neither should it be read as a call for radical change; it is far more modest than that. In presenting a history of the idea of apathy, I have worked to reveal the connections between apathy and larger philosophical problems, and to detail and connect possible responses that have been proposed by various modern thinkers (who participate in an ancient tradition that understands philosophy as something lived, and which relies on áskēsis), and this in 
effort to grant perspective enough to engage in a critique of the present, reveal the ties which bind us to antiquity, and cajole awareness of our predicament.

The question of apathy, and the methods here entertained speak to the value of an interdisciplinary approach which takes its inspiration from antiquity, prior to the sundering of specialized disciplines. Foucault's genealogical method and the elliptical probes of McLuhan work to estrange and grant us perspective enough to garner an awareness of the present. Both thinkers participate in the ancient tradition of áskēsis, and their work should be read as transformative spiritual exercises that work to jar us out of the commonsensness of everyday life. I have attempted to bring together the work of Foucault and McLuhan, as (through historical analysis) both respond to the problems which accompany modernity, and both exhibit concern with the spiritual present.

Despite my best efforts, this work is not without limitations, and thoughtful readers may be left with questions. If, as I have claimed, modern apathy is a kind of carelessness resulting from the privileging of knowledge over care, then apathy must be a uniquely modern problem. If so, is everyone under modernity (every disengaged self) apathetic? This is certainly not the case. Apathy in its current iteration (as carelessness and distance from the Good) is dependent on modernity, which is to say modernity was the necessary, if not sufficient, condition of apathy. But as my look back to thinkers connected with the ancient tradition of spiritual exercises illustrates, there are those under modernity working to care for the self and thereby re-orient themselves toward the Good. No phenomenon, no matter how widespread, can be total.

Though I make reference to a number of literary examples, readers may ask why I do not explore other aesthetic forms. Is literature the only aesthetic form available to us? 
Surely not. My eclecticism and recourse to literature is indicative of the McLuhanist in me. Artists are on the forefront of awareness, thus, examples from nineteenth and twentieth century literature (during the transition from a literate to an electronic age) are well poised to illustrate the attitudes of late modernity. While I have focused on literary examples, further work might chart other aesthetic forms, such as music, cinema, ${ }^{79}$ or physical art forms. ${ }^{80}$ Each of these forms offers the potential for estrangement and transcendence.

I have obliquely touched on the effects of electric media, but length restrictions and the potential to spin off into diffuse territory precluded an in-depth treatment of this matter. Future research might offer an assessment of apathy in the electronic age, and ask such questions as: if apathy accompanies a visual literate orientation, might it simply evaporate once we are re-tribalized? According to McLuhan, the electric age demands complete involvement; it permits no detached, objective point of view. The aural-electric orientation ensconces, and yet, where the flow of information is instantaneous and enveloping, the overabundance of information reads as a cacophonous whirl rather than as harmonious symphony. Considering this, how will an electric-aural orientation alter our relation to the Good?

In researching apathy, I have been forced to make some difficult decisions. I have, out of necessity, treated certain historical periods (the middle ages and the electronic age) in passing. The already (admittedly) wide scope of this project demanded that I focus on

\footnotetext{
${ }^{79}$ Particularly non-narrative cinema, for to restate Elder's claim, "narrative is the artistic structure of technocracy." I think that contemporary examples, such as the work of Stan Brakhage, Harry Smith, Bruce Elder, Godfrey Reggio, and Ron Fricke would make an excellent starting point in such an analysis of modern cinematic aesthetic exercises.

${ }^{80}$ Examples of physical art forms include (but are not limited to) dance, yoga, internal martial arts, urban exploration, and Parkour.
} 
late Stoicism and modernity, as within these distinct intellectual milieus are perhaps the clearest examples of apatheia and apathy respectively. My writing style is at times eclectic, but given the scope of this work, the connections I have attempted to draw, and my frequent use of McLuhan, I feel that the eclecticism helps rather than hinders this work. All of the seemingly disparate concepts examined in this dissertation (ancient áskēsis and apatheia, progress, modern aesthetic exercises, negative capability, the Platonic Good) are called together by an investigation of apathy, which I have claimed is a problem of the sundering of care from knowledge, and the disconnect from the Good. Apathy then, is a problem of the sunderings which have been intensified and normalized under modernity. If this "calling together" broadens discussions of apathy by breaking it away from a purely political perspective and forcing a dialogue between Stoicism, communications studies, metaphysics, aesthetics, and Romanticism, all the better.

This dissertation is a starting point, one which works at describing the historical trajectory of apathy, rather than just lamenting its effects in specific forums. It is an attempt at encouraging an awareness of means which may allow us to live philosophical lives and orient ourselves toward the Good. Finally, it is a call to recall the importance of care, as caring for the self is the first step out of the modern spiritual malaise. 


\section{Bibliography}

Abbott, Edwin A. Flatland: A Romance of Many Dimensions. New York: Dover, 1992.

Althusser, Louis. The Future Lasts Forever: A Memoir. Trans. Richard Veasey. New York: The New Press, 1993.

Arendt, Hannah. Between Past and Future: Eight Exercises in Political Thought. New York: Penguin, 2006.

Arendt, Hannah. The Life of the Mind. New York: Harcourt Inc.,1981.

Arendt, Hannah. The Promise of Politics. New York: Schocken, 2005.

Arnheim, Rudolf. "Early Stirrings" Visual Thinking. Berkeley: University of California P, 1997.

Arnold, Matthew. "Marcus Aurelius" Aurelius, Marcus. Meditations. Trans. Robin Hard. Hertfordshire: Wordsworth Editions Limited, 1997. (157-180)

Asiedu, F. B. A. "Intimations of the Good: Iris Murdoch, Richard Swinburne and the Promise of Theism." Heythrop Journal. Vol 42.1 (Jan 2001): 26-49.

Aurelius, Marcus. Meditations. Trans. Robin Hard. Hertfordshire: Wordsworth Editions Limited, 1997.

Barber, Benjamin. Strong Democracy: Participatory Politics for a New Age. Berkeley: University of California P, 2004.

Barthelme, Donald. Snow White. New York: Atheneum, 1967.

Bate, Walter Jackson. "Negative Capability.” Keats: A Collection of Critical Essays. Walter Jackson Bate. Ed. New Jersey: Prentice-Hall Inc., 1964.

Bauman, Zygmunt. Identity. Cambridge: Polity, 2007.

Bauman, Zygmunt. Liquid Modernity. Cambridge: Polity, 2009.

Belitt, Ben. "Toward a Poetics of Uncertainty." Southwest Review. Vol. 76.2 (1991).

Bergson, Henri. "Introduction to Metaphysics." The Creative Mind: An Introduction to Metaphysics. Trans. Mabelle Andison. New York: Dover, 2007. 133-169.

Berman, Marshall. All that is Solid Melts into Air: The Experience of Modernity. New York: Penguin, 1988. 
Blake, William. "English Encouragement of Art." The Complete Poetry and Prose of William Blake. Ed. David V. Erdman. New York: Anchor, 1988.

Blumenberg, Hans. The Legitimacy of the Modern Age. Trans. Robert M. Wallace. Cambridge Massachusetts: MIT P, 1985.

Boyle, Brendan. "Foucault Among the Classicists, Again." Foucault Studies. No. 13 (May 2012): 138-156.

Brecht, Bertolt. "Alienation Effects in Chinese Acting" On Theatre: The Development of an Aesthetic. Trans. John Willett. New York: Hill and Wang, 1992.

Brennan, Tad. The Stoic Life: Emotions, Duties, and Fate. Oxford: Clarendon P, 2007.

Burke, Edmund. A Philosophical Enquiry into the Origin of our Ideas of the Sublime and Beautiful. Ed. Adam Phillips. Oxford: Oxford University P, 1998.

Bury, John Bagnell. The Idea of Progress. (1920). Kessinger P, ND.

Capitani, Diane N. "Ideas of the Good: Iris Murdoch's The Sea The Sea." Christianity and Literature. Vol 53.1 (Autumn 2003): 99-108.

Carey, James W. "A Cultural Approach to Communication" Communication as Culture. New York: Routledge, 2009.

Chesterton, G. K. “On Lying in Bed.” Essays. London: Collins, 1939.

Clement of Alexandria. Fragments of Clemens Alexandrinus. Trans. Rev. William Wilson. Kessinger P, N/D.

Cooper, John M. Pursuits of Wisdom: Six Ways of Life in Ancient Philosophy from Socrates to Plotinus. New Jersey: Princeton University P, 2012.

--- "Introduction: On Philosophy as a Way of Life." Pursuits of Wisdom: Six Ways of Life in Ancient Philosophy from Socrates to Plotinus. 1-23.

--- "Stoicism as a Way of Life." Pursuits of Wisdom: Six Ways of Life in Ancient Philosophy from Socrates to Plotinus. 144-225.

cummings, e. e. "pity this busy monster, manunkind" 100 Selected Poems. New York: Grove P, 1994.

Davis, Steve, Larry Elin and Grant Reeher. Click on Democracy: The Internet's Power to Change Political Apathy into Civic Action. Boulder CO: Westview P, 2002. 
Dean, Dwight G. “Alienation and Political Apathy.” Social Forces. Vol 38 Number 3 (March 1960).

DeLuca, Tom. The Two Faces of Political Apathy. Temple University P, 1995.

Descartes, Rene. A Discourse on Method, Meditations, and Principles. Trans. John Veitch. London: Everyman, 2003.

--- "A Discourse on the Method of Rightly Conducting the Reason, and Seeking Truth in the Sciences." A Discourse on Method, Meditations, and Principles. 3-57.

--- "Meditations on the First Philosophy in which the Existence of God, and the Real Distinction of Mind and Body are Demonstrated." A Discourse on Method, Meditations, and Principles. 61-131

DesJardins, Rosemary. Plato and the Good. Leiden: Brill, 2004.

Dostoevsky, Fyodor. Notes from Underground. Trans. Mirra Ginsburg. New York: Bantam, 2005.

Elder, R. Bruce. "The Cinema We Need.” Documents in Canadian Film. Ed. Douglas Fetherling. Peterborough: Broadview P, 1988.

Elder, R. Bruce. Harmony \& Dissent: Film and Avant-garde Art Movements in the Early Twentieth Century. Wilfred Laurier University P, 2010.

Eliasoph, Nina. Avoiding Politics: How Americans Produce Apathy in Everyday Life. Cambridge: Cambridge University P, 1999.

Eliot, T. S. "Choruses from the Rock." The Complete Poems and Plays. London: Faber \& Faber, 2004. 147-167.

Eliot, T. S. Selected Prose. Ed. John Hayward. Harmondsworth: Penguin, 1953.

--- “The Metaphysical Poets" Selected Prose. 111-120.

--- "Poetry and Philosophy." Selected Prose. 53-56.

--- "Tradition and the Individual Talent.” Selected Prose. 21-30.

Ellul, Jacques. Perspectives on our Age: Jacques Ellul Speaks on his Life and Work. Ed. William H. Vanderburg. Toronto: Anansi P, 2004.

Ellul, Jacques. The Technological Society. Trans. John Wilkinson. New York: Vintage, 1964. 
Ellul, Jacques. The Technological System. Trans. Joachim Neugroschel. New York: Continuum, 1980.

Epictetus. The Discourses, The Handbook, Fragments. Trans. Robin Hard. London: Everyman, 1995.

Estelrich, Bartomeu. "Simone Weil's Concept of Grace." Modern Theology. Vol 25.2 (April 2009): 239-251.

Euben, J. Peter. "Arendt's Hellenism.” The Cambridge Companion to Hannah Arendt. Ed. Dana Villa. Cambridge: Cambridge University P, 2000.

Evans, B. Ifor. "The Romantic Poets" A Short History of English Literature. Harmondsworth: Pelican, 1940.

Ferry, Luc. A Brief History of Thought: A Philosophical Guide to Living. Trans. Theo Cuffe. New York: Harper Perennial, 2011.

Feynman, Richard. "Lecture 6: Probability and Uncertainty" Messenger Lectures. Cornell University, 1964. Recording.

Fillion, Real. "Foucault on History and the Self." Laval Theologique et Philosophique. Vol. 54(1) (February 1998): 143-162.

Fishman, Donald A. "Rethinking Marshall McLuhan: Reflections on a Media Theorist." Journal of Broadcasting and Electronic Media. Vol. 50(3) (September 2006): 567-574.

Fögel, Stan. The Postmodern University: Essays on the Deconstruction of the Humanities. Toronto: ECW P, 1988.

Foucault, Michel. "The Cultivation of the Self" The Care of the Self: The History of Sexuality (Vol III). Trans. Robert Hurley. New York: Vintage, 1988.

Foucault, Michel. "Space, Power and Knowledge." The Cultural Studies Reader, 3rd edition. Ed. Simon During. New York: Routledge, 2008.

Foucault, Michel. "Technologies of the Self." Ethics, Subjectivity and Truth. Ed. Paul Rainbow. Trans. Robert Hurley et al. New York: The New P, 1997.

Foucault, Michel. The Hermeneutics of the Subject: Lectures at the College de France 1981-1982. Trans. Graham Burchell. New York: Picador, 2005.

Foucault, Michel. "Nietzsche, Genealogy, History.” Language, Counter-memory, Practice: Selected Essays and Interviews by Michel Foucault. Trans. Donald F. Bouchard and Sherry Simon. New York: Cornell University P, 1980. 
Foucault, Michel. "Introduction." The Use of Pleasure: The History of Sexuality (Vol. II). Trans. Robert Hurley. New York: Vintage, 1990.

Franklin, Benjamin. The Autobiography and Other Writings. Ed. Kenneth Silverman. New York: Penguin, 2003.

Fromm, Erich. The Art of Loving. New York: Harper Perennial, 2006.

Fromm, Erich. To Have or to Be. London: Continuum, 2008.

Fromm, Erich. Man for Himself: An Inquiry into the Psychology of Ethics. New York: Holt, 1990.

Gadamer, Hans-Georg. The Idea of the Good in Platonic-Aristotelian Philosophy. Trans. P. Christopher Smith. New haven: Yale University P, 1986.

Gadamer, Hans-Georg. "Language as the Medium of Hermeneutic Experience" Truth and Method. Trans. Joel Weinsheimer and Donald G. Marshall. London: Continuum, 2006.

Gaiser, Konrad. "Plato's Enigmatic Lecture 'On the Good"' Phronesis. Vol 25.1 (1980): 5-37.

Gamson, William A., David Croteau, William Hoynes, and Theodore Sasson. "Media Images and the Social Construction of Reality" Annual Review of Sociology. Vol. 18 (1992).

Gans, Herbert J. "Political Participation and Apathy." Phylon (1940-1956), Vol. 13, No. 3 (3rd Qtr., 1952).

Gardiner, Michael. Critiques of Everyday Life. London: Routledge, 2000.

Gill, Christopher. "The School in the Roman Imperial Period." The Cambridge Companion to the Stoics. Brad Inwood. Ed. Cambridge: Cambridge University P, 2003.

Gozzi, Raymond Jr. "What if Media are not "Extensions" of our Senses, But "Intrusions" on our Senses?" ETC: A Review of General Semantics. Issue 64:1 (January 2007).

Grabiner, Ellen. "The Heideggerian Disruptions of Zippy the Pinhead.” Philosophy Now. Issue 84 (May/June 2011): 26-29. 
Granata, Paolo. "The Aesthetics of Marshall McLuhan: The Medium as Expressive Form" Then $\mid$ Now $\mid$ Next: McLuhan Centenary International Conference.

Toronto, Canada. November 7-10, 2011. Conference Paper.

Grant, George. The George Grant Reader. Ed. William Christian and Sheila Grant. Toronto: University of Toronto P, 1998.

--- “A Critique of the New Left (1966)” The George Grant Reader. 84-90.

--- "A Platitude" The George Grant Reader. 448-453.

--- "The Computer Does Not Impose on Us the Ways It Should Be Used (1976)" The George Grant Reader. 418-434.

--- "Faith and the Multiversity" The George Grant Reader. 461-482

--- "Heidegger" The George Grant Reader. 297-311

--- "Simone Weil.” The George Grant Reader. 237-265

--- "Value and Technology." The George Grant Reader. 387-394.

Grant, George. Technology and Justice. Toronto: Anansi, 1986.

Graver, Margaret R. Stoicism and Emotion. Chicago: University of Chicago P, 2007.

Hadas, Moses. Ed. Essential Works of Stoicism. Bantam, 1961.

Hadot Pierre. The Inner Citadel: The Meditations of Marcus Aurelius. Cambridge MA: Harvard University P, 1998.

Hadot, Pierre. Philosophy as a Way of Life: Spiritual Exercises from Socrates to Foucault. Malden: Blackwell, 1995.

Hadot, Pierre. What is Ancient Philosophy? Trans. Michael Chase. Belknap, 2004.

Hall, Edward T. “Why Context?” Beyond Culture. New York: Anchor Books, 1989.

Halliwell, Stephen. The Aesthetics of Mimesis: Ancient Texts and Modern Problems. Princeton: Princeton University P, 2002.

Havers, Grant. "George Grant and Leo Strauss: Modernist and Postmodernist Conservatisms." Topia. No 8. (Fall 2002): 91-106.

Heidegger, Martin. Basic Writings. Ed. David Farrell Krell. San Francisco: HarperSanFrancisco, 1993. 
--- "The Origin of the Work of Art." Basic Writings. 143-212.

--- "What is Metaphysics?" Basic Writings. 93-110.

Heidegger, Martin. "The Way back into the Ground of Metaphysics." Existentialism from Dostoevsky to Sartre. Ed. Walter Kaufmann. New York: Meridian, 1975.

Heidegger, Martin. Discourse on Thinking. Trans. John M. Anderson and E. Hans Freund. New York: Harper \& Row, 1966.

--- “Conversation on a Country Path about Thinking." Discourse on Thinking. 58-90.

--- “Memorial Address.” Discourse on Thinking. 43-57.

Hesiod. "Works and Days.” Theogony, Works and Days. Trans. M. L. West. Oxford: Oxford University P, 1999.

Inwood, Brad. Ethics and Human Action in Early Stoicism. Oxford: Clarendon P, 1987.

Inwood, Brad. "Getting to Goodness" Reading Seneca: Stoic Philosophy at Rome. Oxford: Clarendon P, 2005.

Irvine, William B. A Guide to the Good Life: The Ancient Art of Stoic Joy. Oxford: Oxford University P, 2009.

Jacoby, Russell. The End of Utopia: Culture and Politics in an Age of Apathy. Basic Books, 1999.

Jacoby, Russell. Picture Imperfect: Utopian Thought for an Anti-Utopian Age. New York: Columbia University P, 2005.

James, William. "What Pragmatism Means." Essays in Pragmatism. Ed. Alburey Castell. New York: Hafner, 1969. 141-158.

Jones, R. M. Fundamental Ends of Life. New York: MacMillan, 1925.

Kant, Immanuel. Ethical Philosophy $2^{\text {nd }}$ Ed. Trans. James W. Ellington. Indianapolis: Hackett, 1994.

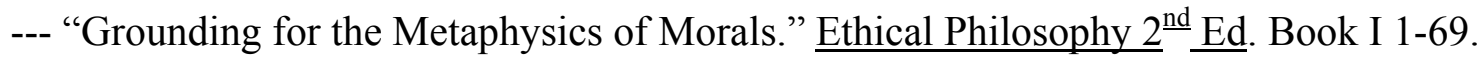

--- "Metaphysical Principles of Virtue: Introduction" Ethical Philosophy $2^{\text {nd }}$ Ed. Book II 31-73. 
Keats, John. "To George and Thomas Keats" The Complete Works of John Keats vol. IV: Letters I 1814 to January 1819. Ed H. Buxton Forman. Glasgow: Gowars \& Gray, 1923.

Keats, John. "To George and Georgina Keats" The Complete Works of John Keats vol. V: Letters II 1819 to 1820 . Ed H. Buxton Forman. Glasgow: Gowars \& Gray, 1923.

Kisner, Matthew J. "The good" Spinoza on Human Freedom: Reason, autonomy, and the good life. Cambridge: Cambridge University P, 2011.

Knuuttila, Simo. Emotions in Ancient and Medieval Philosophy. Oxford: Clarendon P, 2004.

Kracauer, Siegfried. "Those Who Wait", The Mass Ornament: Weimar Essays. Trans. Thomas Y. Levin. Cambridge: Harvard University P, 1995.

Kroker, Arthur. "Technological Dependency: George Grant as the Nietzsche of the New World" Technology and the Canadian Mind: Innis/McLuhan/Grant. Montreal: New World Perspectives, 1987.

Latour, Bruno. We have Never Been Modern. Trans. Catherine Porter. Cambridge Massachusetts: Harvard University P, 1993.

Leff, Gordon. Medieval Thought from Saint Augustine to Ockham. Harmondsworth: Pelican, 1958.

Lipovetsky, Gilles. The Empire of Fashion: Dressing Modern Democracy. Trans. Catherine Porter. Princeton NJ: Princeton University P, 2002.

Lodge, R. C. "The Platonic Highest Good" Plato's Theory of Ethics: The Moral Criterion and the Highest Good. London: Kegan Paul, Trench, Trubner \& Co, 1966.

Long, A. A. "Stoicism.” Hellenistic Philosophy: Introductory Readings. Ed. Brad Inwood, and L. P. Gerson. Indianapolis: Hackett, 1988. 73-156.

MacIntyre, Alasdair. A Short History of Ethics. New York: MacMillan, 1966.

MacIntyre, Alasdair. After Virtue: A Study in Moral Theory $3^{\text {rd }}$ ed. Notre Dame: University of Notre Dame P, 2010.

de Maistre, Xavier. A Journey Around my Room and a Nocturnal Expedition Around my Room. Trans. Andrew Brown. London: Hesperus Classics, 2004. 
Marx, Karl \& Frederick Engels. "Manifesto of the Communist Party." The Communist Manifesto and Other Revolutionary Writings. Ed. Bob Blaisdell. Mineola: Dover, 2003.

Marchand, Philip. Marshall McLuhan: The Medium and the Messenger. Toronto: Random House, 1989.

Marcuse, Herbert. "The Aesthetic Dimension.” Eros and Civilization. Boston: Beacon P, 1974.

Marcuse, Herbert. The Aesthetic Dimension: Towards a Critique of Marxist Aesthetics. Boston: Beacon P, 1978.

Marcuse, Herbert. Negations: Essays in Critical Theory. Trans. Jeremy J. Shapiro. Boston: Beacon P, 1969.

Marcuse, Herbert. One Dimensional Man: Studies in the Ideology of Advanced Industrial Society. Boston: Beacon P, 1991.

Marcuse, Herbert. Reason and Revolution: Hegel and the Rise of Social Theory. Boston: Beacon P, 1960.

McGushin, Edward F. Foucault's Áskesis: An Introduction to the Philosophical Life. Evanston Illinois: Northwestern University P, 2007.

McLuhan, Marshall. The Classical Trivium: The Place of Thomas Nashe in the Learning of His Time. Ed. W. Terrence Gordon. Corte Madera: Gingko P, 2006.

McLuhan, Marshall. The Gutenberg Galaxy. Toronto: University of Toronto P, 2002.

McLuhan, Marshall, and Eric McLuhan. Laws of Media: The New Science. Toronto: University of Toronto P, 1988.

McLuhan, Herbert Marshall. The Mechanical Bride: Folklore of Industrial Man. Berkley: Gingko P, 2001.

McLuhan, Marshall. The Medium and the Light: Reflections on Religion. Ed. Eric McLuhan and Jacek Szklarek. Toronto: Stoddart, 1999.

--- "G. K. Chesterton: A Practical Mystic" The Medium and the Light. 3-13.

--- " "Spiritual Acts": Letter to Corinne Lewis" The Medium and the Light. 24-30.

McLuhan, Marshall and Quentin Fiore. The Medium is the Massage: An Inventory of Effects. New York: Bantam, 1967. 
McLuhan, Marshall. Understanding Me: Lectures and Interviews. Ed. Stephanie McLuhan and David Staines. Toronto: McClelland \& Stewart, 2005.

--- "Art as Survival in the Electric Age" Understanding Me. 206-224.

--- "Man and Media" Understanding Me. 277-298.

McLuhan, Marshall. Understanding Media: The Extensions of Man. New York: Signet, 1964.

McLuhan's Wake. Dir. Kevin McMahon and David Sobelman. Primitive Entertainment and NFB of Canada, 2002. DVD.

Melville, Herman. Moby Dick. London: Vintage, 2007.

de Montaigne, Michel. "That it is Madness to Judge the True and the False from Our Own Capacities" The Essays: A Selection. Trans. M. A. Screech. London: Penguin, 2003.

Murdoch, Iris. The Sovereignty of Good. London: Routledge, 1970.

Melberg, Arne. Theories of Mimesis. Cambridge: Cambridge University P, 1995.

Meyer, Susan Sauvé. "Chain of Causes: What is Stoic Fate?" God and Cosmos in Stoicism. Ed. Ricardo Salles. Oxford: Oxford University P, 2009.

Mosby, Speed. "The Danger of Political Apathy.” The North American Review. Vol 167 No 503 (October 1898).

Nelsen, Randle W. "Books, Boredom, and behind Bars: An Explanation of Apathy and Hostility in Our Schools." Canadian Journal of Education, Vol. 10, No. 2 (Spring, 1985).

Newton, Kenneth. "Mass Media Effects: Mobilization or Media Malaise?" British Journal of Political Science, Vol. 29, No. 4 (Oct., 1999).

Nicol, Brian. "Iris Murdoch's Aesthetics of Masochism." Journal of Modern Literature. Vol 29.2 (Winter 2006):148-165.

Nietzsche, Friedrich. "Book One: European Nihilism.” The Will to Power. Ed. Walter Kaufmann. New York: Vintage, 1968.

Nisbet, Robert. History of the Idea of Progress. New Brunswick: Transaction, 2009.

Norberg, Jakob. "Arendt in Crisis: Political Thought in Between Past and Future." College Literature. 38.1 (Winter 2011):131-149. 
Ong, Walter J. Orality and Literacy: The Technologizing of the Word. London: Routledge, 2008.

Orwell, George. "Politics and the English Language.” Propaganda. Ed. Robert Jackall. New York: New York University P, 1995.

Ou, Li. Keats and Negative Capability. London: Continuum, 2009.

Ovid. Metamorphosis. Trans. John Dryden et al. Hertfordshire: Wordsworth Editions Limited, 1998.

Paglia, Camille. “American Decadents: Poe, Hawthorne, Melville” Sexual Personae: Art and Decadence from Nefertiti to Emily Dickinson. New York: Vintage, 1991.

Pateman, Carole. Participation and Democratic Theory. Cambridge: Cambridge University P, 1976.

Penty, Arthur J. The Gauntlet: A Challenge to the Myth of Progress. Norfolk VA: IHS P, 2004.

Perec, Georges. Avoid. Trans. Gilbert Adair. Boston: David R. Godine P, 2005.

Perec, Georges. “Approaches to What?” Species of Spaces and Other Places. Trans. John Sturrock. London: Penguin, 1999.

Perry, Marvin. An Intellectual History of Modern Europe. Boston: Houghton Mifflin, 1992.

Peters, F. E. Greek Philosophical Terms: A Historical Lexicon. New York: New York University P, 1967.

Peters, John Durham. "McLuhan's Grammatical Theology.” Canadian Journal of Communication. Vol 36 (2011) 227-242.

Peters, John Durham. "Introduction: The Problem of Communication" Speaking Into the Air: A History of the Idea of Communication. Chicago: University of Chicago P, 1999.

Plato. "Book VI" The Republic. Trans. Desmond Lee. London: Penguin, 1987.

Plato. "Philebus" Statesman, Philebus, Ion. Trans. H. N. Fowler. Cambridge, MA: (Loeb Classical Library) Harvard University P, 2006 (1925).

Plutarch. "Platonic Questions" Moralia, Volume XIII part 1. Trans. Harold Cherniss. Cambridge, MA: (Loeb Classical Library) Harvard University P, 1976. 
Popper, Karl R. The Open Society and its Enemies Vol 1: The Spell of Plato. Princeton: Princeton University P, 1971.

Postman, Neil. Building a Bridge to the $18^{\text {th }}$ Century: How the Past Can Improve Our Future. New York: Vintage, 1999.

Quade, Kenneth. Apathy and the Media: You Give the People What They Want to Know, Not What They Ought to Know. Vantage P, 2007.

Robertson, Neil G. "George Grant: intimations of Deprival, Intimations of Beauty." Modern Age. 46.1/2 (Winter/Spring 2004):74-83.

Roderick, Rick. "The Death of God" Nietzsche and the Postmodern Condition. [Recorded Lecture]. TTC, 1991.

Rosenberg, Morris. "The Meaning of Politics in Mass Society." The Public Opinion Quarterly, Vol. 15, No. 1, (Spring, 1951).

Rosenberg, Morris. "Some Determinants of Political Apathy." The Public Opinion Quarterly, Vol. 18, No. 4 (Winter, 1954-1955).

Russell, Bertrand. A History of Western Philosophy. London: Routledge, 2010.

Santas, Gerasimos. "Plato's Metaphysical Theory of the Form of the Good" Goodness and Justice: Plato, Aristotle, and Moderns. Malden MA: Blackwell, 2001.

Saul, John Ralston. Voltaire's Bastards: The Dictatorship of Reason in the West. Toronto: Penguin, 1993.

Sawicki, John D. Towards a Politics of Apathy: Baudrillard, Bartleby, and Adorno. MA dissertation, University of Western Ontario, 1997.

Schumpeter, Joseph A. "Another Theory of Democracy.” Capitalism, Socialism and Democracy, $3^{\text {rd }}$ Ed. New York: Harper Perennial Modern Thought, 2008.

Schiller, Friedrich. On the Aesthetic Education of Man. Trans. Reginald Snell. New York: Dover, 2004.

Seneca, Lucius Annaeus. Dialogues and Essays. Trans. John Davie. Oxford: Oxford University P, 2007.

Seneca, Lucius Annaeus. Letters From a Stoic. Trans. Robin Campbell. Penguin, 2004.

Seneca, Lucius Annaeus. The Stoic Philosophy of Seneca: Essays and Letters. Trans. Moses Hadas. New York: W. W. Norton, 1968. 
Sevy, Grace. "Vitality in an Age of Apathy: The Development of Spirited Human Traits in Contemporary American Culture." Political Psychology, Vol. 4, No. 4 (Dec., 1983).

Shklovsky, Viktor. "Art as Device" Theory of Prose. Trans. Benjamin Sher. Champaign: Dalkey Archive P, 2009.

Simmel, Georg. "The Metropolis and Mental Life." The Sociology of Georg Simmel. Trans. Kurt H. Wolff. New York: The Free P, 1964.

Smith, Steven. "The Concept of the Good Life." The Greeks and the Good Life: Proceedings of the Ninth Annual Philosophy Symposium, California State University, Fullerton. Ed. David J. Depew. Indianapolis: Hackett, 1980.

Solomon, Robert C. Ethics: A Brief Introduction. New York: McGraw-Hill, 1984.

Sontag, Susan. On Photography. New York: Picador, 1990.

Sontag, Susan. Styles of Radical Will. New York: Picador, 2002.

Sorabji, Richard. Emotion and Peace of Mind: From Stoic Agitation to Christian Temptation - The Gifford Lectures. Oxford: Oxford University P, 2000.

Spinoza, Benedict. "On the Improvement of the Understanding." The Chief Works of Benedict De Spinoza (Vol II): On the Improvement of the Understanding, The Ethics, Correspondence. Trans R. H. M. Elwes. New York: Dover, 1955.

Sturrock, John. "Georges Perec." The Word from Paris: Essays on Modern French Thinkers and Writers. London: Verso, 1998.

Taylor, Charles. The Malaise of Modernity. Concord: Anansi, 1991.

Taylor, Charles. Sources of the Self: The Making of Modern Identity. Cambridge: Harvard University P, 1989.

Thompson, E. P. ed. Out of Apathy. London: Stevens, 1960.

Thompson, Patrick. The Minimalist Conception of Democracy as Informed by The Works of Schumpeter, Riker, and Hardin. MA dissertation, University of Saskatchewan, 2007.

Tocqueville, Alexis. Democracy in America. Trans. George Lawrence. New York: Harper Perennial, 2006. 
Tolkien, J. R. R. "Letter to Milton Waldman, 1951" The Silmarillion. Ed. Christopher Tolkien. London: Harper Collins, 2007.

Voller, Diana. "Negative Capability: The Psychotherapists' X-Factor?” Existential Analysis Vol 22.2 (July 2011) 344-355.

Warry, J. G. "The Sense of Harmony" Greek Aesthetic Theory: A Study of Callistic and Aesthetic Concepts in the Works of Plato and Aristotle. London: Methuen, 1962.

Weber, Max. "Science as a vocation." From Max Weber: Essays in Sociology. New York: Oxford University P, 1946.

Weil, Simone. Gravity and Grace. London: Routledge, 2010.

Weil, Simone. "Draft for a Statement of Human Obligations" Simone Weil: An Anthology. Ed. Siân Miles. London: Penguin, 2005.

Weil, Simone. Waiting for God. Trans. Emma Craufurd. New York: Harper Perennial Modern Classics, 2009.

Wells, H. G. A Short History of the World. London: Penguin, 1937.

Wertime, Theodore A. "Marshall McLuhan and the Extensions of Man." Technology and Culture. Vol. 7. No 4. (Autumn 1966): 504-510.

Wigod, Jacob D. "Negative Capability and Wise Passiveness". Publications of the Modern Language Association of America. Vol 67.4 (1952): 383-390.

Wilson, J. Eric, and R. Justen Collins. We Surround Them: Our Journey From Apathy to Action. Georgetown Grassroots Publication, 2010.

Wordsworth, William. "Expostulation and Reply." Understanding Poetry. Ed. Cleanth Brooks \& Robert Penn Warren. New York: Henry Holt and Co., 1952.

Wright, Ronald. A Short History of Progress. Toronto: Anansi P, 2004.

Yack, Bernard. "Myth and Modernity: Hans Blumenberg's Reconstruction of Modern Theory." Political Theory. Vol. 15 No 2 (May 1987): 244-261.

Zamyatin, Yevgeny. We. Trans. Mirra Ginsburg. New York: Harper Collins, 1999.

Zerzan, John. Running on Emptiness: The Pathology of Civilization. Los Angeles: Feral House, 2002.

Zukin, Cliff, Scott Keeter, et al. A New Engagement? Political Participation, Civic Life, and the Changing American Citizen. Oxford: Oxford University P, 2006. 